\section{To: (Receiving Organization)}

Distribution

5. Proj./Prog./Dept./Div.:

Az-101 Mixer Pump Test

8. Originator Remarks:

This EDT is for approval and release of document RPP-6104, "AZ-101 Gamna Cart Opertational Test Report".

11. Receiver Remarks:

\author{
3. From: (Originating Organization) \\ Az-101 Mixer Pump Engineering \\ 6. Design Authority/Design Agent/Cog. Engr.: \\ G Tardiff/B Ulbricht/D Bragg
}

4. Related EDT No.:
N/A
7. Purchase Order No.:
N/A
9. Equip./Component No.:

AZ-101 gamma cart 10. System/BIdg./Facility:

241-AZ

12. Major Assm. Dwg. No.:

$\mathrm{H}-2-79234$

13. Permit/Permit Application No.:

$\mathrm{N} / \mathrm{A}$

14. Required Response Date:

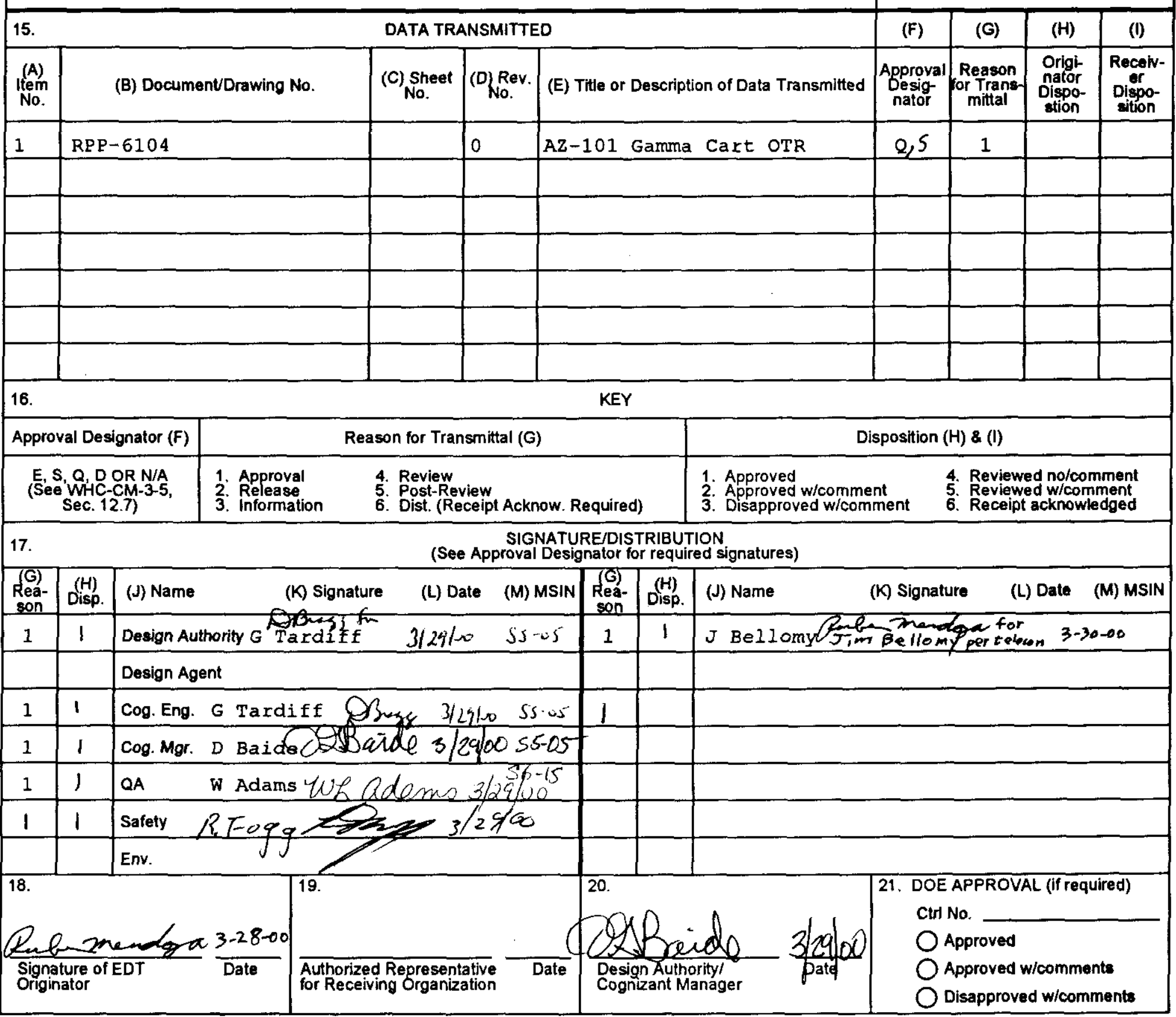




\title{
AZ-101 Gamma Cart Operational Test Report
}

RE. Mendoza

Cogema Engineering

Richland, WA 99352

U.S. Department of Energy Contract DE-AC06-96RL13200

\author{
EDT/ECN: 628306 \\ UC: \\ Org Code: \\ B\&R Code: \\ Charge Code: \\ Total Pages: 240
}

Key Words: Az-101, 241-AZ-101, Mixer Pumps, Gamma Cart, sludge Mobilizati on, W-151, Test Report

Abstract:

Test Report documenting the successful completion of the Operational Test Procedure for the AZ-101 Gamma Carts. Gamma carts are in support of the Az-101 Mixer Pump Test.

TRADEMARK DISCLAIMER, Reference herein to any specific commercial product, process, or service by trade name, trademark, manufacturer, or otherwise, does not necessarily constitute or imply its endorsement, recommendation, or favoring by the United States Government or any agency thereof or its contractors or subcontractors.

Printed in the United States of America. To obtain copies of this document, contact: Document Control Services, P.O. Box 950, Mailstop H6-08, Richland WA 99352, Phone (509) 372-2420; Fax (509) 376-4989.
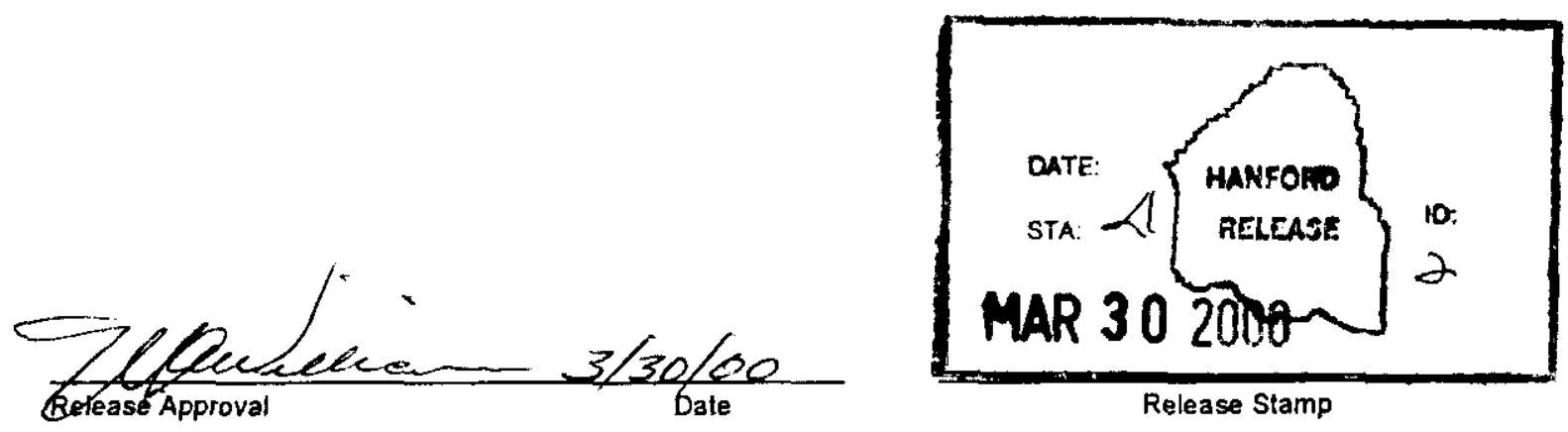

Release Stamp 


\section{RPP-6104 \\ AZ-101 Gamma Cart \\ Operational Test Report}




\subsection{Purpose}

The purpose of this test report is to document the successful completion of the gamma (also known as the Sludge Mobilization) cart system Operational Test Procedure (OTP). This OTP, OTP-260-004, "241-AZ Gamma Cart Operational Test Procedure," was performed between $2 / 12 / 2000$ and $3 / 10 / 2000$ within work package $2 \mathrm{E}-00-00054$. The completed OTP is attached as Appendix A.

This field OTP followed the successful completion of RPP-5577, "241-AZ-101 Mixer Pump Demonstration Test Gamma Cart ATP/QTP".

\subsection{System Description}

The gamma carts were designed to provide data to help determine the effectiveness of the AZ-101 Mixer Pump Test.

There are two identical gamma cart systems, labeled A and B. Each system includes the cart itself housing the motor control unit and probe deployment cable, a gamma probe, a riser extension assembly, a data acquisition and control system, and associated communications/power cables. The gamma cart system description is documented in RPP-5576, "241-AZ-101 Mixer Pump Gamma Cart System Description of Operation". The system arrangement and assemblies are shown on H-2-79234, "TWRS Sludge Mobilization Cart Arrangement", H-2-79235, “TWRS Sludge Mobilization Cart Assembly", and H-2-830024, "Sheave Riser Extension Assembly".

The systems are used to lower the probes to various depths within drywells in the tank to measure the energies emitted by the sludge and slurry. The mixing of the sludge/slurry can be detected because the components of the sludge radiate at gamma energies greater than the slurry (greater than Cs-137 energy). The drywells are located at several positions around the tank allowing several test locations.

\subsection{Test Summary}

The gamma cart OTP tested each of the two complete systems including speed and position indicators, remote software and local control, and data acquisition.

Various combinations of the two carts and their modes of testing were tested in nine of the tank drywells (risers 14B, 14D, 14E, 14F, 15B, 15C, 15E, 15F, and 15I). The probes were deployed to several depths and data was acquired. The same depths were used in each of the drywells to assist in assembling tank baseline data. 


\subsection{Test Exceptions}

There were a total of 7 test exceptions generated. These exceptions and their resolutions are summarized below. Copies of the signed off resolutions are included in Appendix A.

TE \#1 - Step to route cable from gamma cart to extension tool was needed in procedure. Resolution - Procedure was changed with a Procedure Change Authorization.

TE \#2 - Incorrect amplifier was referred to, settings were incorrect.

Resolution - Accepted As-Is, correct settings were noted on exception sheet.

TE \#3 - Steps 5.2.32 and 5.2.33 out of order.

Resolution - Accepted As-Is, procedure allowed Test Director to perform the steps as needed.

TE \#4 - Step 5.2.32 required a hard copy of data files, no printer was available. Resolution - Accepted after hard copies were printed from a different computer with a printer.

TE \#5 - Step 5.3.3 did not include information to ensure the REAL/LIVE toggle button was set to LIVE.

Resolution - Accepted As-Is after note made on the exception sheet. Information was provided as input to the Gamma Cart Operating procedure.

TE \#6 - Step 5.3.9 required a hard copy of data files, no printer was available.

Resolution - Accepted after hard copies were printed from a different computer with a printer.

TE \#7 - Steps 5.2 .32 and 5.2.33 out of order.

Resolution - Accepted As-Is, procedure allowed Test Director to perform the steps as needed.

\subsection{Conclusions}

The completion of the gamma cart OTP signifies that the gamma cart systems operate in the field as designed and are ready to perform monitoring activities during the mixer pump test. 


\section{Appendix A \\ Completed Operational Test Procedure}


RISER 14D

GAMMA CART - B 


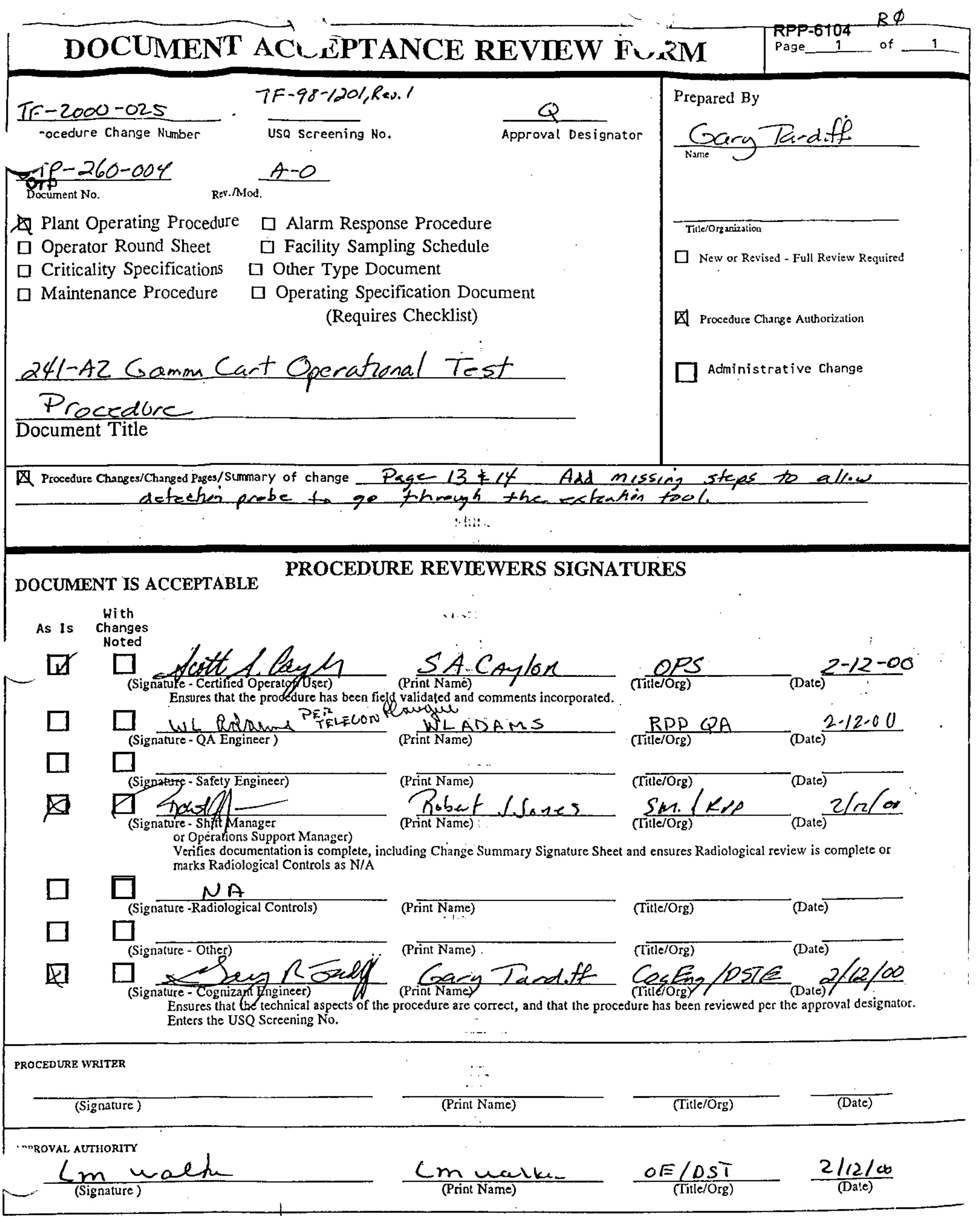




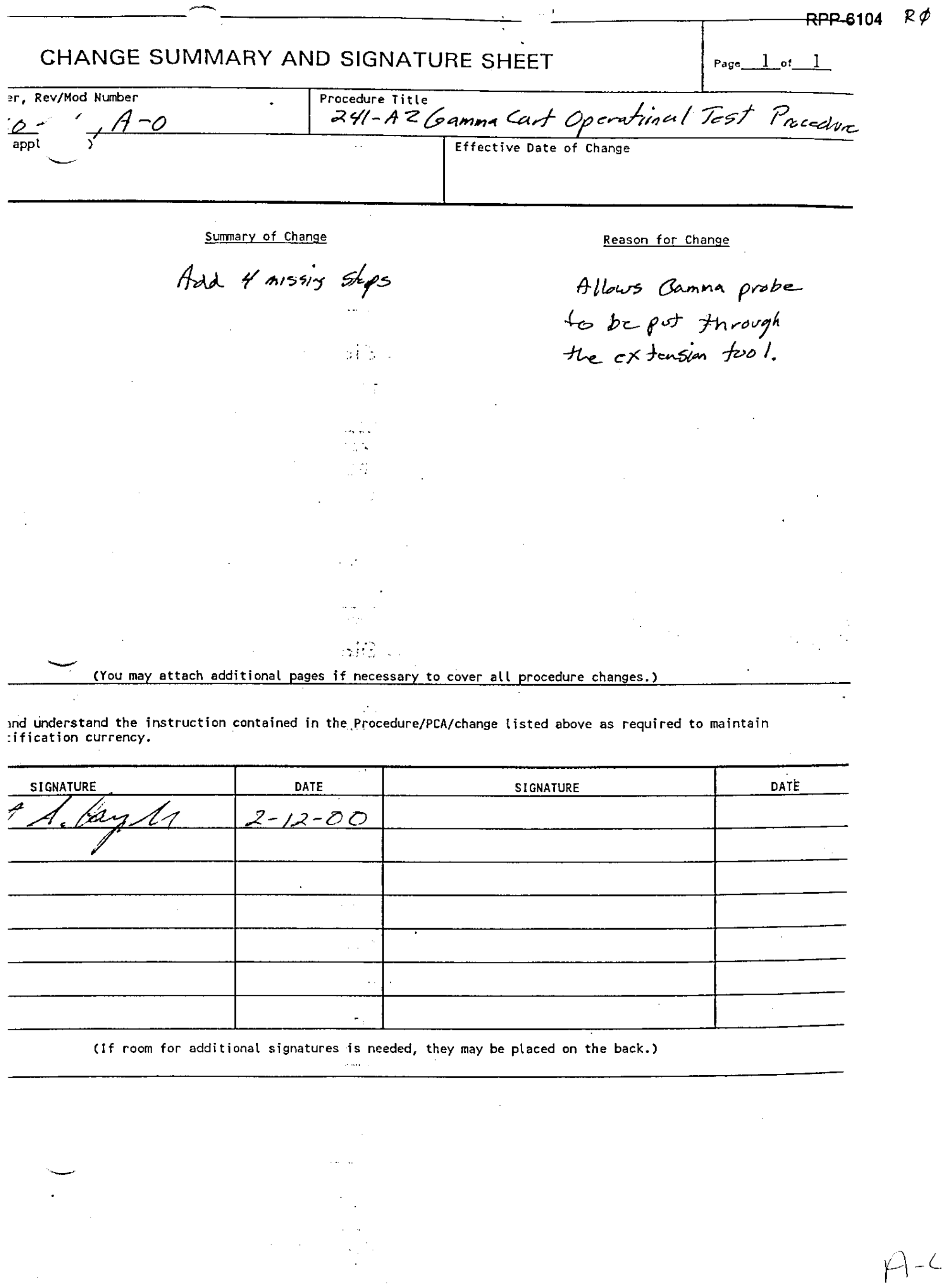




\section{1-AZ GAMMA CART OPERATIONAL TEST PROCEDURE}

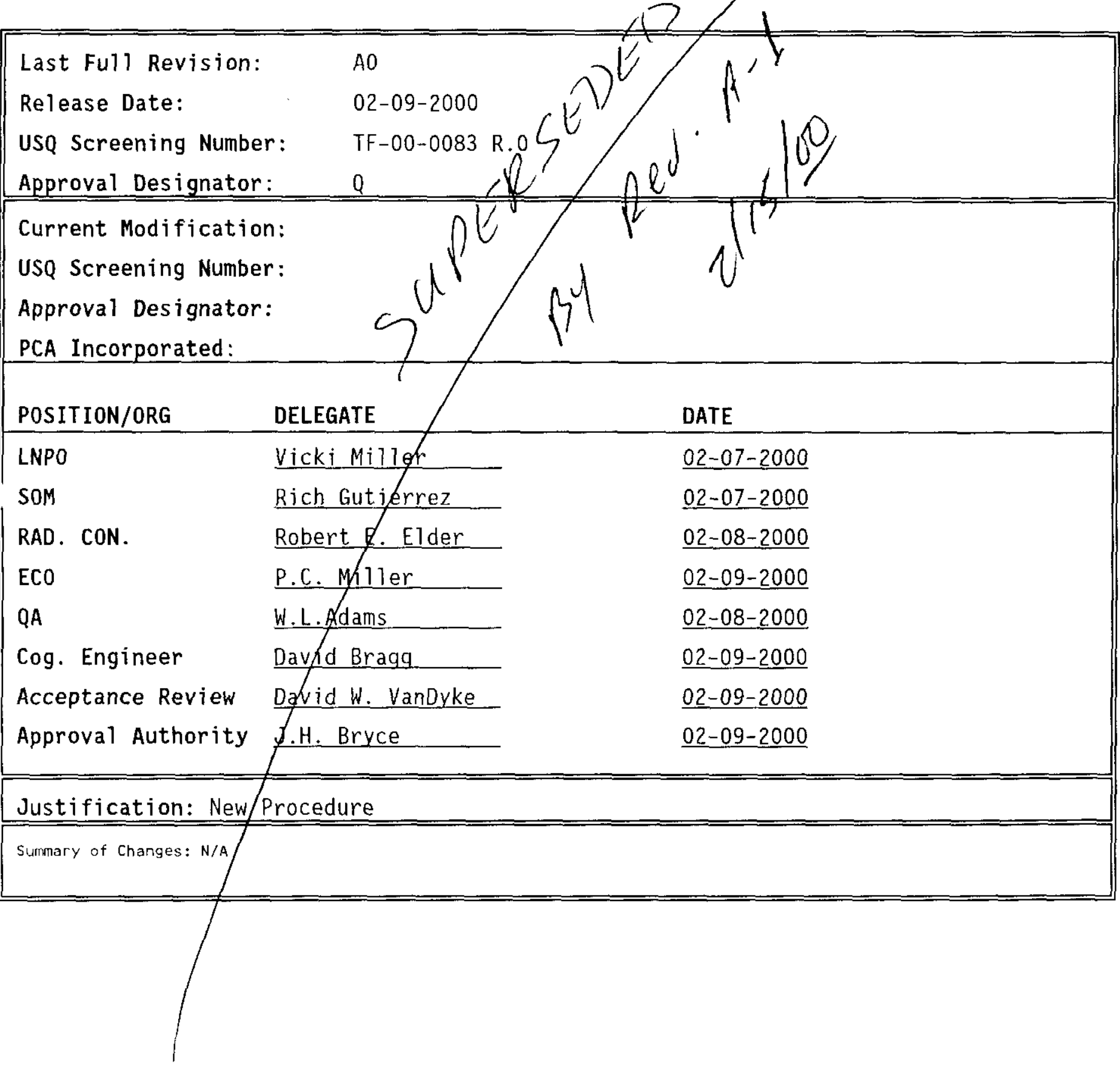

Iype CONTINUOUS
Dociment 10

OTP. $260-004$
Rev/Mod

A.0
Release bate

$02 / 09 / 2000$
1 of 30 


\section{TABLE OF CONTENTS}

TEST EXECUTION SHEET . . . . . . . . . . . . . . . . . . 3

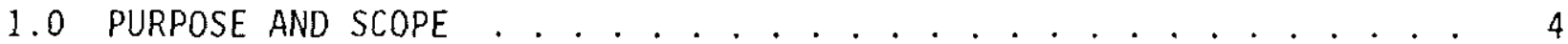

1.1 PURPOSE . . . . . . . . . . . . . . . . . . . . . 4

1.2 SCOPE . . . . . . . . . . . . . . . 4

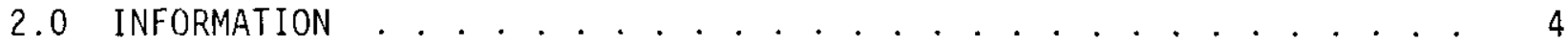

2.1 TERMS AND DEFINITIONS ..................... 4

2.2 RESPONSIBILITIES . . . . . . . . . . . . . . . . . . . . . . . 4

2.3 REFERENCES . . . . . . . . . . . . . . . . . . . . . . 6

2.4 GENERAL INFORMATION . . . . . . . . . . . . . . . . 7

2.5 RECORDS ............................. 10

3.0 PRECAUTIONS AND LIMITATIONS . . . . . . . . . . . . . . . . . . . . 11

3.1 PERSONNEL SAFETY ............................. 11

3.2 RADIATION AND CONTAMINATION CONTROL . . . . . . . . . . 11

4.0 PREREQUISITES . . . . . . . . . . . . . . . . . . . 12

4.1 SPECIAL TOOLS, EQUIPMENT, AND SUPPLIES .......... 12

4.2 PERFORMANCE DOCUMENTS . . . . . . . . . . . . . . . . . . . 12

4.3 CONDITIONS AND ACTIONS . . . . . . . . . . . . . . . . . . 12

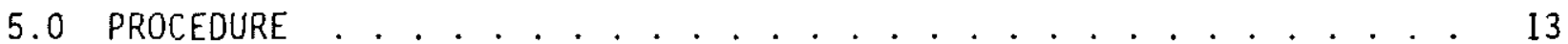

5.1 SETUP . . . . . . . . . . . . . . . . . . . 13

5.2 TEST INCREMENTAL SAMPLE MODE .............. 16

5.3 TEST USER DEF INED MODE . . . . . . . . . . . . . . . 23

TEST LOG . . . . . . . . . . . . . . . . . . . . 26

TEST PROCEDURE EXCEPTION LOG . . . . . . . . . . . . . . 27

TEST PROCEDURE EXCEPTION RECORD . . . . . . . . . . . . 27

SIGNATURE VERIFICATION LOG . . . . . . . . . . . . . . . 29

PROCEDURE HISTORY SIGNATURE SHEET . . . . . . . . . . . . 30

\begin{tabular}{|c|c|c|c|c|}
\hline CONT & $\begin{array}{l}\text { Dociment No: } \\
\text { OTP-260-004 }\end{array}$ & $\begin{array}{l}\text { RevfMod } \\
\text { A.0 }\end{array}$ & $\begin{array}{l}\text { Release Date } \\
02 / 09 / 2000\end{array}$ & $\begin{array}{l}\text { Page } \\
2 \text { of } 30\end{array}$ \\
\hline
\end{tabular}




\section{TEST EXECUTION SHEET}

\begin{tabular}{|c|c|}
\hline Date: & DOCUMENT NUMBER: \\
\hline \multicolumn{2}{|c|}{ Document Title: $241-A Z$ Gamma Cart Operational Test Procedure } \\
\hline \multicolumn{2}{|c|}{ TEST PERSONNEL (PRINT NAMES) } \\
\hline 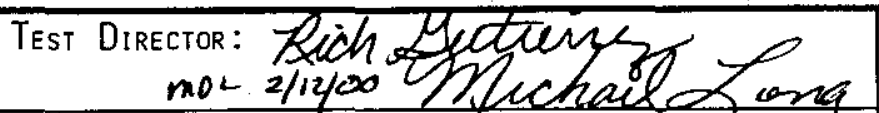 & Recorder: fich L \\
\hline \multicolumn{2}{|l|}{ Operations Enomeres: } \\
\hline \multicolumn{2}{|c|}{ TEST EXECUTION } \\
\hline Test Direcior Signature/Date: Rich gyatery & $\begin{array}{l}\text { Test Engineer Signature/Date: } \\
\text { Dubermentoga }\end{array}$ \\
\hline Operations Signature/Date: & Recorder Signature/Date:Pich sestateng \\
\hline \multicolumn{2}{|c|}{ APPROVAL AND ACCEPTANCE OF TEST RESULTS } \\
\hline $\begin{array}{cc}\text { Without EXCEPTION } & \text { With Exceptions } \\
\end{array}$ & $\begin{array}{c}\text { Resolved With Exceptions Remaining } \\
(\checkmark)\end{array}$ \\
\hline Test Director Signature/Date: & $\begin{array}{l}\text { Project Manager SignatuRE/Date: 3-30-00 } \\
\text { Pabamandoza for Sim Bellomy } \\
\text { per telecen }\end{array}$ \\
\hline Test Engineer Signature/Date: & $\begin{array}{l}\text { Quality Assurance Signature/Date: } \\
\text { wh aclanes 3/30/00 }\end{array}$ \\
\hline $\begin{array}{l}\text { Design Authority Signature/Date: } 3-30-00 \\
\text { Pube-menatoo for David Bragy per } \\
\text { zelecon }\end{array}$ & $\begin{array}{l}\text { Operations Engineer Signature/Date: } \\
\qquad \varepsilon a \text { andar } 3 / \% / 00\end{array}$ \\
\hline Authorized Inspector Signature/Date: & \\
\hline
\end{tabular}

\begin{tabular}{|c|c|c|c|c|}
\hline COpe & 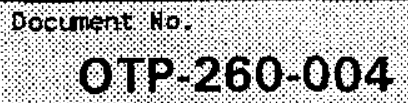 & Revraros & $02 / 09 / 2000$ & 3 of 30 \\
\hline
\end{tabular}




\subsection{PURPOSE AND SCOPE}

\subsection{PURPOSE}

This procedure provides instructions for performing an Operational Test Procedure for the Sludge Mobilization Cart System.

\subsection{SCOPE}

This procedure involves testing the Instrumentation involved with the Sludge Cart System, including: speed indicators, depth indicators, profile parameters, and retrieval functions.

This procedure may be repeated for either GAMMA CART A or GAMMA CART $B$ as applicable. The procedure(s) may work independently or simultaneously as work progresses in field.

\subsection{INFORMATION}

\subsection{TERMS AND DEFINITIONS}
2.1 .1
ALARA
- As Low As Reasonably Achievable

\subsection{RESPONSIBILITIES}

2.2.1 Test Engineer is responsible for the following:

- All preparations for this Test have been completed

- Support Test Director and Test Personnel with the technical information and support necessary to complete this procedure

2.2.2 Operation Personnel are responsible for operating the equipment per the Test Engineer and Test Director's direction. 


\subsection{RESPONSIBILITIES (cont.)}

2.2.3 Test Director is responsible for the following:

- The safe, efficient, and productive performance of the test

- Coordination of all testing activities

- Scheduling and conducting a pre-job meeting with test participants

- Notification of the persons performing and witnessing the test prior to the start of testing

- Notification of all involved test personnel when a change is made in the testing schedule

- Act as liaison between the participants involved with the testing

- Stopping any test or section which may cause damage to the system

- Obtaining revisions to the Test Procedure, to comply with authorized field changes or to accommodate existing field conditions

- Taking actions to resolve exceptions to the Test Procedure

- Signing the operational Test Procedure Exception Record when a test exception has been resolved

- Evaluating recorded data, discrepancies, and exceptions

- Signing Test Execution Sheet when this Test Procedure has been performed

- Signing Exception Record when a retest to clear an exception has been executed and accepted

- Obtaining required signatures on the Test Procedure Working Copy prior to reproduction and distribution

- Preparing and issuing an Operational Test Report for the approved, accepted and completed Test Procedure

\begin{tabular}{|c|c|c|c|c|}
\hline CONTINUOUS & OTP-260-004 & $\begin{array}{r}\text { Rev/Mad } \\
\mathbf{A - O} \mathbf{O}\end{array}$ & $02 / 09 / 2000$ & 5 of 30 \\
\hline
\end{tabular}




\subsection{RESPONSIBILITIES (cont.)}

2.2.4 QC Inspector is responsible for witnessing test execution and signing the completed sections of the test.

2.2.5 The Authorized Inspector is responsible for the following:

- Witnessing test execution

- Approval and signature of acceptance upon completion of this procedure.

\subsection{REFERENCES}

- HNF-SD-WM-PTP-027, Rev 3 Mixer Pump Test Plan for Double Shel1 Tank AZ-101

- HNF-3839 Data Collection PIan for AZ-101 Mixer Pump Tests

- RPP-5576 Gamma Cart System Description

- H-2-78973, R1 TANK AZ-101 TEMPERATURE PROBE INST PLAN AND ELEVATION

- H-2-79319, R2 TANK 101-AZ TEMPERATURE PROBE INSTALLATION SEQUENCE

- H-2-79215, R2 TWRS SLUDGE CART ENCL ELEC ASSEMBLY

- H-2-79232, Rl TWRS SLUDGE CART ENCL ELEMENTARY DIAGRAM

- H-2-79233, RO TWRS SLUDGE CART ENCL WIRING DIAGRAM

- H-2-79234, R3 TWRS SLUDGE MOBILIZATION CART ARRANGEMENT

- H-14-010507, RO DOME PENETRATION SCHEDULES TANK 241-AZ-101

Type Docloment No CONTINUOUS

OTP-260-004

Rev/Mod

A. 0
Release bate

$02 / 09 / 2000$ page

6 of 30 


\subsection{GENERAL. INFORMATION}

2.4.1 Procedural and technical requirement changes must be processed by Procedure Change Authorization in accordance with approved procedures. If a need for such a change is discovered in the course of running the test, the applicable portion of the test shall be stopped, and the test equipment shall be placed in a safe configuration, until the Procedure Change Authorization is approved. However, this does not prevent the running of another portion of the test unaffected by the change.

2.4.2 Operational Test steps detailed in individual Tests in Section 5.0 shall be performed sequentially, unless otherwise noted or as directed by the Test Director.

- Individual Test Procedure Sections may be performed out of sequence at the direction of the Test Director, if the intent of the test is not compromised

- As each step is completed, each step will be checked off (or enter "N/A" for), as required in the spaces provided on the Working Copy of this Operational Test Procedure

- Any step that requires verification of data must include recording data on the Working Copy.

2.4.3 Any non-conformance of the instrumentation, unexpected results or exceptions during testing shall be sequentially numbered and recorded in the Operational Test Procedure Exception Log and on individual Operational Test Procedure Exception Records. Thus, case-by-case resolution, recording, approval, and distribution of each exception will be achieved. 


\subsection{GENERAL INFORMATION (Cont).}

2.4.4 Resolve test exceptions in the following manner:

- Record the action taken to resolve each exception in the "Resolution of Exception" section of the Operational Test Procedure Exception Record.

- When the action taken results in an acceptable retest, initial and date the Correction Approval section of the Exception Sheet

- When the action taken does not result in an acceptable retest, provide a detailed explanation of why the retest action was not acceptable, and what additional plans are required. The Test Engineer then signs and dates the Resolution of Exception section of the Operational Test Procedure Exception Record, and obtains any other approvals required

2.4.5 Upon completion of the Operational Test Procedure, obtain approval of the test performance. Each Test Execution Sheet will stand alone as approval for the system under test. The Operational Test will be complete when all the outstanding tests have been performed and the Operational Test Report is prepared. The test will be approved by checking the proper response, with or without exceptions, on the Test Execution Sheet under the "Approval and Acceptance of Test Results" section of the Test Execution Sheet. 


\subsection{GENERAL INFORMATION (Cont).}

NOTE - The following steps detail the possible conditions that may exist at the completion of the Operational Test Procedure, and the steps necessary to complete acceptance in those conditions.

2.4.6 The completed test may be approved without test exceptions:

- Check applicable space on Test Execution Sheet to show that the Operational Test Procedure has been performed and no exceptions have been recorded

- Appropriate individual Test Performers will sign and date the Test Execution Sheet in the spaces provided

- Distribute requisite copies as directed by the client

- Send the Master Copy of the completed Operational Test Procedure to the client.

2.4.7 The completed test may be approved with exceptions resolved:

- $\quad$ Check applicable space on Test Execution Sheet to show that this procedure has been performed with exceptions recorded and resolved

- Appropriate individual Test Performers will sign and date the Test Execution Sheet in the spaces provided

- Distribute requisite copies as directed by the client

- Send the Master Copy of the completed Operational Test Procedure to the client. 


\subsection{RECORDS}

2.5.1 All personnel involved in the performance of this test shall sign in Procedure Signature Sheet.

2.5.2 Test results shall be recorded. All entries into this test procedure shall be made in black ink. Unless specific data is required, the signature or initials as applicable, of the person accepting the item will be entered in the blank provided to indicate compliance with the stated requirements or the successful completion of the given test step.

2.5.3 Errors shall be corrected by crossing out the incorrect data with a single line and the correct response shall be written in the direct vicinity of the original item. The person making the correction shall initial and date the correction.

2.5.4 A complete working copy of this procedure and any exception records generated shall be maintained as a permanent record.

2.5.5 An Exception Log and Exception Record sheet is attached in the event exceptions to the test are made when the test is being performed. All exceptions to the test are to be dispositioned and agreed to by all witnesses. Actions taken regarding disposition are noted on the exception sheet.

2.5.6 During the performance of this test, errors in test may be encountered which require correction or adjustment to complete the test. Such corrections are to be noted in the OTP and listed as an exception.

\begin{tabular}{|c|c|c|c|c|}
\hline CONTINUOUS & $\begin{array}{l}\text { Document No } \\
\text { OTP } 260-004\end{array}$ & $\begin{array}{l}\text { Rev/Mod } \\
\text { A.O }\end{array}$ & $\begin{array}{l}\text { Release bate } \\
02 / 09 / 2000\end{array}$ & 10 of 30 \\
\hline
\end{tabular}




\subsection{PRECAUTIONS AND LIMITATIONS}

\section{1 PERSONNEL SAFETY}

3.1.1 If the performance of this procedure is suspended for any reason, ensure the equipment is left in a safe state.

3.1.2 All lockouts and tagouts or over-tagging requirements shall be performed in accordance with Tank Farm Administration Manual, HNF-IP-0842, Vol II, Section 4.9.1.

3.1.3 If any equipment problem is observed during the performance of this procedure, immediately notify the Test Director.

3.1.4 Proper lifting techniques shall be utilized throughout the procedure and personnel shall take precautions to ensure back strain, pinchpoints and protective clothing are observed.

\subsection{RADIATION AND CONTAMINATION CONTROL}

3.2.1 Work in radiological areas will be performed using a radiation work permit following review by Radiological Control per the ALARA procedure HNF-IP-0842, Volume VII, Section 1.1. 


\subsection{PREREQUISITES}

\subsection{SPECIAL TOOLS, EQUIPMENT, AND SUPPLIES}

The following supplies may be needed to perform this procedure:

- Riser Swabbing equipment

- Riser extension tool

\subsection{PERFORMANCE DOCUMENTS}

The following procedures may be needed to perform this procedure:

- TO-040-333 LIQUID OBSERVATION WELL (LOW) SURVEILLANCE VAN STARTUP AND OPERATION PROCEDURE

\subsection{CONDITIONS AND ACTIONS}

NOTE -

All signators on this procedure shall document their signature on Procedure Signature Sheet.

4.3.1 All pre-testing and inspection of the system or portions of the system to be tested has been completed.

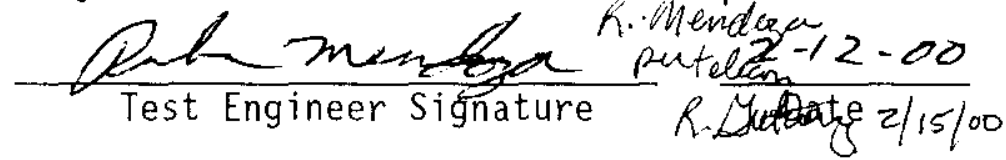

4.3.2 A pre-job briefing has been held. and all participants have been thoroughly briefed on job safety, hazards, and their responsibilities before performing this ATP.

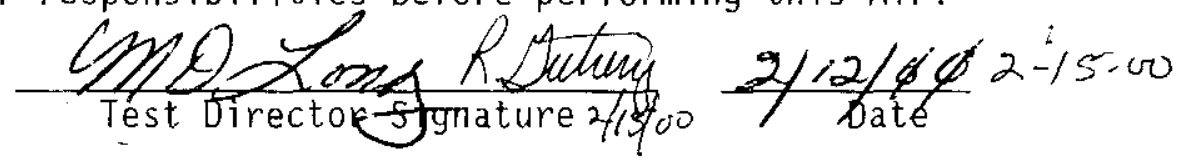

4.3.3 Test Director VERIFY section 4.3 has been COMPLETED.

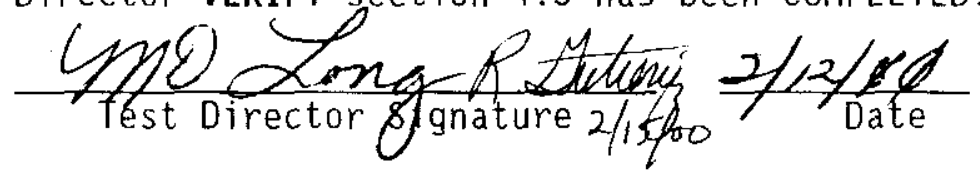




\subsection{PROCEDURE}

\subsection{SETUP}

NOTE - This procedure may be repeated for either GAMMA CART A or GAMMA CART B as applicable. N/A may be entered in blocks or steps per Test Director as applicable.

5.1.1 RECORD GAMMA CART CPU number for the system being tested. GAMMA CART IDENTIFIER \# $\frac{B}{B} \frac{w S T-R Y 403}{\text { CPU Number }}$

$\checkmark$ 5.1.2 PERFORM cleanliness check in applicable riser listed on TABLE II, per section 5.10 in procedure T0-040-333 1atest rev, prior to mounting riser extension tool.

5.1.3 ENSURE GAMMA CART riser extension tool is mounted on the applicable riser.

5.1.4 ENSURE GAMMA CART is placed in line with riser extension tool to facilitate installation of probe and cables.

$\checkmark$ 5.1.5 CHECK route to riser for obstacles and clearances.

5.1.6 LEVEL cart using jacks,

5.1.7 CONNECT gamma cart power cables, as follows:

- One end to gamma cart power receptacle

- $\quad$ other end to Junction Box, JB-101-100, Power

Receptacle, OR Junction Box, JB-101-101

5.1.8 CONNECT gamma cart communications cable, as follows:

- One end to gamma cart communications receptacle

- $\quad$ other end to Tank 241-AZ-101 Gamma Cart A AND/OR B

Data Collection Subsystem communications receptacle

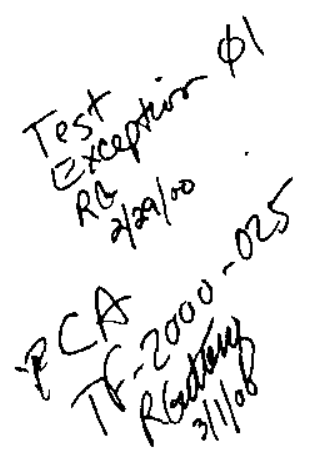

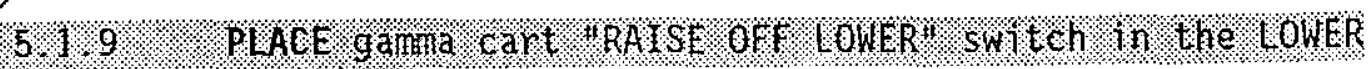
pos 1 . 101 \%

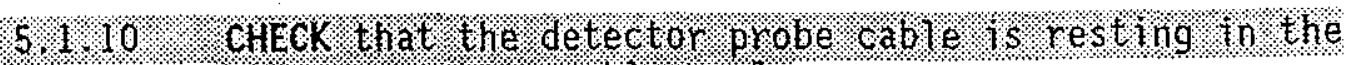

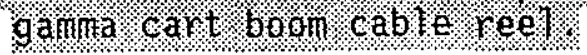

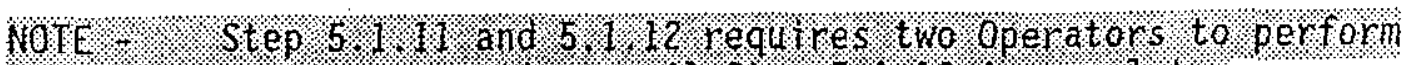

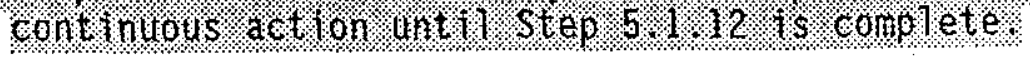




\section{WARNIMG}

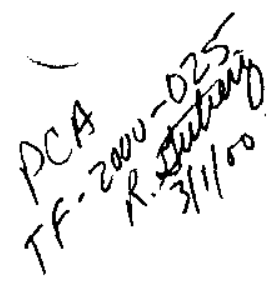

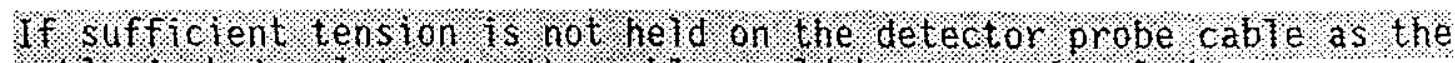
cable is be ing let aut, the cable coutd becone entangled.

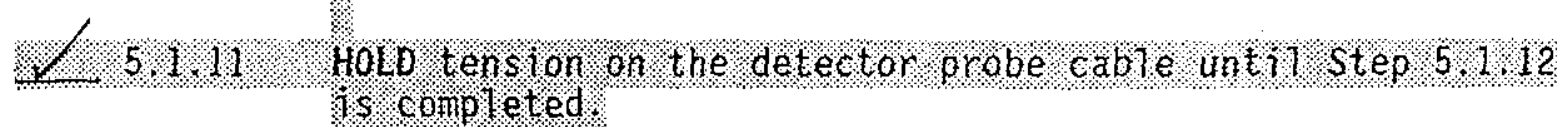

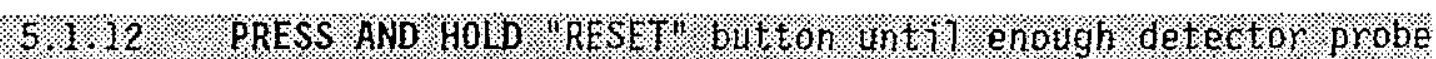

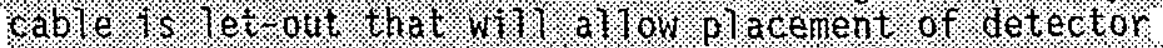

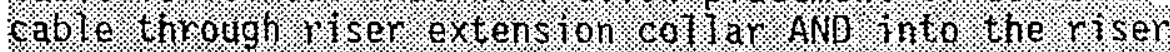
arote 1.00

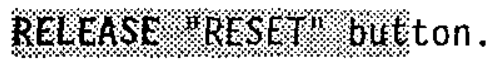

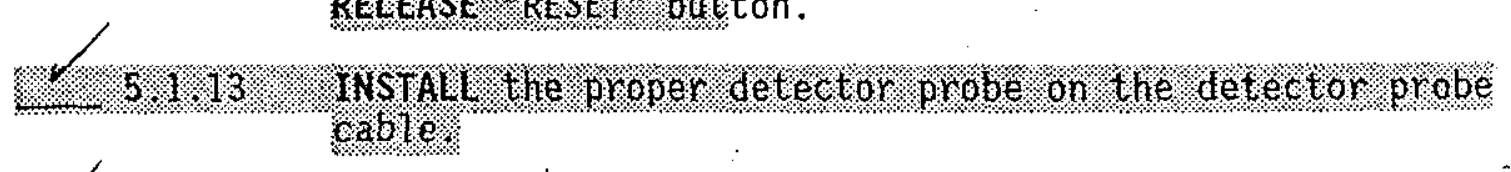

$\checkmark$ 5.1.14 ENSURE that the detector probe connections are correct and tight. AND

- INSERT probe into riser extension tool. 


\subsection{SETUP (Cont).}

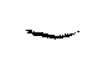

5.1 .10

ENSURE limit switch cable is connected from limit switch on riser extension tool, to the connection point on the front of the GAMMA CART.

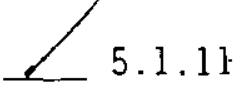

ENSURE the "Raise - Off - Lower" selector switch is in the "OFF" position.

\section{1 .12}

ENSURE the emergency stop button is pulled out.

5.1 .13

POSITION the "SPEED" control potentiometer to MIN speed (fully counter-clockwise).

\section{CAUTION}

There is no limit switch to stop the motion when the cable is fully unwound. The cable will rewind backwards on the reel. Damage to the cable may result.

NOTE - When the cart is first powered up, or the emergency stop button has been pushed, or power has been restored after a power failure, the cable reel will not move up or down until "RESET" button is activated.

- The "Raise-OFF-Lower" Switch is Manually controlled and is operator Dependent.

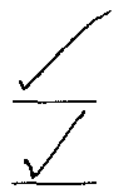

5.1 .14

ENSURE LOCAL/REMOTE switch is in the "LOCAL" position.

5.1 .15

ENERGIZE the cart.

$\stackrel{\swarrow}{\longleftarrow} 5.1 .16$

SET the "SPEED" potentiometer to 2 on the GAMMA Cart.

SET the "RAISE -OFF- LOWER" switch to the "LOWER" position.

5.1 .18

PUSH "EMERGENCY STOP" button on GAMMA CART.

5.1 .19

VERIFY the system has stopped.

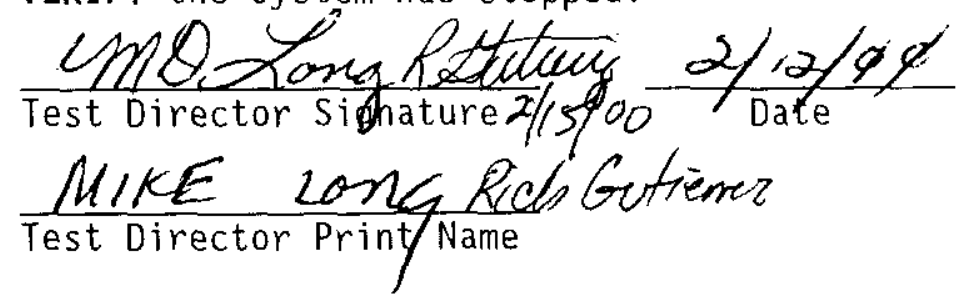




\subsection{SETUP (Cont).}

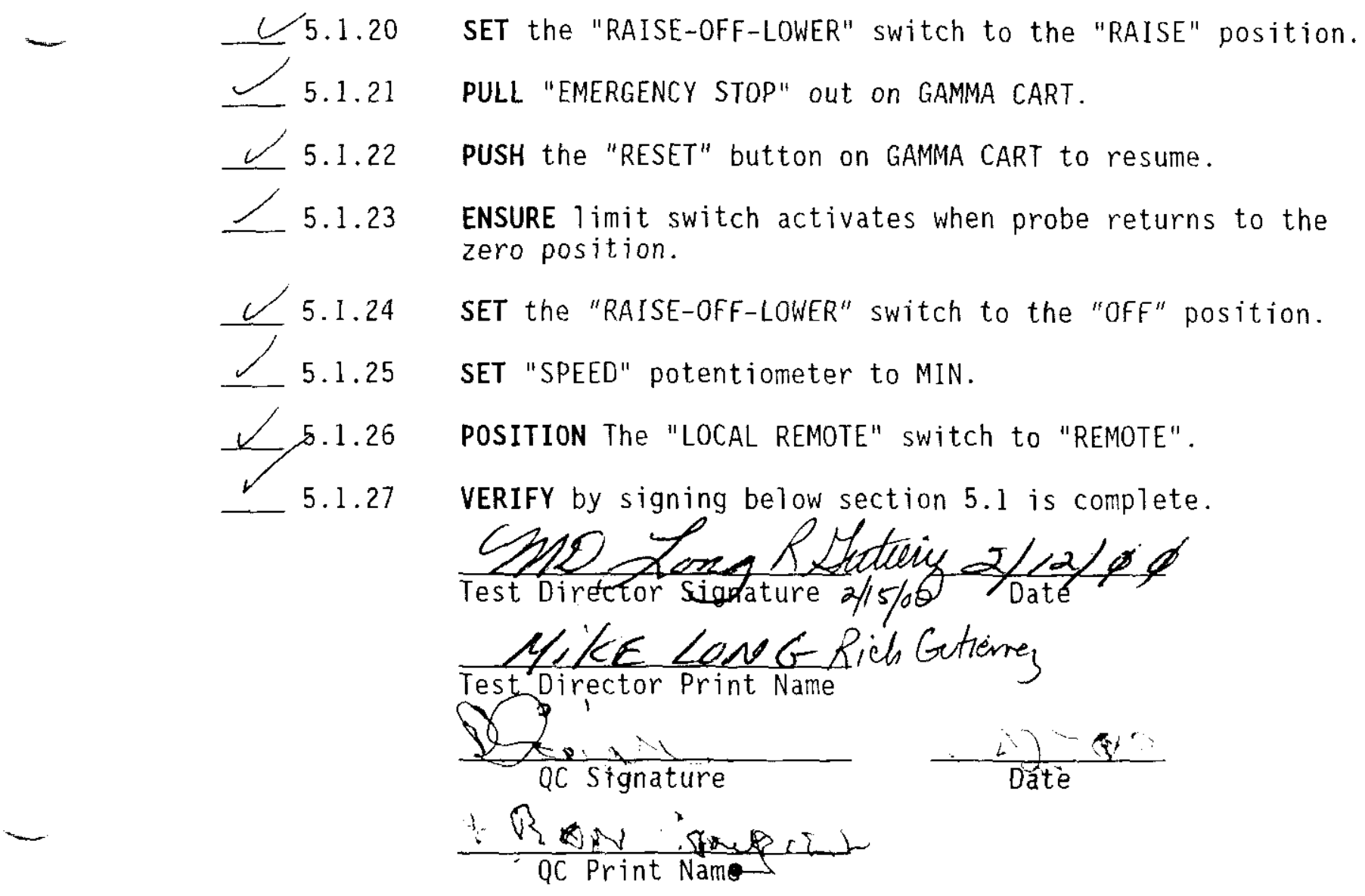




\subsection{TEST INCREMENTAL SAMPLE MODE}

\section{SETUP}

NOTE - All Steps in this section apply to either cart, except in those steps where the specific cart is indicated.

\section{INSTRUMENT CHECK}

5.2.1 IF the pushbutton for Tank 241-AZ-101 Gamma Cart A AND/OR $B$ Data Collection System Central Processing Unit (CPU), AND/OR asSOciated MONITOR, are NOT ON, PRESS the

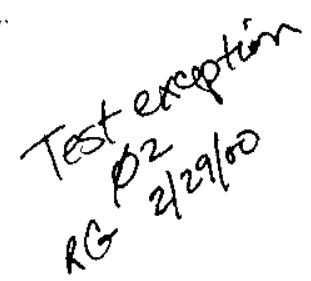
applicable ON pushbuttons.

ENSURE the following systems are ON AND

ENSURE settings are correct for the following:

- $\quad$ ORTEC MINIBIN

- pOWer suppl.y

Detector Bias Power Supply (HVPS): ORTEC Mod. 478.

- $\mathrm{kV}: .5$

- 0 to 1000v: (+60 volts)

Amplifier (AMP): ORTEC Mod. 673

- COARSE GAIN: 200

- FINE GAIN: 0.680

- SHAPING TIME: Both knobs set to 2 microseconds

- PZ Adjust: Do NOT change settings (in this procedure)

- BLR: Switch in AUTO (up) position

- INPUTS: Switch in POS (up) position BNC cable on terminal (from pre amplifier)

- OUTPUTS: cable on UNIPOLAR terminal(to single channel Analyzer)

5.2.3 WHEN WINDOWS login screen appears CLICK ON "CANCEL". 


\subsection{TEST INCREMENTAL SAMPLE MODE (Cont).}

NOTE - After canceling windows login, GAMMA CART software should automatically load.

5.2.4 VERIFY "GAMMA CART SPECTRUM ANALYZER AND CONTROL SYSTEM" screen is displayed on Tank 241-AZ-101 Gamma Cart A AND/OR B Data Collection System Monitor.

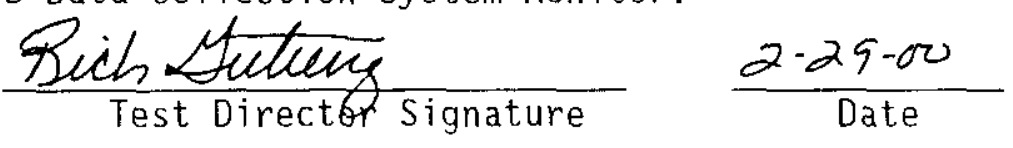

Tich Gutierrez

Test Director Print Name

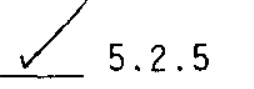

SELECT "Login" on the "GAMMA CART SPECTRUM ANALYZER AND CONTROL SYSTEM" screen.

NOTE - LOGIN passwords and information may be obtained from Test Director.

5.2.6 LOG-IN.

5.2.7 VERIFY LOCAL/REMOTE switch on display screen is in "REMOTE" pOSition.

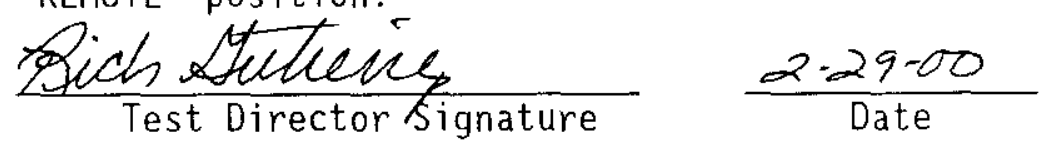

$\frac{\text { Pich Gutienes }}{\text { Test Director Print Name }}$ 


\subsection{TEST INCREMENTAL SAMPLE MODE (Cont).}

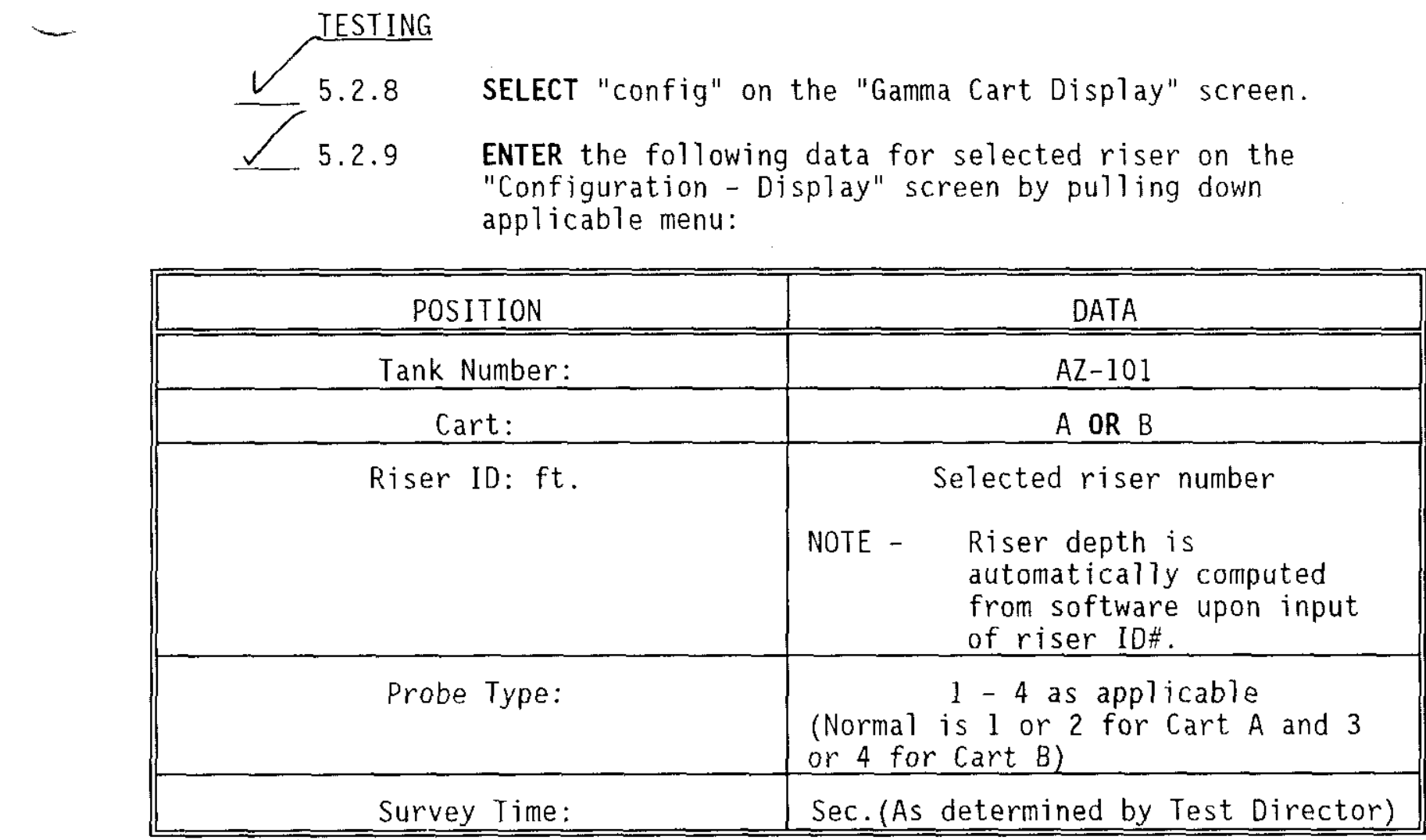

5.2.10 ENSURE REAL/LIVE toggle button indicates "LIVE".

5.2.11 On the Data Collection Configuration window, SELECT the "Incremental" button.

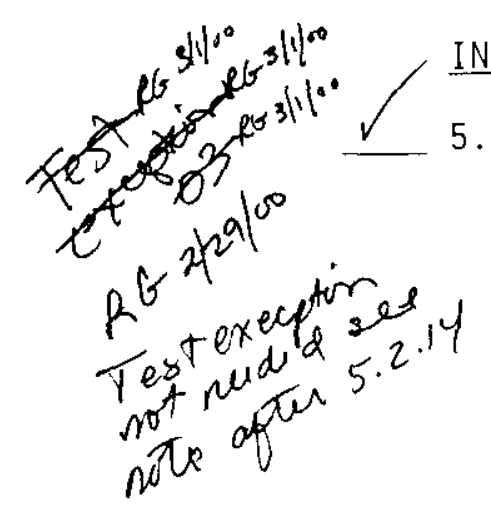

INCREMENTAL PARAMETERS

5.2.12 INPUT the following Sample Collection Data:

\begin{tabular}{|l|l|}
\hline $\begin{array}{l}\text { Sample Start } \\
\text { Depth: }\end{array}$ & 50 \\
\hline Interval Size: & $10.0 \mathrm{ft}$ \\
\hline Sample End Depth: & $5.0 \mathrm{ft}$ \\
\hline
\end{tabular}

\begin{tabular}{|c|c|r|r|r|r|}
\hline CONTINUOUS & OTP-260-004 & A-0 & $02 / 09 / 2000$ & 18 of 30 \\
\hline
\end{tabular}




\subsection{TEST INCREMENTAL SAMPLE MODE (Cont).}

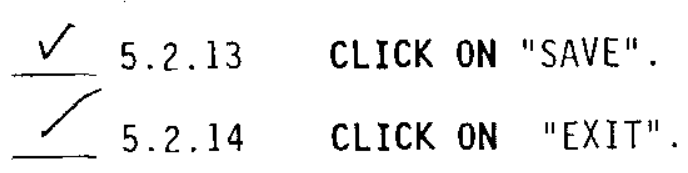

NOTE - Test Engineer may manipulate parameters at any time during the following steps as necessary to ensure data retrieval and system configuration, with concurrence of Test Director.

- After the following step, the program should automatically run.

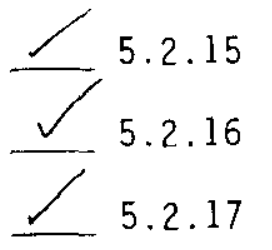

CLICK ON "Start" button.

CLICK ON "EMERGENCY STOP" button on computer screen.

VERIFY System stopped.

Pichnetieny $\frac{2-29-00}{\text { Date }}$

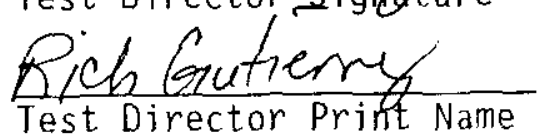

5.2.18 CLICK ON "EMERGENCY STOP" again to RESET the emergency stop button on computer screen.

5.2.19 CLICK ON "ZERO" on display screen.

5.2.20 ENSURE GAMMA PROBE begins to RAISE.

5.2.21 CLICK ON "STOP" button on display screen. 


\subsection{TEST INCREMENTAL SAMPLE MODE (Cont).}

5.2.22 VERIFY System stopped.

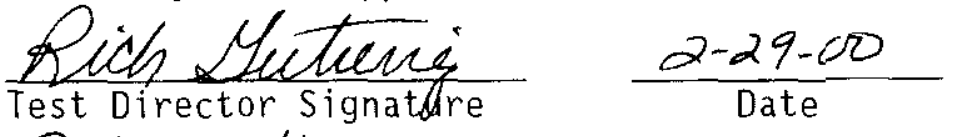

$\frac{\text { fich Gutiewez }}{\text { Test Director Print Name }}$

5.2 .23

CLICK ON "ZERO" again on display screen.

5.2.24 ENSURE GAMMA PROBE begins to RAISE.

5.2.25 When probe and system zeros, CLICK ON "START" on display screen.

VERIFY System resumed program.

Dichsfuterneg $\frac{2-29-00}{\text { Date }}$

BichGutiorrez

Test Director Print Name

5.2.27 CLICK ON "STOP" button on computer screen.

5.2.28 VERIFY System stopped.

$\frac{\text { Sichsoutreines }}{\text { Test Director Signature }} \frac{2-29-00}{\text { Date }}$

Bich Gufiernz

5.2.29 CLICK ON "ZERO" on display screen.

5.2.30 When probe and system zeros, CLICK ON "START" on display screen.

5.2.31 VERIFY system resumed program.

Fich Netury $\frac{2-29-00}{\text { Date }}$

$\frac{\text { Rich Gutierrez }}{\text { Test Director Print Name }}$ 


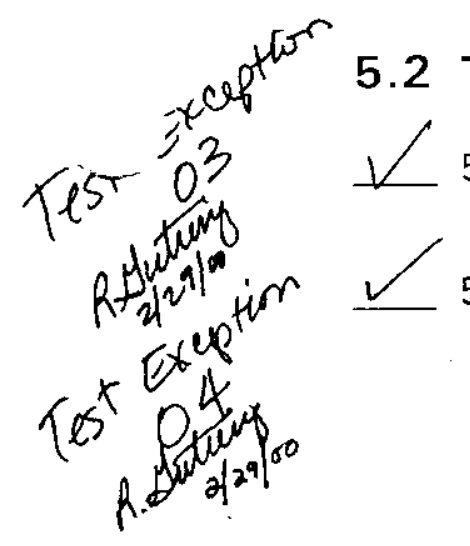

5.2.32 Test Engineer ENSURE data is received, AND both hard-copy and electronic files can be retrieved.

5.2.33 VERIFY system automatically ZEROs and data is collected at zero position.

Olchenatemis

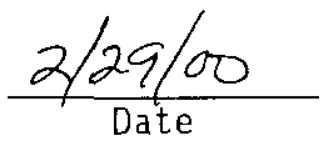

$\frac{\text { Pich Guterrez }}{\text { Test Director Print Name }}$

NOTE - The steps in section 5.1, applicable to the Emergency stop, need not be repeated if completed for an individual GAMMA CART. The Emergency stop on BOTH GAMMA CART $A$ and $B$, need to be tested only once.

NOTE - It is NOT necessary to do ALL risers in one procedure.

Test Director is responsible for ensuring ALL risers have been profiled by one AND/OR the other GAMMA CART(S).

* $\checkmark$ 5.2.34 REPEAT applicable SETUP Steps in section 5.1 AND

Incremental testing steps 5.2.1 - 5.2.15 AND Steps 5.2.32 and 5.2 .33 for each of the following risers and depths per Test Director's direction.

TABLE I

\begin{tabular}{|l|l|}
\hline RISER & $\begin{array}{l}\text { Depth } \\
\text { inches (ft) }\end{array}$ \\
\hline $14 A$ & $660(55.0)$ \\
\hline $14 E$ & $660(55.0)$ \\
\hline $14 D$ & $660(55.0)$ \\
\hline $14 F$ & $660(55.0)$ \\
\hline $14 G$ & $660(55.0)$ \\
\hline $14 B$ & $660(55.0)$ \\
\hline $14 E$ & $660(55.0)$ \\
\hline $15 I$ & $684(57.0)$ \\
\hline $15 C$ & $684(57.0)$ \\
\hline $15 E$ & $684(57.0)$ \\
\hline $15 B$ & $684(57.0)$ \\
\hline $15 F$ & $684(57.0)$ \\
\hline \hline
\end{tabular}

* 14 D riser completed with this procedure. 
WORKING OOF

Print 1 on: Feb $12,007: 25$ am

5.2 INCREMENTAL SAMPLE MODE (Cont).

NOTE - In the following Table, Test Director N/A blocks that are tested with a different GAMMA CART.

5.2.35 VERIFY the applicable riser in step 5.2 .34 has been tested.

TABLE II

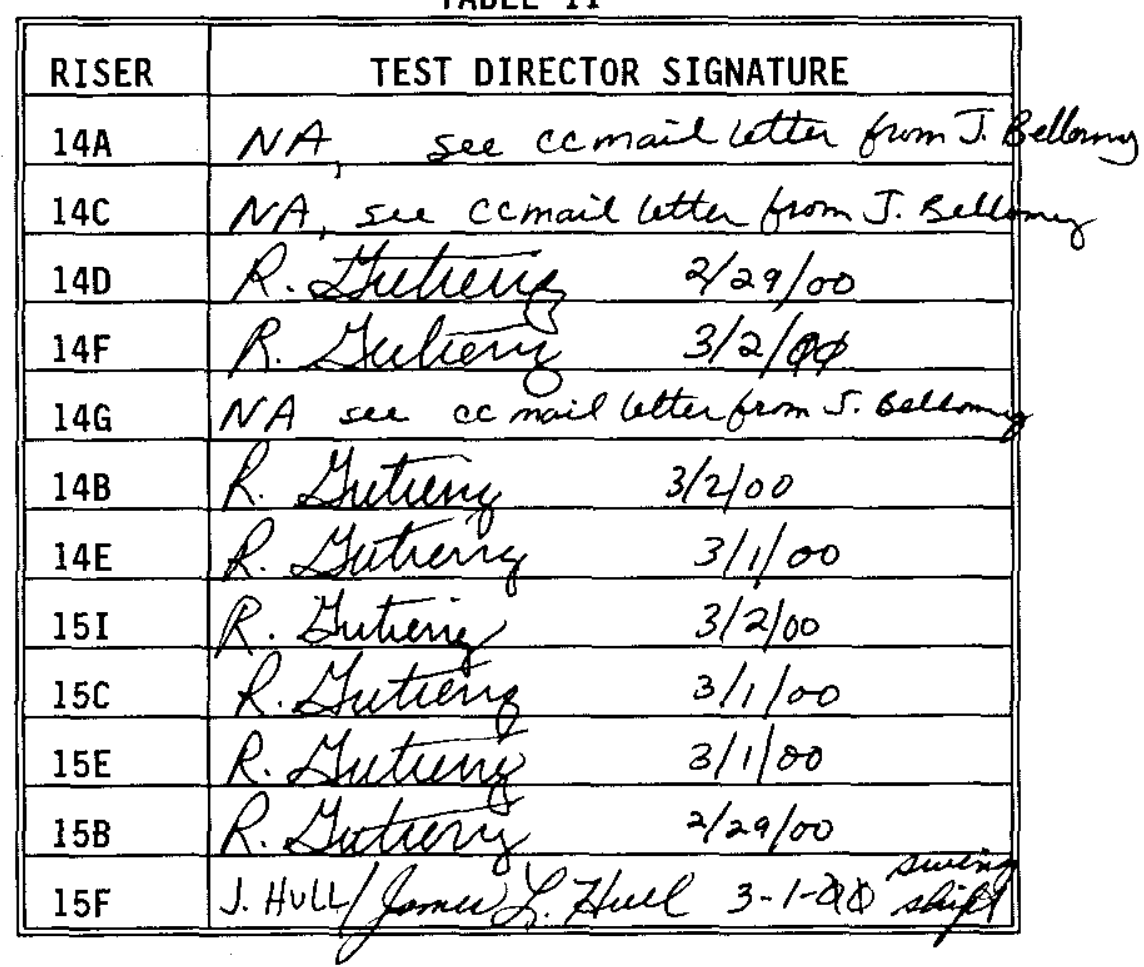

5.2.36 VERIFY by signing below section 5.2 is complete.

Rich Syetwery

Rich Gutierrez

Testoirector Print Name

$$
\frac{\text { ant Wen }}{\text { QT Signature }} \frac{2-29-00}{\text { Date }}
$$

GulA. Werner

QC Print Name

Unresolved test exceptions at this time.
$5: 470 m$ 2-29-9o

PAW

Riser /4D

\begin{tabular}{|l|r|r|r|r|r|}
\hline CONTINUOUS & OTP-260-004 & Al & Release date \\
$02 / 09 / 2000$ & 22 of 30 \\
\hline
\end{tabular}




\subsection{TEST USER DEFINED MODE}

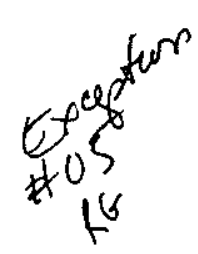

5.3.1 ENSURE applicable SETUP Steps in section 5.1 are
completed.

\section{CART CONTROL SCREEN}

$\int 5.3 .2$ On the Gamma cart Control, Cl.ICK oN the "Config." button.

5.3.3 INPUT the following data:

\begin{tabular}{|c|c|}
\hline POSITION & DATA \\
\hline Tank Number: & $A Z-101$ \\
\hline Cart: & $\mathrm{A} O \mathrm{OR} B$ \\
\hline Riser ID: ft. & $\begin{array}{l}\text { Selected riser number } \\
\text { NOTE - } \quad \text { Riser depth is } \\
\text { automatically computed } \\
\text { from software upon input } \\
\text { of riser ID\#. }\end{array}$ \\
\hline Probe Type: & $\begin{array}{l}1-4 \text { as applicable } \\
\text { (Normal is } 1 \text { or } 2 \text { for Cart A and } 3 \\
\text { or } 4 \text { for Cart B) }\end{array}$ \\
\hline Survey Time: & Sec. (As determined by Test Director) \\
\hline
\end{tabular}

USER DEFINED PARAMETERS

5.3 .4 CLICK ON "USER DEFINED".

5.3.5 ENTER depths desired for testing per Test Engineer

Direction.

5.3.6 CLICK ON "SAVE" on display screen.

5.3.7 CLICK ON "EXIT". 


\subsection{TEST USER DEFINED MODE (Cont).}

NOTE - Test Engineer may manipulate parameters at any time during the following steps as necessary to ensure data retrieval and system configuration, with concurrence of Test Director.

- After the following step, the program should automatically run.

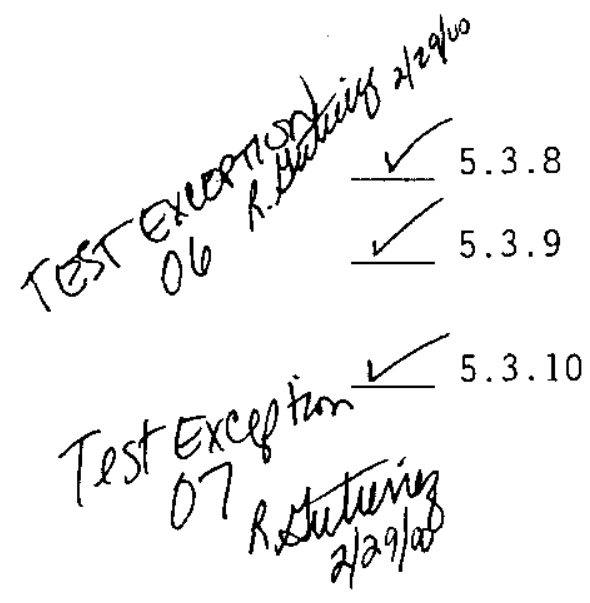

- The "EMERGENCY STOP" may be used to stop at any time during the next step if unit fails to stop at limit switch. The "RESET" button will need to be pushed to resume the program.

CLICK ON Start button.

Test Engineer ENSURE data is received, AND both hard-copy and electronic files can be retrieved.

VERIFY system automatically ZEROs and data is collected at zero position.

$\frac{\text { Pich Gutzenes) }}{\text { Test Director Signature }} \frac{2-29-00}{\text { Date }}$

Fich Gutiemez 
WORKING COP

Priv Ion: Feb $12,007: 25$ am

5.3 TEST USER DEFINED MODE (Cont).

4.3 .11 CLICK ON "LOGOUT" on display screen.

5.3.12 REMOVE Probe, riser extension tool, and associated equipment AND

STORE per Test Director direction.

$\mathrm{OR}$

CONTINUE in this procedure.

5.3 .13

REPEAT the steps in this section (5.3) as directed for any risers as directed by Test Director.

$\sqrt{5.3 .14}$

VERIFY by signing below section 5.3 is complete.

Richdyetrewe

$$
\frac{2 / 2 q / 00}{\text { Date }}
$$

Rich Gutierrez

Test Director Print Name

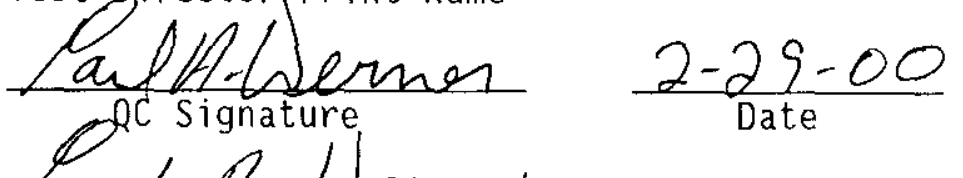

$\frac{\text { Pul A. Werner }}{\text { Qc Print Name }}$

Unresdued test exceptions at this time. $6: 45$ pm 2-29-00 PAC

Riser $14 D$

CONTINUOUS $/$ Document No. $260-004$

Release Date

$02 / 09 / 2000$

25 of 30

$A-30$ 
WORKING CC

Pr Jon: Feb 12, 00 7:25 am

\begin{tabular}{||c|c|c||}
\hline \multicolumn{2}{|c|}{ TEST LOG } & Page / of \\
\hline Date & comment & Name \\
\hline$S /$ KG & Test Engines troubleshooting communication. \\
\hline $2 / 15 / 00$ &
\end{tabular}

cable from Gamma Cart B to Monitoring system in

Az-156. We are experiencing frequency interference. Roth ts.

2/29/00 Inst. Techs installed comm, cable per R. stutieney

ECN 2E-99-0099. Started off

260.004 at 1430 . Risen 140

2030 Completed testing on Riser 14D,

Set up to contender on riser 15B.

We fils sow with concurrence

from Test Engineer, Test Director, QA,

QC, +AI the applicable steps in

$5.1+5.2 \times 5.3$ can be performed at

Test Directors direction. The step

in question is 5.2.34, we interpreted

this step as stating that repeating steps

in sections $5.1,5.2+5.3$ can be left up to

Test Directors direction.

CE Concurance rex Adam 34100

Rtemestats per telecoms concurrent dated $2 / 29 / 0^{\circ}$

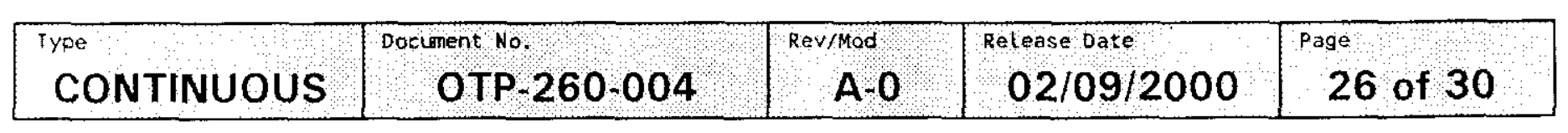

$A-3$ 


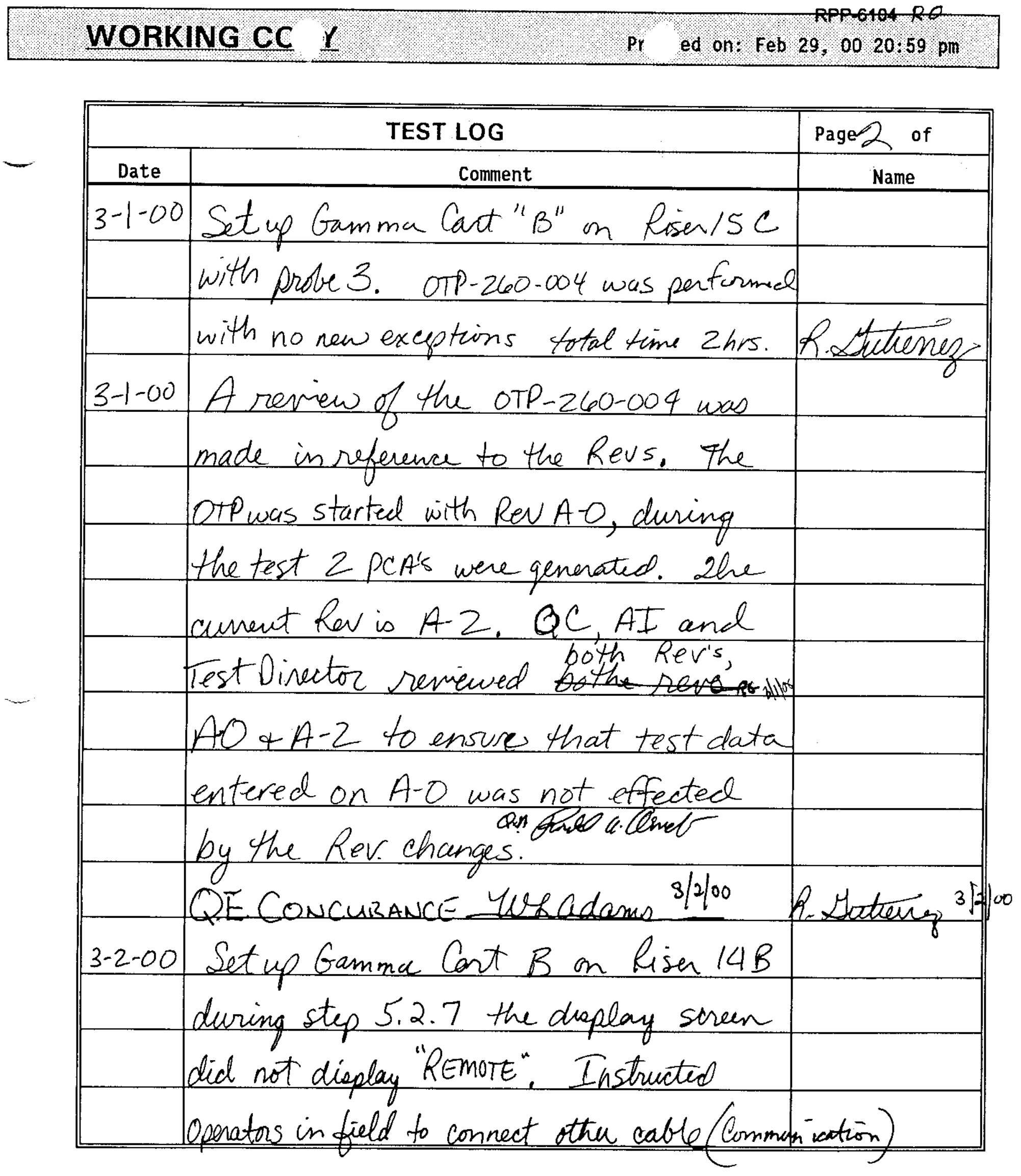

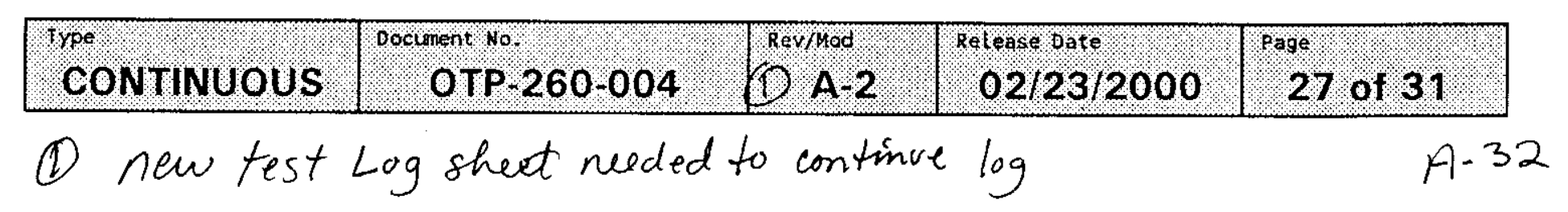


WORKING CO.

Pr. d on. Mar 1, 0012.39 pm

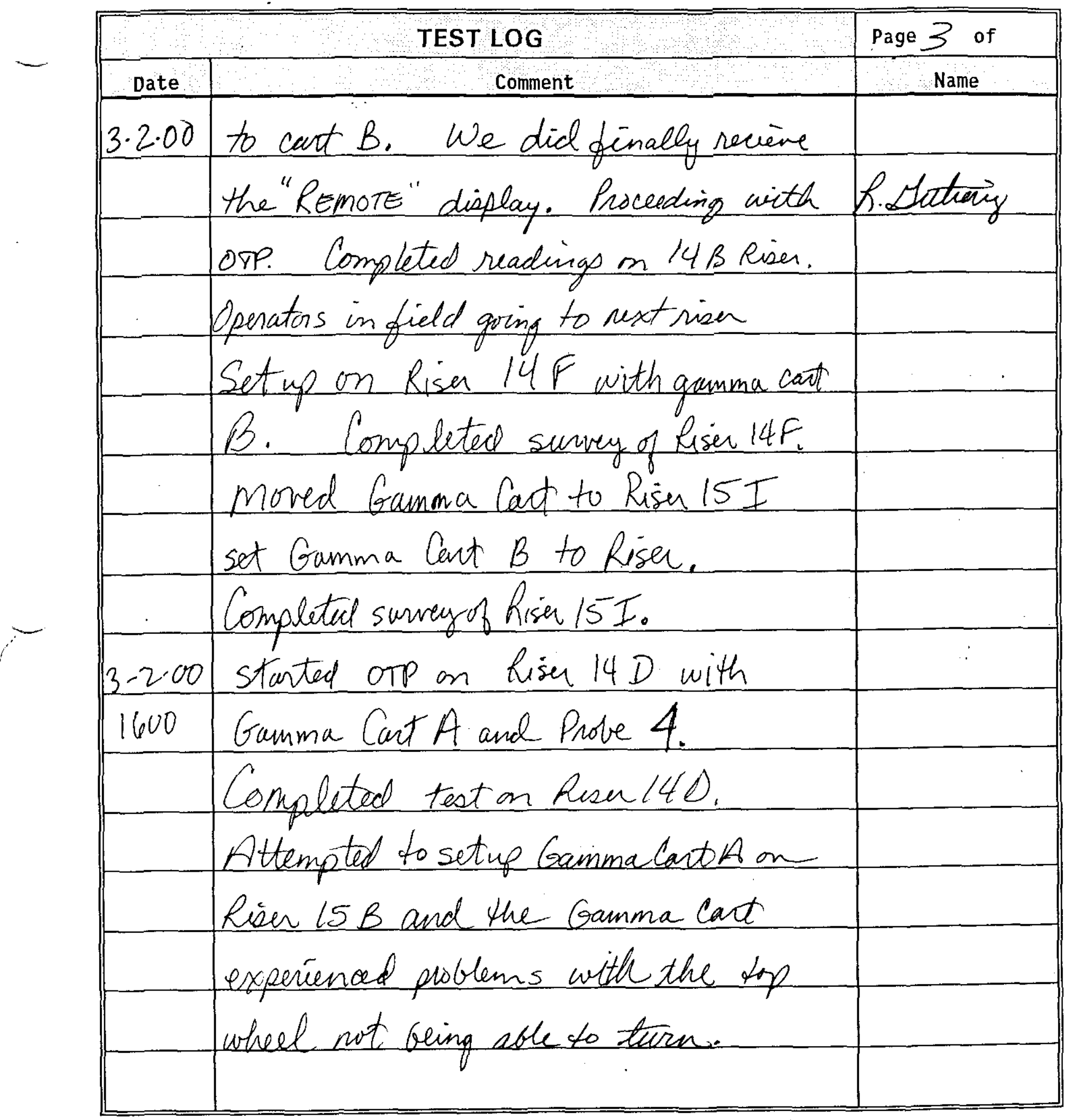

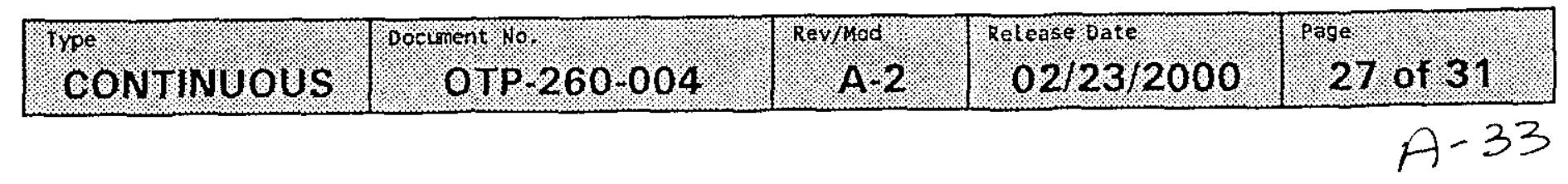


WORKING CC 1

Pp 6104 PO

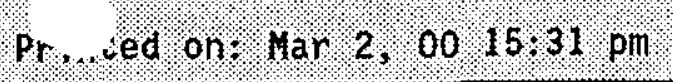

$-$

2045 Completed testing on Riser 14D with Rifutrum Gumma Cart $A$. With concuneme from Test Engine, Test De rector, QA, QC \&AL the applicable steps in $5.1+5.2+5.3$ can be performed at Test Directors diction. The step in question is 5.2.34, we intupietel this step as stating stating that repeating steps in sections 5.1,5.245.3 can be left up to Test Directors direction.

QE Concurrence: Wo adams $3 / 2100$

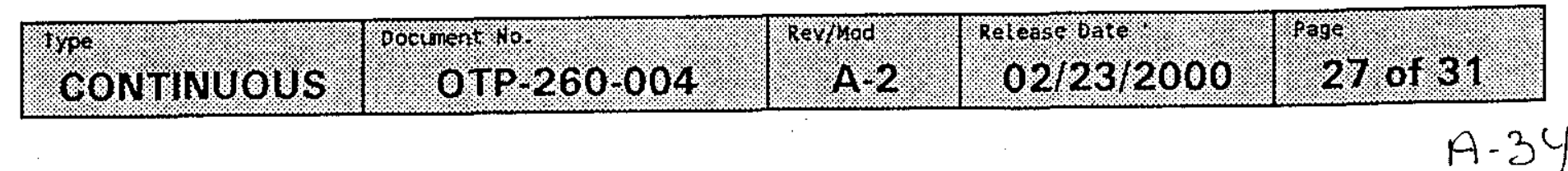


WORKING CC Y

Pl fed on: Mar 2, $00 \quad 15: 31 \mathrm{pm}$

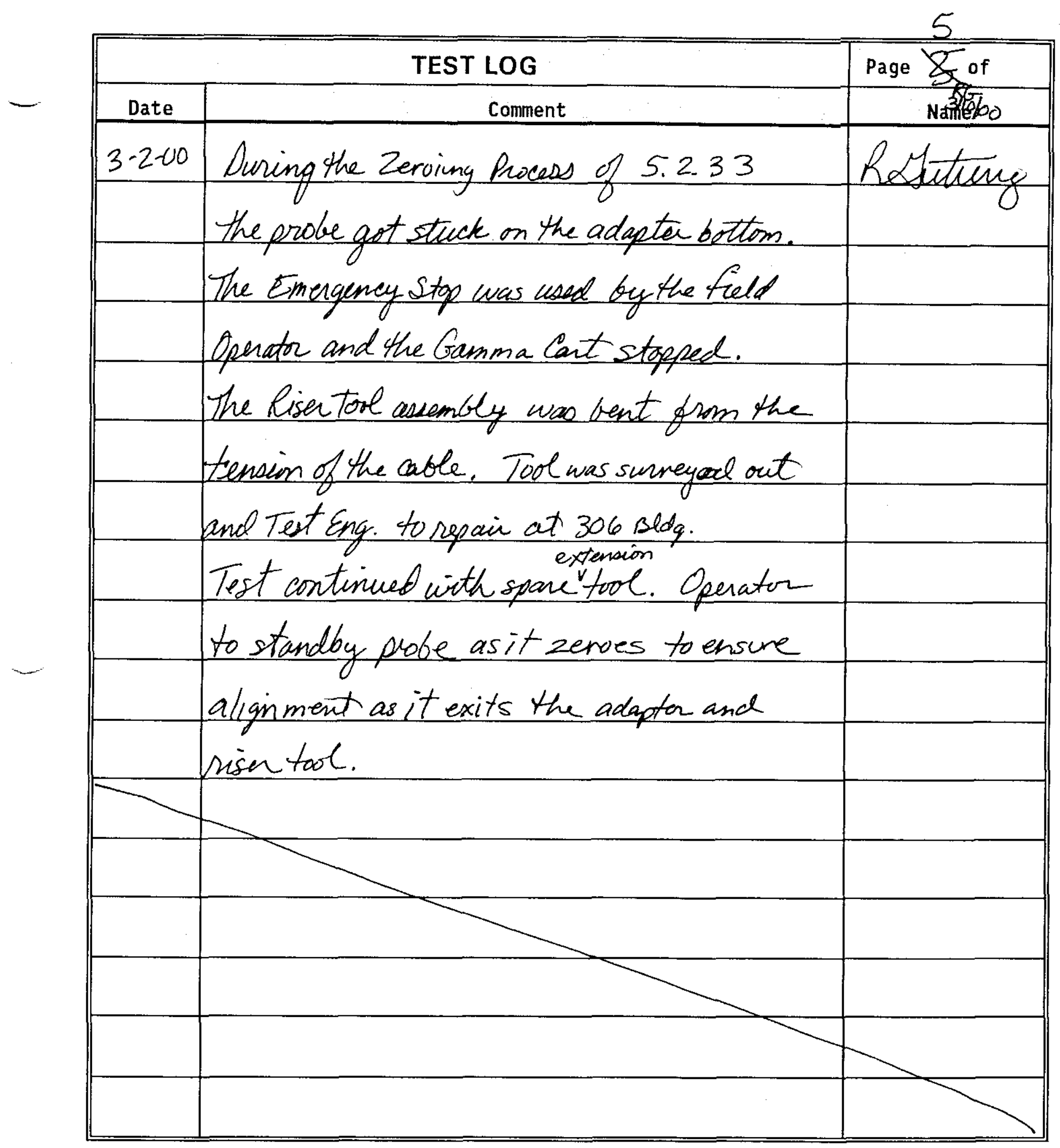

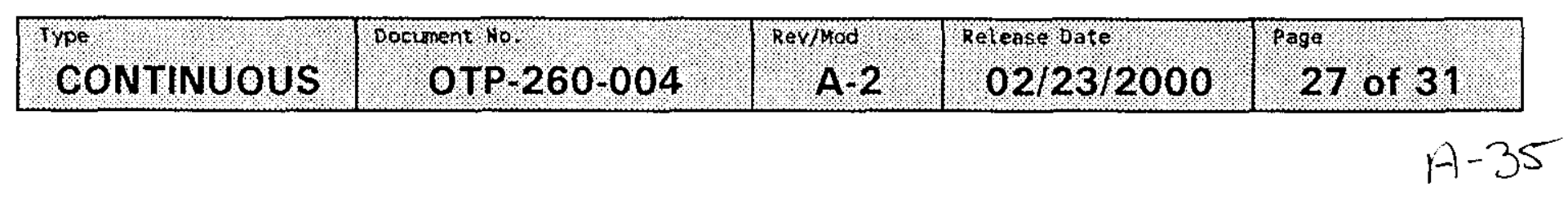


WORKING CL $r$

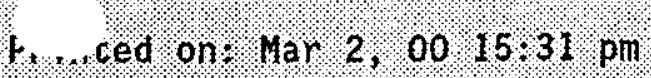

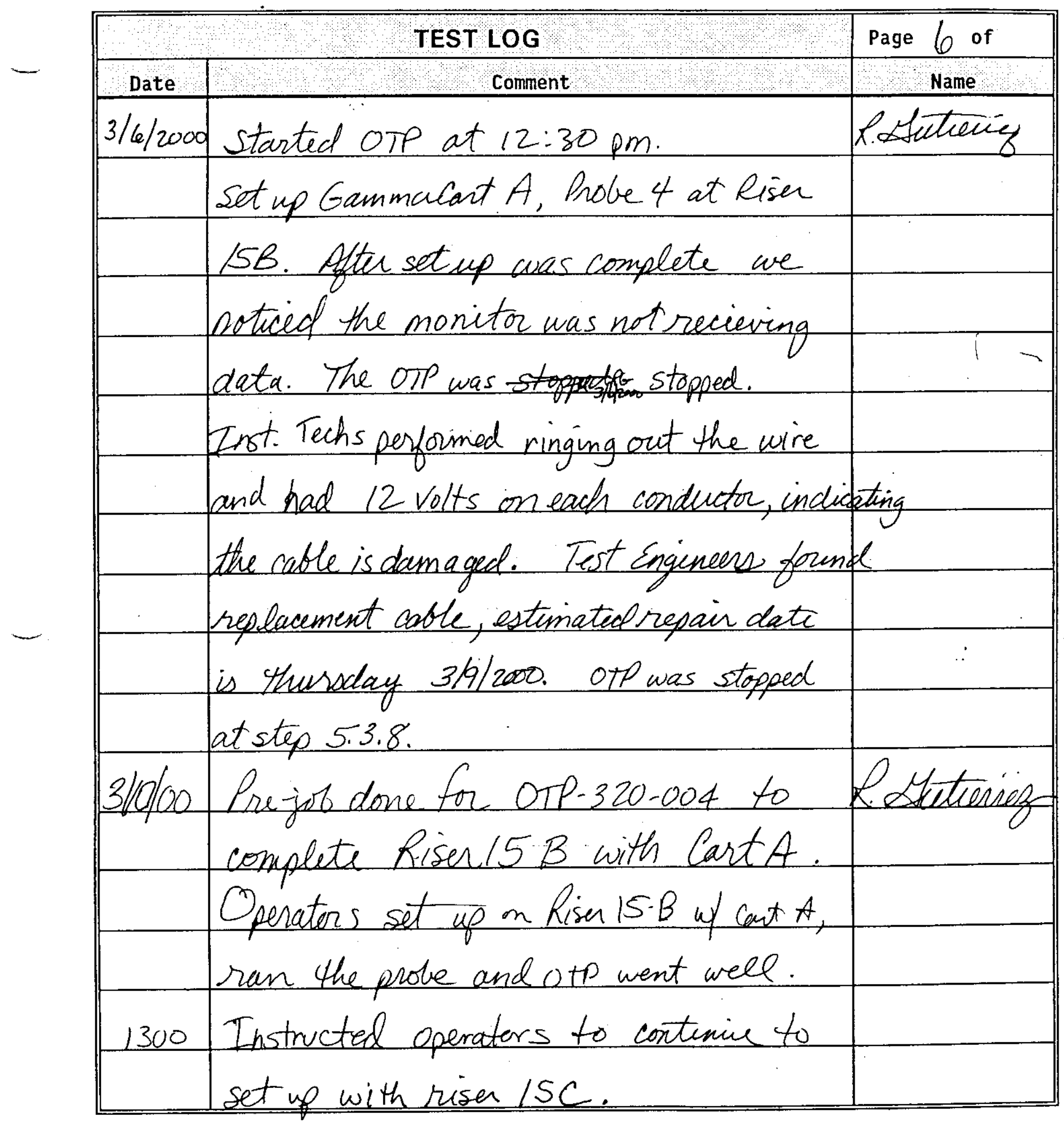

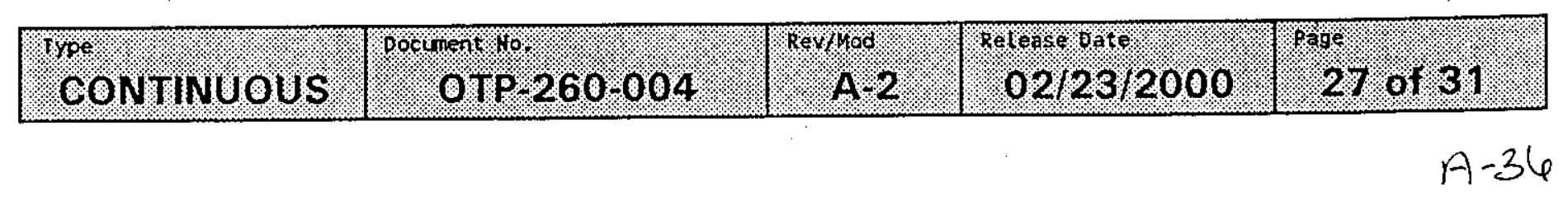




\section{WORKING CL.Y}

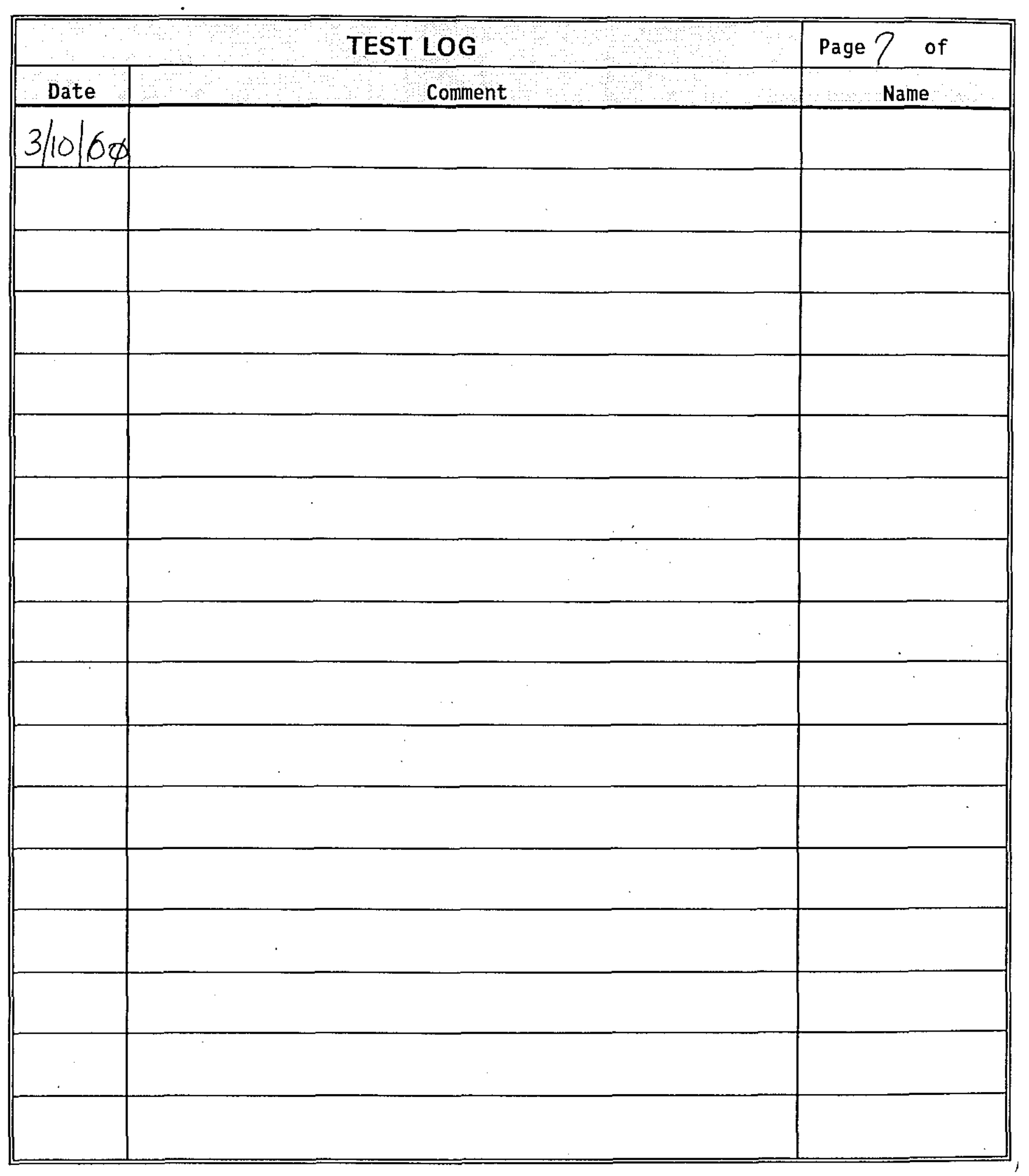

$\mathrm{ReN100}$

A. 2 .
Releas 6 ore

$02 / 23 / 2000$ 
WORKING CC :

P. don: Feb $12,007: 25 \mathrm{am}$

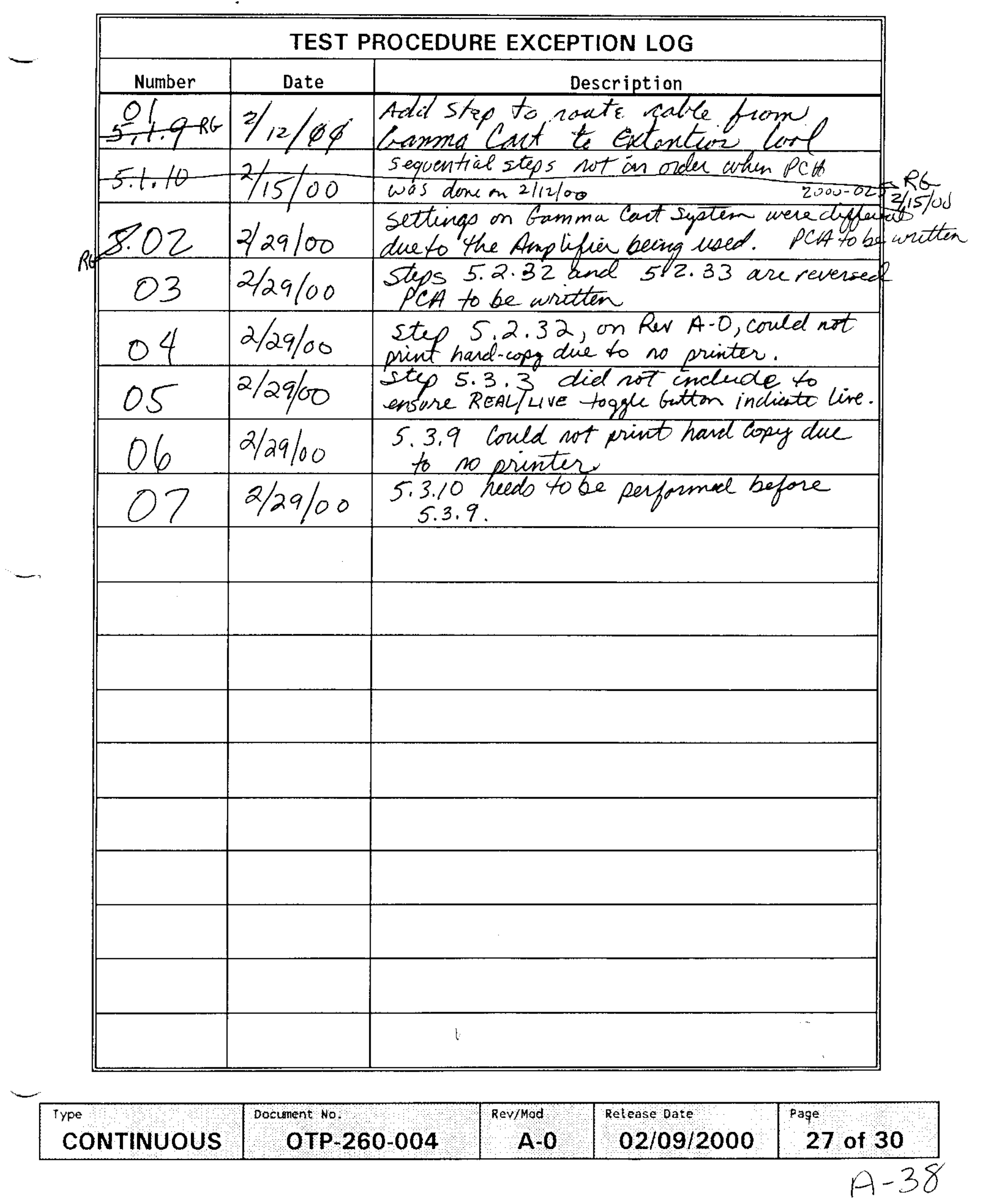




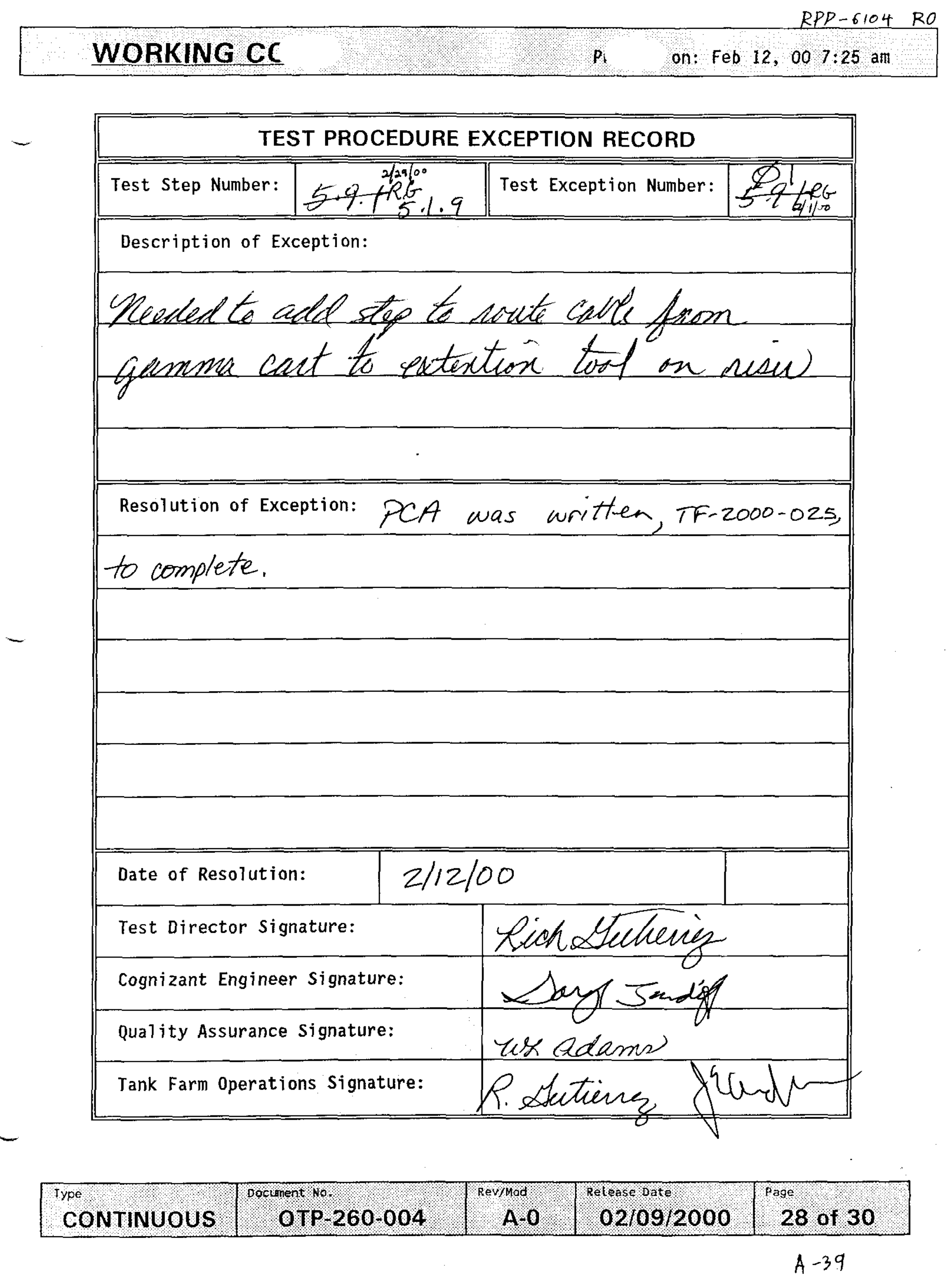




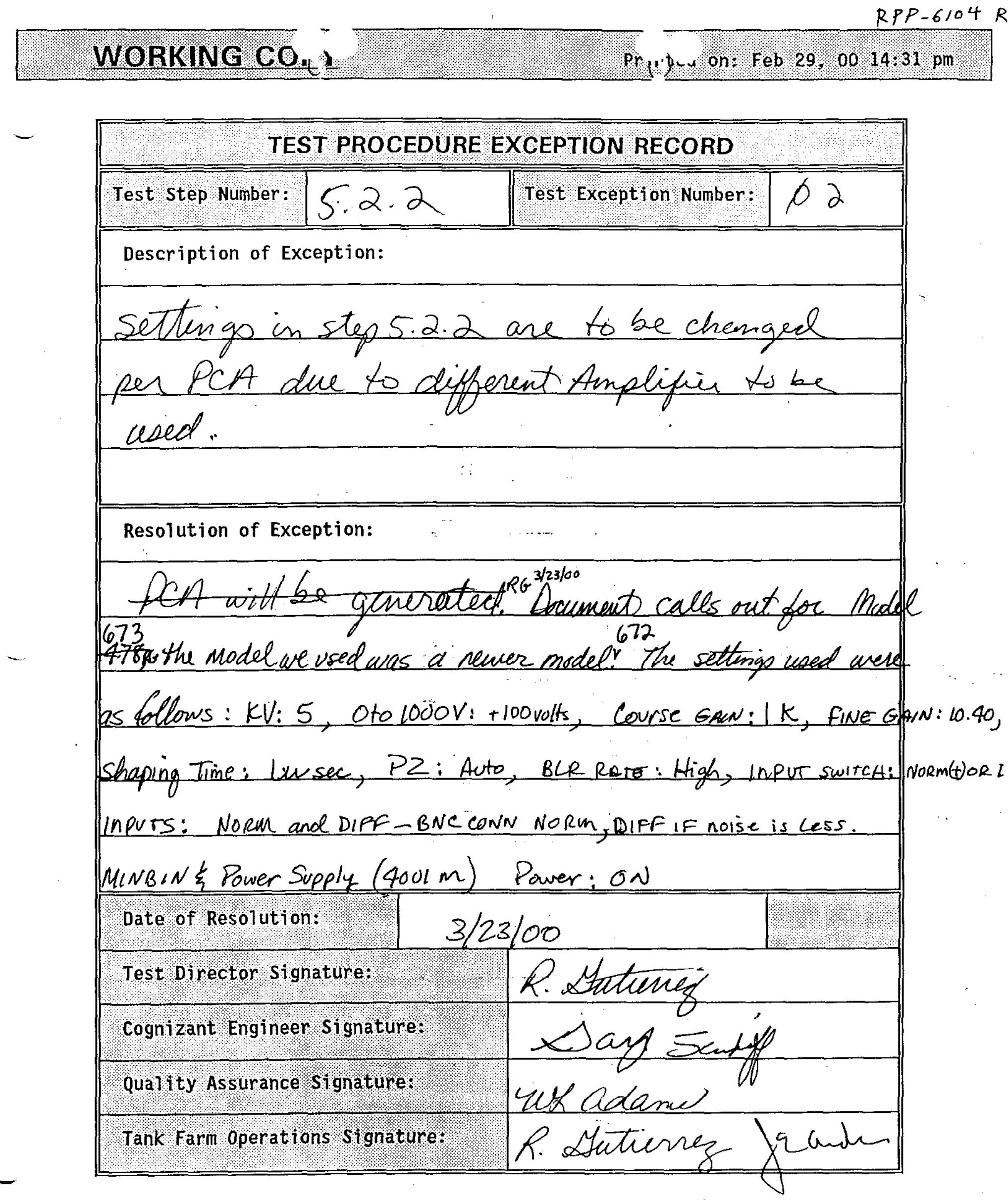

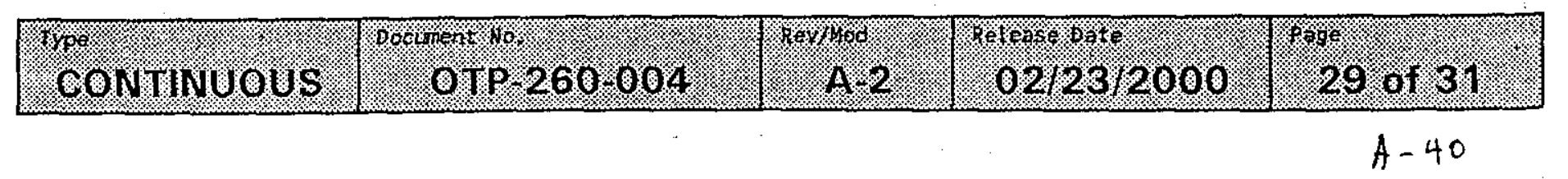


$R P P-6104 R 0$

WORKING COPY

Printed on: feb 29.00 15.45 pm

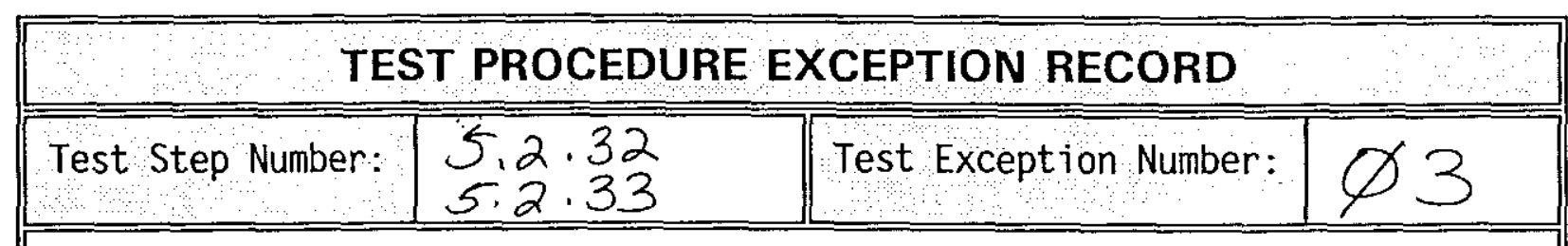

Description of Exception:

delete steps 5.2 .18 following

Step ${ }^{R} 5.2 .32$ reeds to be performed often 5.2.33?

Data needs to be recieved often system zeros.

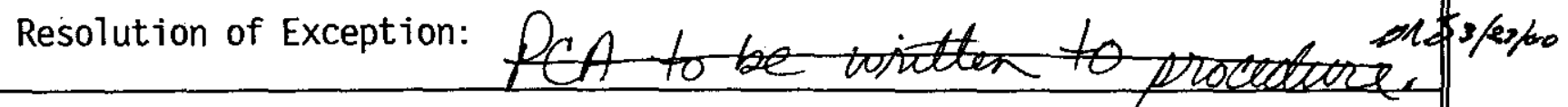

Step 2.4.2 states that individual tests in 5.0 can be performed out of order as directed by Test Director.

After procedure was ran a couple of times, $Q C$ and A and Test Director concurred that step 2.4 .2 allows Test Director to perform steps as needed.

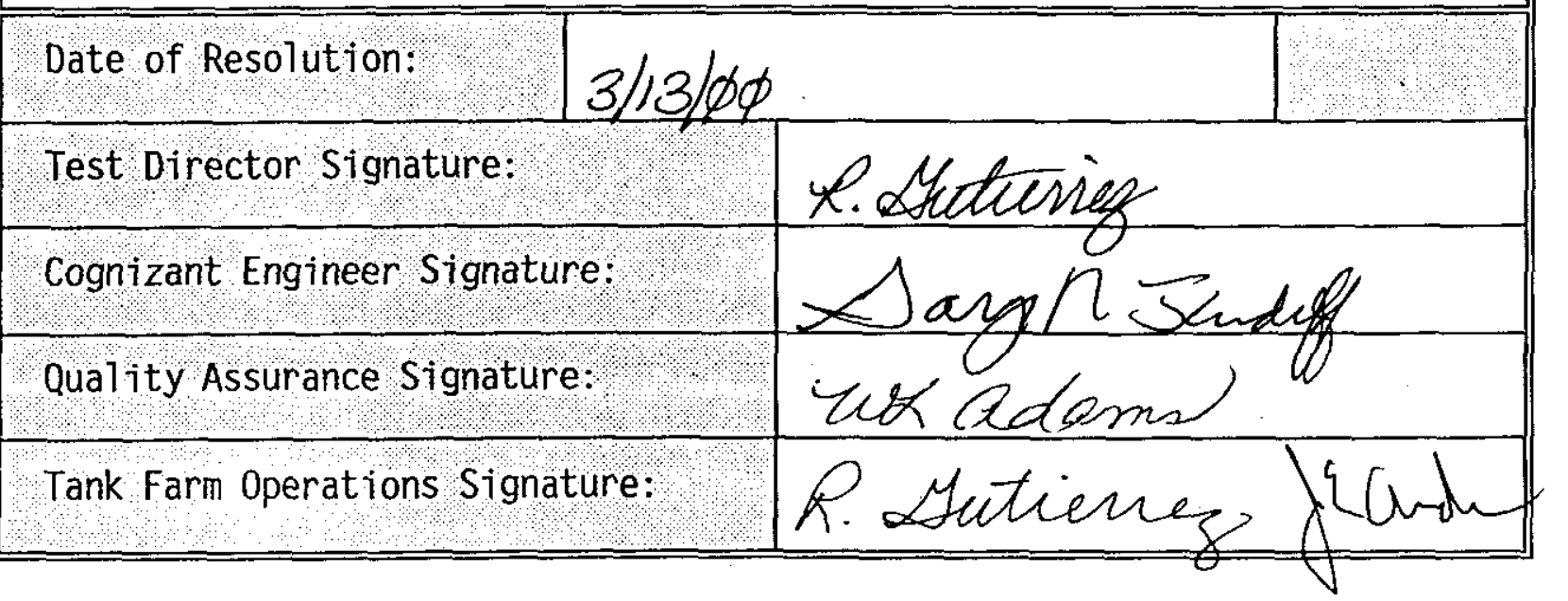

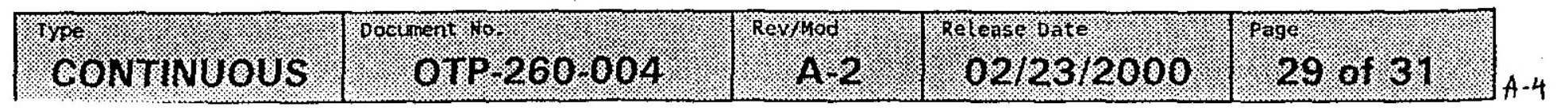




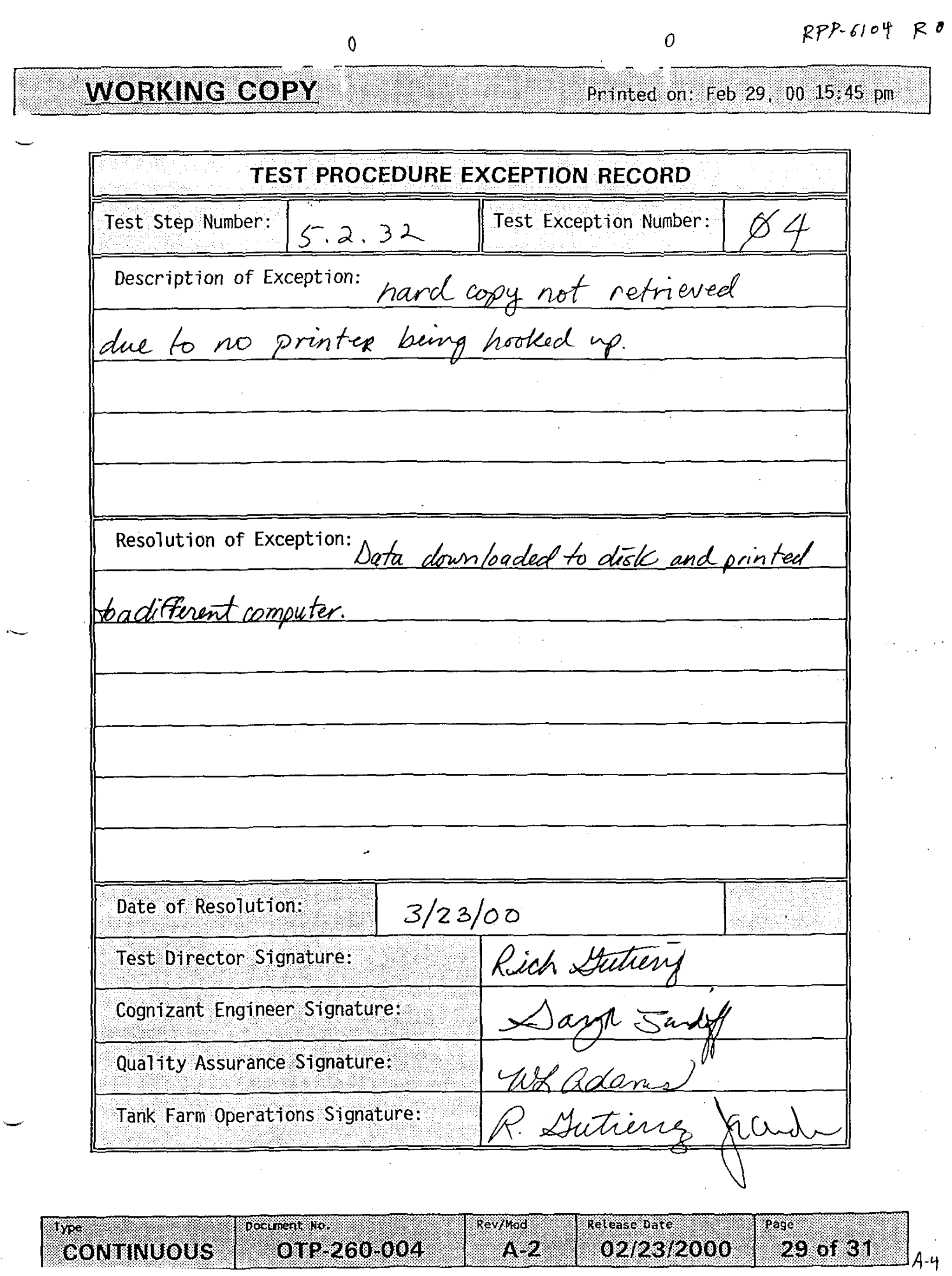


$R P P-6104 \quad R O$

WORKING COPY

Printed on: Feb 29.00 .15 .45 pm

\begin{tabular}{|l|l|l|l|}
\hline \multicolumn{3}{|c|}{ TEST PROCEDURE EXCEPTION RECORD } \\
\hline \hline Test Step Number: & 5.3 .3 & Test Exception Number: & $\varnothing 5$ \\
\hline \hline Description of Exception: step did not include to \\
\hline
\end{tabular}

ENSURE REA4LVE Hugh button indicates "LIVE".

Resolution of Exception: $P C A$ to be fating

Procedure TO-260.230, Rev A-D, "OPERATE TANK 241-A 2-101

GAMMA CARTS SYSTEM" steps $5.4 .2 \& 5.5 .2$ has the

operator chuck that the "REALIUVE" button indicates "UVE".

Lieut was incorporated in TO-260-230

Date of Resolution: : $] 3-13-\phi \phi$

Test Director Signature:

R. Shutting

Cognizant Engineer Signature:

Dap sind

Quality Assurance Signature:

Tox Adams

Tank Farm Operations Signature:

R. Autreniz fecund

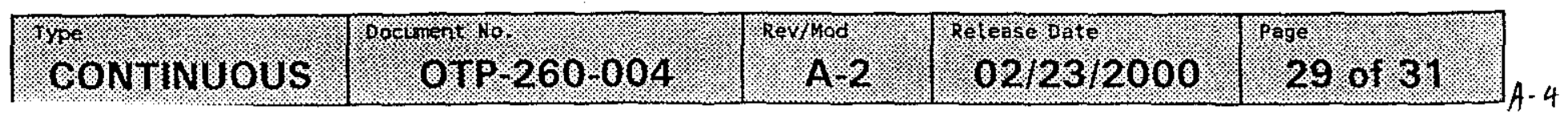


$R P P-6104 \quad R O$

WORKING COPY

Printed on: Feb $29,00 \quad 15.45 \mathrm{pm}$

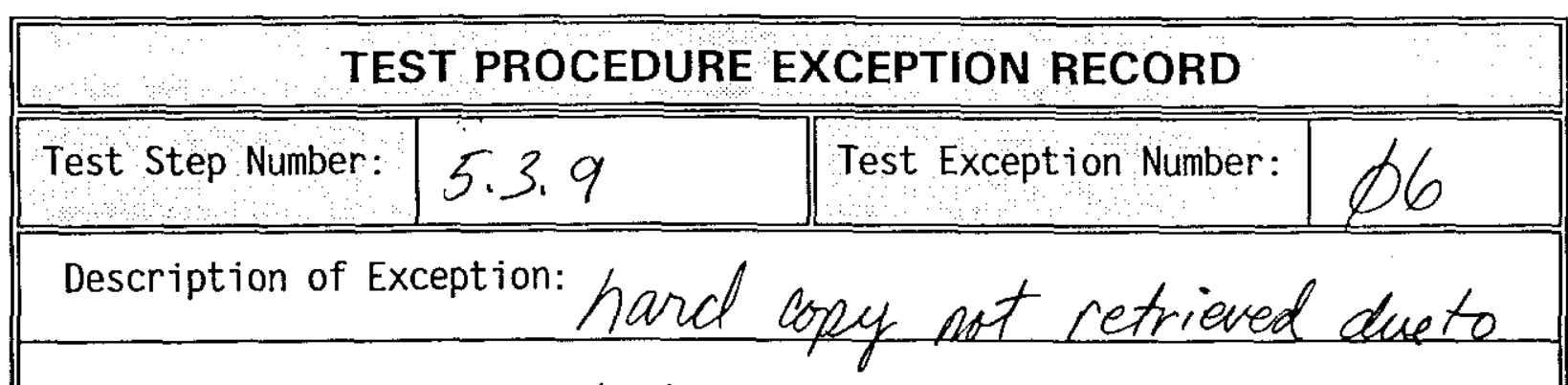

noprinter being hooked up.

Resolution of Exception:

This Test Exception is equivalent to

Lest Exception \# D4. Steps 5.3.9 \$5.2.32 are identical

asking for the same information in two different

sections of the procedure. Answering Test Exception $\varnothing 4$

will answer Test Exception \# $\not 6$. Hard Copy printed

from different computer after downloading to a disk.

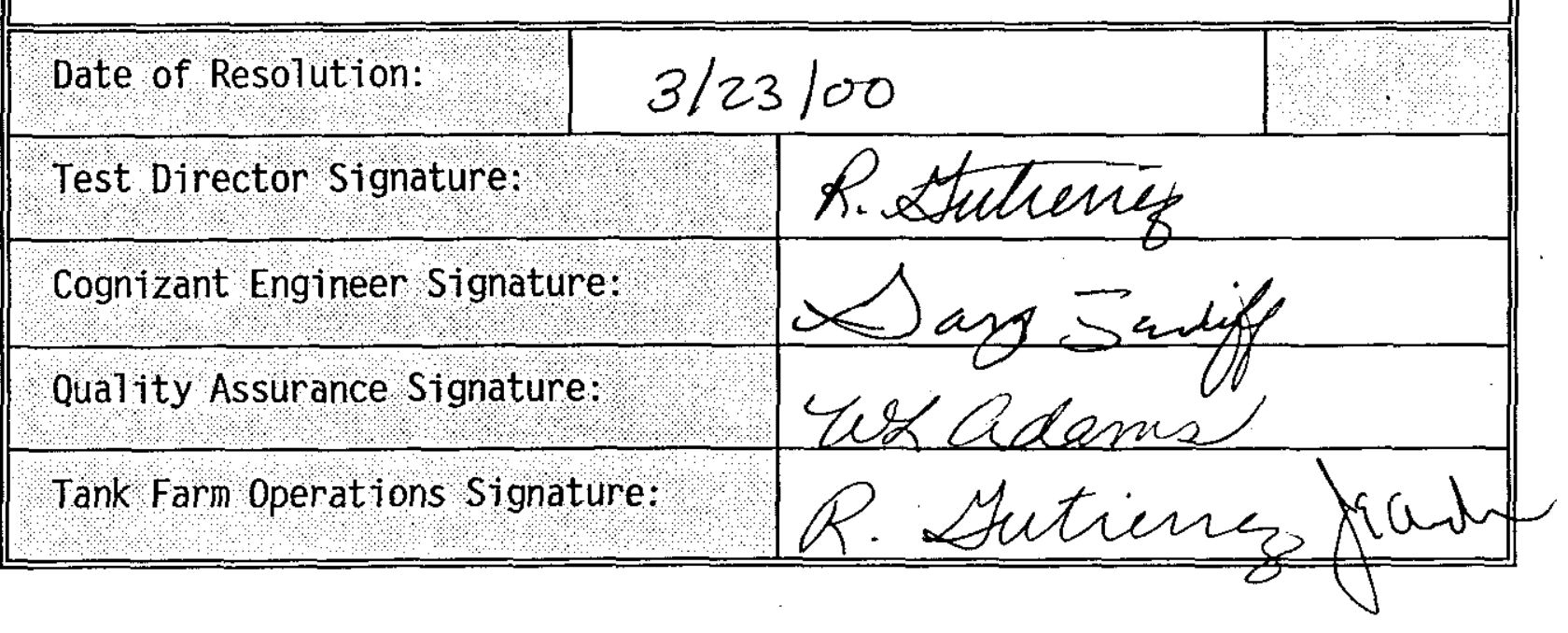

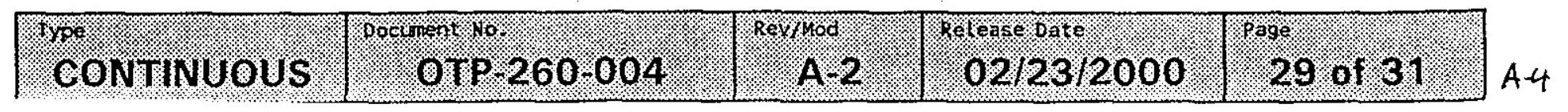


$R P P-6104 R 0$

WORKING COPY?

Printed on? Feb 29, $00 \quad 15.45$ pl

\begin{tabular}{|l|l|l|l|}
\hline \multicolumn{3}{|c|}{ TEST PROCEDURE EXCEPTION RECORD } \\
\hline Test Step Number: & 5.3 .10 & Test Exception Number: & $\varnothing 7$ \\
\hline
\end{tabular}

Description of Exception:

step needs to be performed

before 5.3.9. Data reeds to be recieved after

it zero's

Resolution of Exception:

Step 2.4.2 states that individual tests in 5.0 can be performed out of ordo as directed by Test Director. After procedure was ran a couple of times, QC, AI and Test Director concurred that step 2.4.2 allow Test Director to perform steps as needed.

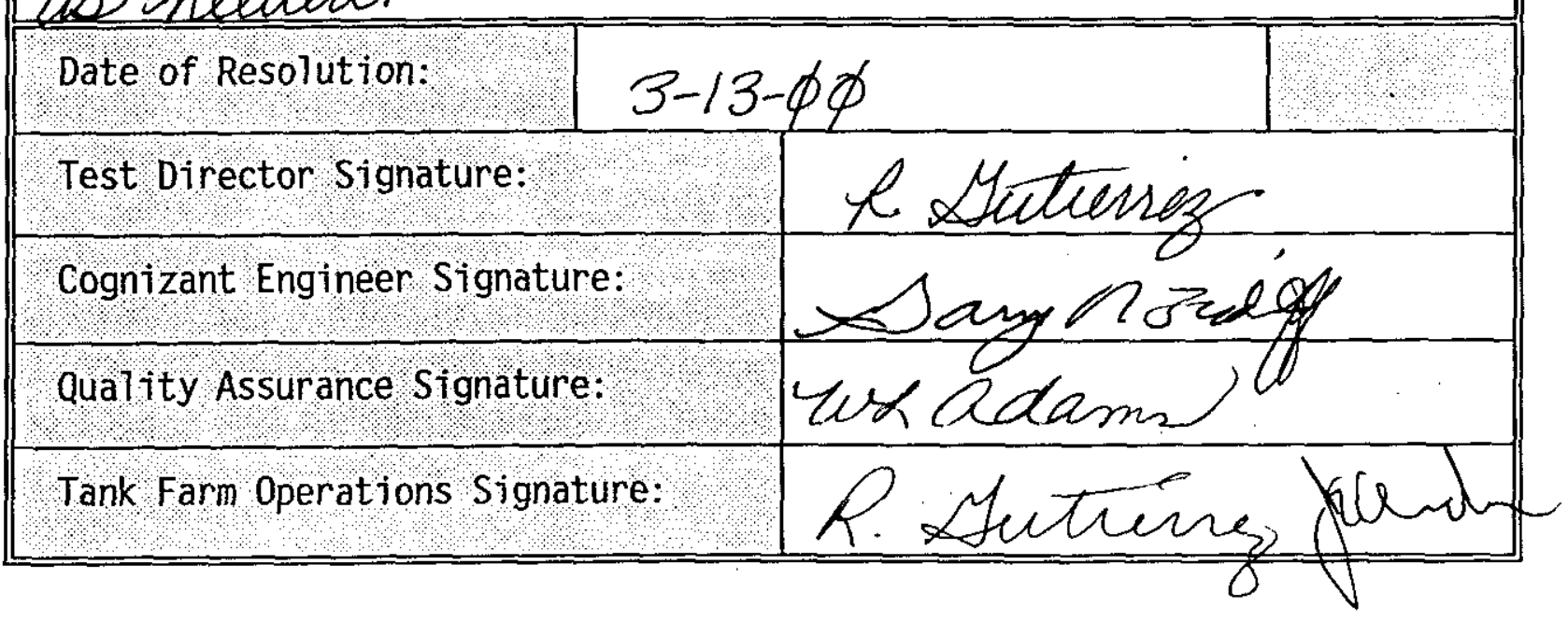

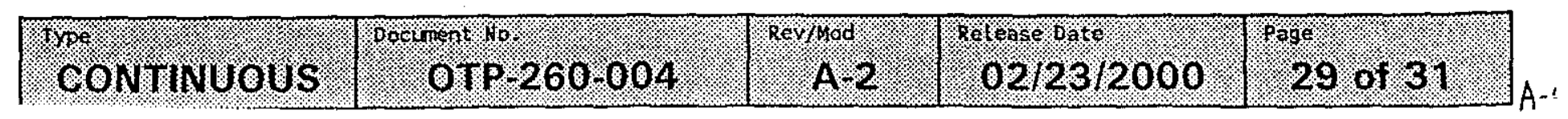




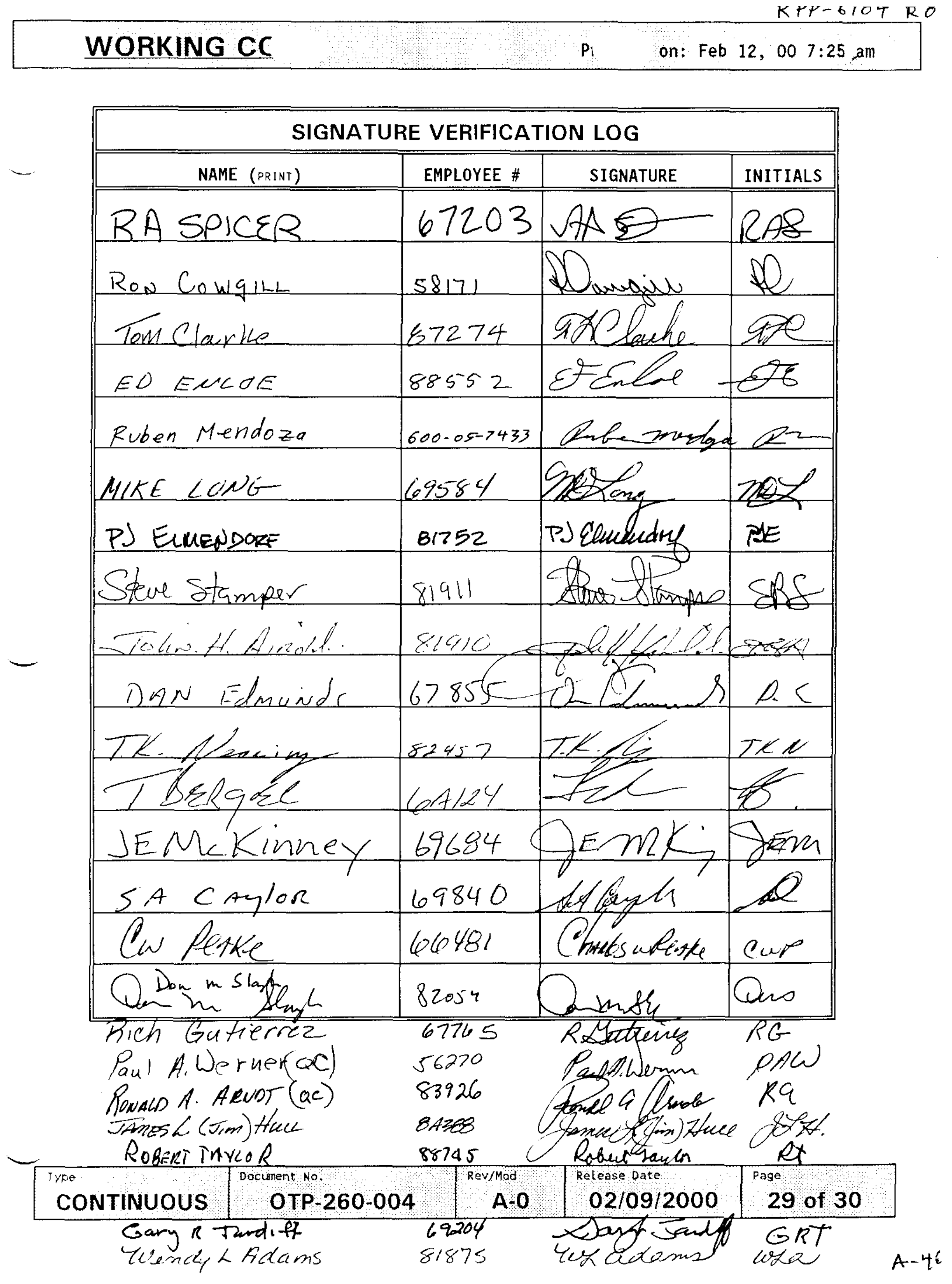


PROCEDURE HISTORY SIGNATURE SHEET

Type

Document No.

Rev/Mod CONTINUOUS

OTP. $260-004$

A-0

Release date

Page 


\section{BOLT TORQUING GUIDELINES}

\begin{tabular}{|c|c|c|}
\hline \multicolumn{3}{|c|}{$\begin{array}{l}\text { Last Ful1 Revision: C-0 } \\
\text { Release Date: } 12 / 27 / 99 \\
\text { USQ Screening Number: TF-98-1201, Rev } 1 \\
\text { Approval Designator: S }\end{array}$} \\
\hline \multicolumn{3}{|c|}{$\begin{array}{l}\text { Current Modification: C-0 } \\
\text { USQ Screening Number: } \\
\text { Approval Designator: } \\
\text { PCA Incorporated: }\end{array}$} \\
\hline POSITION/ORG & DELEGATE & DATE \\
\hline Pipefitter & Glenn Anderson & $12 / 2 / 99$ \\
\hline Maint Manager & R.G. Lee & $12 / 2 / 99$ \\
\hline Safety & Ernie Hurst & $\underline{12 / 9 / 99}$ \\
\hline $\mathrm{ECO}$ & P.C. Miller & $\underline{12 / 7 / 99}$ \\
\hline EQ Eng. & R.S. Robinson & $12 / 21 / 99$ \\
\hline RadCon & Mark Kornish & $\underline{12 / 21 / 99}$ \\
\hline Acceptance Review & K.0. Smith & $\underline{12 / 27 / 99}$ \\
\hline Approval Authority & R.L. Legg & $12 / 21 / 99$ \\
\hline Pages Affected & Summary of Change & Reason for Change \\
\hline all & Reformat, full revision & 2 year review \\
\hline
\end{tabular}

NEXT DUE DATE: $12 / 27 / 2001$

\begin{tabular}{|c|c|c|c|c|}
\hline $\begin{array}{l}\text { Type } \\
\text { REFERENCE }\end{array}$ & $\begin{array}{l}\text { Document No } \\
2 \text {-MISC. } 049\end{array}$ & $\begin{array}{r}\text { Revipod } \\
\text { C-O }\end{array}$ & $\begin{array}{l}\text { Release oate } \\
12 / 27 / 99\end{array}$ & Page of 18 \\
\hline
\end{tabular}




\section{RISER 15B}

GAMMA CART - B 


\section{1-AZ GAMMA CART OPERATIONAL TEST PROCEDURE}

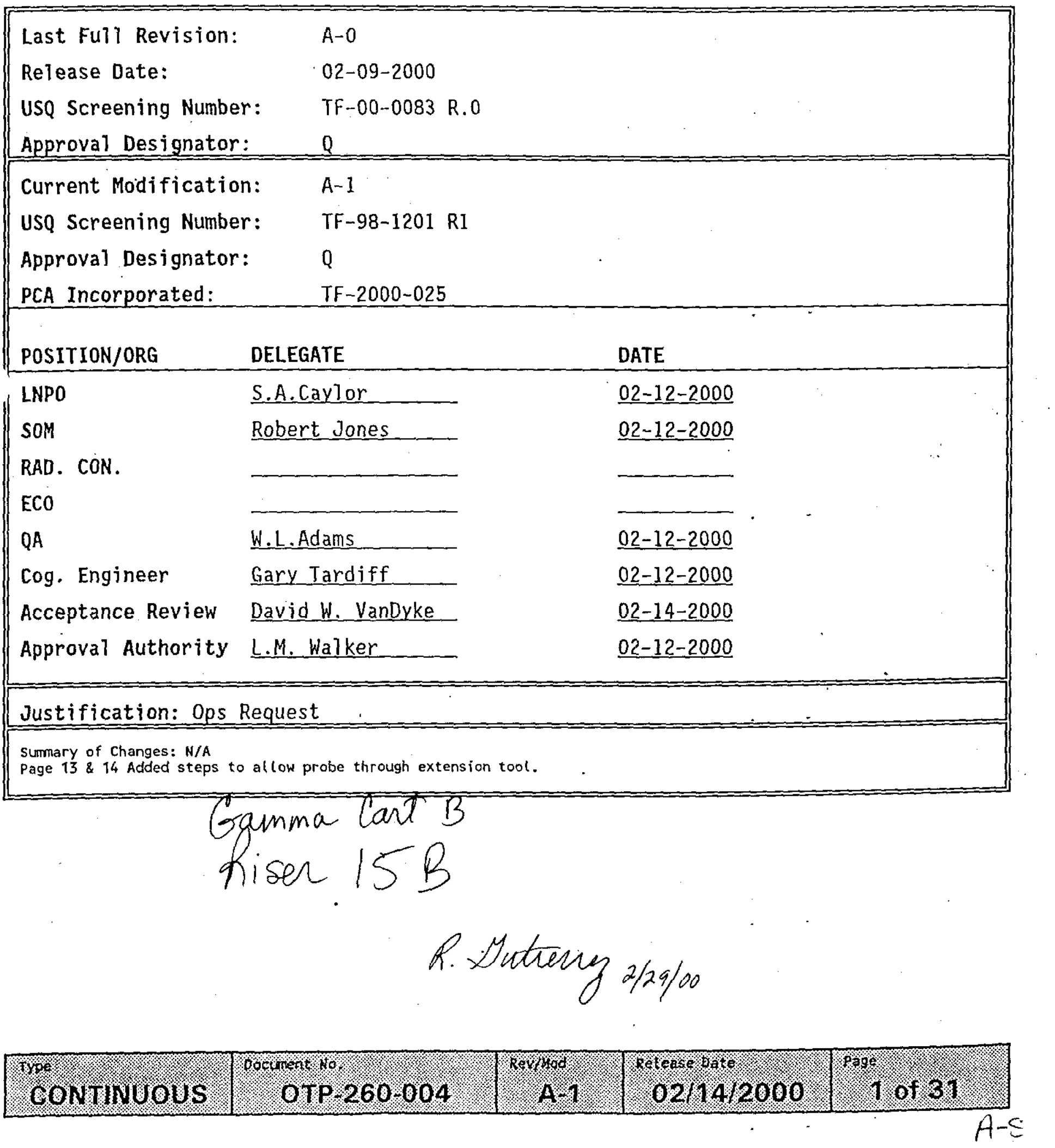




\subsection{PREREQUISITES}

\subsection{SPECIAL TOOLS, EQUIPMENT, AND SUPPLIES}

The following supplies may be needed to perform this procedure:

- Riser Swabbing equipment

- Riser extension tool

\subsection{PERFORMANCE DOCUMENTS}

The following procedures may be needed to perform this procedure:

- TO-040-333 LIqUID OBSERVATION WELL (LOW) SURVEILLANCE VAN STARTUP AND OPERATION PROCEDURE.

\subsection{CONDITIONS AND ACTIONS}

NOTE - All signators on this procedure shall document their signature on Procedure Signature Sheet.

4.3.1 All pre-testing and inspection of the system or portions of the system to be tested has been completed.

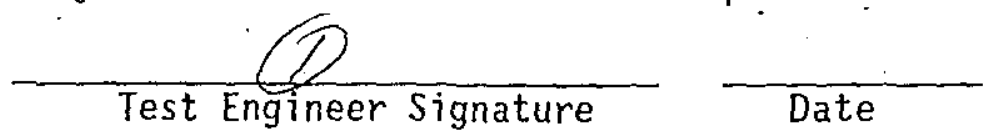

4.3.2 A pre-job briefing has been held. and all participants have been thoroughily briefed on job safety, hazards, and their responsibilities before performing this ATP.

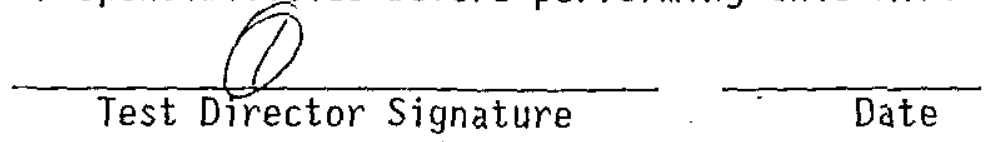

4.3.3 Test Director VERIFY section 4.3 has been COMPLETED.

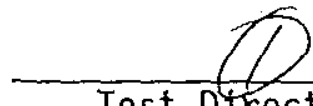

Test Dfrector Signature Date

(1) abready tested per OTP-260-004, rew A-O.

Rotativing $2 / 29 / 00$ 


\subsection{PROCEDURE}

\subsection{SETUP}

NOTE - This procedure may be repeated for either GAMMA CART A or GAMMA CART B as applicable. N/A may be entered in blocks or steps per Test Director as applicable.

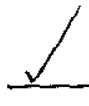

5.1 .1

RECORD GAMMA CART CPU number for the system being tested. GAMMA CART IDENTIFIER \#
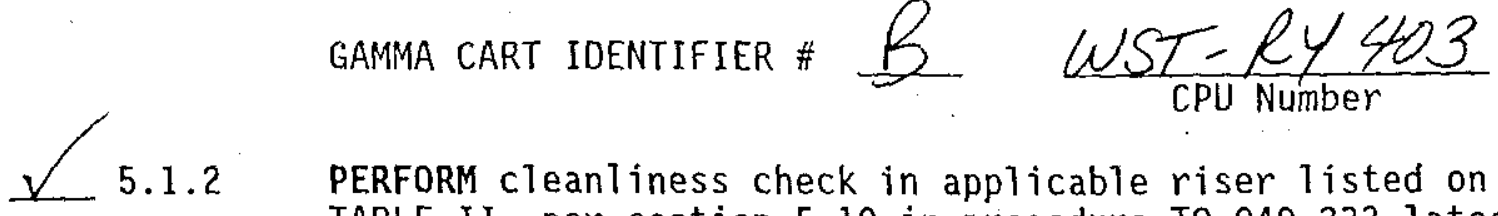

PERFORM cleanliness check in applicable riser listed on TABLE II, per section 5.10 in procedure T0-040-333 1atest rev, prior to mounting riser extension tool.

\section{$\underline{\sim} 5.1 .3$}

ENSURE GAMMA CART riser extension tool is mounted on the applicable riser.

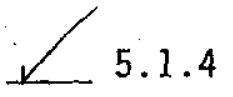

ENSURE GAMMA CART is placed in line with riser extension tool to facilitate installation of probe and cables.

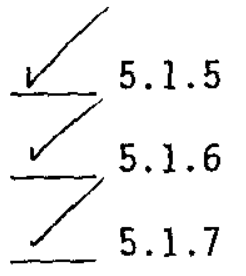

CHECK route to riser for obstacles and clearances.

LEVEL cart using jacks .

CONNECT gamma cart power cables, as follows:

- One end to gamma cart power receptacle

- $\quad$ other end to Junction Box, JB-101-100, Power

Receptacle, OR Junction Box, JB-101-101

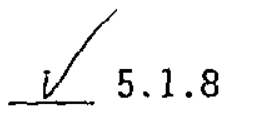

CONNECT gamma cart communications cable, as follows:

- One end to gamma cart communications receptacle

- Other end to Tank 241-AZ-101 Gamma Cart A AND/ÖR B Data Collection Subsystem communications receptacle
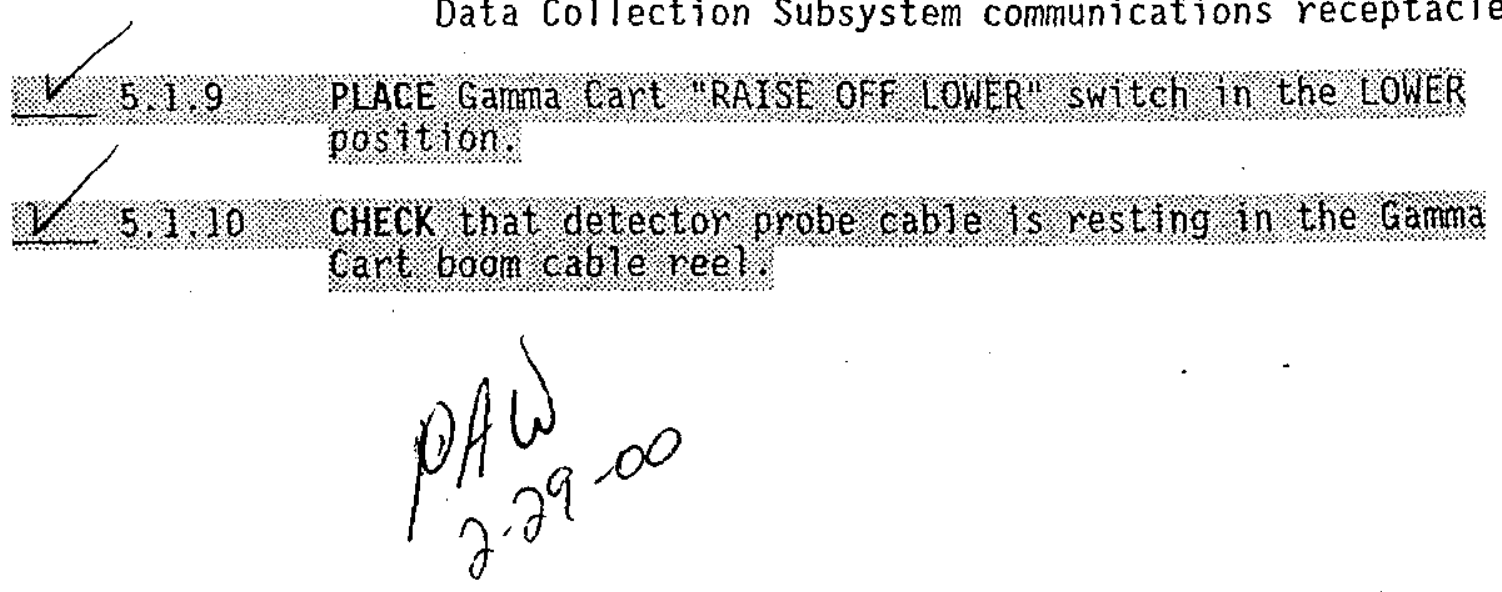

\begin{tabular}{|c|c|c|c|c|}
\hline SONITHOSUS & DTP 260.004 & Reymod. A & 10271412000 & 1. \\
\hline
\end{tabular}




\subsection{SETUP (Cont).}

\section{CAUTION}

If suff to tent tens on ls NOt fielo on the detertor probe cable as the cable ls beling let out, the ceble could becone entangled.

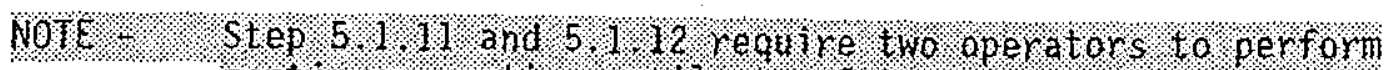

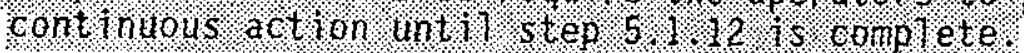

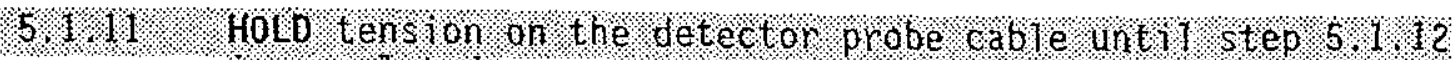
$15.001010 t e d$.

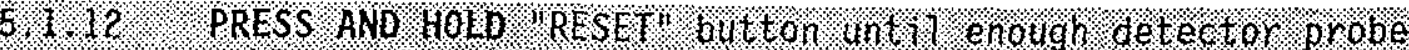

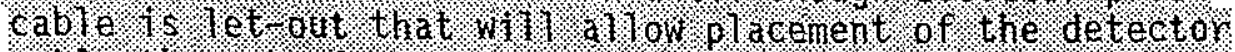

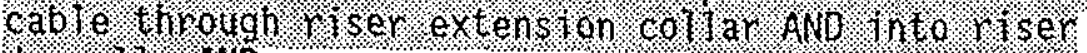

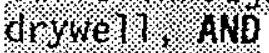

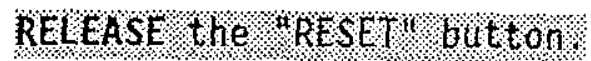

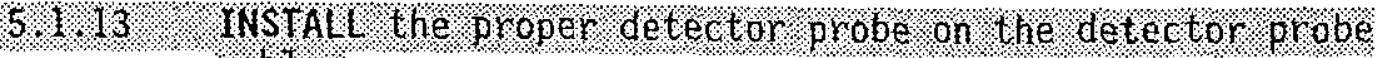
cable.

5.1.14 ENSURE that the detector probe connections are correct and tight. AND

INSERT probe into riser extension tool.

$\underline{\simeq} 5.1 .15$

ENSURE Timit switch cable is connected from limit switch on riser extension tool, to the connection point on the front of the GAMMA CART.

5.1.16 ENSURE the "Raise - Off - Lower" selector switch is in the "OFF" position.

5.1.17 ENSURE the emergency stop button is pulled out.

5.1.18 POSITION the "SPEED" control potentiometer to MIN speed (fully counter-clockwise).

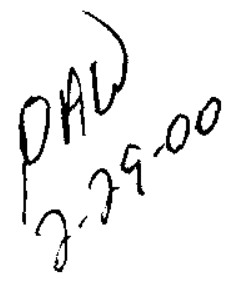

\begin{tabular}{|c|c|c|c|c|}
\hline hy & 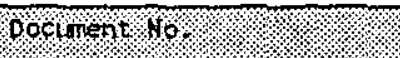 & RevfFod. & 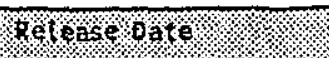 & ras \\
\hline OONTINUOUS & . OTP 260.004 & - & 0.27142000 & $140 \mathrm{rog}$ \\
\hline
\end{tabular}


RPP-6104 R 0

WORKING OOF,

Printed on: Feb 15, 00 8:59: am

5.1 SETUP (Cont).

CAUTION

There is no limit switch to stop the motion when the cable is fully unwound. The cable will rewind backwards on the reel. Damage to the cable may result.

NOTE - When the cart is first powered up, or the emergency stop button has been pushed, or power has been restored after a power failure, the cable reel will not move up or down until "RESET" button is activated.

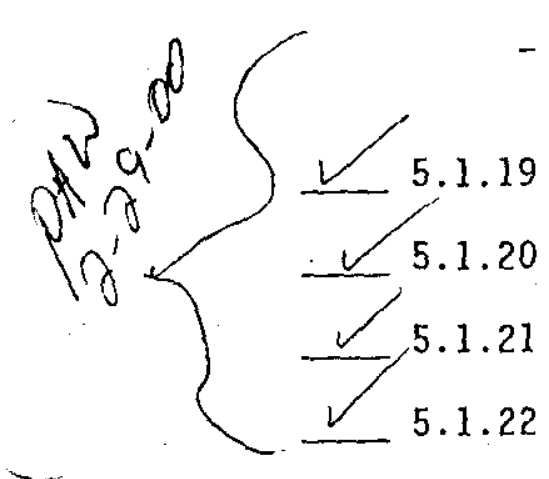

(1) 5.1 .23

(t) 5.1 .24

The "Raise-OFF-Lower" Switch is Manually controlled and is Operator Dependent.

ENSURE LOCAL/REMOTE switch is in the "LOCAL" position. ENERGIZE the Cart.

SET the "SPEED" potentiometer to 2 on the GAMMA Cart.

SET the "RAISE -OFF- LOWER" switch to the "LOWER" position.

PUSH "EMERGENCY STOP" button on GAMMA CART.

VERIFY the system has stopped.

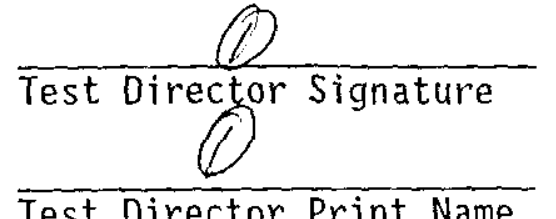

Date

Test Director Print Name

(1) already Tested per OTP-260-004, Rev A-O . see Test log entry 2/29/00 2030.

R. Asuturing

$2 / 29 / 00$

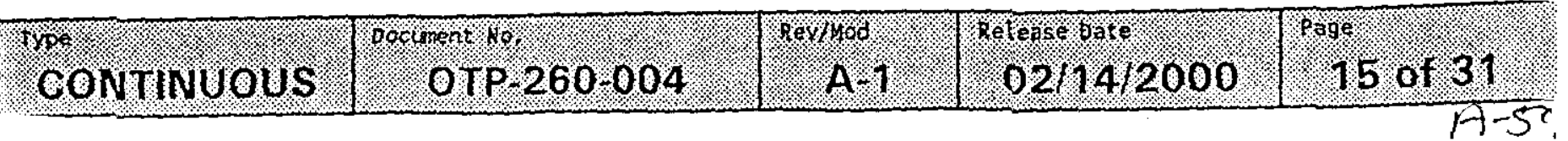


RPP-6104 RO

WORKING COF.

Prinued oht feb 15,00 8:59 am

5.1 SETUP (Cont).

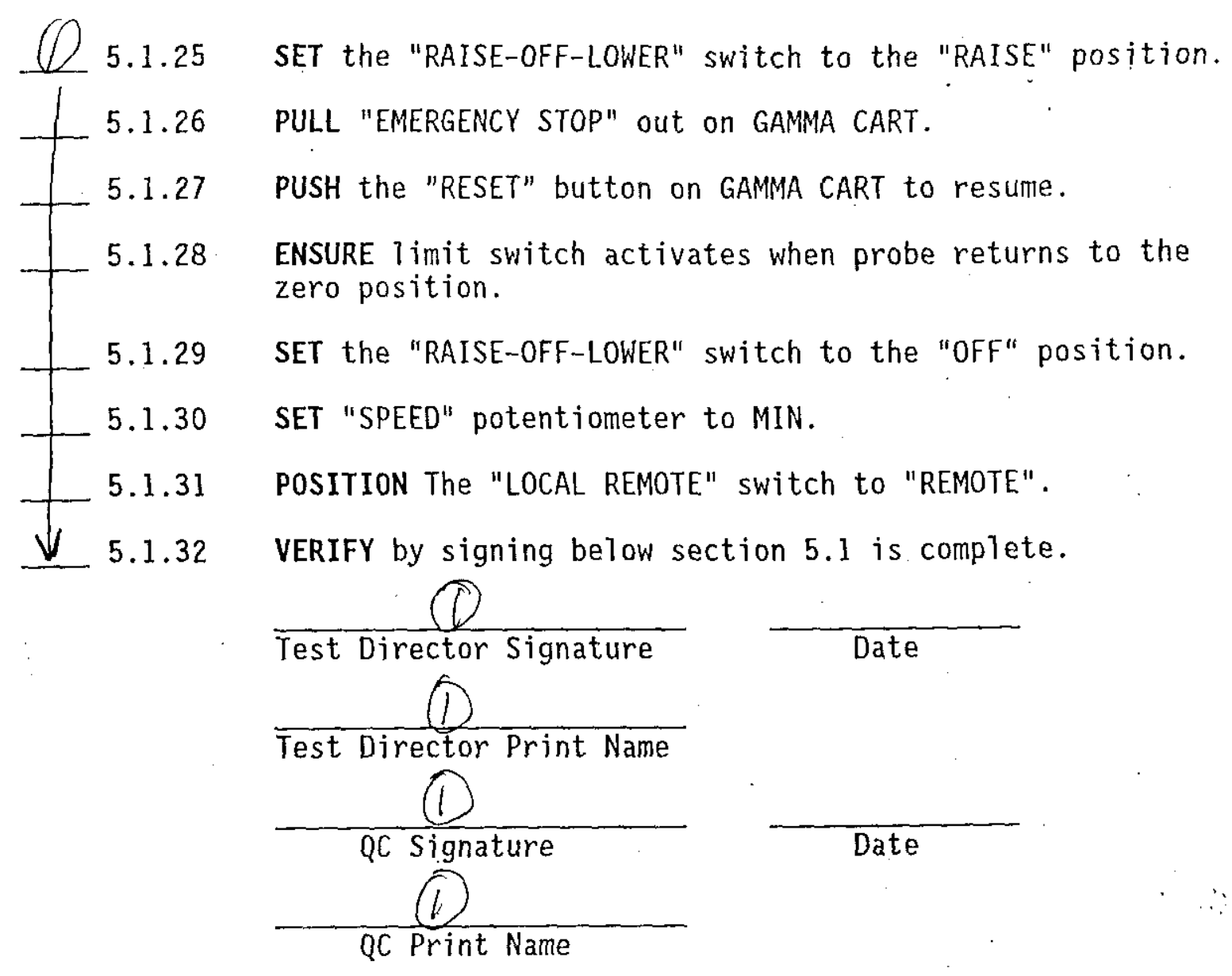

(1) aheady tested per OTP-260-004, Rev A-O. su Test log enty 2/29/10, 2030.

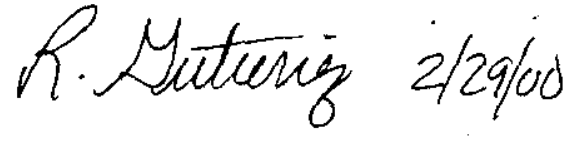

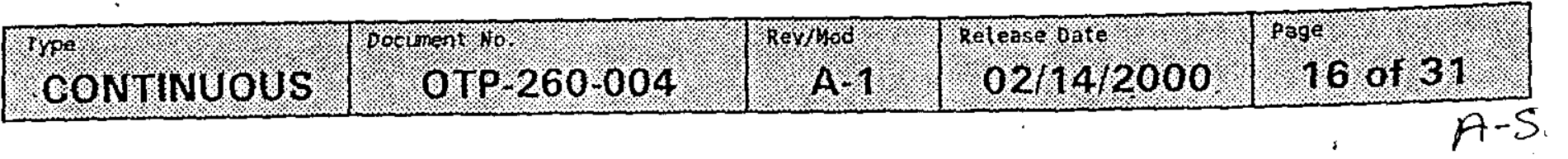




\subsection{TEST INCREMENTAL SAMPLE MODE}

\section{SETUP}

NOTE - All Steps in this section apply to either cart, except in those steps where the specific cart is indicated.

\section{INSTRUMENT CHECK}

5.2.1 IF the pushbutton for Tank 241-AZ-101 Gamma Cart A AND/OR $B$ Data Collection System Central Processing Unit (CPU), AND/OR associated MONITOR, are NOT ON, PRESS the

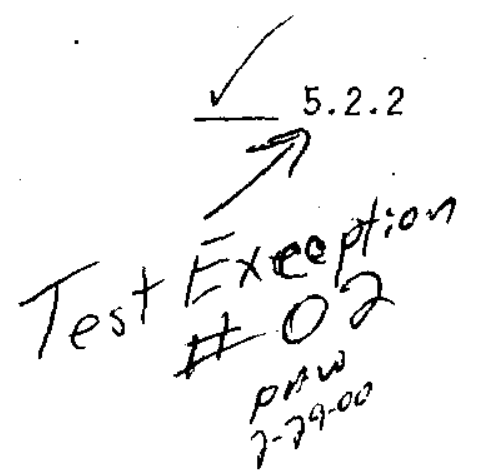
applicable on pushbuttons.

ENSURE the following systems are ON AND

ENSURE settings are correct for the following:

- ORTEC MINIBIN

- POWER SUPPLY

Detector Bias Power Supply (HVPS): ORTEC Mod. 478.

- $k V: .5$

- 0 to 1000V: ( +60 volts)

Amplifier (AMP): ORTEC Mod. 673

- coARSE gAIN: 200

- FINE GAIN: 0.680

- SHAPING TIME: Both knobs set to 2 microseconds

- $\quad$ PZ Adjust: Do NOT change settings (in this procedure)

- BLR: Switch in AUTO (up) position

- INPUTS: Switch in POS (up) position BNC cable on terminal (from pre amplifier)

- OUTPUTS: cable on UNIPOLAR terminal(to single channel Analyzer)

5.2.3 WHEN WINDOWS login screen appears CLICK ON "CANCEL".

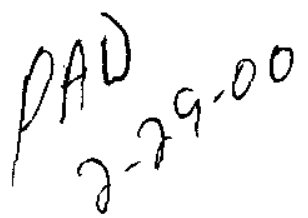


WORKING COP.

RPP-6104 RP

Pron .d on: Feb 15, 00.8 .59 an

5.2 TEST INCREMENTAL SAMPLE MODE (Cont).

NOTE - After canceling windows login, GAMMA CART software should automatically load.

5.2.4 VERIFY "GAMMA CART SPECTRUM ANALYZER AND CONTROL SYSTEM" screen is displayed on Tank 241-AZ-101 Gamma Cart A AND/OR B Data Collection System Monitor.

R. Dectieñ

$$
\frac{2 / 29 / 00}{\text { date }}
$$

R. Suturing R. Gutierrez

SELECT "Login" on the "GAMMA CART SPECTRUM ANALYZER AND CONTROL SYSTEM" screen.

NOTE - LOGIN passwords and information may be obtained from Test Director.

LOGIN.

VERIFY LOCAL/REMOTE switch on display screen is in "REMOTE" pOSition.

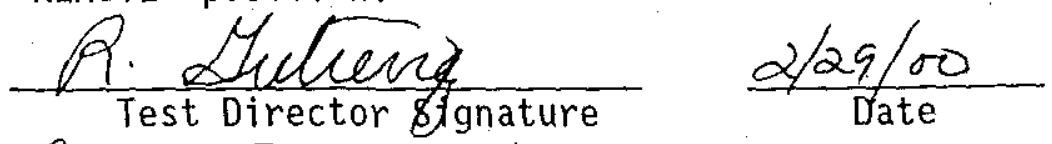

R. Gutiener

Test Director Print Name

PAD ${ }_{\partial 9^{9}}$

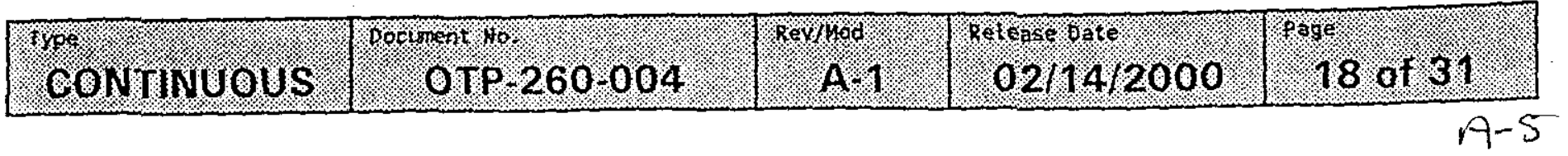




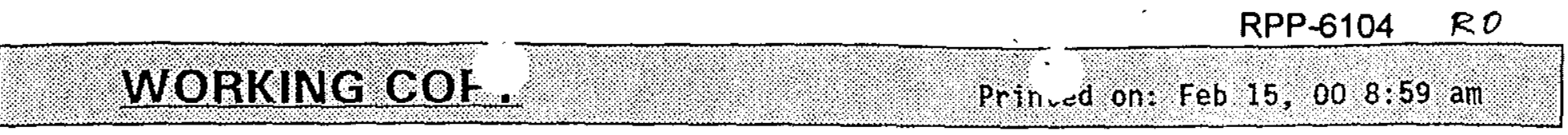

5.2 TEST INCREMENTAL SAMPLE MODE (Cont).

TESTING

(1) 5.2.8 SELECT "config" on the "Gamma Cart Display" screen.

(1) 5.2.9 ENTER the following data for selected riser on the "Configuration - Display" screen by pulling down applicable menu:

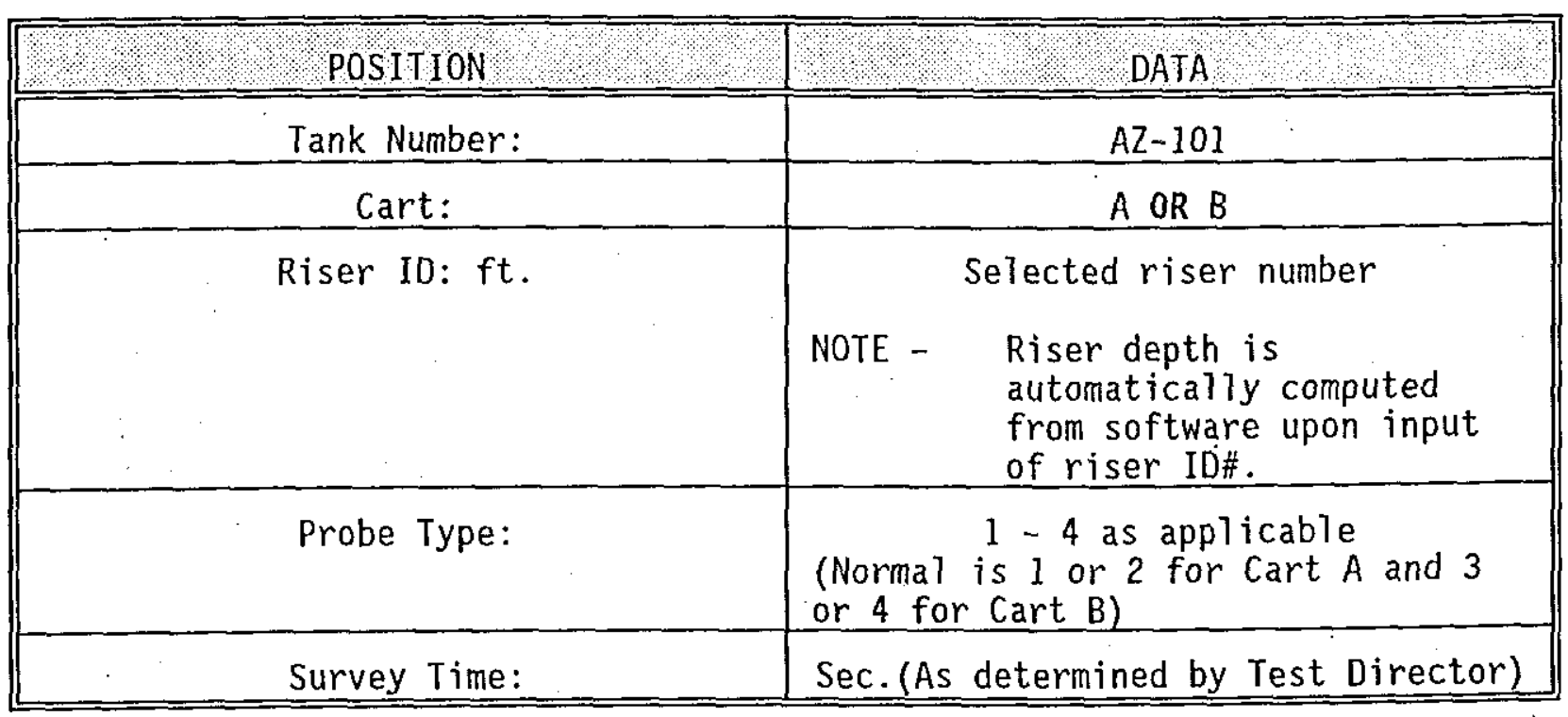

(1) 5.2.10 ENSURE REAL/LIVE toggle button indicates "LIVE".

(1) 5.2.11 On the Data Collection Configuration window, SELECT the "Incremental" button.

INCREMENTAL PARAMETERS

5.2.12 INPUT the following Sample Collection Data:

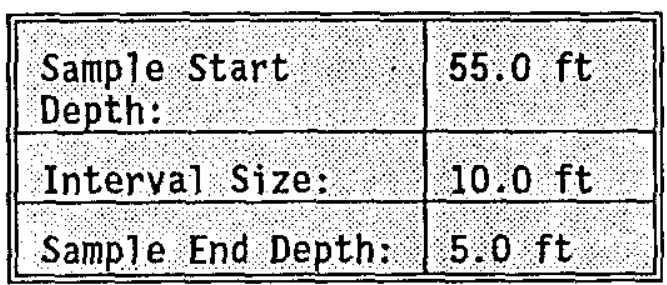

(1) already tested per 0+P-260-004, Rev A.O, See Test log Entity 2/24/80, 2080.

R. Anteing $2 / 29 \% 0$

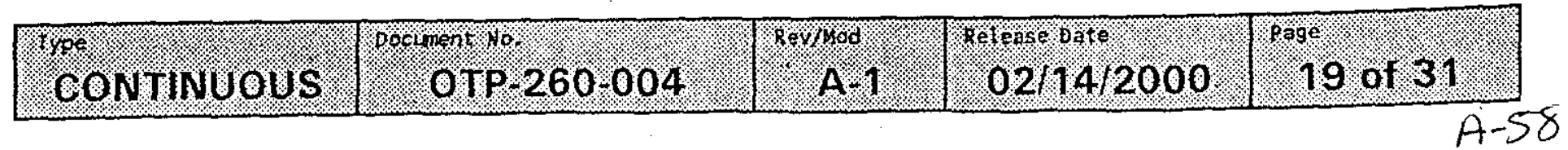


RPP-6104 RP

WORKING COP.

Printed on: Feb $15,00,8: 59$ am

5.2 TEST INCREMENTAL SAMPLE MODE (Cont).

(1) 5.2 .13 CLICK ON "SAVE".

(A) 5.2.14 CLICK ON "EXIT".

NOTE - Test Engineer may manipulate parameters at any time during the following steps as necessary to ensure data retrieval and system configuration, with concurrence of Test Director.

- After the following step, the program should automatically run.

5.2.15 CLICK ON "Start" button.

(1) 5.2.16 CLICK ON "EMERGENCY STOP" button on computer screen.

(1) 5.2.17 VERIFY system stopped.

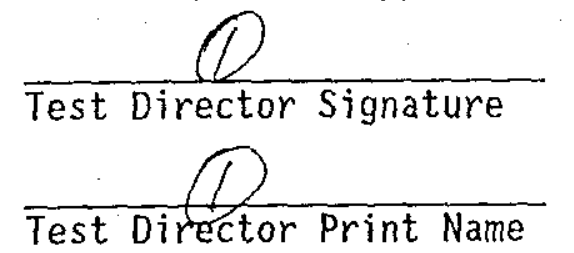

5.2.18 CLICK ON "EMERGENCY STOP" again to RESET the emergency stop button on computer screen.

(1) 5.2.19 CLICK ON "ZERO" on display screen.

(1) 5.2.20 ENSURE GAMMA PROBE begins to RAISE.

(1) 5.2.21 CLICK ON "STOP" button on display screen.

(1) already tested per GTP-260-004, nev AO, see test log entry 2/29/80, 2030.

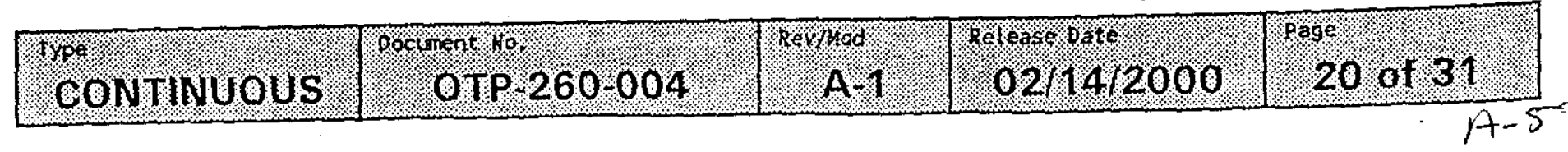


RPP-6104 RD

WORKING COP

Protruded on: Feb $15,00,8: 59$ am

5.2 TEST INCREMENTAL SAMPLE MODE (Cont).

5.2.22 VERIFY System stopped.

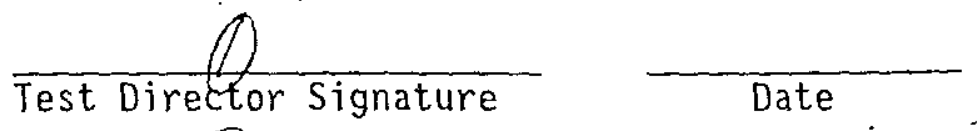

(D 5.2.23 CLICK ON "ZERO" again on display screen.

(t) 5.2.24 ENSURE GAMMA PROBE begins to RAISE. W 5.2 .25 When probe and system zeros, CLICK ON "START" on display
screen.

(i) 5.2 .26 VERIFY system resumed program.

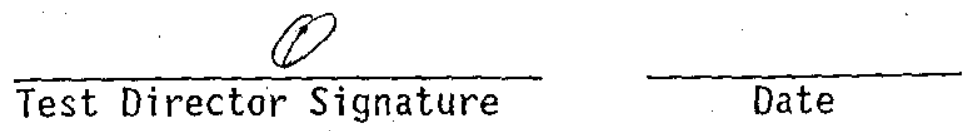

Test Director Print Name

5.2.27 CLICK ON "STOP" button on computer screen.

5.2 .28 VERIFY System stopped.

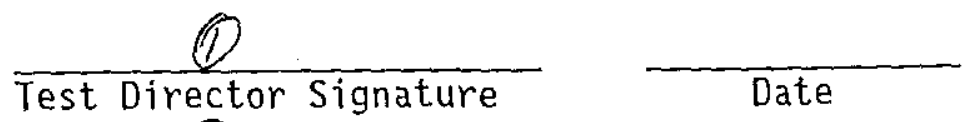

(1)

Test Director Print Name

(1. 5.2.29 CLICK ON "ZERO" on display screen.

(1) 5.2.30 When probe and system zeros, CLICK ON "START" on display screen.

(1) 5.2.31 VERIFY system resumed program.

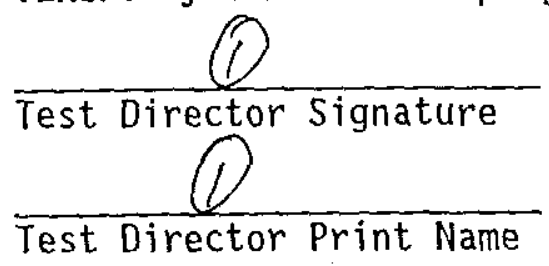

(1) already tested per OT P-260-004, rev A.O see test Log entry, 2030.

R. Station y 2/29/00

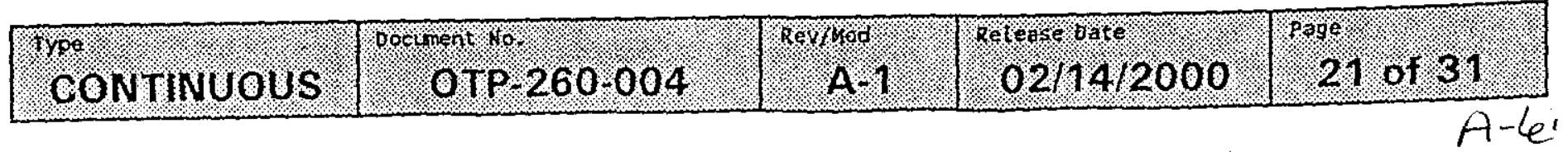




\subsection{TEST INCREMENTAL SAMPLE MODE (Cont).}

\subsubsection{Test Engineer ENSURE data is recejved, AND both hard-copy} and electronic files can be retrieved.

(1) 5.2 .33

VERIFY system automatically ZEROs and data is collected at zero position.

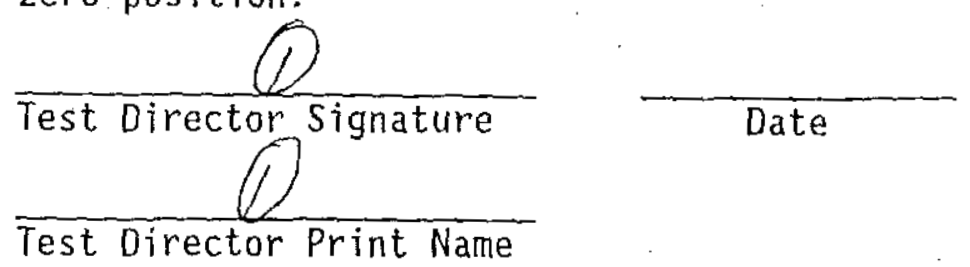

NOTE - The steps in section 5.1, applicable to the Emergency stop, need not be repeated if completed for an individual GAMMA CART. The Emergency stop on BOTH GAMMA CART A and B, need to be tested only once.

NOTE - It is NOT necessary to do ALL risers in one procedure. Test Director is responsible for ensuring ALL.risers have been profiled by one AND/OR. the other GAMMA CART(S).

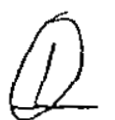

5.2 .34

REPEAT applicable SETUP Steps in section 5.1 AND Incremental testing steps 5.2.1 - 5.2.15 ANO Steps 5.2.32 and 5.2.33 for each of the following risers and depths per Test Director's direction.

TABLE I

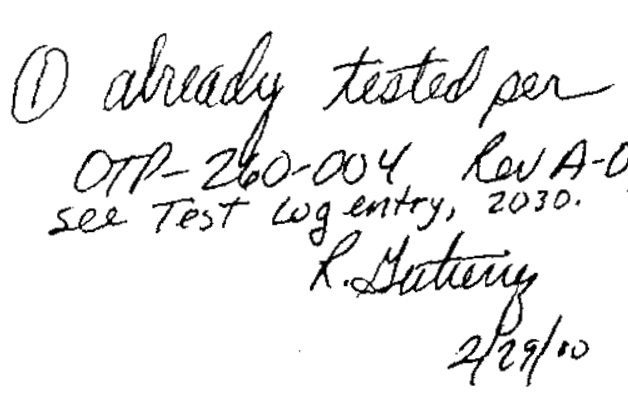

\begin{tabular}{|c|c|}
\hline RISER & $\begin{array}{l}\text { Depth } \\
\text { inches }(\mathrm{ft})\end{array}$ \\
\hline $14 A$ & $660(55,0)$ \\
\hline $14 \mathrm{C}$ & $660(55,0)$ \\
\hline 140 & $660(55.0)$ \\
\hline $14 F$ & $660(55.0)$ \\
\hline $14 \mathrm{G}$ & $660(55,0)$ \\
\hline $14 B$ & $660(55.0)$ \\
\hline $14 E$ & $660(55,0)$ \\
\hline 151 & $684(57,0)$ \\
\hline $15 \mathrm{C}$ & $684(57,0)$ \\
\hline $15 E$ & $684(57,0)$ \\
\hline 158 & $684(57 \quad 0)$ \\
\hline $15 \mathrm{~F}$ & $684(57,0)$ \\
\hline
\end{tabular}

\begin{tabular}{|c|c|c|c|c|}
\hline OONTINUOUS & 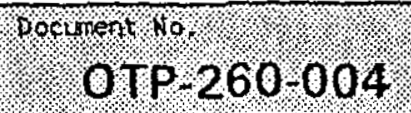 & $\begin{array}{l}\text { Revingorl. } \\
\text { A-1 }\end{array}$ & 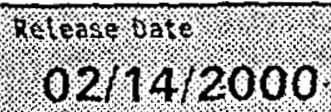 & 22 or 31 \\
\hline
\end{tabular}


RPP-6104 RP

WORKING CG RY

Printed on: Feb $15,00,8: 59$ an

5.2 INCREMENTAL SAMPLE MODE (Cont).

NOTE - In the following Table, Test Director N/A blocks that are tested with a different GAMMA CART.

(1) 5.2.35 VERIFY the applicable riser in step 5.2.34 has been tested.

TABLE II

\begin{tabular}{|c|c|}
\hline RISER & TEST DIRECTOR SIGNATURE \\
\hline $14 \mathrm{~A}$ & \\
\hline $14 \mathrm{C}$ & \\
\hline $14 \mathrm{D}$ & \\
\hline $14 \mathrm{~F}$ & \\
\hline $14 \mathrm{G}$ & \\
\hline $14 \mathrm{~B}$ & \\
\hline $14 \mathrm{E}$ & \\
\hline $15 \mathrm{I}$ & \\
\hline $15 \mathrm{C}$ & \\
\hline $15 \mathrm{E}$ & \\
\hline $15 \mathrm{~B}$ & \\
\hline $15 \mathrm{~F}$ & \\
\hline
\end{tabular}

5.2.36 VERIFY by signing below section 5.2 is complete.

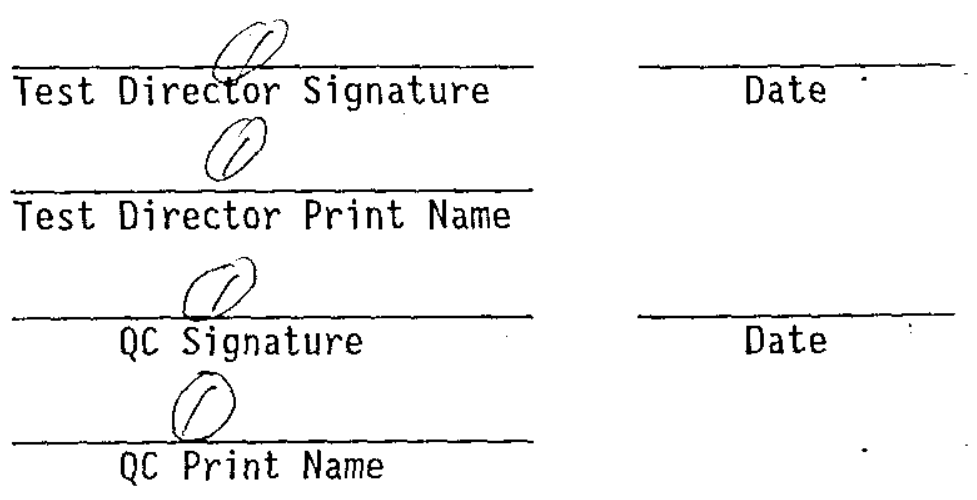

already tested per 0tP-260-004, Rev A-D,

see Test Log entry, 2030.

Resiting 2/29/00

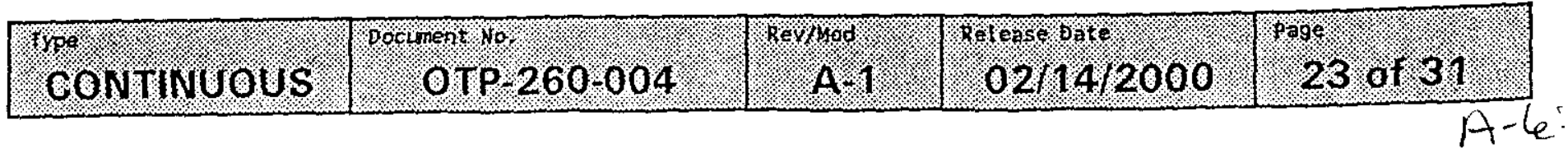




\subsection{TEST USER DEFINED MODE}

5.3.1 ENSURE applicable SETUP Steps in section 5.1 are completed.

CART CONTROL SCREEN

5.3.2 On the Gamma Cart Control, CLICK ON the "Config." button.

5.3.3 INPUT the following data:

\begin{tabular}{|c|c|}
\hline POSITION & DATA \\
\hline Tank Number: & $A Z-101$ \\
\hline Cart: & $A O R B$ \\
\hline Riser ID: ft. & $\begin{array}{l}\text { Selected riser number } \\
\text { NOTE - } \quad \text { Riser depth is } \\
\text { automatically computed } \\
\text { from software upon input } \\
\text { of riser ID\#. }\end{array}$ \\
\hline Probe Type: & $\begin{array}{l}1-4 \text { as applicable } \\
\text { (Normal is } 1 \text { or } 2 \text { for Cart } A \text { and } 3 \\
\text { or } 4 \text { for Cart B) }\end{array}$ \\
\hline Survey Time: & Sec. (As determined by Test Director) \\
\hline
\end{tabular}

ox of $R G$. $2 l^{a j 0}$ USER DEFINED PARAMETERS

5.3.4 CLICK ON "USER DEFINED".

5.3.5 ENTER depths desired for testing per Test Engineer Direction.

5.3.6 CLICK ON "SAVE" on display screen.

5.3.7 CLICK ON "EXIT". 


\subsection{TEST USER DEFINED MODE (Cont).}

NOTE - Test Engineer may manipulate parameters at any time during the following steps as necessary to ensure data retrieval and system configuration, with concurrence of Test

Director.

- After the following step, the program should automatically run.

- The "EMERGENCY STOP" may be used to stop at any time during. the next step if unit fails to stop at 1 imit switch. The "RESET" button will need to be pushed to resume the program.
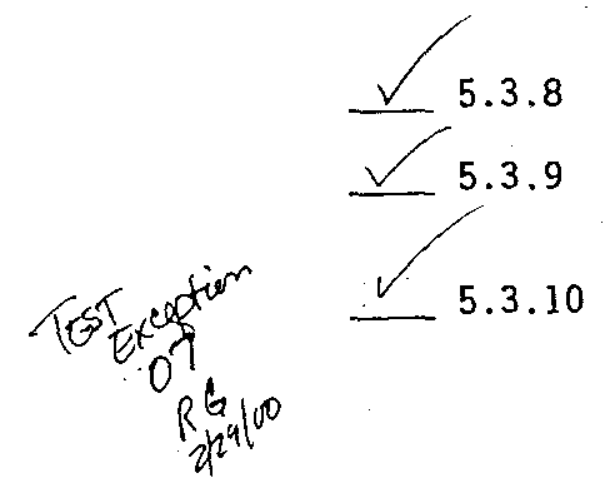

CLICK oN Start button.

Test Engineer ENSURE data is received, AND both hard-copy and electronic files can be retrieved.

VERIFY system automatically ZEROs and data is collected at zero posjtion.

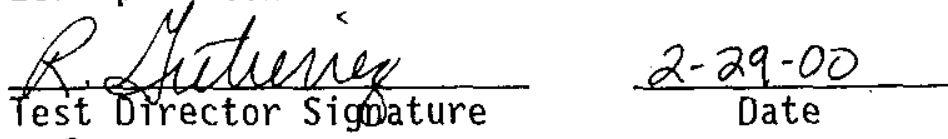

Rich Gutiernez 


\subsection{TEST USER DEFINED MODE (Cont).}
5.3.11 CLICK ON "LOGOUT" on display screen.
5.3.12 REMOVE Probe, riser extension tool, and associated equipment AND

STORE per Test Director direction.

\section{OR}

CONTINUE in this procedure.

5.3.13 REPEAT the steps in this section (5.3) as directed for any risers as directed by Test Director.

5.3.14 VERIFY by signing below section 5.3 is complete.

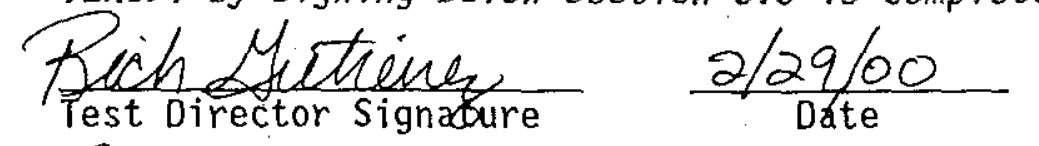

Rich Gutierrez

Test Director Print Name
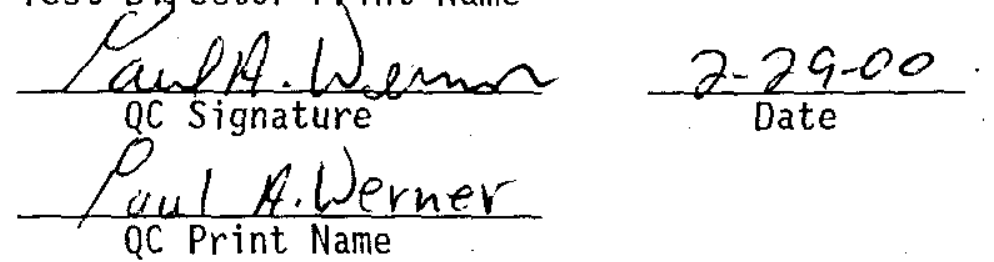

\begin{tabular}{|c|c|c|c|c|}
\hline Wy & 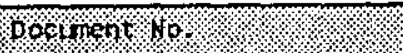 & ReX Mod $/$. & releassorte & Page, : , : \\
\hline OONINLOUS & . OTP 260.004 & 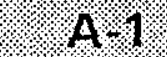 & $02,14 \% 2000$ & 26 of 31 \\
\hline
\end{tabular}




\section{RISER 15C \\ GAMMA CART - B}




\section{1-AZ GAMMA CART OPERATIONAL TEST PROCEDURE}

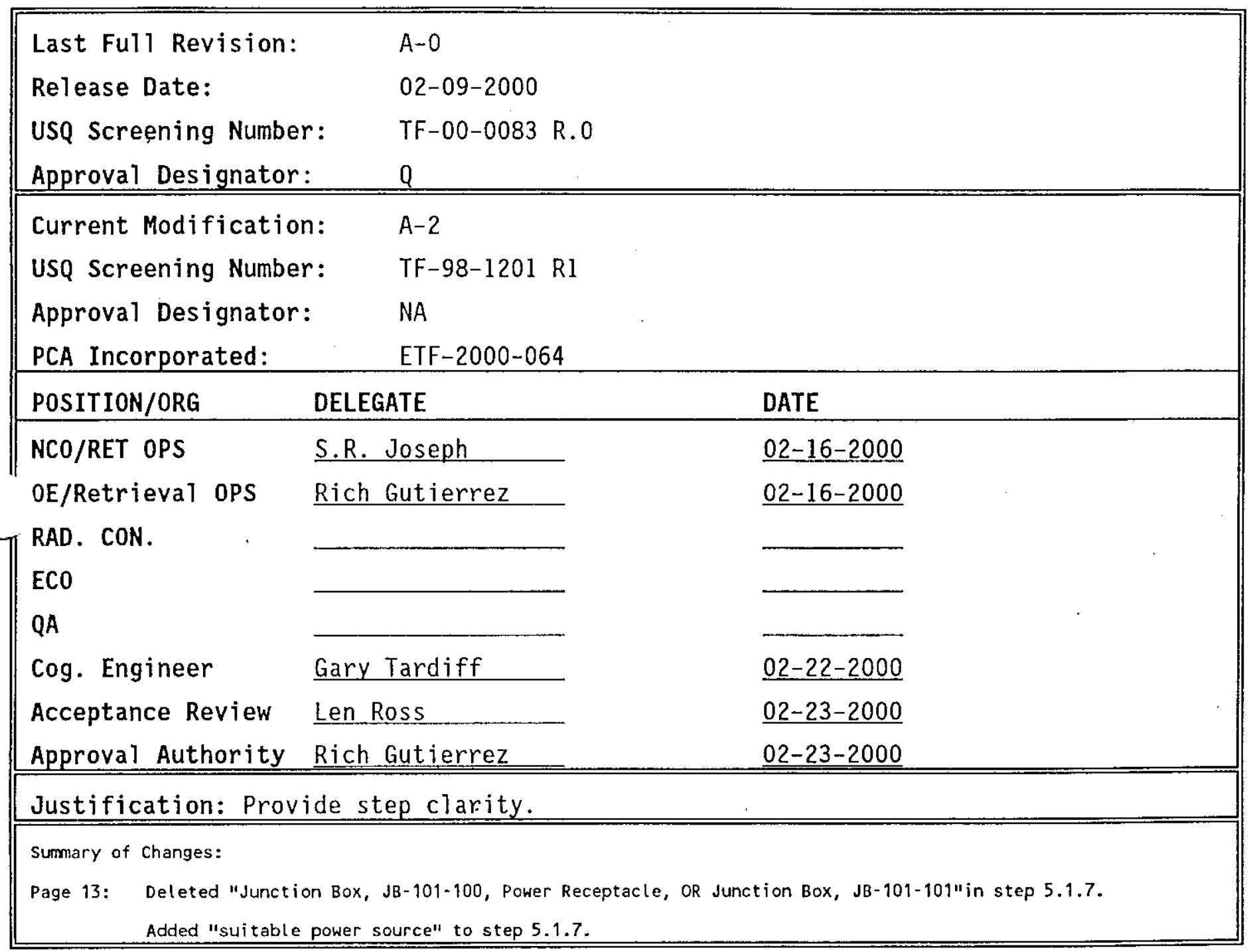

$$
\text { Goummolant } 15 \text { C Breser }
$$




\subsection{PREREQUISITES}

\subsection{SPECIAL TOOLS, EQUIPMENT, AND SUPPLIES}

The following supplies may be needed to perform this procedure:

- Riser Swabbing equipment

- Riser extension tool

\subsection{PERFORMANCE DOCUMENTS}

The following procedures may be needed to perform this procedure:

- TO-040-333 LIQUID OBSERVATION WELL (LOW) SURVEILLANCE VAN STARTUP AND OPERATION PROCEDURE

\subsection{CONDITIONS AND ACTIONS}

NOTE - All signators on this procedure shall document their signature on Procedure Signature Sheet.

4.3.1 All pre-testing and inspection of the system or portions of the system to be tested has been completed.

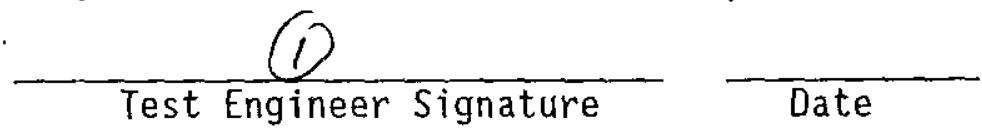

4.3.2 A pre-job briefing has been held. and all participants have been thoroughly briefed on job safety, hazards, and their responsibilities before performing this ATP.

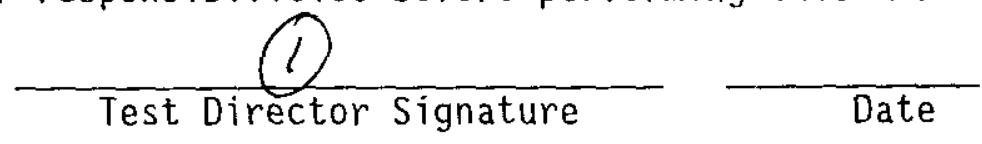

4.3.3 Test Director VERIEY section 4.3 has been COMPLETED.

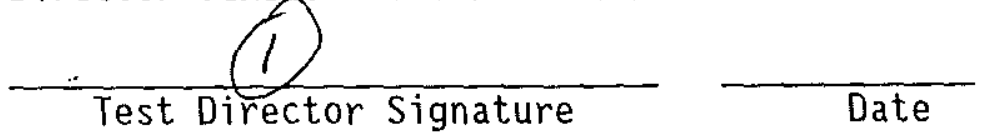

(1) ARREAOY TESTED PER OTP-260-004, REV A-O

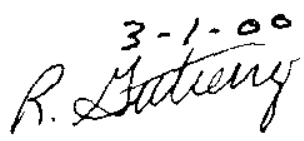




\subsection{PROCEDURE}

\subsection{SETUP}

NOTE - This procedure may be repeated for either GAMMA CART A or GAMMA CART B as applicable. N/A may be entered in blocks or steps per Test Director as applicable.

$\checkmark 5.1 .1$

RECORD GAMMA CART CPU number for the system being tested. GAMMA CART IDENTIFIER \#

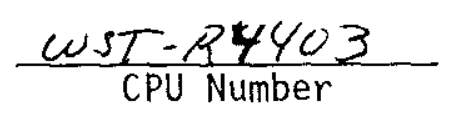

5.1.2 PERFORM cleanliness check in applicable riser listed on TABLE II, per section 5.10 in procedure T0-040-333 latest rev, prior to mounting riser extension tool.

5.1.3 ENSURE GAMMA CART riser extension tool is mounted on the applicable riser.

L 5.1 .4 ENSURE GAMMA CART is placed in line with riser extension tool to facilitate installation of probe and cables.

5.1.5 CHECK route to riser for obstacles and clearances.

5.1.6 LEVEL cart using jacks.

5.1.7 CONNECT gamma cart power cables, as follows:

- One end to gamma cart power receptacle

- other end to surtable power source-Junction-Box, JB-101 100, Power Receptacle, OR Junction Box; IB-101-101

5.1.8 CONNECT gamma cart communications cable, as follows:

- One end to gamma cart communications receptacle

- $\quad$ other end to Tank 241-AZ-101 Gamma Cart A AND/OR B Data Collection Subsystem communications receptacle

5.1.9 PLACE Gamma Cart "RAISE OFF LOWER" switch in the LOWER position.

5.1.10 CHECK that detector probe cable is resting in the Gamma cart boom cable reel. 


\subsection{SETUP (Cont).}

\section{CAUTION}

If sufficient tension is NOT held on the detector probe cable as the cable is being let out, the cable could become entangled.

NOTE - Step 5.1.11 and 5.1 .12 require two operators to perform continuous action until step 5.1 .12 is complete.

5.1 .11 HOLD tension on the detector probe cable until step 5.1.12 is completed.

5.1.12 PRESS AND HOLD "RESET" button until enough detector probe cable is let-out that will allow placement of the detector cable through riser extension collar AND into riser drywel1, AND

RELEASE the "RESET" button.

$\simeq 5.1 .13$ INSTALL the proper detector probe on the detector probe cable.

L 5.1.14 ENSURE that the detector probe connections are correct and tight. AND

INSERT probe into riser extension tool.

C 5.1 .15 ENSURE limit switch cable is connected from limit switch on riser extension tool, to the connection point on the front of the GAMMA CART.

L 5.1.16 ENSURE the "Raise - Off - Lower" selector switch is in the "OFF" position.

$\checkmark 5.1 .17$ ENSURE the emergency stop button is pulled out.

5.1.18 POSITION" the "SPEED" control potentiometer to MIN speed (fully counter-clockwise). 


\subsection{SETUP (Cont).}

\section{CAUTION}

There is no limit switch to stop the motion. when the cable is fully unwound. The cable will rewind backwards on the reel. Damage to the cable may result.

NOTE - When the cart is first powered up, or the emergency stop button has been pushed, or power has been restored after a power failure, the cable reel will not move up or down until "RESET" button is activated.

- The "Raise-OFF-Lower" Switch is Manually controlled and is Operator Dependent.

5.1.19 ENSURE LOCAL/REMOTE switch is in the "LOCAL" position.

5.1.20 ENERGIZE the Cart.

5.1.21 SET the "SPEED" potentiometer to 2 on the GAMMA Cart.

5.1.22 SET the "RAISE -OFF- LOWER" switch to the "LOWER" position.

(1) 5.1.23 PUSH "EMERGENCY STOP" button on GAMMA CART.

(1) 5.1 .24 VERIFY the system has stopped.

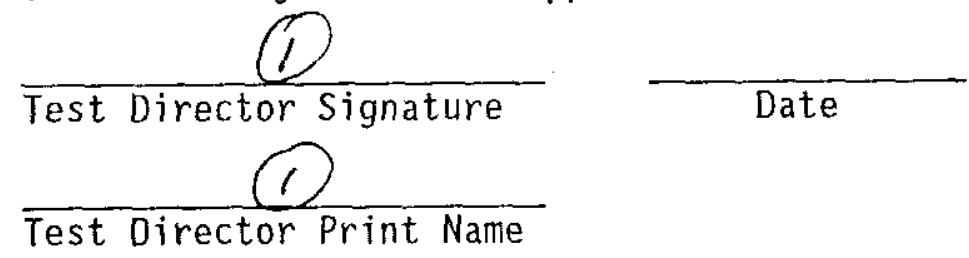

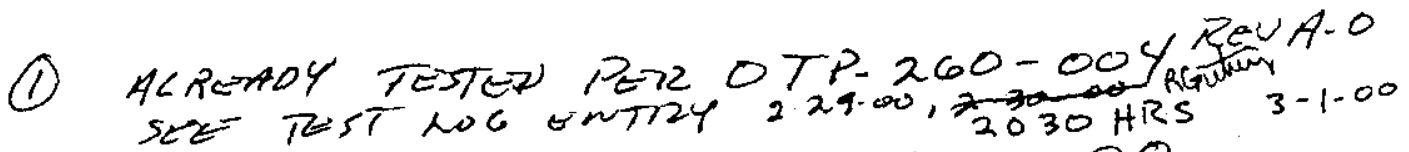
$3-1-00$

P. Muturiz 


\subsection{SETUP (Cont).}

1) 5.1.25 SET the "RAISE-OFF-LOWER" switch to the "RAISE" position.

(1) 5.1.26 PULL "EMERgENCY STOP" out on GAMMA CART.

(1) 5.1.27 PUSH the "RESET" button on GAMMA CART to resume.

(1) 5.1.28 ENSURE limit switch activates when probe returns to the zero position.

(1) 5.1.29 SET the "RAISE-OFF-LOWER" switch to the "OFF" position.

(1) 5.1 .30 SET "SPEED" potentiometer to MIN.

(1) 5.1.31 POSITION The "LOCAL REMOTE" switch to "REMOTE".

(1) 5.1 .32 VERIFY by signing below section 5.1 is complete.

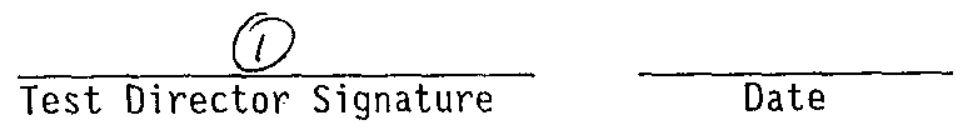

$\frac{1}{\text { Test Director Print Name }}$

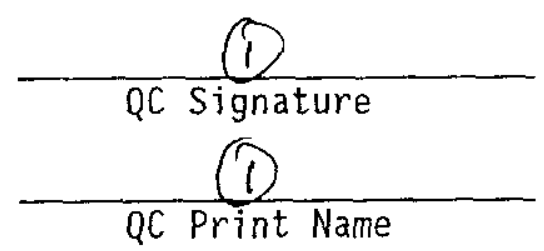

(1) ALREMOY TESTED PER OTP-260-0OY, REV A-O

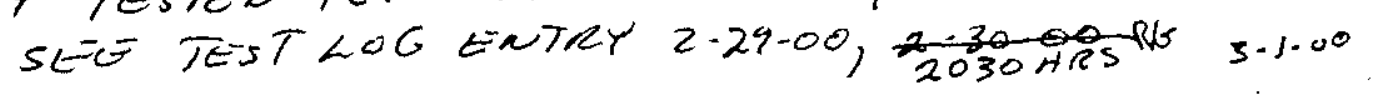
$3-1-00$ P. Satury 


\subsection{TEST INCREMENTAL SAMPLE MODE}

SETUP

NOTE - All Steps in this section apply to either cart, except in those steps where the specific cart is indicated.

\section{INSTRUMENT CHECK}

5.2.1 IF the pushbutton for Tank 241-AZ-101 Gamma Cart A AND/OR $B$ Data Collection System Central Processing Unit (CPU), AND/OR associated MONITOR, are NOT ON, PRESS the applicable on pushbuttons.

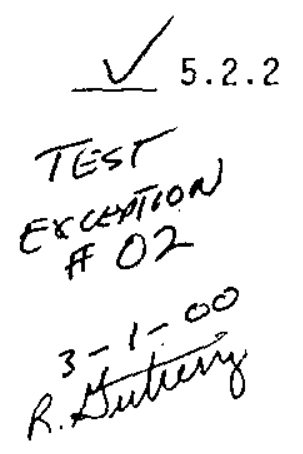

ENSURE the following systems are ON AND

ENSURE settings are correct for the following:

- ORTEC MINIBIN

- pOWer suppLy

Detector Bias Power Supply (HVPS): ORTEC Mod. 478.

- $k V: .5$

- 0 to 1000V: (+60 volts)

Amplifier (AMP): ORTEC Mod. 673

- COARSE GAIN: 200

- FINE GAIN: 0.680

- SHAPING TIME: Both knobs set to 2 microseconds

- PZ Adjust: Do NOT change settings (in this procedure)

- BLR: Switch in AUTO (up) position

- INPUTS: Switch in POS (up) position BNC cable on terminal (from pre amplifier)

- OUTPUTS: cable on UNIPOLAR terminal (to single channel Analyzer)

5.2.3 WHEN WINDOWS login screen appears CLICK ON "CANCEL". 


\subsection{TEST INCREMENTAL SAMPLE MODE (Cont).}

NOTE - After canceling windows login, GAMMA CART software should automatically load.

5.2.4 VERIFY "GAMMA CART SPECTRUM ANALYZER AND CONTROL SYSTEM" screen is displayed on Tank 241-AZ-101 Gamma Cart A AND/OR B Data Collection System Monitor.

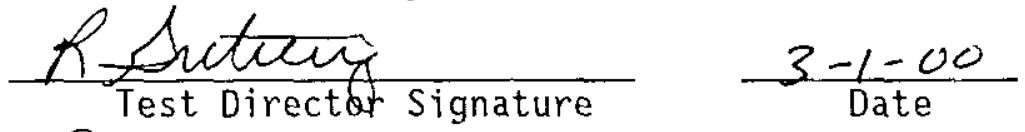

$\frac{R \text { Gutierrez }}{\text { Test Director Print Name }}$

5.2.5 SELECT "Login" on the "GAMMA CART SPECTRUM ANALYZER AND CONTROL SYSTEM" screen.

NOTE - LOGIN passwords and information may be obtained from Test Director.

5.2 .6 LOG-IN.

5.2.7 VERIFY LOCAL/REMOTE switch on display screen is in "REMOTE" pOSition.

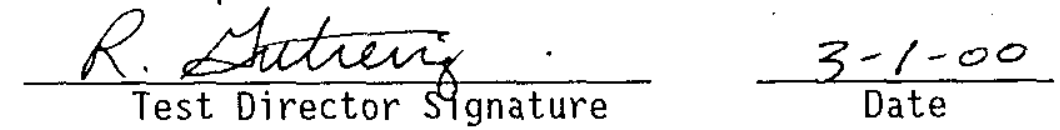

$\frac{\text { P. Gutierver }}{\text { Test Director Print Name }}$ 


\subsection{TEST INCREMENTAL SAMPLE MODE (Cont).}

\section{IESTING}

(1) 5.2.8 SELECT "config" on the "Gamma Cart Display" screen.

(1) 5.2.9 ENTER the following data for selected riser on the "Configuration - Display" screen by pulling down applicable menu:

\begin{tabular}{|c|c|}
\hline POSITION & DATA \\
\hline Tank Number: & $A Z-101$ \\
\hline Cart: & $A O R B$ \\
\hline Riser ID: ft. & $\begin{array}{ll} & \text { Selected riser number } \\
\text { NOTE - } \quad \text { Riser depth is } \\
\text { automatically computed } \\
\text { from software upon input } \\
\text { of riser ID\#. }\end{array}$ \\
\hline Probe Type: & $\begin{array}{l}1-4 \text { as applicable } \\
\text { (Normal is } 1 \text { or } 2 \text { for Cart A and } 3 \\
\text { or } 4 \text { for Cart B) }\end{array}$ \\
\hline Survey Time: & Sec. (As determined by Test Directo \\
\hline
\end{tabular}

(1) 5.2.10 ENSURE REAL/LIVE toggle button indicates "LIVE".

(1) 5.2.11 On the Data Collection Configuration window, SELECT the "Incremental" button.

INCREMENTAL PARAMETERS

(1) 5.2.12 INPUT the following Sample Collection Data:

\begin{tabular}{|l|l|}
\hline $\begin{array}{l}\text { Sample start } \\
\text { Depth: }\end{array}$ & $55.0 \mathrm{ft}$ \\
\hline Interval Size: & $10.0 \mathrm{ft}$ \\
\hline Sample End Depth: & $5.0 \mathrm{ft}$ \\
\hline
\end{tabular}

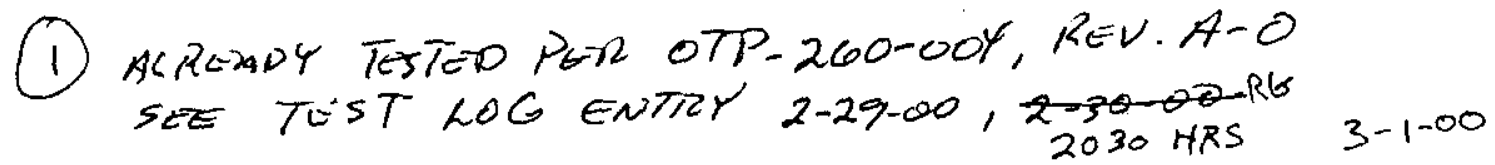
R. Sutury

\begin{tabular}{|c|c|c|c|c|}
\hline YOONGINUOUS & Poctinent OTP $260-004$ & 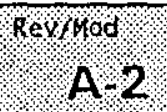 & Reterse forte & . \\
\hline
\end{tabular}




\subsection{TEST INCREMENTAL SAMPLE MODE (Cont).}

(D 5.2 .13 CLICK ON "SAVE".
(D $5.2 .14 \quad$ CLICK ON "EXIT".

NOTE - Test Engineer may manipulate parameters at any time during the following steps as necessary to ensure data retrieval and system configuration, with concurrence of Test Director.

- After the following step, the program should automatically run.

(1) 5.2 .15 CLICK oN "Start" button.

(1) 5.2.16 CLICK ON "EMERGENCY STOP" button on computer screen.

(1) 5.2 .17 VERIFY System stopped.

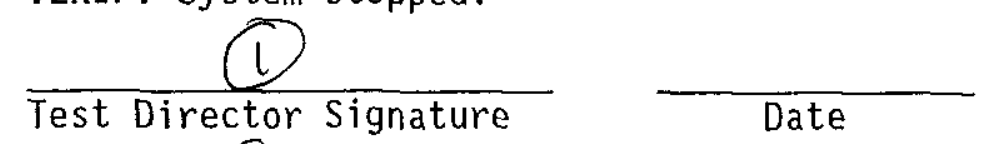

(1) 5.2.18 CLICK ON "EMERGENCY STOP" again to RESET the emergency stop button on computer screen.

(1) 5.2.19 CLICK ON "ZERO" on display screen.

(1) 5.2 .20 ENSURE GAMMA PROBE begins to RAISE.

(1) 5.2 .21 CLICK ON "STOP" button on display screen.

(1) AnREAOY TESTleP PER OTP-260-OOX, ReV.A-O SEE TEST LOG ENTIY $2-24-00, \frac{2.3000 R}{2030 \text { HRS }} 3-1.00$

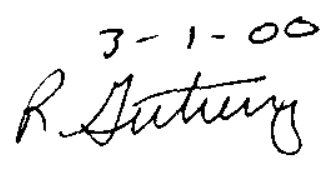


RPP-6104 RD

WORKING COPY

Printed on: Mar $1,00.12 .39 \mathrm{pm}$

5.2 TEST INCREMENTAL SAMPLE MODE (Cont).

(1) 5.2.22 VERIFY System stopped.

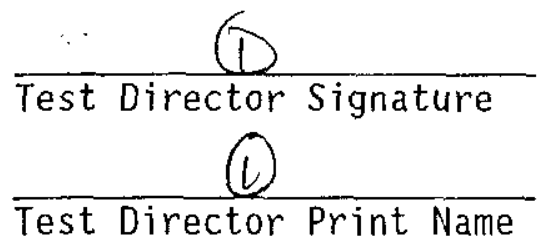

(1) 5.2 .23
(1) 5.2 .24
5.2 .25 CLICK ON "ZERO" again on display screen. ENSURE GAMMA PROBE begins to RAISE.

When probe and system zeros, CLICK ON "START" on display screen.

(1) 5.2 .26 VERIFY system resumed program.

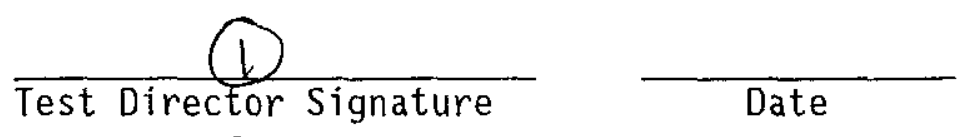

(2)

Test Director Print Name

(1) 5.2.27 CLICK ON "STOP" button on computer screen.

(1) 5.2 .28 VERIFY system stopped.

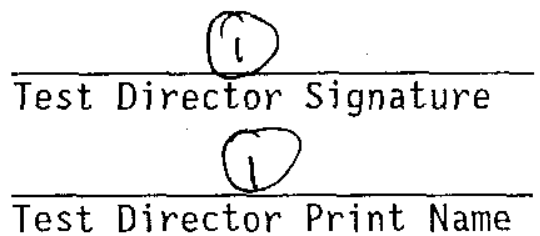

(1) 5.2.29 CLICK ON "ZERO" on display screen.

(1) 5.2.30 When probe and system zeros, CLICK ON "START" on display screen.

D 5.2 .31 vERIFY system resumed program.
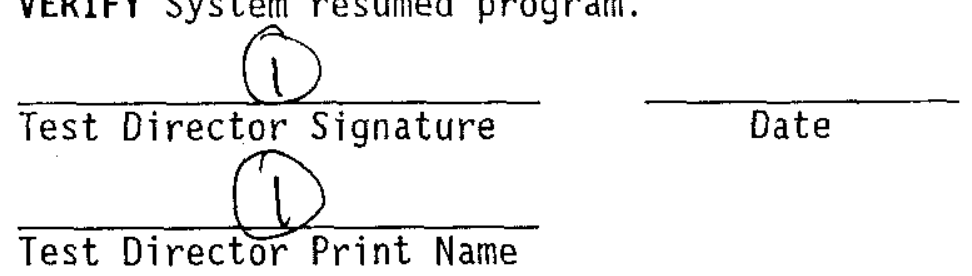

(1) AlrEadY RESTED PER OTP 260-004, $2 E=U$ ADO. SEE TEST LOG ENTRY $2.29-00,2-30-00$ RI $2030 \mathrm{HRS} 3-1.00$

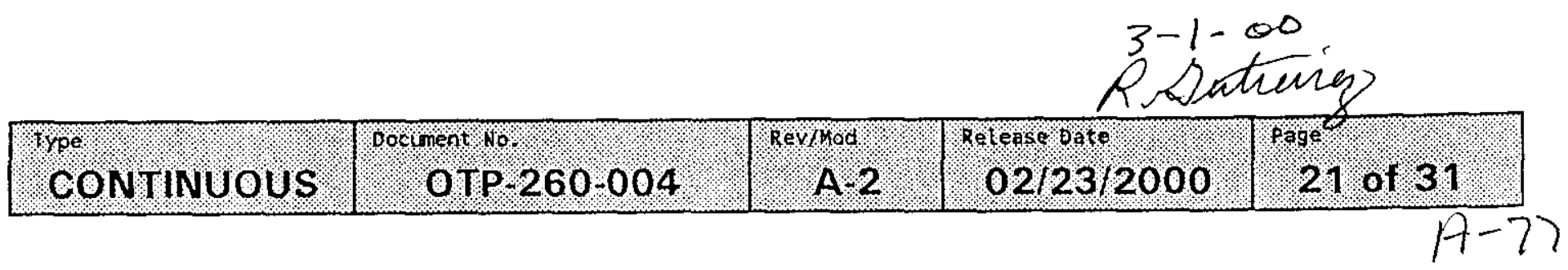




\subsection{TEST INCREMENTAL SAMPLE MODE (Cont).}

(1) 5.2.32 Test Engineer ENSURE data is received, AND both hard-copy and electronic files can be retrieved.

(1) 5.2 .33 VERIFY system automatically ZEROs and data is collected at zero position.

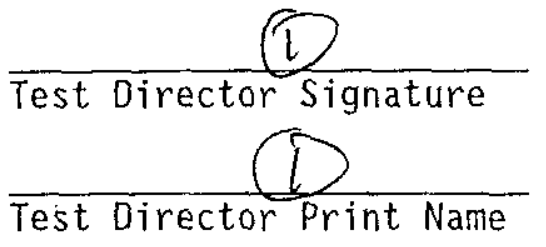

NOTE - The steps in section 5.1, applicable to the Emergency stop, need not be repeated if completed for an individual GAMMA CART. The Emergency stop on BOTH GAMMA CART $A$ and $B$, need to be tested only once.

NOTE - It is NOT necessary to do ALL risers in one procedure. Test Director is responsible for ensuring ALL risers have been profiled by one AND/OR the other GAMMA CART(S).

REPEAT applicable SETUP Steps in section 5.1 AND Incremental testing steps 5.2.1 - 5.2.15 AND Steps 5.2.32 and 5.2 .33 for each of the following risers and depths per Test Director's direction.

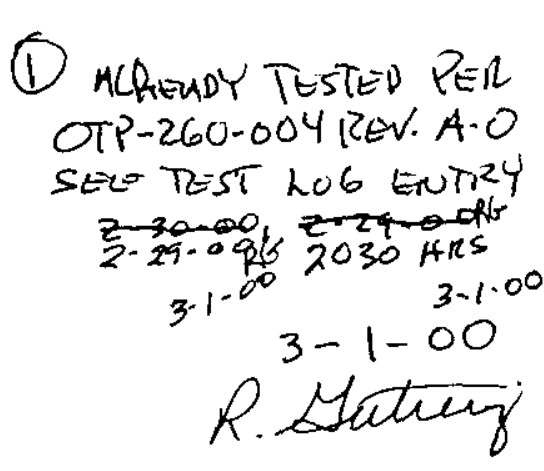

TABLE I

\begin{tabular}{|c|l|}
\hline RISER & $\begin{array}{l}\text { Depth } \\
\text { inches }(\mathrm{ft})\end{array}$ \\
\hline $14 \mathrm{~A}$ & $660(55.0)$ \\
\hline $14 \mathrm{C}$ & $660(55.0)$ \\
\hline $14 \mathrm{D}$ & $660(55.0)$ \\
\hline $14 \mathrm{~F}$ & $660(55.0)$ \\
$14 \mathrm{G}$ & $660(55.0)$ \\
\hline $14 \mathrm{~B}$ & $660(55.0)$ \\
\hline $14 \mathrm{E}$ & $660(55.0)$ \\
\hline $15 \mathrm{I}$ & $684(57.0)$ \\
\hline $15 \mathrm{C}$ & $684(57.0)$ \\
\hline $15 \mathrm{E}$ & $684(57.0)$ \\
\hline $15 \mathrm{~B}$ & $684(57.0)$ \\
\hline $15 \mathrm{~F}$ & $684(57.0)$ \\
\hline
\end{tabular}

GONTINUOUS : |




\subsection{INCREMENTAL SAMPLE MODE (Cont).}

NOTE - In the following Table, Test Director N/A blocks that are tested with a different GAMMA CART.

(1) 5.2.35 VERIFY the applicable riser in step 5.2.34 has been tested.

\begin{tabular}{|c|c|}
\hline \multicolumn{1}{|c|}{ TABLE I I } \\
\hline RISER & TEST DIRECTOR SIGNATURE \\
\hline $14 \mathrm{~A}$ & \\
\hline $14 \mathrm{C}$ & \\
\hline $14 \mathrm{D}$ & \\
\hline $14 \mathrm{~F}$ & \\
\hline $14 \mathrm{G}$ & \\
\hline $14 \mathrm{~B}$ & \\
\hline $14 \mathrm{E}$ & \\
\hline $15 \mathrm{I}$ & \\
\hline $15 \mathrm{C}$ & \\
\hline $15 \mathrm{E}$ & \\
\hline $15 \mathrm{~B}$ & \\
\hline $15 \mathrm{~F}$ & \\
\hline
\end{tabular}

(1) 5.2 .36 VERIFY by signing below section 5.2 is complete.

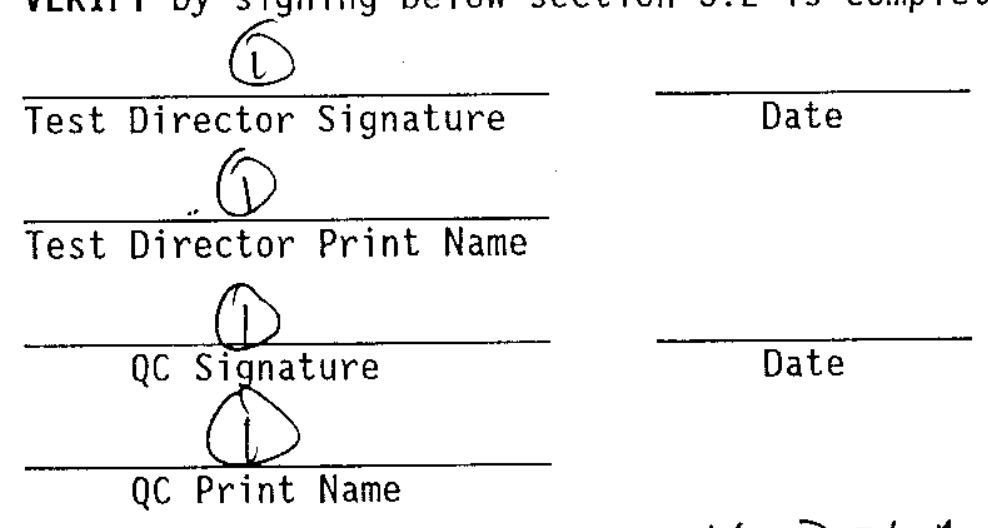

(1) ALreADY TESTED PER OTP-260-Od RGV. A.O,

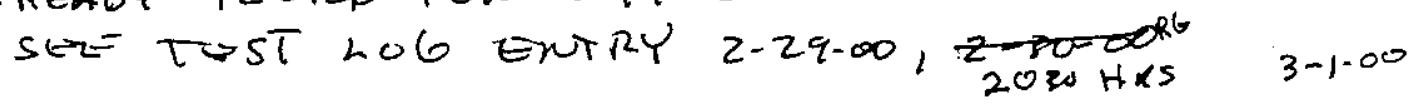




\subsection{TEST USER DEFINED MODE}

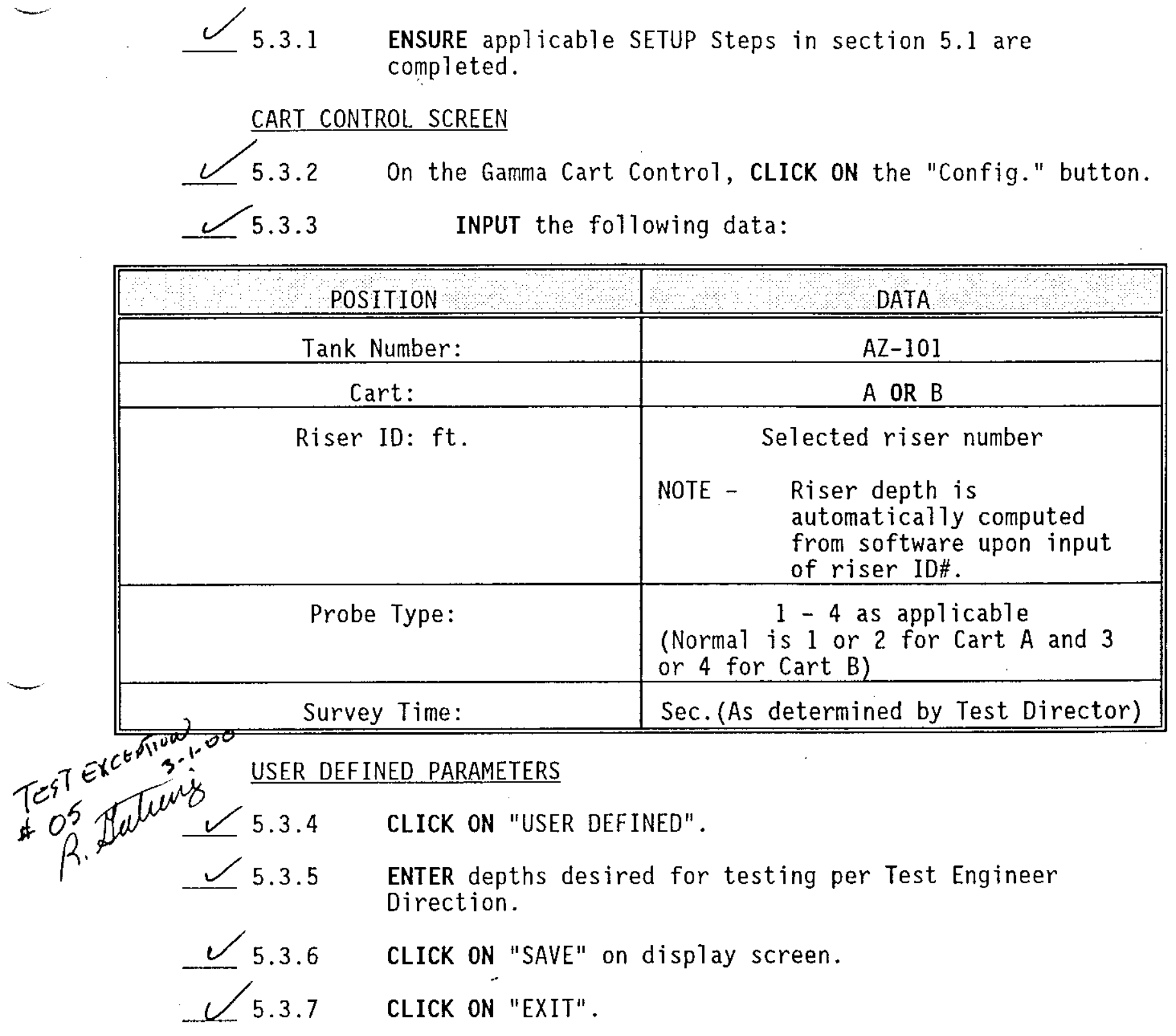




\subsection{TEST USER DEFINED MODE (Cont).}

NOTE - Test Engineer may manipulate parameters at any time during the following steps as necessary to ensure data retrieval and system configuration, with concurrence of Test Director.

- After the following step, the program should automatically run.

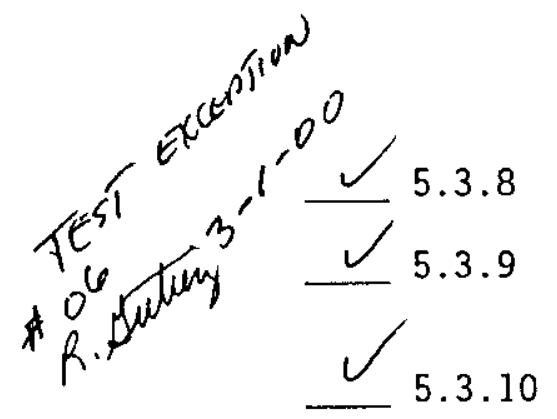

- The "EMERGENCY STOP" may be used to stop at any time during the next step if unit fails to stop at limit switch. The "RESET" button will need to be pushed to resume the program.

CLICK ON Start button.

Test Engineer ENSURE data is received, AND both hard-copy and electronic files can be retrieved.

VERIFY system automatically ZEROs and data is collected at zero position.

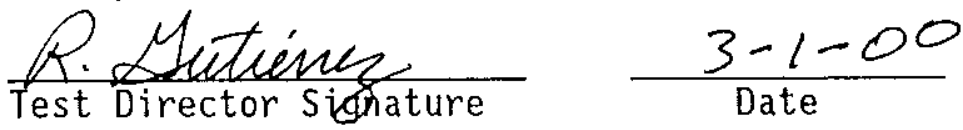

$\frac{\text { R. Gutierrez }}{\text { Test Director Print Name }}$ 
RPP-6104

RD

WORKING COPY

Printed on: Mar 1,00 12:39 pm

5.3 TEST USER DEFINED MODE (Cont).

5.3.11 CLICK ON "LOGOUT" on display screen. $\checkmark 5.3 .12$ REMOVE Probe, riser extension tool, and associated

STORE per Test Director direction.

OR

CONTINUE in this procedure.

5.3.13 REPEAT the steps in this section (5.3) as directed for any risers as directed by Test Director.

5.3.14 VERIFY by signing below section 5.3 is complete.

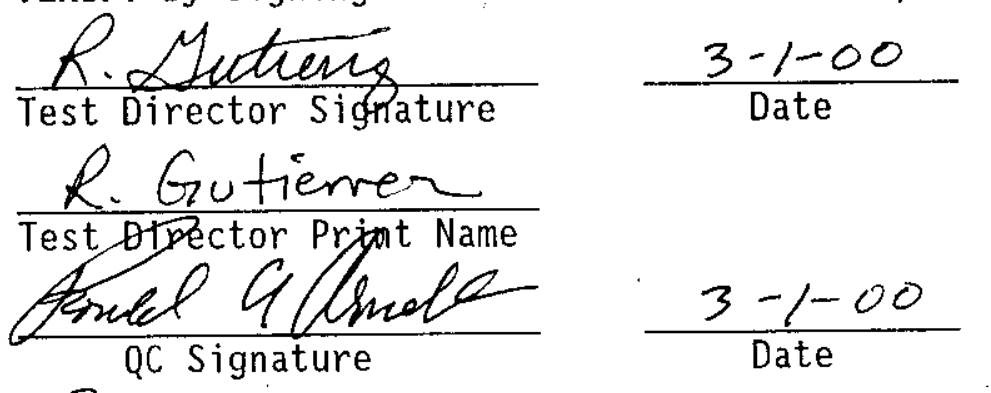

$\frac{\text { RoweLS A. ARUDT }}{\text { QC Print Name }}$

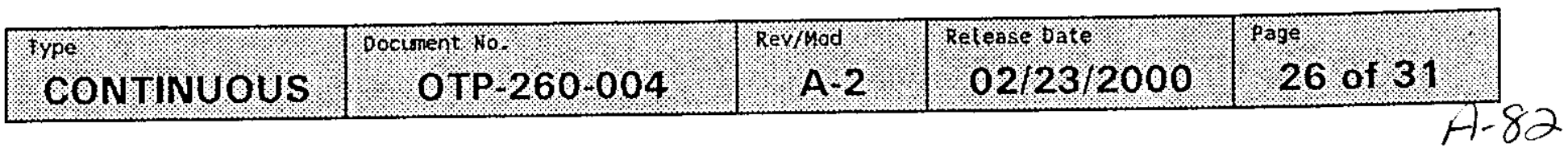




\section{RISER 14E \\ GAMMA CART - B}




\section{1-AZ GAMMA CART OPERATIONAL TEST PROCEDURE}

\begin{tabular}{|c|c|c|}
\hline $\begin{array}{l}\text { Last Full Revision: } \\
\text { Release Date: } \\
\text { USQ Screening Number: } \\
\text { Approval Designator: }\end{array}$ & $\begin{array}{ll}A-0 & \\
02-09-2000 \\
r: \quad \text { TF-00-0083 R.0 } \\
Q\end{array}$ & \\
\hline $\begin{array}{l}\text { Current Modification } \\
\text { USQ Screening Number } \\
\text { Approval Designator: } \\
\text { PCA Incorporated: }\end{array}$ & $\begin{array}{l}A-2 \\
T F-98-1201 \quad R 1 \\
N A \\
\text { ETF-2000-064 }\end{array}$ & \\
\hline \multicolumn{2}{|c|}{ POSITION/ORG DELEGATE } & DATE \\
\hline $\begin{array}{l}\text { NCO/RET OPS } \\
\text { OE/Retrieval OPS }\end{array}$ & S.R. Joseph & $\underline{02-16-2000}$ \\
\hline $\begin{array}{l}\text { OE/Retrieval OPS } \\
\text { RAD. CON. } \\
\text { ECO }\end{array}$ & Rich Gutierrez & $\underline{02-16-2000}$ \\
\hline \multicolumn{3}{|l|}{ QA } \\
\hline \multirow{3}{*}{$\begin{array}{l}\text { Cog. Engineer } \\
\text { Acceptance Review } \\
\text { Approval Authority }\end{array}$} & Gary Tardiff & $\underline{02-22-2000}$ \\
\hline & Len Ross & $\underline{02-23-2000}$ \\
\hline & Rich Gutierrez & $02-23-2000$ \\
\hline \multicolumn{3}{|c|}{ Justification: Provide step clarity. } \\
\hline \multicolumn{3}{|c|}{$\begin{array}{l}\text { Surmary of Changes: } \\
\text { Page 13: Deleted "Junction Box, JB-101-100, Power Receptacle, OR Junction Box, JB-101-101"in step 5.1.7. } \\
\text { Added "suitable power source" to step 5.1.7. }\end{array}$} \\
\hline
\end{tabular}

$$
\begin{aligned}
& \text { Sam ma Cart } B \\
& \text { P.ser } 14 E \\
& \begin{array}{c}
3-1-\infty 0 \\
R \text {-yation }
\end{array}
\end{aligned}
$$




\subsection{PREREQUISITES}

\subsection{SPECIAL TOOLS, EQUIPMENT, AND SUPPLIES}

The following supplies may be needed to perform this procedure:

- Riser Swabbing equipment

- Riser extension tool

\subsection{PERFORMANCE DOCUMENTS}

The following procedures may be needed to perform this procedure:

- TO-040-333 LIQUID OBSERVATION WELL (LOW) SURVEILLANCE VAN STARTUP AND OPERATION PROCEDURE

\subsection{CONDITIONS AND ACTIONS}

NOTE - All signators on this procedure shall document their signature on Procedure Signature Sheet.

4.3.1 All pre-testing and inspection of the system or portions of the system to be tested has been completed.

(i)
Test Engineer Signature
Date

4.3.2 A pre-job briefing has been held. and all participants have been thoroughly briefed on job safety, hazards, and their responsibilities before performing this ATP.

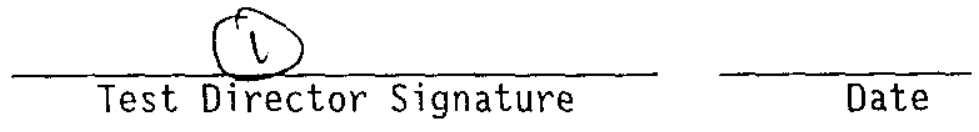

4.3.3 Test Director VERIFY section 4.3 has been COMPLETED.

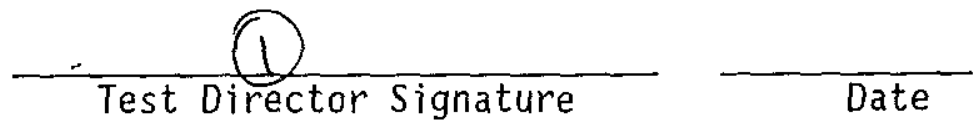

(1) ALRGHY TESTED ON OTP-260-00Y, ReV.A-O

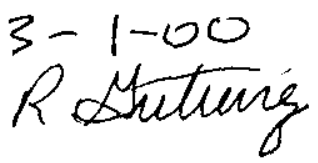




\subsection{PROCEDURE}

\subsection{SETUP}

NOTE - This procedure may be repeated for either GAMMA CART A or GAMMA CART B as applicable. N/A may be entered in blocks or steps per Test Director as applicable.

5.1.1 RECORD GAMMA CART CPU number for the system being tested. GAMMA CART IDENTIFIER \# $3 \frac{\text { UST-RYYO3 }}{\text { CPU Number }}$

5.1.2 PERFORM cleanliness check in applicable riser listed on TABLE II, per section 5.10 in procedure T0-040-333 latest rev, prior to mounting riser extension tool.

ENSURE GAMMA CART riser extension tool is mounted on the applicable riser.

5.1.4 ENSURE GAMMA CART is placed in line with riser extension tool to facilitate installation of probe and cables.

5.1.5 CHECK route to riser for obstacles and clearances.

5.1.6 LEVEL cart using jacks.

5.1.7 CONNECT gamma cart power cables, as follows:

- One end to gamma cart power receptacle

- Other end to sultable power source-Junction-Box, JB 101,100 , power-Receptacte, OR Junction Box, AB- $101-101$

5.1.8 CONNECT gamma cart communications cable, as follows:

- One end to gamma cart communications receptacle

- $\quad$ other end to Tank 241-AZ-101 Gamma Cart A AND/OR B Data Collection Subsystem communications receptacle

5.1.9 PLACE Gamma Cart "RAISE OFF LOWER" switch in the LOWER position.

5.1.10 CHECK that detector probe cable is resting in the Gamma Cart boom cable reel.

.




\subsection{SETUP (Cont).}

\section{CAUTION}

If sufficient tension is NOT held on the detector probe cable as the cable is being let out, the cable could become entangled.

NOTE - Step 5.1.11 and 5.1 .12 require two operators to perform continuous action until step 5.1 .12 is complete.

5.1.11 HOLD tension on the detector probe cable until step 5.1.12 is completed.

5.1.12 PRESS AND HOLD "RESET" button until enough detector probe cable is let-out that will allow placement of the detector cable through riser extension collar AND into riser drywe 11, AND

RELEASE the "RESET" button.

5.1.13 INSTALL the proper detector probe on the detector probe cable.

C 5.1.14 ENSURE that the detector probe connections are correct and tight. AND

INSERT probe into riser extension tool.

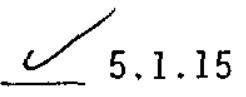

ENSURE 7 imit switch cable is connected from limit switch on riser extension tool, to the connection point on the front of the GAMMA CART.

$1 / 5.1 .16$ ENSURE the "Raise - Off - Lower" selector switch is in the "OFF" position.

5.1.17 ENSURE the emergency stop button is pulled out.

5.1.18 POSITION the "SPEED" control potentiometer to MIN speed (fully counter-clockwise). 


\subsection{SETUP (Cont).}

\section{CAUTION}

There is no limit switch to stop the motion when the cable is fully unwound. The cable will rewind backwards on the reel. Damage to the cable may result.

NOTE - When the cart is first powered up, or the emergency stop button has been pushed, or power has been restored after a power failure, the cable reel will not move up or down until "RESET" button is activated.

- The "Raise-OFF-Lower" Switch is Manually controlled and is Operator Dependent.

5.1.19 ENSURE LOCAL/REMOTE switch is in the "LOCAL" position.

5.1.20 ENERGIZE the Cart.

5.1.21 SET the "SPEED" potentiometer to 2 on the GAMMA Cart.

5.1.22 SET the "RAISE -OFF- LOWER" switch to the "LOWER" position.

(1) 5.1.23 PUSH "EMERGENCY STOP" button on GAMMA CART.

(1) 5.1 .24 VERIFY the system has stopped.
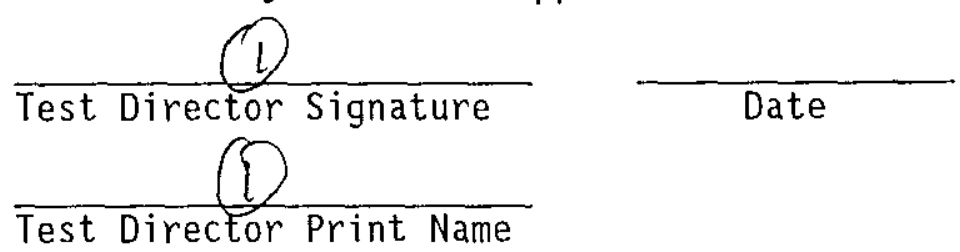

(1) ALREANY TEST PER OTP-260-0OY REV. A-O

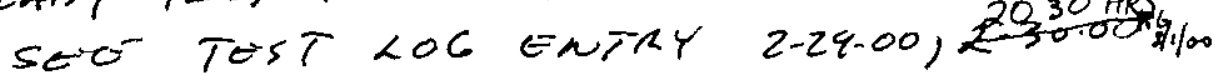

$$
\text { R. Stutieng }
$$




\subsection{SETUP (Cont).}

(1) 5.1.25 SET the "RAISE-OFF-LOWER" switch to the "RAISE" position.

(1) 5.1 .26 PULi "EMERgENCY STOP" out on GAMMA CART.

(Q) 5.1 .27 PUSH the "RESET" button on GAMMA CART to resume.

(1) 5.1.28 ENSURE limit switch activates when probe returns to the zero position.

(1) 5.1 .29 SET the "RAISE-OFF-LOWER" switch to the "OFF" pos
(1) 5.1 .30 SET "SPEED" potentiometer to MIN.
5.1 .31 POSITION The "LOCAL REMOTE" switch to "REMOTE".
5.1 .32 VERIFY by signing below section 5.1 is complete.

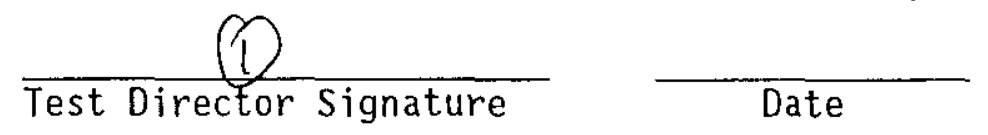

(1)

Test Director Print Name

(D)

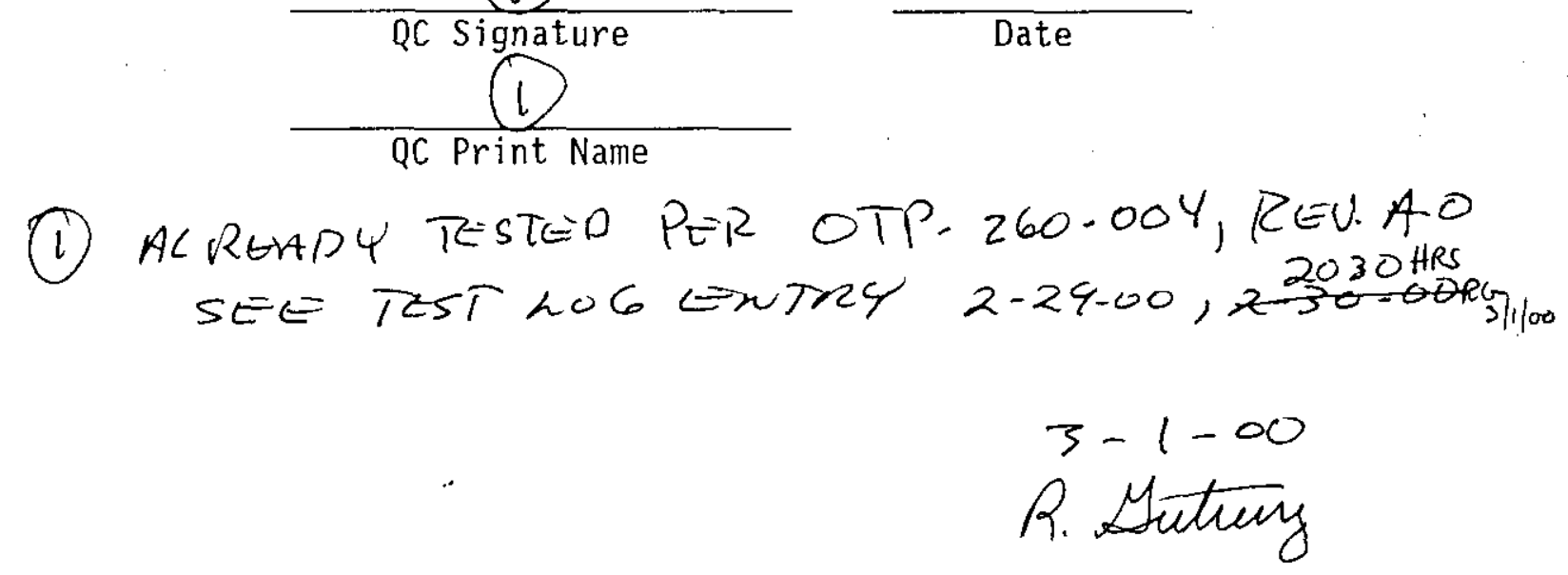

Date 


\subsection{TEST INCREMENTAL SAMPLE MODE}

SETUP

NOTE - All Steps in this section apply to either cart, except in those steps where the specific cart is indicated.

\section{INSTRUMENT CHECK}

L5.2.1 IF the pushbutton for Tank 241-AZ-101 Gamma Cart A AND/OR B Data Collection System Central Processing Unit (CPU), AND/OR associated MONITOR, are NOT ON, PRESS the applicable ON pushbuttons.

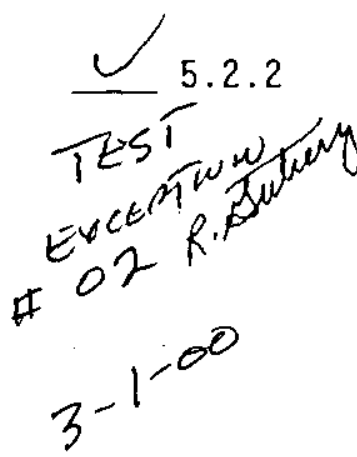

ENSURE the following systems are ON AND

ENSURE settings are correct for the following:

- $\quad$ ORTEC MINIBIN

- pOWER SUPPLy

Detector Bias Power Supply (HVPS): ORTEC Mod. 478.

- $\mathrm{kV}: .5$

- 0 to 1000V: (+60 volts)

Amplifier (AMP): ORTEC Mod. 673

- COARSE GAIN: 200

- FINE GAIN: 0.680

- SHAPING TIME: Both knobs set to 2 microseconds

- PZ Adjust: Do NOT change settings (in this procedure)

- BLR: Switch in AUTO (up) position

- INPUTS: Switch in POS (up) position BNC cable on terminal (from pre amplifier)

- OUTPUTS: cable on UNIPOLAR terminal to single channel Analyzer)

5.2.3 WHEN WINDOWS login screen appears CLICK ON "CANCEL". 


\subsection{TEST INCREMENTAL SAMPLE MODE (Cont).}

NOTE - After canceling windows login, GAMMA CART software should automatically load.

5.2.4 VERIFY "GAMMA CART SPECTRUM ANALYZER AND CONTROL SYSTEM" screen is displayed on Tank 241-AZ-101 Gamma Cart A AND/OR B Data Collection System Monitor.

$\frac{\text { R. Eutury }}{\text { Test Director Signature }} \frac{3-1-00}{\text { Date }}$

$\frac{\text { Ri. Gutierre } 2}{\text { Test Director Print Name }}$

5.2 .5 SELECT "Login" on the "GAMMA CART SPECTRUM ANALYZER AND CONTROL SYSTEM" screen.

NOTE - LOGIN passwords and information may be obtained from Test Director.

5.2.6 LOG-IN.

5.2.7 VERIFY LOCAL/REMOTE switch on display screen is in "REMOTE" pOSition.

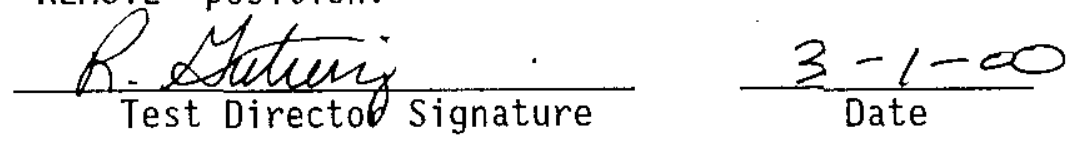

R. Gutuerrez

Test Director Print Name 


\subsection{TEST INCREMENTAL SAMPLE MODE (Cont).}

\section{TESTING}

(1) 5.2 .8 SELECT "config" on the "Gamma Cart Display" screen.

(1) 5.2 .9 ENTER the following data for selected riser on the "Configuration - Display" screen by pulling down applicable menu:

\begin{tabular}{|c|c|}
\hline POSITION & DATA \\
\hline Tank Number: & $A Z-101$ \\
\hline Cart: & $A O R \quad B$ \\
\hline Riser ID: ft. & $\begin{array}{ll}\text { Selected riser number } \\
\text { NOTE - } & \text { Riser depth is } \\
\text { automatically computed } \\
\text { from software upon input } \\
\text { of riser ID\#. }\end{array}$ \\
\hline Probe Type: & $\begin{array}{l}1-4 \text { as applicable } \\
\text { (Normal is } 1 \text { or } 2 \text { for Cart } A \text { and } 3 \\
\text { or } 4 \text { for Cart B) }\end{array}$ \\
\hline Survey Time: & Sec. (As determined by Test Director) \\
\hline
\end{tabular}

5.2.10 ENSURE REAL/LIVE toggle button indicates "LIVE".

(1) 5.2.11 On the Data Collection Configuration window, SELECT the "Incrementa1" button.

INCREMENTAL PARAMETERS

(1) 5.2 .12 INPUT the following Sample Collection Data:

\begin{tabular}{|l|l|}
\hline Sample start & $55.0 \mathrm{ft}$ \\
Depth: & \\
\hline Interval Size: & $10.0 \mathrm{ft}$ \\
\hline Sample End Depth. & $5.0 \mathrm{ft}$ \\
\hline
\end{tabular}

1) ALREADU TESTED PER OTP-260-00Y, REV.A.O SEE TEST LOGENTRY $2.29-00,2030$ HRs 
RPS 6104 PO

WORKING COPY

Printed on: Mar $1,0012: 39 \mathrm{pm}$

5.2 TEST INCREMENTAL SAMPLE MODE (Cont).

(1) 5.2 .13

CLICK ON "SAVE".

(1) 5.2 .14

CLICK ON "EXIT".

NOTE -

Test Engineer may manipulate parameters at any time during the following steps as necessary to ensure data retrieval and system configuration, with concurrence of Test Director.

- After the following step, the program should automatically run.

(D) 5.2.15 CLICK ON "Start" button.

(1) 5.2 .16 CLICK ON "EMERGENCY STOP" button on computer screen. VERIFY System stopped.

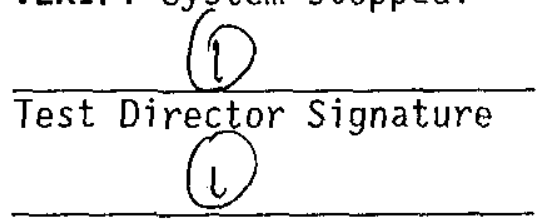

Date

Test Director Print Name

(1.) 5.2 .18 CLICK ON "EMERGENCY STOP" again to RESET the emergency stop button on computer screen.

(1) 5.2 .19

(1) 5.2 .20 CLICK ON "ZERO" on display screen. ENSURE GAMMA PROBE begins to RAISE.

(1) 5.2 .21 CLICK ON "STQP" button on display screen.

(1) AL ROHDY TOSTED PER OTP-260-004 REV. A-O

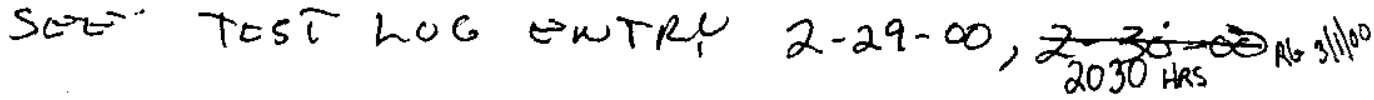

$$
3-1-00
$$

R. Stathengy

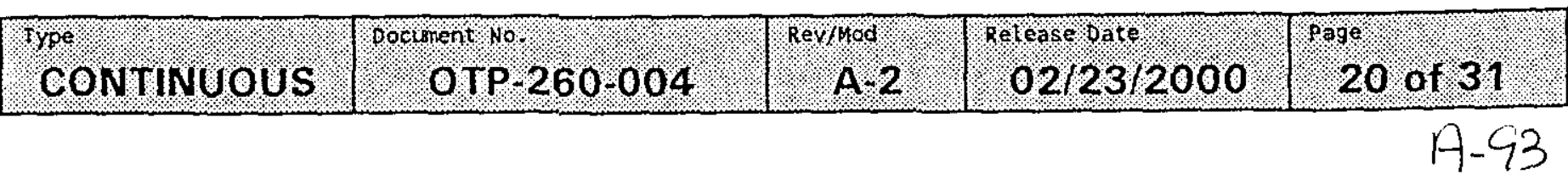




\subsection{TEST INCREMENTAL SAMPLE MODE (Cont).}

\section{(1) 5.2 .22 VERIFY System stopped.}

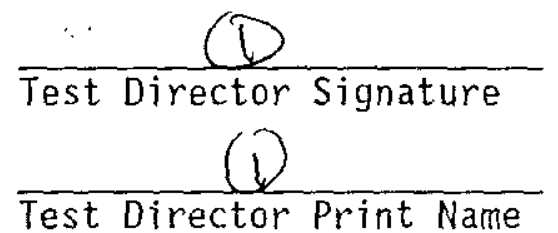

\section{(1) 5.2.23 CLICK ON "ZERO" again on display screen.}

(1) 5.2.24 ENSURE GAMMA PROBE begins to RAISE.

(1) 5.2.25 When probe and system zeros, CLICK ON "START" on display screen.

(1) 5.2 .26 VERIFY system resumed program.

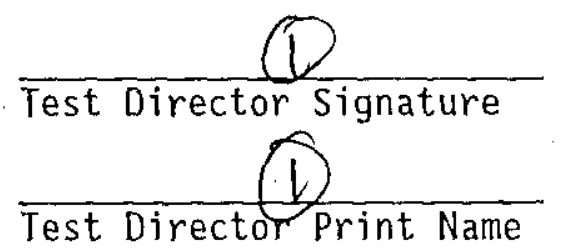
(1) 5.2 .27
CLICK ON "STOP" button on computer screen.
5.2 .28
VERIFY System stopped.

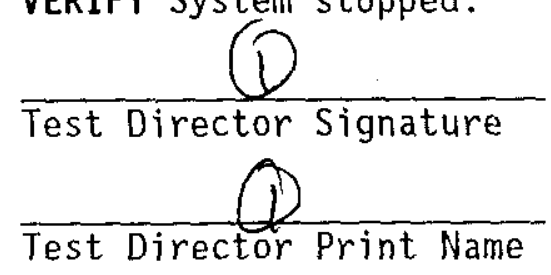

(1) 5.2.29 CLICK ON "ZERO" on display screen.

(1) 5.2 .30 When probe and system zeros, CLICK ON "START" on display screen.

(1) 5.2.31 VERIFY system resumed program.

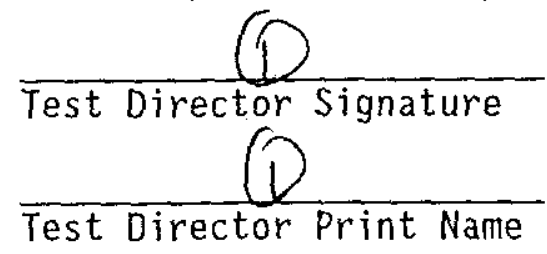

Date

Date 


\subsection{TEST INCREMENTAL SAMPLE MODE (Cont).}

5.2.32 Test Engineer ENSURE data is received, AND both hard-copy and electronic files can be retrieved.

(1) 5.2 .33

VERIFY system automatically ZEROs and data is collected at zero position.

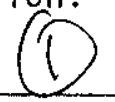

Test Director Signature

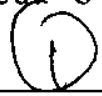

Test Director Print Name

NOTE - The steps in section 5.1, applicable to the Emergency stop, need not be repeated if completed for an individual GAMMA CART. The Emergency stop on BOTH GAMMA CART A and B, need to be tested only once.

NOTE - It is NOT necessary to do ALL risers in one procedure. Test Director is responsible for ensuring ALL risers have been profiled by one AND/OR the other GAMMA CART(S).

(?.2.34

REPEAT applicable SETUP Steps in section 5.1 AND

Incremental testing steps 5.2.1 - 5.2.15 AND Steps 5.2.32 and 5.2.33 for each of the following risers and depths per Test Director's direction.

(1) ALRUADQ TESTED RER OTP-260-0OY REV. A.O SEZ TEST NO6 ENTRY z-3000 $2-29-00$

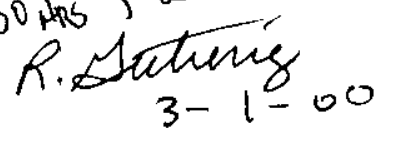

TABLE I

\begin{tabular}{|c|c|}
\hline RISER & $\begin{array}{l}\text { Depth } \\
\text { inches }(\mathrm{ft})\end{array}$ \\
\hline $14 \mathrm{~A}$ & $660(55,0)$ \\
\hline $14 \mathrm{C}$ & $660(55.0)$ \\
\hline 140 & $660(55.0)$ \\
\hline $14 \mathrm{~F}$ & $660(55.0)$ \\
\hline $14 \mathrm{G}$ & $660(55.0)$ \\
\hline $14 \mathrm{~B}$ & $660(55.0)$ \\
\hline $14 \mathrm{E}$ & $660(55.0)$ \\
\hline $15 \mathrm{I}$ & $684(57.0)$ \\
\hline $15 \mathrm{C}$ & $684(57.0)$ \\
\hline $15 \mathrm{E}$ & $684(57.0)$ \\
\hline 15B & $684(57.0)$ \\
\hline $15 \mathrm{~F}$ & $684(57,0)$ \\
\hline
\end{tabular}




\subsection{INCREMENTAL SAMPLE MODE (Cont).}

NOTE - In the following Table, Test Director N/A blocks that are tested with a different GAMMA CART.

(1) 5.2.35 VERIFY the applicable riser in step 5.2.34 has been tested.

TABLE II

\begin{tabular}{|l|l||}
\hline RISER & TEST DIRECTOR SIGNATURE \\
\hline $14 \mathrm{~A}$ & \\
\hline $14 \mathrm{C}$ & \\
\hline $14 \mathrm{D}$ & \\
\hline $14 \mathrm{~F}$ & \\
\hline $14 \mathrm{G}$ & \\
\hline $14 \mathrm{~B}$ & \\
\hline $14 \mathrm{E}$ & \\
\hline $15 \mathrm{I}$ & \\
\hline $15 \mathrm{C}$ & \\
\hline $15 \mathrm{E}$ & \\
$15 \mathrm{~B}$ & \\
\hline $15 \mathrm{~F}$ & \\
\hline
\end{tabular}

(1) 5.2.36 VERIFY by signing below section 5.2 is complete.
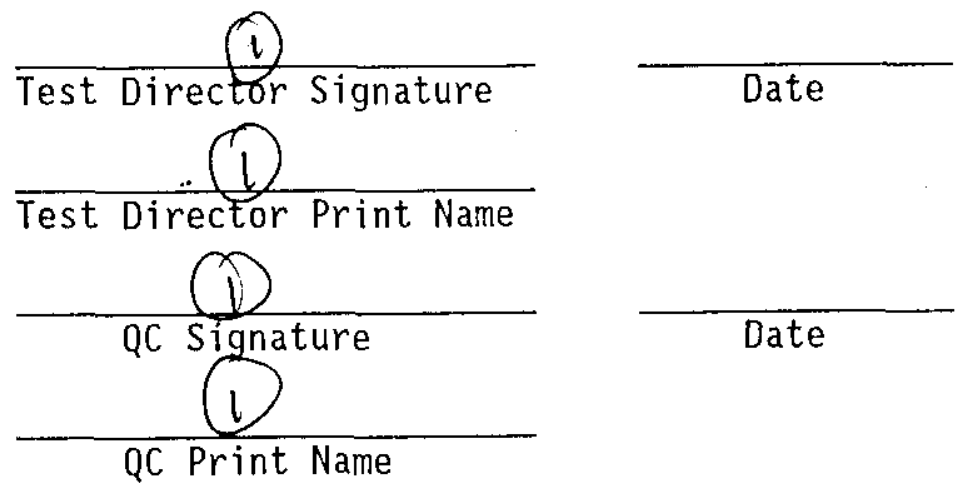

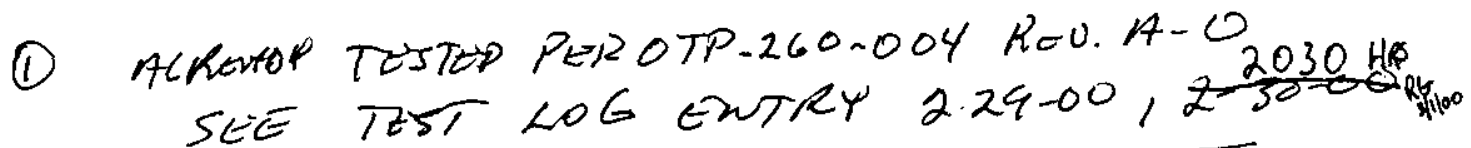

$$
\text { R.sutien }
$$




\subsection{TEST USER DEFINED MODE}

5.3.1 ENSURE applicable SETUP Steps in section 5.1 are completed.

\section{CART CONTROL SCREEN}

5.3.2 On the Gamma Cart Control, CLICK oN the "Config." button.

5.3.3 INPUT the following data:

\begin{tabular}{|c|c|}
\hline POSITION & DATA \\
\hline Tank Number: & $A Z-101$ \\
\hline Cart: & A OR B \\
\hline Riser ID: ft. & $\begin{array}{l}\text { Selected riser number } \\
\text { NOTE - } \quad \text { Riser depth is } \\
\text { automatically computed } \\
\text { from software upon input } \\
\text { of riser ID\#. }\end{array}$ \\
\hline Probe Type: & $\begin{array}{l}1-4 \text { as appl icable } \\
\text { (Normal is } 1 \text { or } 2 \text { for Cart A and } 3 \\
\text { or } 4 \text { for Cart B) }\end{array}$ \\
\hline Survey Time: & Sec. (As determined by Test Director) \\
\hline
\end{tabular}

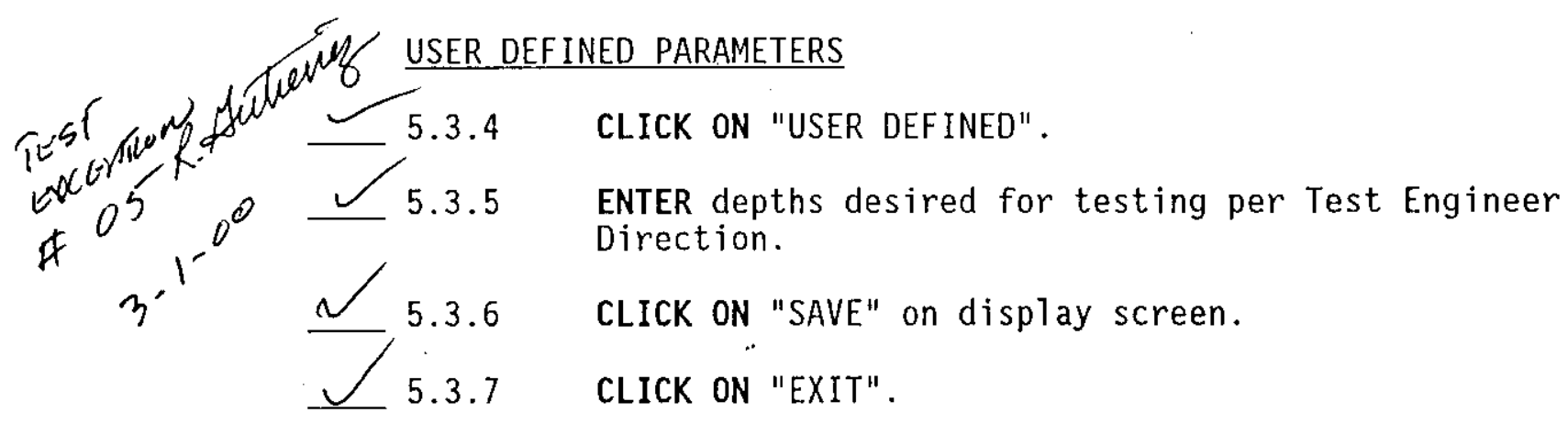




\subsection{TEST USER DEFINED MODE (Cont).}

NOTE - Test Engineer may manipulate parameters at any time during the following steps as necessary to ensure data retrieval and system configuration, with concurrence of Test Director.

- After the following step, the program should automatically run.

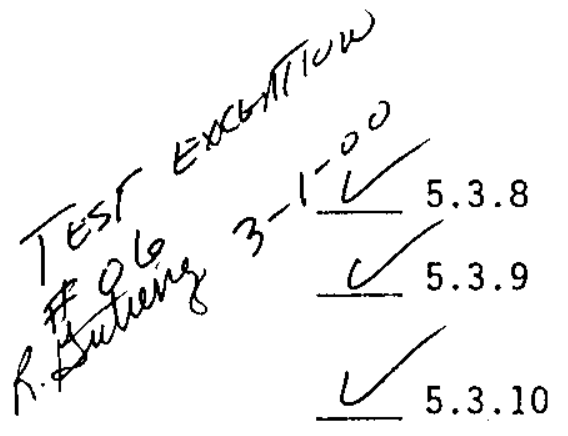

- The "EMERGENCY STOP" may be used to stop at any time during the next step if unit fails to stop at limit switch. The "RESET" button will need to be pushed to resume the program.

CLICK ON Start button.

Test Engineer ENSURE data is received, AND both hard-copy and electronic files can be retrieved.

VERIFY system automatically ZEROs and data is collected at zero position.

$\frac{\text { M.teneny }}{\text { Test Director Signature }} \frac{3-1-00}{\text { Date }}$

R. Gutierrez

Test Director Print Name 


\subsection{TEST USER DEFINED MODE (Cont).}

4 CLICK ON "LOGOUT" on display screen.

5.3.12 REMOVE Probe, riser extension tool, and associated equipment AND

STORE per Test Director direction.

OR

CONTINUE in this procedure.

5.3.13 REPEAT the steps in this section (5.3) as directed for any risers as directed by Test Director.

5.3.14 VERIFY by signing below section 5.3 is complete.

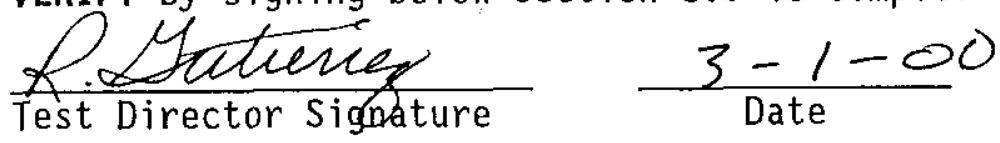

$\frac{\text { R. Gutiervez }}{\text { Test Director Print Name }}$

- Fondel 4 QC Signature $\frac{3-1-00}{\text { Date }}$

$\frac{\text { Rowses At. Hewp }}{\text { QC Print Name }}$ 


\section{RISER 15E GAMMA CART - B}




\section{1-AZ GAMIMA CART OPERATIONAL TEST PROCEDURE}

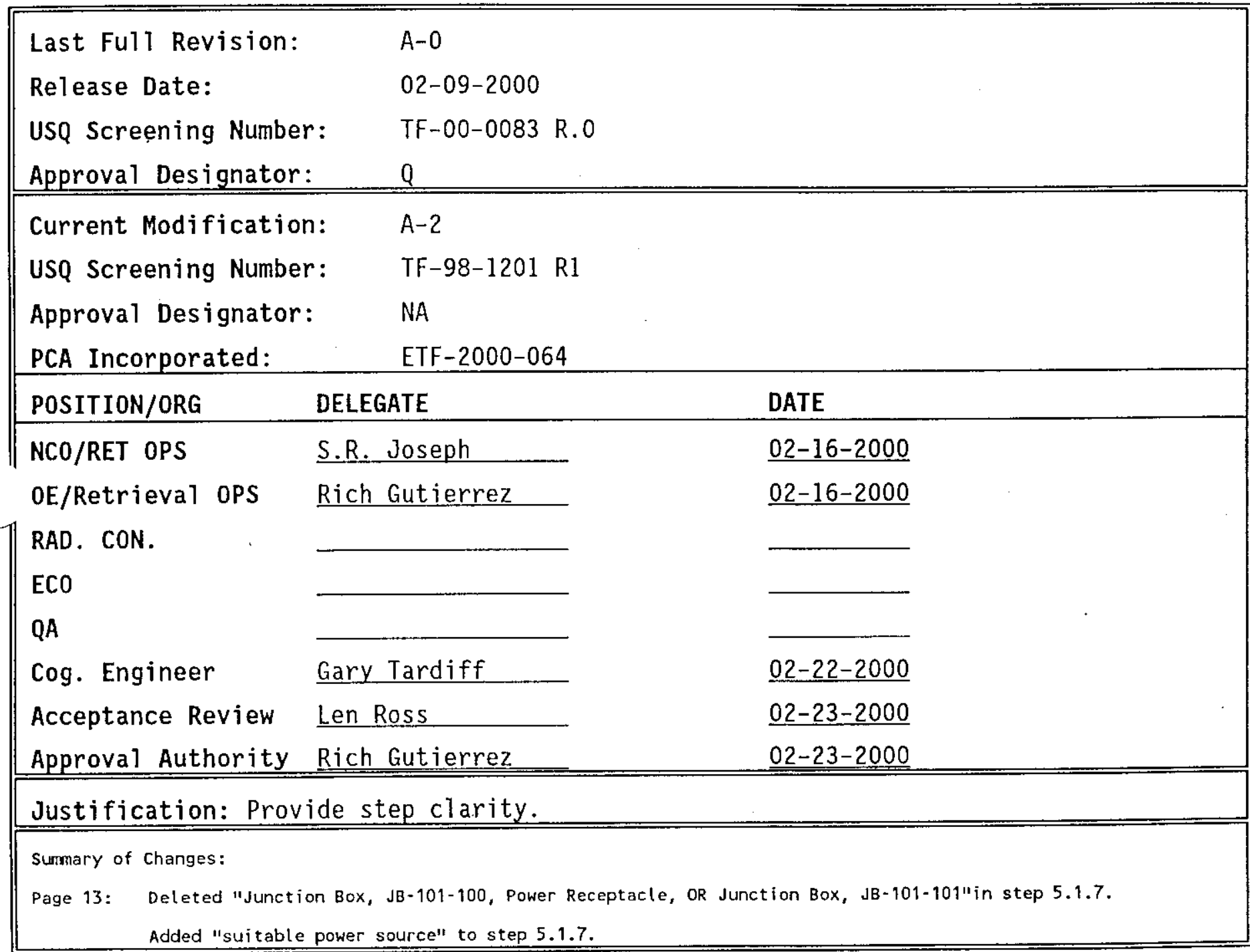

Gamma Cart B

R. teitury 3/100 


\subsection{PREREQUISITES}

\subsection{SPECIAL TOOLS, EQUIPMENT, AND SUPPLIES}

The following supplies may be needed to perform this procedure:

- Riser Swabbing equipment

- Riser extension tool

\subsection{PERFORMANCE DOCUMENTS}

The following procedures may be needed to perform this procedure:

- T0-040-333 LIQUIO OBSERVATION WELL (LOW) SURVEILLANCE VAN STARTUP AND OPERATION PROCEDURE

\subsection{CONDITIONS AND ACTIONS}

NOTE - All signators on this procedure shall document their signature on Procedure Signature Sheet.

4.3.1 All pre-testing and inspection of the system or portions of the system to be tested has been completed.

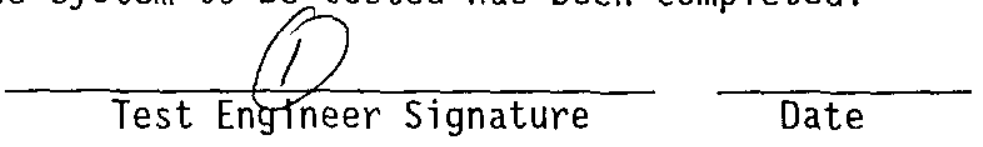

4.3.2 A pre-job briefing has been held. and all participants have been thoroughly briefed on job safety, hazards, and their responsibilities before performing this ATP.

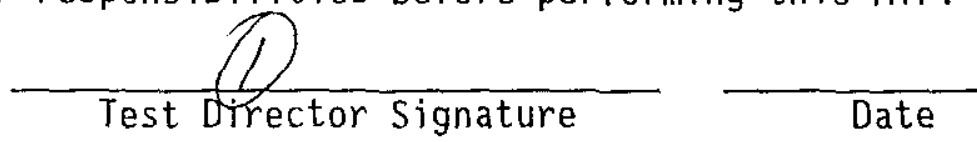

4.3.3 Test Director YERIFY section 4.3 has been COMPLETED.

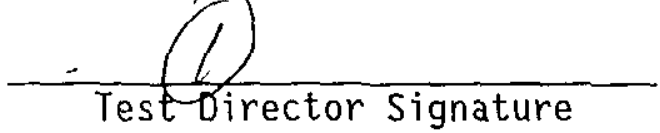

Date

(1) alveady tested per pen orp-260-004 hev A-O see test logenting 2/29/00,2030. 


\subsection{PROCEDURE}

\subsection{SETUP}

NOTE - This procedure may be repeated for either GAMMA CART A or GAMMA CART $B$ as applicable. N/A may be entered in blocks or steps per Test Director as applicable.

5.1.1 RECORD GAMMA CART CPU number for the system being tested. GAMMA CART IDENTIFIER \#

$$
\frac{k S T-R Y 403}{\text { CPU Number }}
$$

5.1.2 PERFORM cleanliness check in applicable riser listed on TABLE II, per section 5.10 in procedure TO-040-333 latest rev, prior to mounting riser extension tool.

5.1.3 ENSURE GAMMA CART riser extension tool is mounted on the applicable riser.

ENSURE GAMMA CART is placed in line with riser extension tool to facilitate installation of probe and cables.

$\checkmark$ 5.1.5 CHECK route to riser for obstacles and clearances.

5.1.6 LEVEL cart using jacks.

5.1.7 CONNECT gamma cart power cables, as follows:

- One end to gamma cart power receptacle

- $\quad$ ther end to surtalue power souree-Junction-Box, IB 101 100, power Reeeptacle, or Junction Box. IB-101-101

5.1.8 CONNECT gamma cart communications cable, as follows:

- One end to gamma cart communications receptacle

- $\quad$ Other end to Tank 241-AZ-101 Gamma Cart A AND/OR B Data Collection Subsystem communications receptacle

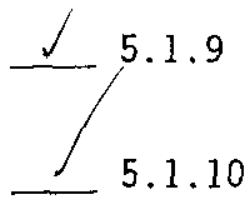

PLACE Gamma Cart "RAISE OFF LOWER" switch in the LOWER position.

CHECK that detector probe cable is resting in the Gamma Cart boom cable reel. 


\subsection{SETUP (Cont).}

\section{CAUTION}

If sufficient tension is NOT held on the detector probe cable as the cable is being let out, the cable could become entangled.

NOTE - Step 5.1.11 and 5.1 .12 require two operators to perform continuous action until step 5.1 .12 is complete.

5.1.11 HOLD tension on the detector probe cable until step 5.1.12 is completed.

5.1.12 PRESS AND HOLD "RESET" button untiT enough detector probe cable is let-out that will allow placement of the detector cable through riser extension collar AND into riser drywe 11, AND

RELEASE the "RESET" button.

$\sqrt{1.1 .13}$ INSTALL the proper detector probe on the detector probe cable.

5.1.14 ENSURE that the detector probe connections are correct and tight. AND

INSERT probe into riser extension tool.

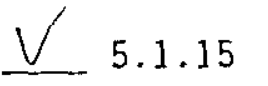

ENSURE limit switch cable is connected from limit switch on riser extension tool, to the connection point on the front of the GAMMA CART.

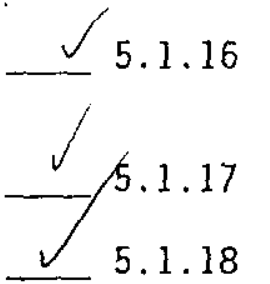

\section{ENSURE the "Raise - Off - Lower" selector switch is in the} "OFF" position.

ENSURE the emergency stop button is pulled out.

POSITION the "SPEED" control potentiometer to MIN speed (fully counter-clockwise). 
RPP-6104 RP

WORKING COPY

Printed on: Mar $1,0012.39$ pm

5.1 SETUP (Cont).

CAUTION

There is no limit switch to stop the motion when the cable is fully unwound. The cable will rewind backwards on the reel. Damage to the cable may result.

NOTE -

When the cart is first powered up, or the emergency stop button has been pushed, or power has been restored after a power failure, the cable reel will not move up or down uniT "RESET" button is activated.

- The "Raise-OFF-Lower" Switch is Manually controlled and is Operator Dependent.

5.1.19 ENSURE LOCAL/REMOTE switch is in the "LOCAL" position.

4 ENERGIZE the cart.

(1) 5.1.21 SET the "SPEED" potentiometer to 2 on the GAMMA Cart.

(1) 5.1 .22

SET the "RAISE -OFF- LOWER" switch to the "LOWER" position.

(1) 5.1 .23 PUSH "EMERGENCY STOP" button on GAMMA CART.

(1) 5.1 .24 VERIFY the system has stopped.

Rich Leterizy

$\frac{3-1-00}{\text { Date }}$

$\frac{\text { Rich Gutierrez }}{\text { Test Director Print Name }}$

1 already tested on 0+R-260-004 Rev A.O see Test $\log$ entry 2/24/00,2030.

R. Setetreng 31100

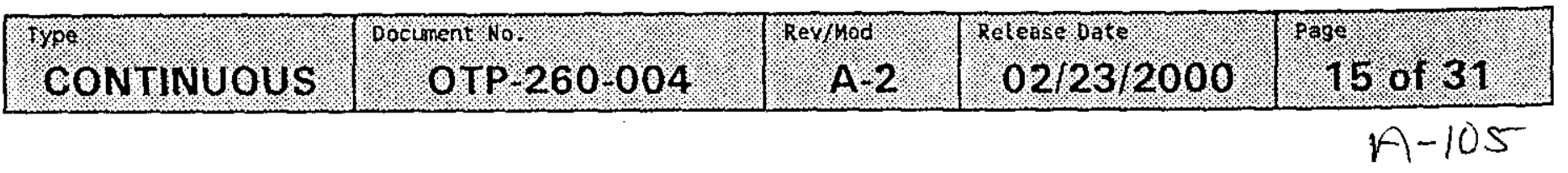


RPP-6104 RP

WORKING COPY

Printed on: Mar 1, $00.12: 39 \mathrm{pm}$

5.1 SETUP (Cont).

(1) 5.1 .25

(1) 5.1 .26

(1) 5.1 .27

(1) 5.1 .28

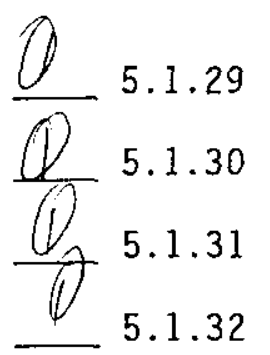

SET the "RAISE-OFF-LOWER" switch to the "RAISE" position. PULL "EMERGENCY STOP" out on GAMMA CART.

PUSH the "RESET" button on GAMMA CART to resume.

ENSURE 1 imit switch activates when probe returns to the zero position.

SET the "RAISE-OFF-LOWER" switch to the "OFF" position.

SET "SPEED" potentiometer to MIN.

POSITION The "LOCAL REMOTE" switch to "REMOTE".

VERIFY by signing below section 5.1 is complete.

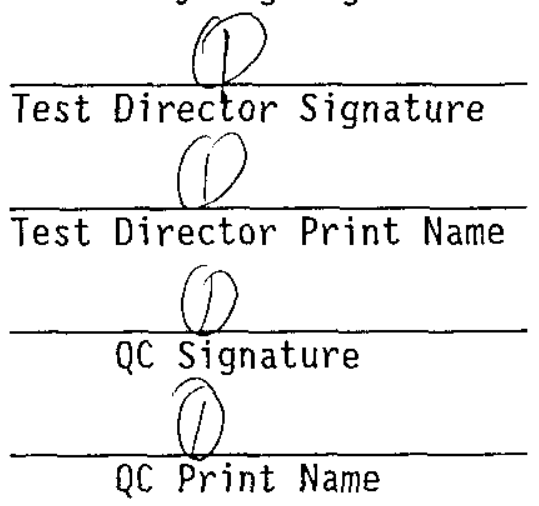

Date

Date

(1) already tested per OTP-260-004 Rev ADO

see test log entry 2/24/00, 2030.

R. Afetien $3 / 1 \% 0$

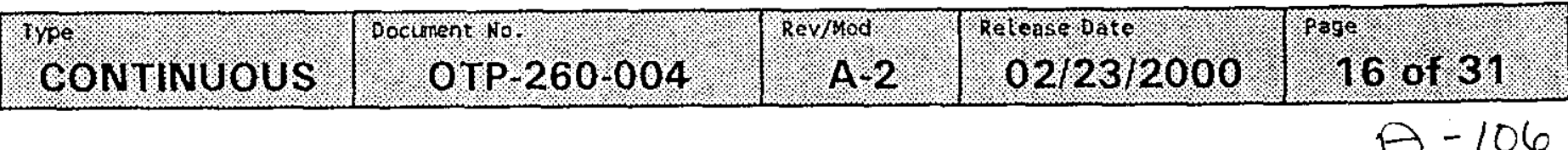

$A-106$ 


\subsection{TEST INCREMENTAL SAMPLE MODE}

SETUP

NOTE - AlT Steps in this section apply to either cart, except in those steps where the specific cart is indicated.

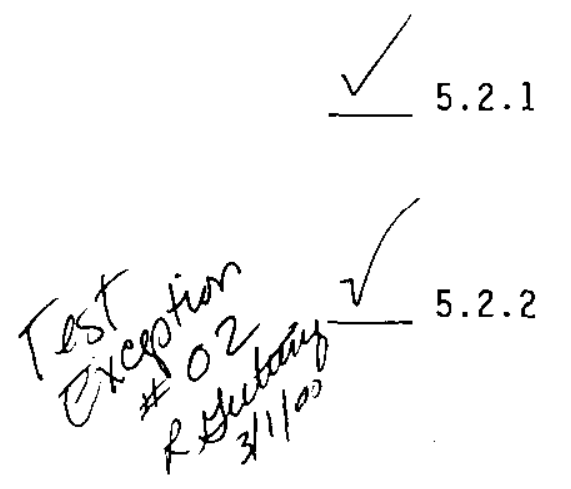

\section{INSTRUMENT CHECK}

IF the pushbutton for Tank 241-AZ-101 Gamma Cart A AND/OR $B$ Data Collection System Central Processing Unit (CPU), AND/OR associated MONITOR, are NOT ON, PRESS the applicable ON pushbuttons.

ENSURE the following systems are ON AND

ENSURE settings are correct for the following:

- ORTEC MINIBIN

- POWER SUPPLY

Detector Bias Power Supply (HVPS): ORTEC Mod. 478.

- $\mathrm{kV}: .5$

- 0 to $1000 \mathrm{~V}:(+60$ volts)

Amplifier (AMP): ORTEC Mod. 673

- COARSE GAIN: 200

- FINE GAIN: 0.680

- SHAPING TIME: Both knobs set to 2 microseconds

- PZ Adjust: Do NOT change settings (in this procedure)

- BLR: Switch in AUTO (up) position

- INPUTS: Switch in POS (up) position BNC cable on terminal (from pre amplifier)

- OUTPUTS: cable on UNIPOLAR terminal(to single channel Analyzer)

5.2.3 WHEN WINDOWS login screen appears CLICK ON "CANCEL".

\begin{tabular}{|c|c|c|c|c|}
\hline "YPON & pocinent no & ReYplod: & $02 / 2312000$ & "rse 17 of 31 \\
\hline
\end{tabular}




\subsection{TEST INCREMENTAL SAMPLE MODE (Cont).}
NOTE - After canceling windows login, GAMMA CART software should automatically load.
5.2.4 VERIFY "GAMMA CART SPECTRUM ANALYZER AND CONTROL SYSTEM"
screen is displayed on Tank 241-AZ-101 Gamma Cart A AND/OR

B Data Collection System Monitor.

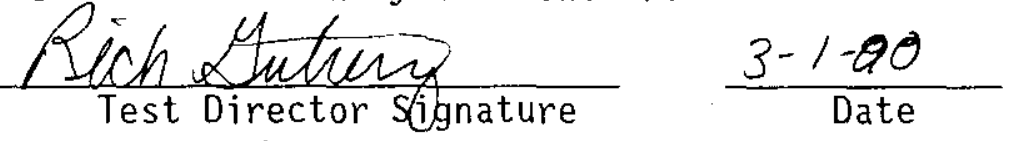

$\frac{\text { Rich Gutierres }}{\text { Test Director Print Name }}$

$\checkmark 5.2 .5$ SELECT "Login" on the "GAMMA CART SPECTRUM ANALYZER AND CONTROL SYSTEM" screen.

NOTE - $\quad$ LOGIN passwords and information may be obtained from Test Director.

$\checkmark 5.2 .6$ LOG-IN.

5.2.7 VERIFY LOCAL/REMOTE switch on display screen is in "REMOTE" pOSition.

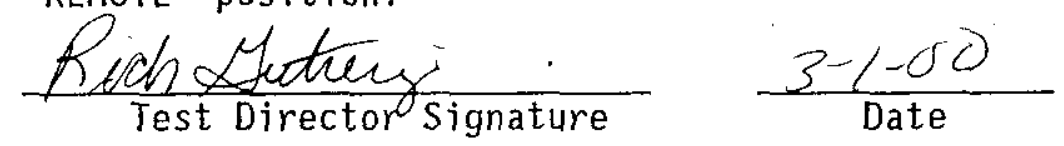

$\frac{\text { Rich Cutierre }}{\text { Test Director Print Name }}$ 
RPP-6104 RP

WORKING COPY

Printed on: Mar: 1, 00 12:39 pi

5.2 TEST INCREMENTAL SAMPLE MODE (Cont).

TESTING

5.2.8 SELECT "Config" on the "Gamma Cart Display" screen.

(1) 5.2.9 ENTER the following data for selected riser on the "Configuration - Display" screen by pulling down applicable menu:

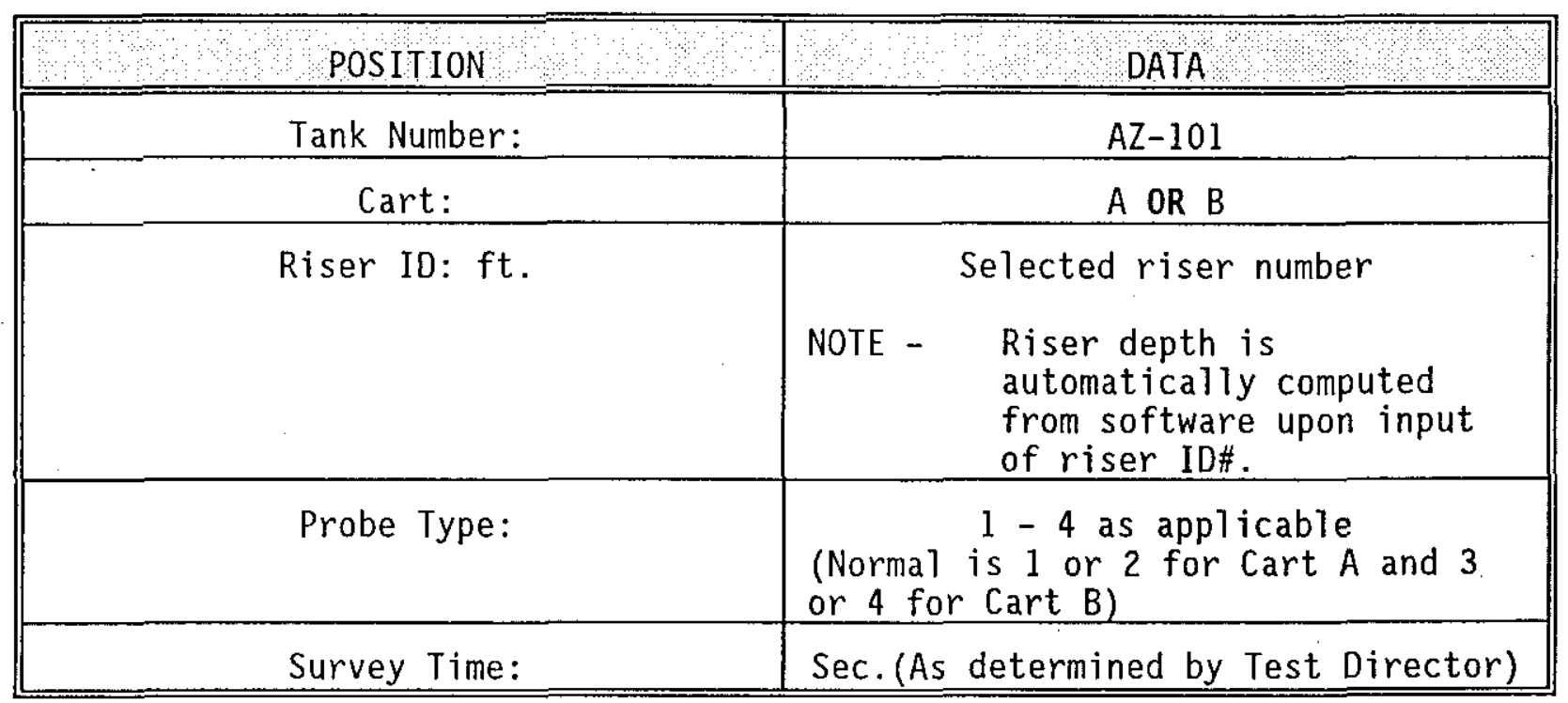

(1 5.2.10 ENSURE REAL/LIVE toggle button indicates "LIVE".

(1) 5.2 .11 On the Data Collection Configuration window, SELECT the "Incremental" button.

INCREMENTAL PARAMETERS

5.2.12 INPUT the following Sample Collection Data:

\begin{tabular}{|l|l|}
\hline Sample Start & $55.0 \mathrm{ft}$ \\
Depth. & \\
\hline Interval 1 Size: & $10.0 \mathrm{ft}$ \\
\hline Sample End Depth:, & $5.0 \mathrm{ft}$ \\
\hline
\end{tabular}

(1) already tested per OTP-260-004 Rev A.O

see Test log Entry 2/29/00, 2030.

R. Mattering 31100

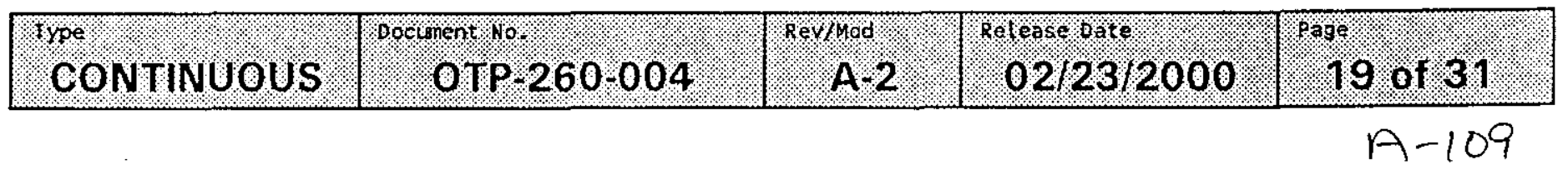


RPP-6104 RD

WORKING COPY

Printed on: Mar 1, $00 \quad 12: 39$ pm

5.2 TEST INCREMENTAL SAMPLE MODE (Cont).

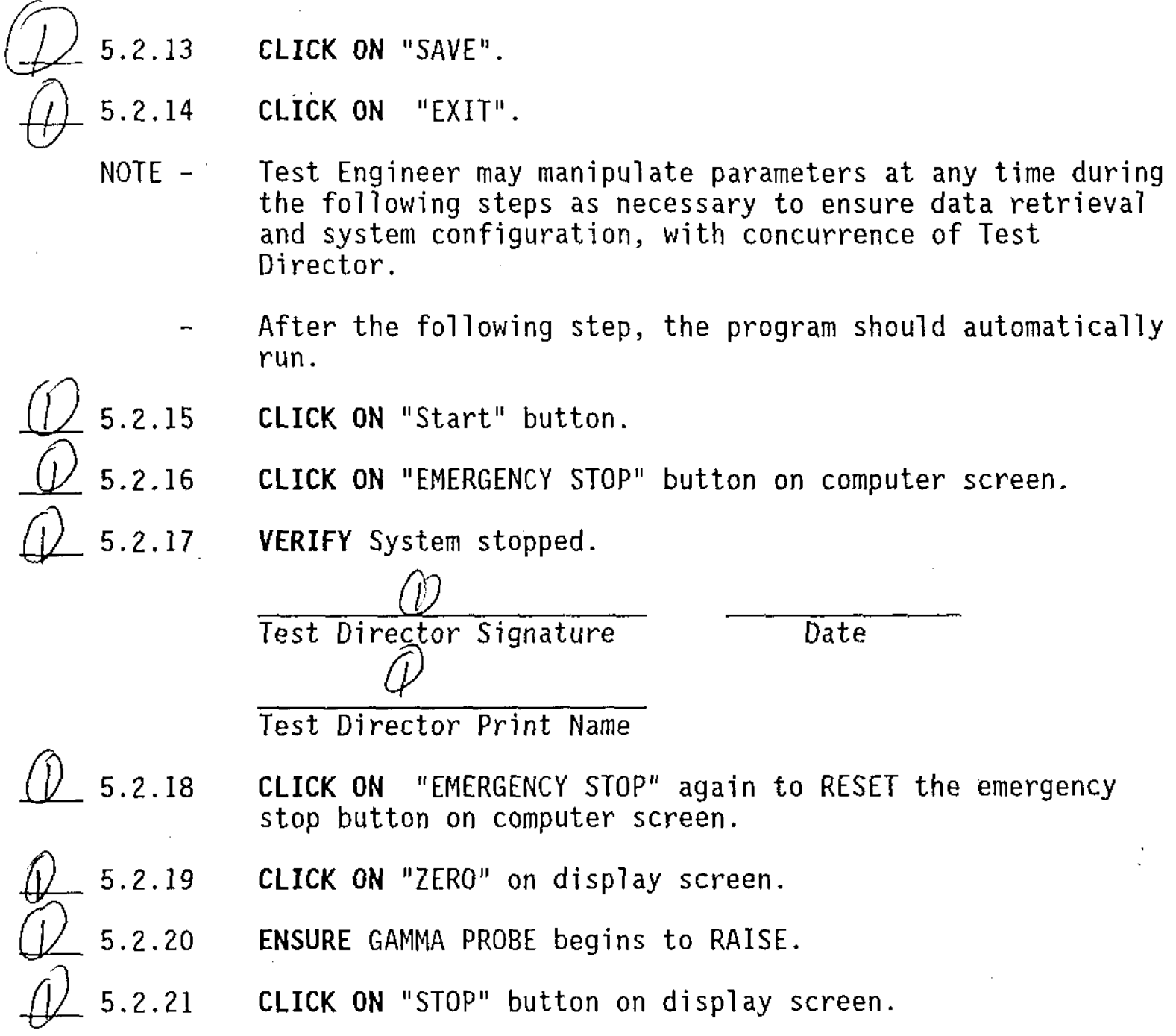

(1) already tested on OTP-260-004. Rev A-O

See Test log entry 2/29/00, 2030.

R. Strong 3/100

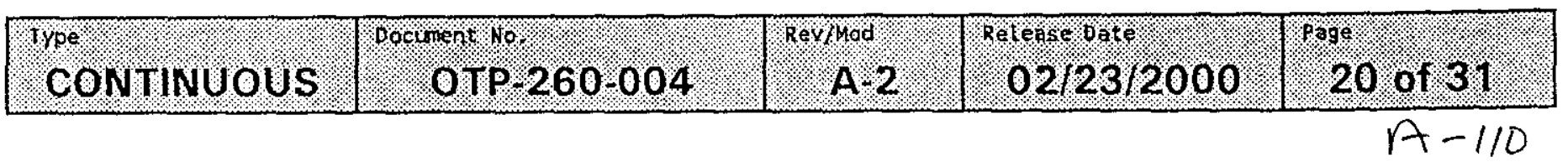


RPP-6104 RD

WORKING COPY

Printed on: Mar 1, 00 12:39 pm

5.2 TEST INCREMENTAL SAMPLE MODE (Cont).

(1) 5.2 .22 VERIFY system stopped.

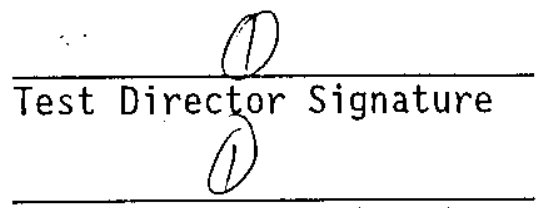

Date

Test Director Print Name

(1) 5.2 .23

CLICK ON "ZERO" again on display screen.

(1) 5.2.24 ENSURE gamma PROBE begins to RAISE.

(1) 5.2.25 When probe and system zeros, CLICK ON "START" on display

(1) 5.2 .26 screen.

VERIFY System resumed program.

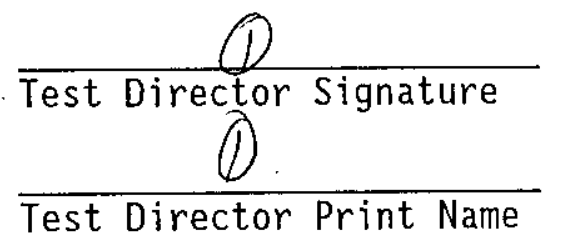

Date

Test Director Print Name

\begin{tabular}{l} 
Q \\
$\underbrace{2} 5.2 .27$ \\
\hline
\end{tabular} 5.28

CLICK ON "STOP" button on computer screen.

VERIFY System stopped.

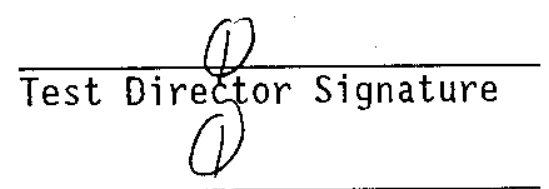

Date

Test Director Print Name

(1) 5.2 .29

CLICK ON "ZERO" on display screen.

(1) 5.2 .30

When probe and system zeros, CLICK ON "START" on display screen.

(1) 5.2 .31

VERIFY System resumed program.

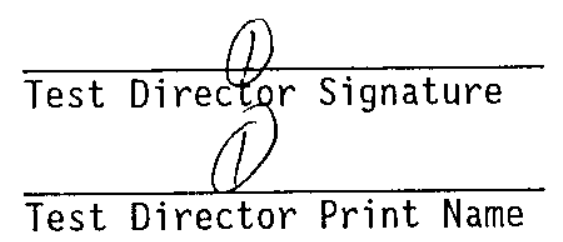

Date

Test Director Print Name

(1) already tested on OTP-260-004 Rev A-O

See Test log entry 2/29/00, 2030.

R. Bathing 3/1\%0

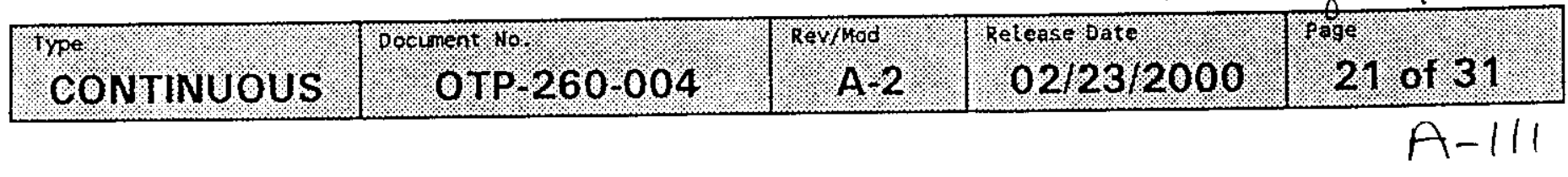




\subsection{TEST INCREMENTAL SAMPLE MODE (Cont).} (1) 5.2.32 Test Engineer ENSURE data is received, AND both hard-copy

15.2.33 VERIFY system automatically ZEROs and data is collected at zero position.

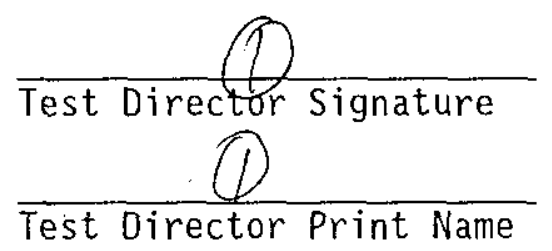

NOTE - The steps in section 5.1, applicable to the Emergency stop, need not be repeated if completed for an individual GAMMA CART. The Emergency stop on BOTH GAMMA CART $A$ and $B$, need to be tested only once.

NOTE - It is NOT necessary to do ALL risers in one procedure. Test Director is responsible for ensuring ALL risers have been profiled by one AND/OR the other GAMMA CART(S).

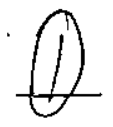

5.2.34 REPEAT applicable SETUP Steps in section 5.1 AND Incremental testing steps 5.2.1 - 5.2.15 AND Steps 5.2.32 and 5.2.33 for each of the following risers and depths per Test Director's direction.

\begin{tabular}{|c|c|c|}
\hline \multirow{14}{*}{$\begin{array}{l}\text { Already-tested on } \\
\text { OTP-260-004 Rev A-O } \\
\text { see Test logenty } 2 / 29 / 00 \text {, } \\
2030 .\end{array}$} & \multicolumn{2}{|r|}{ TABLE I } \\
\hline & RISER & $\begin{array}{l}\text { Depth } \\
\text { inches }(\mathrm{ft})\end{array}$ \\
\hline & $14 \mathrm{~A}$ & $660(55.0)$ \\
\hline & $14 C$ & $660(55.0)$ \\
\hline & 140 & $660(55.0)$ \\
\hline & $214 \mathrm{~F}$ & $660(55.0)$ \\
\hline & $14 G$ & $660(55.0)$ \\
\hline & $14 \mathrm{~B}$ & $660(55.0)$ \\
\hline & $14 \mathrm{E}$ & $660(55.0)$ \\
\hline & 151 & $684(57.0)$ \\
\hline & $15 \mathrm{C}$ & $684(57.0)$ \\
\hline & $15 E$ & $684(57.0)$ \\
\hline & $15 B$ & $684(57.0)$ \\
\hline & $15 \mathrm{~F}$ & $684(57.0)$ \\
\hline
\end{tabular}




\subsection{INCREMENTAL SAMPLE MODE (Cont).}

NOTE - In the following Table, Test Director N/A blocks that are tested with a different GAMMA CART. $\theta 5.2 .35$ verIFY the applicable riser in step 5.2 .34 has been

TABLE II

\begin{tabular}{|l|l|}
\hline RISER & TEST DIRECTOR SIGNATURE \\
\hline $14 \mathrm{~A}$ & \\
\hline $14 \mathrm{C}$ & \\
\hline $14 \mathrm{D}$ & \\
\hline $14 \mathrm{~F}$ & \\
$14 \mathrm{G}$ & \\
\hline $14 \mathrm{~B}$ & \\
\hline $14 \mathrm{E}$ & \\
\hline $15 \mathrm{I}$ & \\
\hline $15 \mathrm{C}$ & \\
\hline $15 \mathrm{E}$ & \\
\hline $15 \mathrm{~B}$ & \\
\hline $15 \mathrm{~F}$ & \\
\hline
\end{tabular}

5.2.36 VERIFY by signing below section 5.2 is complete.

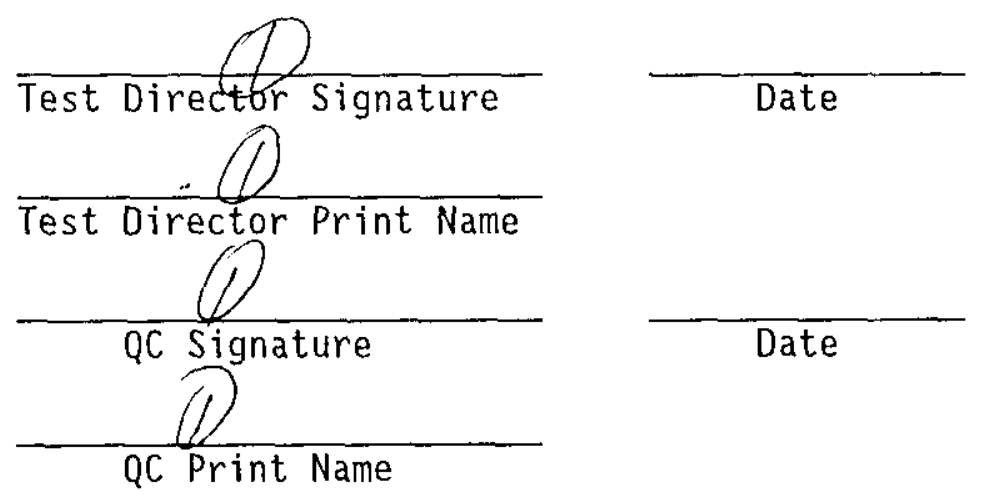

1 ahrady tesled on o TP-260-004, Rev A-O. See Test $\log$ enty 2/29/00, 2030.

\begin{tabular}{|c|c|c|c|c|}
\hline & & & Kutetuer & $3 / 1 / 00$ \\
\hline lype & Docement No. & Rey & Retersoge bate. & \\
\hline CONTINUOUS & OTP-260-004 & A.2 2 & $02 / 23 / 2000$ & 23 of 31 \\
\hline
\end{tabular}




\subsection{TEST USER DEFINED MODE}

5.3.1 ENSURE applicable SETUP Steps in section 5.1 are completed.

CART CONTROL SCREEN

5.3.2 On the Gamma Cart Control, CLICK oN the "Config." button.

5.3 .3

INPUT the following data:

\begin{tabular}{|c|c|}
\hline POSITION & DATA \\
\hline Tank Number: & $A Z-101$ \\
\hline Cart: & $\mathrm{A} O \mathrm{OR} B$ \\
\hline Riser ID: $\mathrm{ft}$. & $\begin{array}{ll} & \text { Selected riser number } \\
\text { NOTE - } \quad \text { Riser depth is } \\
\text { automatically computed } \\
\text { from software upon input } \\
\text { of riser ID\#. }\end{array}$ \\
\hline Probe Type: & $\begin{array}{l}1-4 \text { as applicable } \\
\text { (Normal is } 1 \text { or } 2 \text { for Cart } A \text { and } 3 \\
\text { or } 4 \text { for Cart B) }\end{array}$ \\
\hline Survey Time: & Sec. (As determined by Test Director) \\
\hline
\end{tabular}

USER DEFINED PARAMETERS

5.3.4 CLICK ON "USER DEFINED".

5.3.5 ENTER depths desired for testing per Test Engineer Direction.

5.3.6 CLICK ON "SAVE" on display screen.

5.3.7 CLICK ON "EXIT". 


\subsection{TEST USER DEFINED MODE (Cont).}

NOTE - Test Engineer may manipulate parameters at any time during the following steps as necessary to ensure data retrieval and system configuration, with concurrence of Test Director.

- After the following step, the program should automatically run.

- The "EMERGENCY STOP" may be used to stop at any time during the next step if unit fails to stop at limit switch. The "RESET" button will need to be pushed to
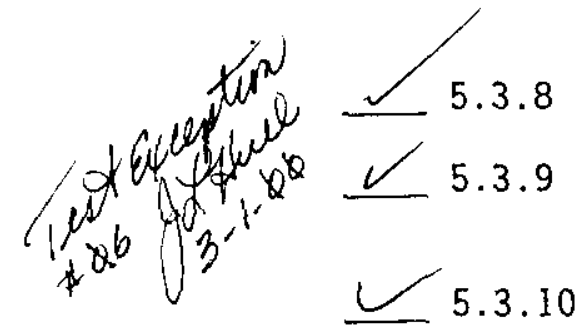
resume the program.

CLICK ON Start button.

Test Engineer ENSURE data is received, AND both hard-copy and electronic files can be retrieved.

VERIFY system automatically ZEROs and data is collected at zero position.

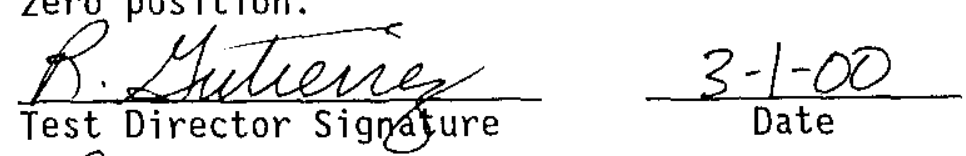

$\frac{\text { E. Gutienrez } 2}{\text { Test Director Print Name }}$ 
RPP-6104 RP

WORKING COPY

Printed on: Mar $1,00,12.39$ pm

5.3 TEST USER DEFINED MODE (Cont).

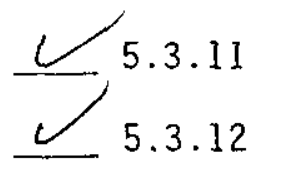

5.3 .12

$\stackrel{\sim}{\sim} 5.3 .13$

$\simeq 5.3 .14$
CLICK ON "LOGOUT" on display screen.

REMOVE Probe, riser extension tool, and associated equipment AND

STORE per Test Director direction.

$\mathrm{OR}$

CONTINUE in this procedure.

REPEAT the steps in this section (5.3) as directed for any risers as directed by Test Director.

VERIFY by signing below section 5.3 is complete.
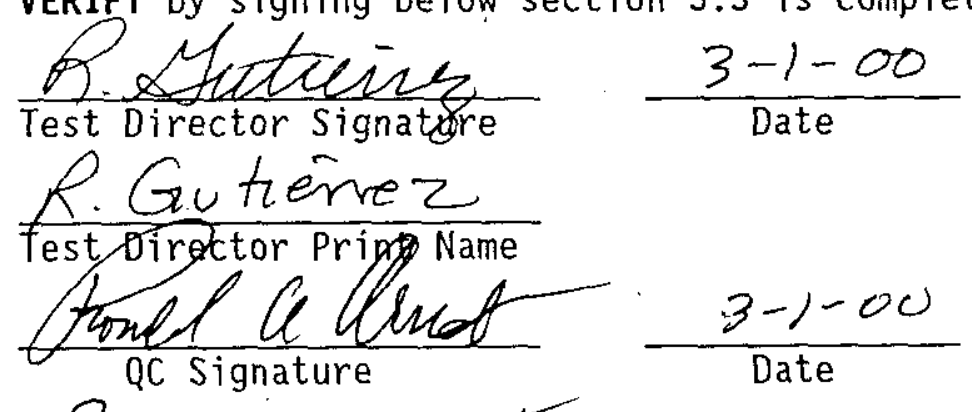

$\frac{\text { Rewed } 1 \text {. AdAMS }}{\text { QC Print Name }}$

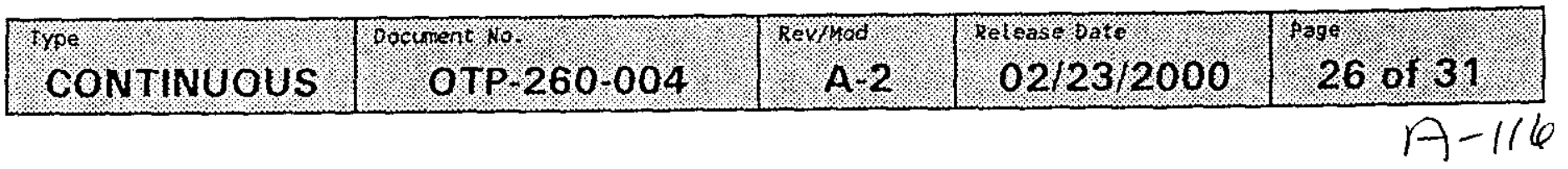




\section{RISER 15F GAMMA CART - B}




\section{1-AZ GAMMIA CART OPERATIONAL TEST PROCEDURE}

\begin{tabular}{|c|c|c|}
\hline $\begin{array}{l}\text { Last Full Revision: } \\
\text { Release Date: } \\
\text { USQ Screening Number: } \\
\text { Approval Designator: }\end{array}$ & $\begin{array}{l}\text { A-0 } \\
02-09-2000 \\
\text { TF-00-0083 R.0 } \\
Q \\
\end{array}$ & \\
\hline $\begin{array}{l}\text { Current Modification: } \\
\text { USQ Screening Number: } \\
\text { Approval Designator: } \\
\text { PCA Incorporated: }\end{array}$ & $\begin{array}{l}\text { A-2 } \\
\text { TF-98-1201 R1 } \\
\text { NA } \\
\text { ETF-2000-064 }\end{array}$ & \\
\hline \multicolumn{2}{|c|}{ POSITION/ORG DELEGATE } & DATE \\
\hline $\begin{array}{l}\text { NCO/RET OPS } \\
\text { OE/Retrieval OPS }\end{array}$ & S.R. Joseph & $\underline{02-16-2000}$ \\
\hline $\begin{array}{l}\text { RAD. CON. } \\
\text { ECO }\end{array}$ & Rich Gutierrez & $\underline{02-16-2000}$ \\
\hline \multicolumn{3}{|r|}{$=$} \\
\hline \multicolumn{2}{|c|}{ Cog. Engineer $\quad$ Gary Tard } & $\underline{02-22-2000}$ \\
\hline \multicolumn{2}{|c|}{ Acceptance Review Len Ross } & $\underline{02-23-2000}$ \\
\hline \multicolumn{2}{|c|}{ Approval Authority Rich Gutierrez } & $02-23-2000$ \\
\hline \multicolumn{3}{|c|}{ Justification: Provide step clarity. } \\
\hline \multicolumn{3}{|c|}{$\begin{array}{l}\text { Surmary of Changes: } \\
\text { Page 13: Deleted "Junction Box, JB-101-100, Power Receptacle, OR Junction Box, JB-101-101" in step 5.1.7. } \\
\text { Added "suitable power source" to step 5.1.7. }\end{array}$} \\
\hline
\end{tabular}

Gamma $\cot B$

Riser $15 F$

311100

\begin{tabular}{|c|c|c|c|c|}
\hline GONTINUOLS & Dorishent & rey/prod & $02 / 23 / 2000$ & 1. \\
\hline
\end{tabular}




\subsection{PREREQUISITES}

\subsection{SPECIAL TOOLS, EQUIPMENT, AND SUPPLIES}

The following supplies may be needed to perform this procedure:

- Riser Swabbing equipment

- Riser extension tool

\subsection{PERFORMANCE DOCUMENTS}

The following procedures may be needed to perform this procedure:

- T0-040-333 LIQUID OBSERVATION WELL (LOW) SURVEILLANCE VAN STARTUP AND OPERATION PROCEDURE

\subsection{CONDITIONS AND ACTIONS}

NOTE - Al1 signators on this procedure shall document their signature on Procedure Signature Sheet.

4.3.1 All pre-testing and inspection of the system or portions of the system to be tested has been completed.

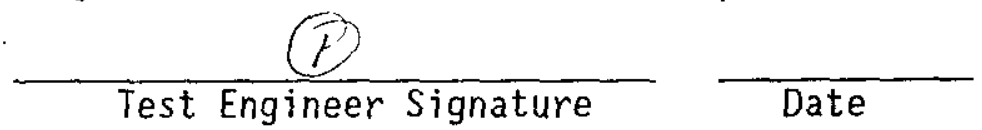

4.3.2 A pre-job briefing has been held. and all participants have been thoroughly briefed on job safety, hazards, and their responsibilities before performing this ATP.

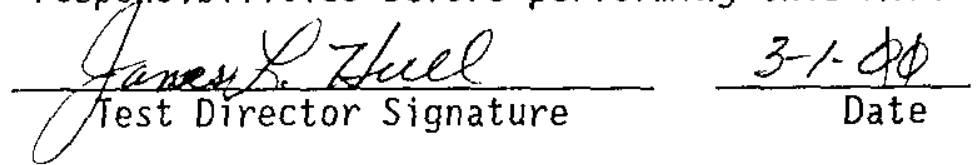

4.3.3 Test Director VERIFY section 4.3 has been COMPLETED.

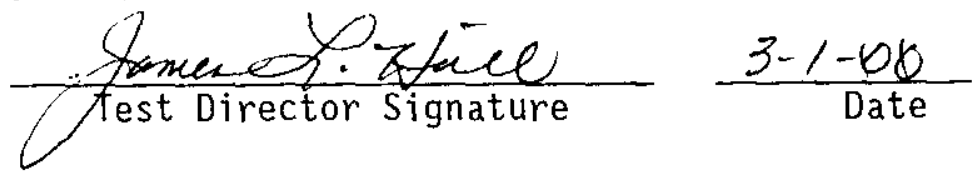

(1) AKRENOY TESTED PER OTP- 260.004 REV.AO

SEE TEST LOG ENNTRY 2.29 .00 ;

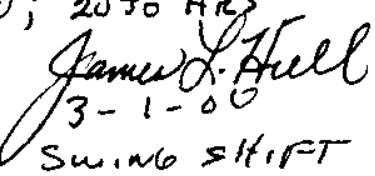




\subsection{PROCEDURE}

\subsection{SETUP}

NOTE - This procedure may be repeated for either GAMMA CART A or GAMMA CART B as applicable. N/A may be entered in blocks or steps per Test Director as applicable.

5.1.1 RECORD GAMMA CART CPU number for the system being tested. GAMMA CART IDENTIFIER \#B $\frac{\omega S T-R Y 4 \$ 3}{\text { CPU Number }}$

5.1.2 PERFORM cleanliness check in applicable riser listed on TABLE II, per section 5.10 in procedure TO-040-333 latest rev, prior to mounting riser extension tool.

5.1 .3

ENSURE GAMMA CART riser extension tool is mounted on the applicable riser.

5.1.4 ENSURE GAMMA CART is placed in line with riser extension tool to facilitate installation of probe and cables.

5.1.5 CHECK route to riser for obstacles and clearances.

- 5.1.6 LEVEL cart using jacks.

5.1 .7

CONNECT gamma cart power cables, as follows:

- One end to gamma cart power receptacle

- Other end to sultable power source-dunction-Box, JB 101,100 , Power Receptacle; OR Junction-Box, IB-101-101

CONNECT gamma cart communications cable, as follows:

- One end to gamma cart communications receptacle

- Other end to Tank 241-AZ-101 Gamma Cart A AND/OR B Data Collection Subsystem communications receptacle

PLACE Gamma Cart "RAISE OFF LOWER" switch in the LOWER position.

5.1 .10

CHECK that detector probe cable is resting in the Gamma Cart boom cable reel. 


\subsection{SETUP (Cont).}

\section{CAUTION}

If sufficient tension is NOT held on the detector probe cable as the cable is being let out, the cable could become entangled.

NOTE - Step 5.1.11 and 5.1 .12 require two operators to perform continuous action until step 5.1 .12 is complete.

5.1 .11

5.1 .12

5.1 .12

HOLD tension on the detector probe cable until step 5.1.12 is completed.

PRESS AND HOLD "RESET" button until enough detector probe cable is let-out that will allow placement of the detector cable through riser extension collar AND into riser drywe 17, AND

RELEASE the "RESET" button.

5.1 .13 INSTALL the proper detector probe on the detector probe cable.

5.1.14 ENSURE that the detector probe connections are correct and tight. AND

INSERT probe into riser extension tool.

$\simeq 5.1 .15$

ENSURE limit switch cable is connected from limit switch on riser extension tool, to the connection point on the front of the GAMMA CART.

$\leftarrow 5.1 .16$

ENSURE the "Raise - Off - Lower" selector switch is in the "OFF" position.

5.1.17 ENSURE the emergency stop button is pulled out.

5.1.18 POSITION the "SPEED" control potentiometer to MIN speed (fully counter-clockwise). 


\subsection{SETUP (Cont).}

\section{CAUTION}

There is no limit switch to stop the motion. When the cable is fully unwound. The cable will rewind backwards on the reel. Damage to the cable may result.

NOTE - When the cart is first powered up, or the emergency stop button has been pushed, or power has been restored after a power failure, the cable reel will not move up or down until "RESET" button is activated.

- The "Raise-OFF-Lower" Switch is Manually controlled and is Operator Dependent.

5.1.19 ENSURE LOCAL/REMOTE switch is in the "LOCAL" position.

5.1.20 ENERGIZE the Cart.

5.1.21 SET the "SPEED" potentiometer to 2 on the GAMMA Cart.

5.1.22 SET the "RAISE -OFF- LOWER" switch to the "LOWER" position.

(1) 5.1.23 PUSH "EMERGENCY STOP" button on GAMMA CART.

(1) 5.1.24 VERIFY the system has stopped.

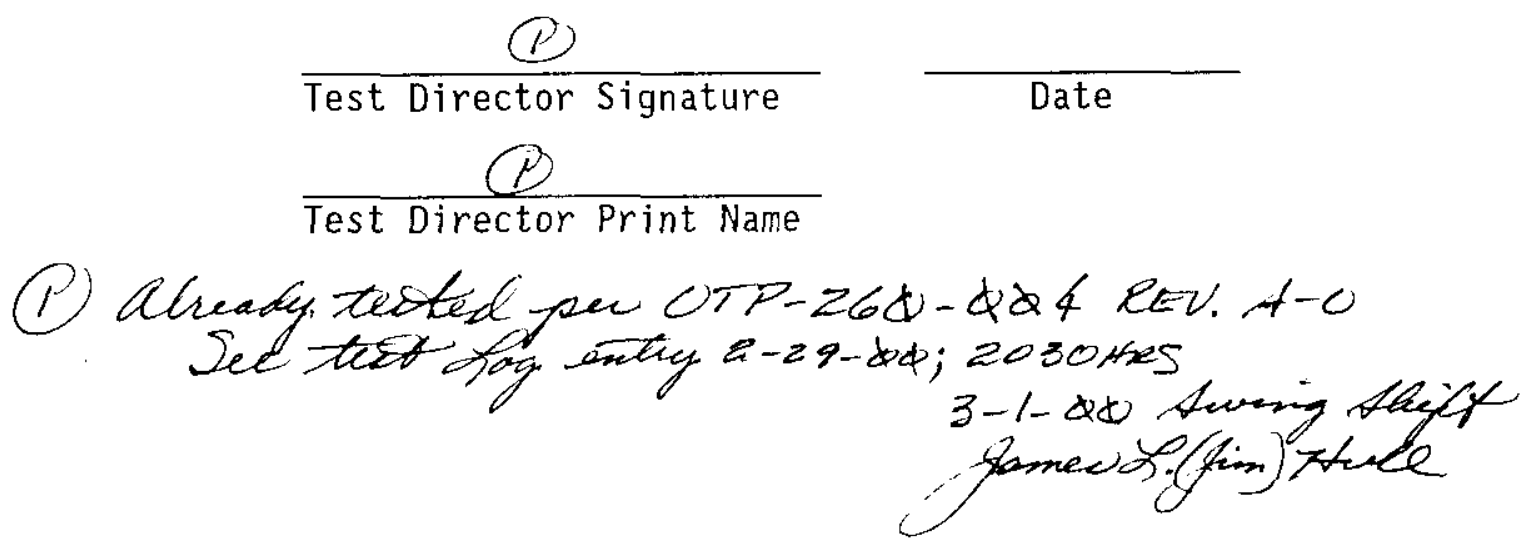


WORKING COPY

RP 6104 RD

Printed on. il ar $1,00: 12: 39 \mathrm{pm}$

5.1 SETUP (Cont).

(1) 5.1.25 SET the "RAISE-OFF-LOWER" switch to the "RAISE" position.

(1) 5.1 .26 PULL "EMERGENCY STOP" out on GAMMA CART.

(1) 5.1.27 PUSH the "RESET" button on GAMMA CART to resume.

(1) 5.1.28 ENSURE limit switch activates when probe returns to the zero position.

(1) 5.1.29 SET the "RAISE-OFF-LOWER" switch to the "OFF" position.

(1) 5.1 .30 SET "SPEED" potentiometer to MIN.

(1) 5.1.31 POSITION The "LOCAL REMOTE" switch to "REMOTE".

(1) 5.1 .32

VERIFY by signing below section 5.1 is complete.
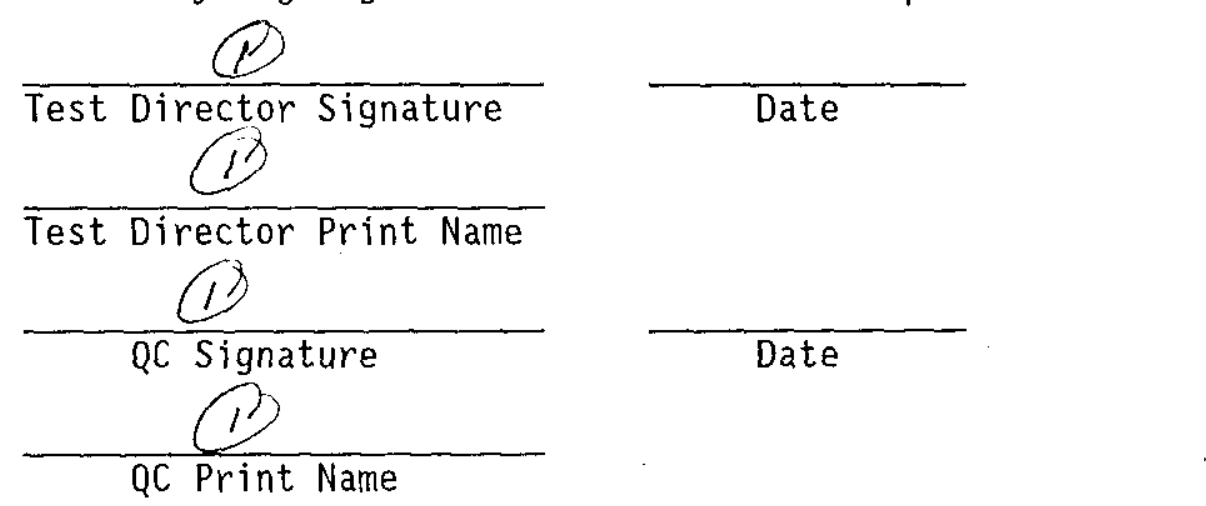

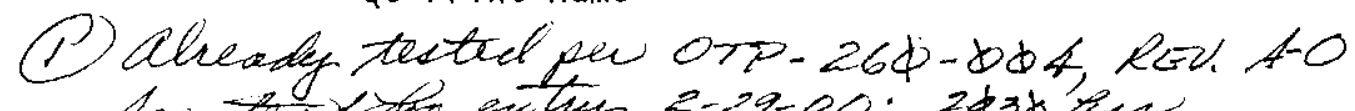

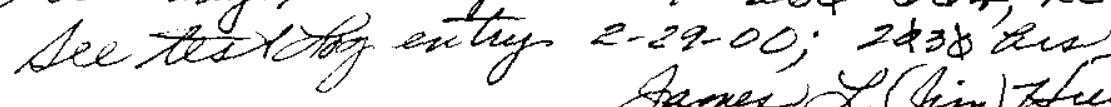

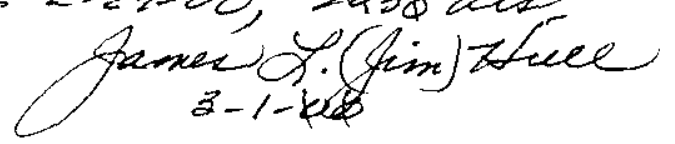

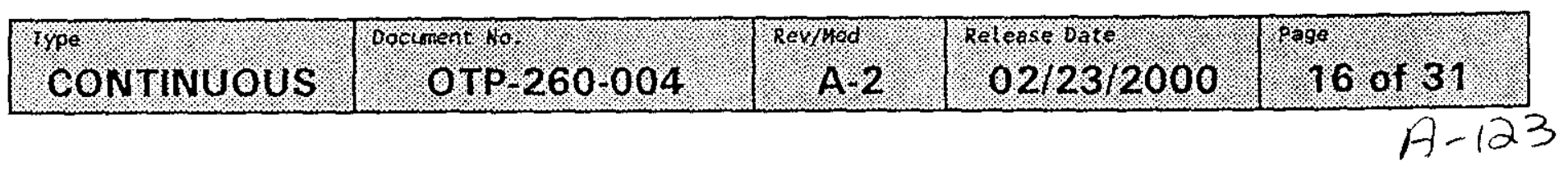




\subsection{TEST INCREMENTAL SAMPLE MODE}

\section{SETUP}

NOTE - All Steps in this section apply to either cart, except in those steps where the specific cart is indicated.

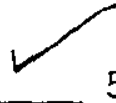

5.2.1 If the pushbutton for Tank 241-AZ-101 Gamma Cart A AND/OR $B$ Data Collection System Central Processing Unit (CPU), AND/OR associated MONITOR, are NOT ON, PRESS the applicable ON pushbuttons.

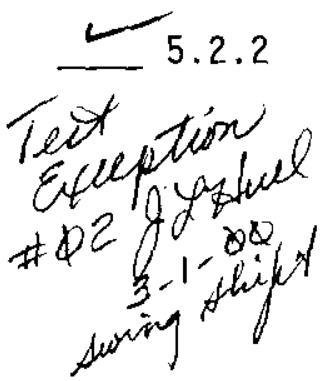

ENSURE the following systems are ON AND

ENSURE settings are correct for the following:

- ORTEC MINIBIN

- pOWER SUPPLY

Detector Bias Power Supply (HVPS): ORTEC Mod. 478.

- $\mathrm{kV}: .5$

- 0 to 1000V: (+60 volts)

Amplifier (AMP): ORTEC Mod. 673

- COARSE GAIN: 200

- FINE GAIN: 0.680

- SHAPING TIME: Both knobs set to 2 microseconds

- PZ Adjust: DO NOT change settings (in this procedure)

- BLR: Switch in AUTO (up) position

- INPUTS: Switch in POS (up) position BNC cable on terminal (from pre amplifier)

- OUTPUTS: cable on UNIPOLAR terminal(to single channel Analyzer)

5.2.3 WHEN WINOOWS login screen appears CLICK ON "CANCEL". 


\subsection{TEST INCREMENTAL SAMPLE MODE (Cont).}

NOTE - After canceling windows login, GAMMA CART software should automatically load.

L 5.2 .4 VERIFY "GAMMA CART SPECTRUM ANALYZER AND CONTROL SYSTEM" screen is displayed on Tank 241-AZ-101 Gamma Cart A AND/OR B Data Collection System Monitor.
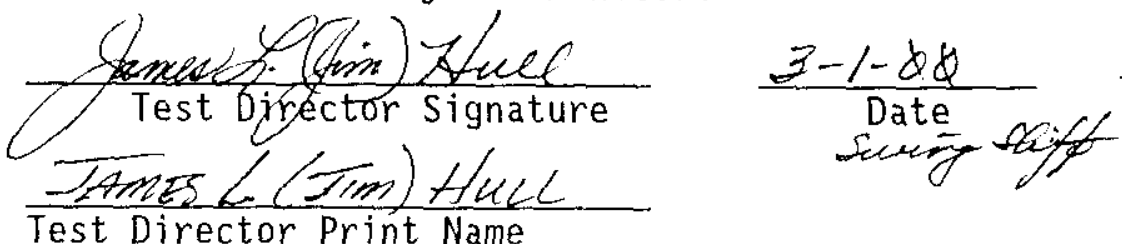

Test Director Print Name

5.2 .5 SELECT "Login" on the "GAMMA CART SPECTRUM ANALYZER AND CONTROL SYSTEM" screen.

NOTE - LOGIN passwords and information may be obtained from Test Director.

5.2.6 LOG-IN.

5.2.7 VERIFY LOCAL/REMOTE switch on display screen is in "REMOTE" pOsition.
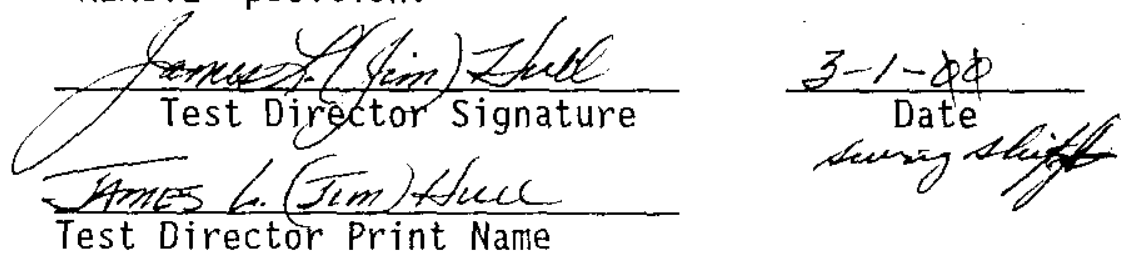


\subsection{TEST INCREMENTAL SAMPLE MODE (Cont).}

IESTING

(1)

5.2.8 SELECT "config" on the "Gamma Cart Display" screen.

(1)

5.2 .9

ENTER the following data for selected riser on the "Configuration - Display" screen by pulling down applicable menu:

\begin{tabular}{|c|c|}
\hline POSITION & 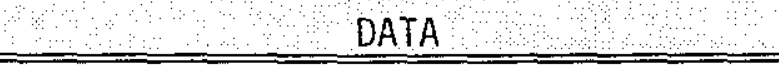 \\
\hline Tank Number: & $A Z-101$ \\
\hline Cart: & A OR B \\
\hline Riser ID: ft. & $\begin{array}{l}\text { Selected riser number } \\
\text { NOTE - } \quad \text { Riser depth is } \\
\text { automatically computed } \\
\text { from software upon input } \\
\text { of riser ID\#. }\end{array}$ \\
\hline Probe Type: & $\begin{array}{l}1-4 \text { as applicable } \\
\text { (Normal is } 1 \text { or } 2 \text { for Cart A and } 3 \\
\text { or } 4 \text { for Cart B) }\end{array}$ \\
\hline Survey Time: & Sec. (As determined by Test Director) \\
\hline
\end{tabular}

5.2.10 ENSURE REAL/LIVE toggle button indicates "LIVE".

(1) 5.2.11 On the Data Collection Configuration window, SELECT the "Incremental" button.

INCREMENTAL PARAMETERS

(1) 5.2.12 INPUT the following Sample Collection Data:

\begin{tabular}{|l|l|}
\hline Sample Start & $55.0 \mathrm{ft}$ \\
Depth: & \\
Interval Size: & $10.0 \mathrm{ft}$ \\
\hline Sample End Depth: & $5.0 \mathrm{ft}$ \\
\hline
\end{tabular}

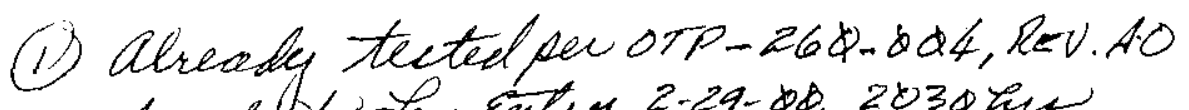
see-testivg enting 2.29- $20,2030 \mathrm{he}$

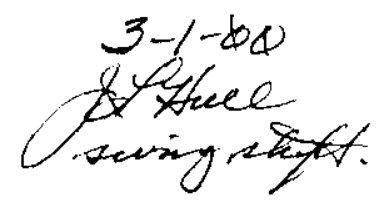




\subsection{TEST INCREMENTAL SAMPLE MODE (Cont).}

\section{CLICK ON "SAVE".
5.2 .13 CLICK ON "EXIT".}

NOTE - Test Engineer may manipulate parameters at any time during the following steps as necessary to ensure data retrieval and system configuration, with concurrence of Test Director.

- After the following step, the program should automatically run.

(1) 5.2 .15 CLICK oN "Start" button.

(1) 5.2 .16 CLICK ON "EMERGENCY STOP" button on computer screen.

(1) 5.2 .17 VERIFY System stopped.

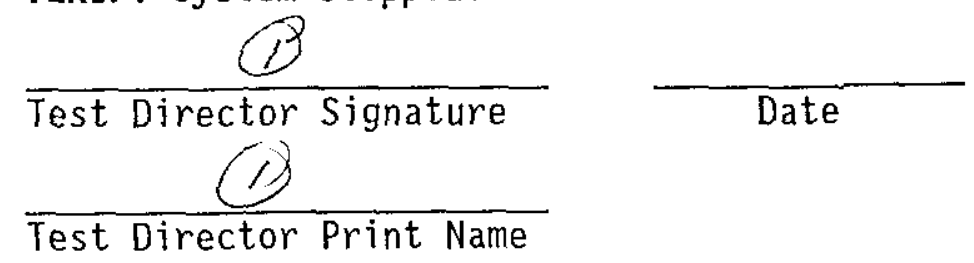

(1) 5.2 .18

CLICK ON "EMERGENCY STOP" again to RESET the emergency stop button on computer screen.

(1) 5.2 .19

CLICK ON "ZERO" on display screen.

5.2.20 ENSURE GAMMA PROBE begins to RAISE.

(1) 5.2 .21

CLICK ON "STOP" button on display screen.

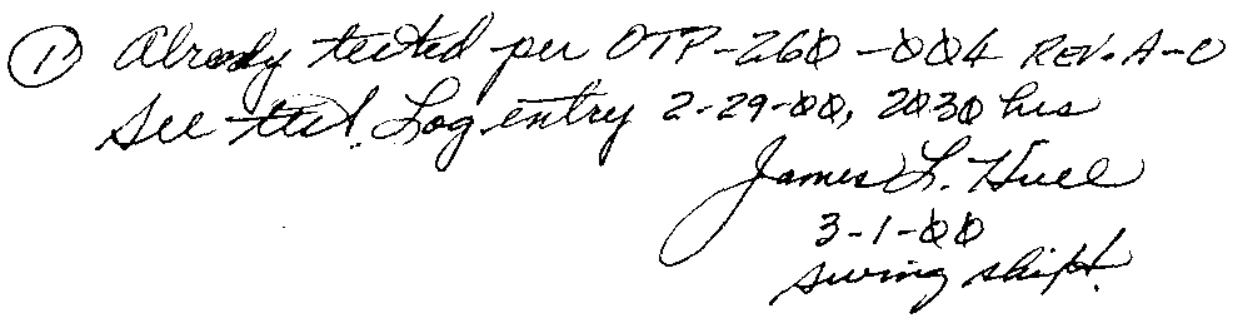




\subsection{TEST INCREMENTAL SAMPLE MODE (Cont).}

(1) 5.2 .22 VERIFY system stopped.

Test Director Signature
Test Director Print Name

(1) 5.2.23 CLICK ON "ZERO" again on display screen.

(1) 5.2.24 ENSURE GAMMA PROBE begins to RAISE.

(1) 5.2.25 When probe and system zeros, CLICK ON "START" on display

(1) 5.2 .26 VERIFY system resumed program.

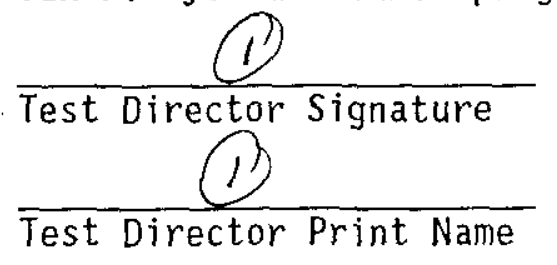

(1) 5.2.27 CLICK ON "STOP" button on computer screen.

(1) 5.2 .28 VERIFY system stopped.

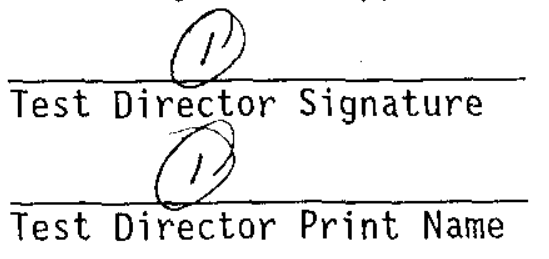

$\begin{array}{ll}\text { (1) } 5.2 .29 & \text { CLICK ON "ZERO" on display screen. } \\ \text { (1) } 5.2 .30 & \begin{array}{l}\text { When probe and system zeros, CLICK ON "START" on display } \\ \text { screen. }\end{array}\end{array}$

(1) 5.2.31 VERIFY system resumed program.

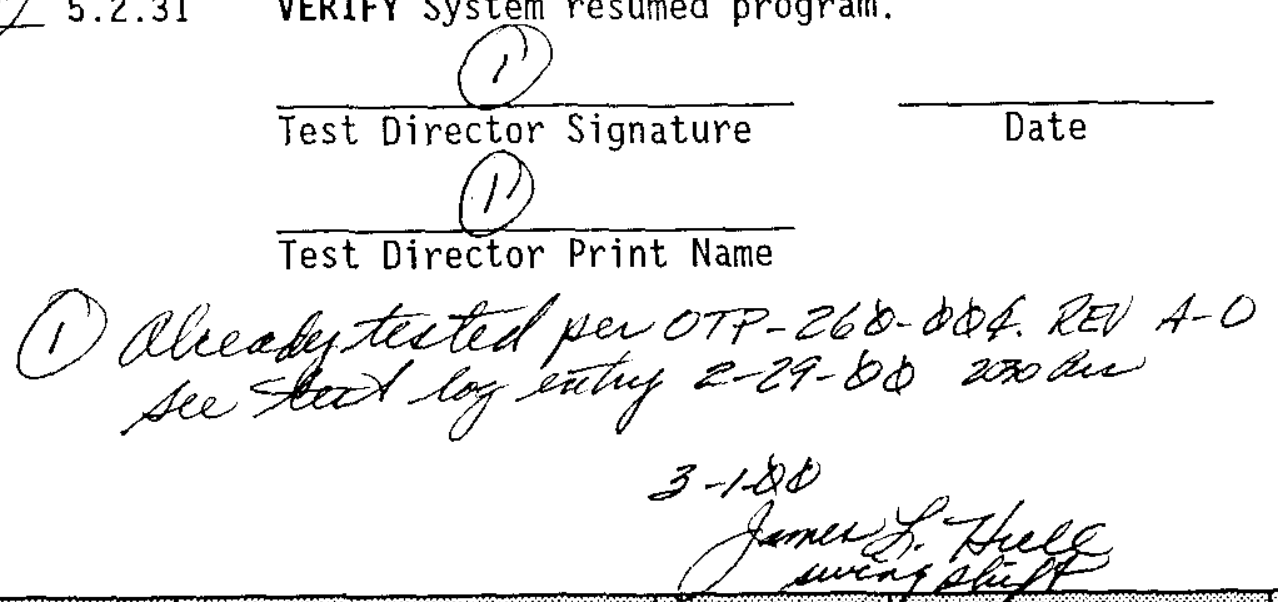




\subsection{TEST INCREMENTAL SAMPLE MODE (Cont).}

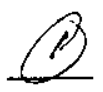

5.2.32 Test Engineer ENSURE data is received, AND both hard-copy and electronic files can be retrieved.

(1) 5.2 .33

VERIFY system automatically ZEROs and data is collected at zero position.

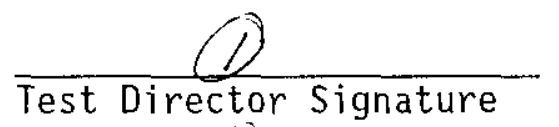

Date

Test Director Print Name

NOTE - The steps in section 5.1, applicable to the Emergency stop, need not be repeated if completed for an individual GAMMA CART. The Emergency stop on BOTH GAMMA CART A and B, need to be tested only once.

NOTE - It is NOT necessary to do ALL risers in one procedure. Test Director is responsible for ensuring ALL risers have been profiled by one AND/OR the other GAMMA CART(S).

(1) 5.2.34 REPEAT applicable SETUP Steps in section 5.1 AND Incremental testing steps 5.2.1 - 5.2.15 AND Steps 5.2.32 and 5.2.33 for each of the following risers and depths per Test Director's direction.

TABLE I

\begin{tabular}{|c|c|c|}
\hline O & RISER & Depth inches $(f t)$ \\
\hline \& REV.AOO & $14 \mathrm{~A}$ & $660(55.0)$ \\
\hline & $14 \mathrm{C}$ & $660(55.0)$ \\
\hline & $14 D$ & $660(55.0)$ \\
\hline & $14 \mathrm{~F}$ & $660(55.0)$ \\
\hline 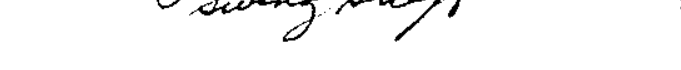 & $14 G$ & $660(55.0)$ \\
\hline & $14 B$ & $660(55.0)$ \\
\hline & $14 \mathrm{E}$ & $660(55.0)$ \\
\hline & 151 & $684(57.0)$ \\
\hline & $15 \mathrm{C}$ & $684(57.0)$ \\
\hline & $15 \mathrm{E}$ & $684(57.0)$ \\
\hline & $15 \mathrm{~B}$ & $684(57.0)$ \\
\hline & $15 \mathrm{~F}$ & $684(57.0)$ \\
\hline
\end{tabular}




\subsection{INCREMENTAL SAMPLE MODE (Cont).}

NOTE - In the following Table, Test Director N/A blocks that are tested with a different GAMMA CART.

(1) 5.2 .35 VERIFY the applicable riser in step 5.2.34 has been tested.

TABLE II

\begin{tabular}{|l|l|}
\hline RISER & TEST DIRECTOR SIGNATURE \\
\hline $14 \mathrm{~A}$ & \\
\hline $14 \mathrm{C}$ & \\
\hline $14 \mathrm{D}$ & \\
\hline $14 \mathrm{~F}$ & \\
\hline $14 \mathrm{G}$ & \\
\hline $14 \mathrm{~B}$ & \\
$14 \mathrm{E}$ & \\
\hline $15 \mathrm{I}$ & \\
\hline $15 \mathrm{C}$ & \\
\hline $15 \mathrm{E}$ & \\
\hline $15 \mathrm{~B}$ & \\
\hline $15 \mathrm{~F}$ & \\
\hline
\end{tabular}

(1) 5.2.36 VERIFY by signing below section 5.2 is complete.

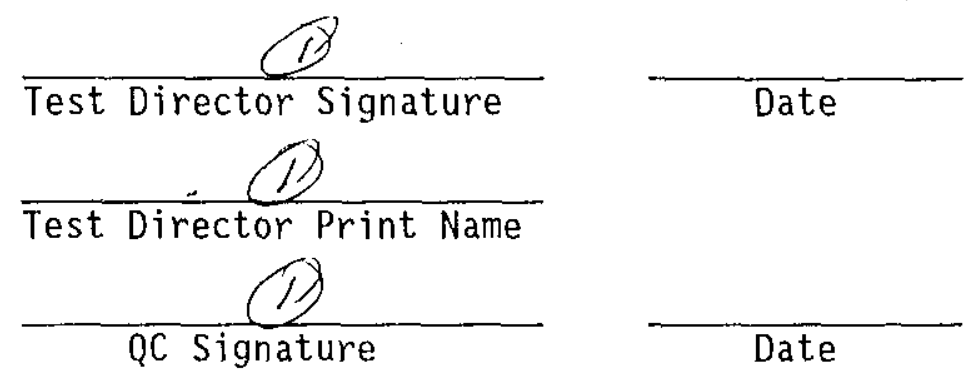

QC Print Name

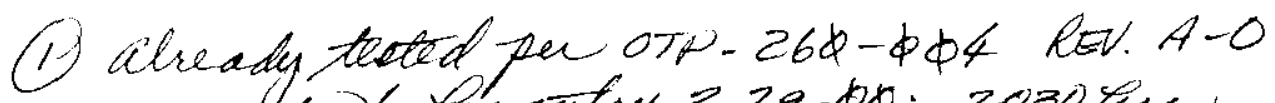
see teit trof entey $2-29-40 ; 2030 \mathrm{he}$

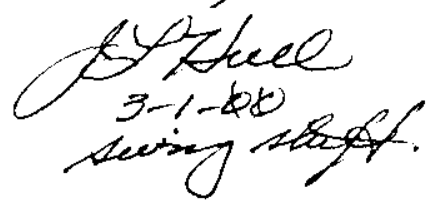




\subsection{TESTं USER DEFINED MODE}

5.3.1 ENSURE applicable SETUP Steps in section 5.1 are completed.

CART CONTROL SCREEN

$\checkmark 5.3 .2$ On the Gamma Cart Control, CLICK oN the "Config." button.

5.3.3 INPUT the following data:

\begin{tabular}{|c|c|}
\hline POSITION & DATA \\
\hline Tank Number: & $\mathrm{AZ}-101$ \\
\hline Cart: & A OR B \\
\hline Riser ID: ft. & $\begin{array}{l}\text { Selected riser number } \\
\text { NOTE - } \quad \text { Riser depth is } \\
\text { automatically computed } \\
\text { from software upon input } \\
\text { of riser ID\#. }\end{array}$ \\
\hline Probe Type: & $\begin{array}{l}1-4 \text { as applicable } \\
\text { (Normal is } 1 \text { or } 2 \text { for Cart } A \text { and } 3 \\
\text { or } 4 \text { for Cart B) }\end{array}$ \\
\hline Survey Time: & Sec. (As determined by Test Director) \\
\hline
\end{tabular}

USER DEFINED PARAMETERS

5.3.4 CLICK ON "USER DEFINED".

5.3.5 ENTER depths desired for testing per Test Engineer Direction.

5.3.6 CLICK ON "SAVE" on display screen.

5.3.7 CLICK ON "EXIT". 


\subsection{TEST USER DEFINED MODE (Cont).}

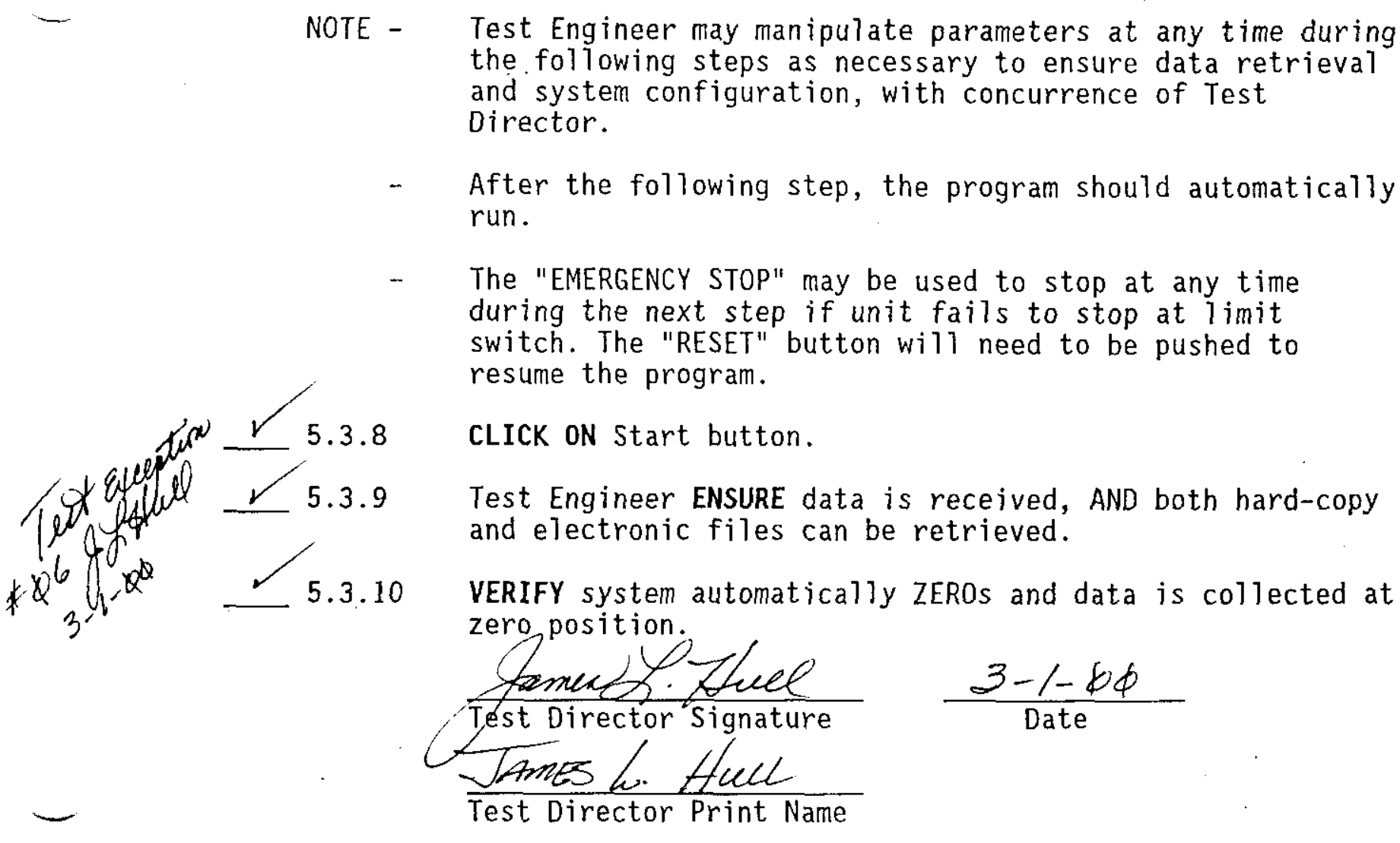

\begin{tabular}{|c|c|c|c|c|}
\hline YOPNTINUOUS & O": & Revarod 1.2 & Telense bater $12123 / 2000$ & 9. 25 of 31 \\
\hline
\end{tabular}




\subsection{TEST USER DEFINED MODE (Cont).}

\subsubsection{CLICK ON "LOGOUT" on display screen.}

5.3.12 REMOVE Probe, riser extension tool, and associated equipment AND

STORE per Test Director direction.

\section{OR}

CONTINUE in this procedure.

5.3.13 REPEAT the steps in this section (5.3) as directed for any risers as directed by Test Director.

5.3.14 VERIFY by signing below section 5.3 is complete.

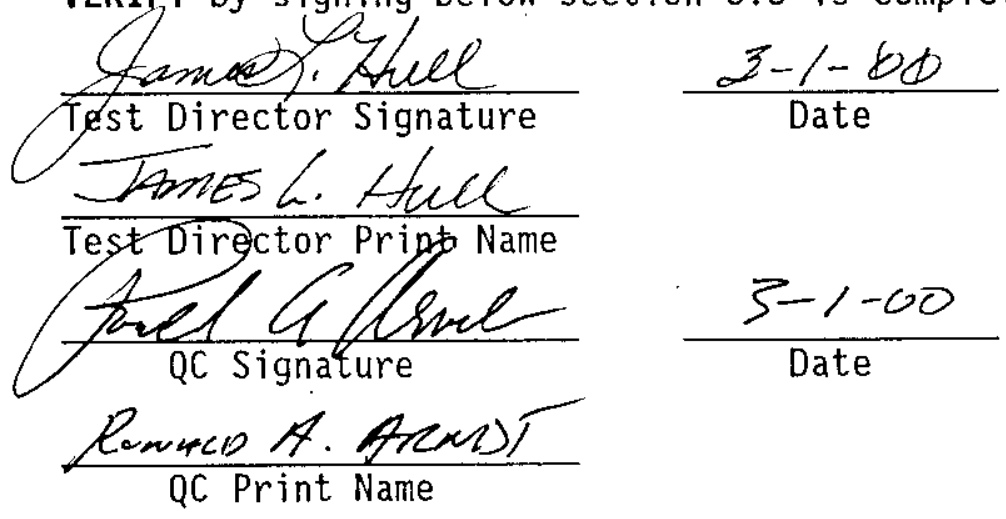




\section{RISER 14B}

GAMMA CART - B 


\section{1-AZ GAMMA CART OPERATIONAL TEST PROCEDURE}

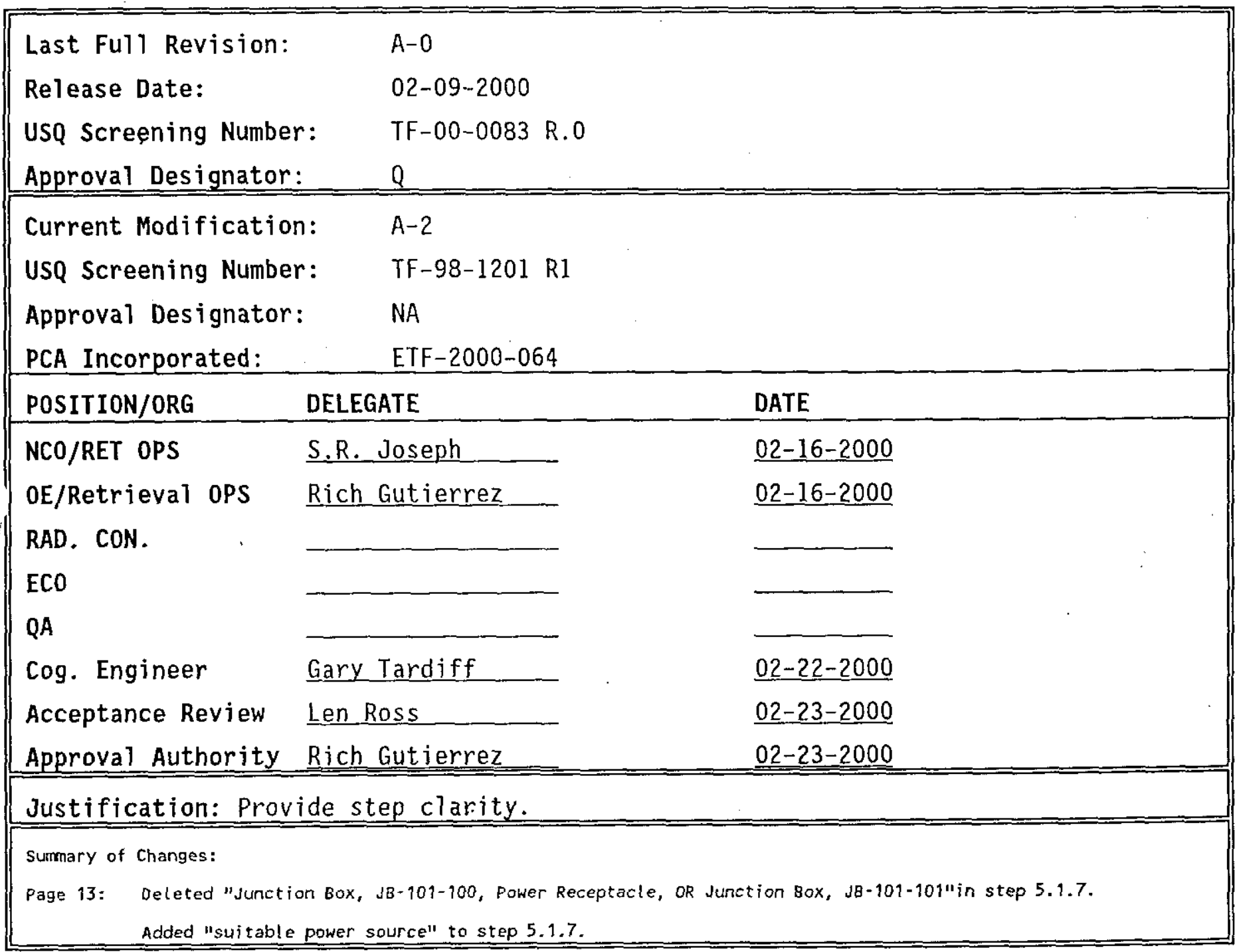

$$
\begin{aligned}
& \text { Gamma Cant B } \\
& \text { Riseti } 14 B_{\text {R.Dutury }}
\end{aligned}
$$

\section{Typo:}

CONTINUOUS
0.00010010

OTP. 260.004 rev1 100

A.2 


\subsection{PREREQUISITES}

\subsection{SPECIAL TOOLS, EQUIPMENT, AND SUPPLIES}

The following supplies may be needed to perform this procedure:

- Riser Swabbing equipment

- Riser extension tool

\subsection{PERFORMANCE DOCUMENTS}

The following procedures may be needed to perform this procedure:

- T0-040-333 LIQUID OBSERVATION WELL (LOW) SURVEILLANCE VAN STARTUP AND OPERATION PROCEDURE

\subsection{CONDITIONS AND ACTIONS}

NOTE - All signators on this procedure shall document their signature on Procedure Signature Sheet.

4.3.1 All pre-testing and inspection of the system or portions of the system to be tested has been completed.

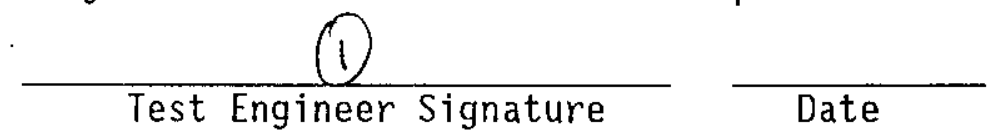

4.3.2 A pre-job briefing has been held. and all participants have been thoroughly briefed on job safety, hazards, and their responsibilities before performing this ATP.

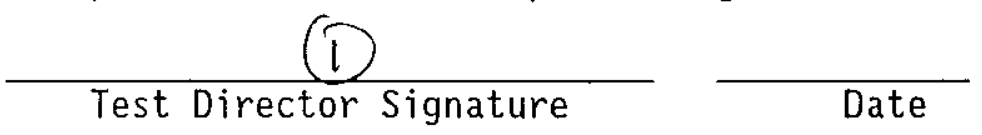

4.3.3 Test Director VERIFY section 4.3 has been COMPLETED.

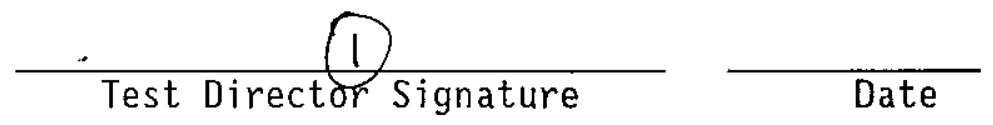

(1) ALREAOY TESTED PER OTP-260-004, PLE A-O

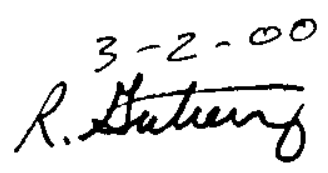




\subsection{PROCEDURE}

\subsection{SETUP}

NOTE - This procedure may be repeated for either GAMMA CART A or GAMMA CART B as applicable. N/A may be entered in blocks or steps per Test Director as applicable.

5.1.1 RECORD GAMMA CART CPU number for the system being tested. GAMMA CART IDENTIFIER \# $\beta$
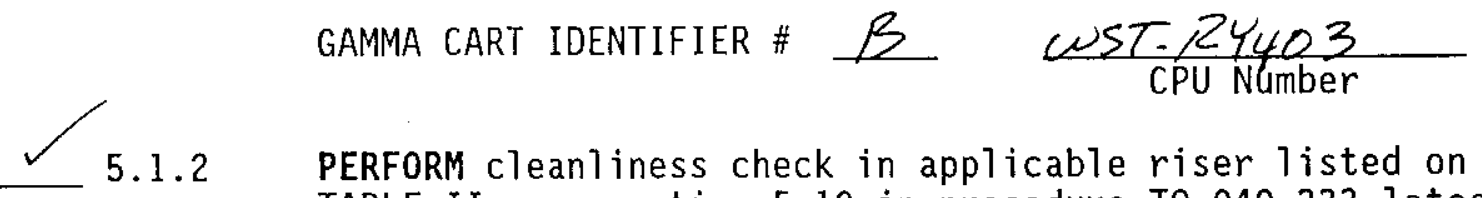

PERFORM cleanliness check in applicable riser listed on TABLE II, per section 5.10 in procedure T0-040-333 1atest rev, prior to mounting riser extension tool.

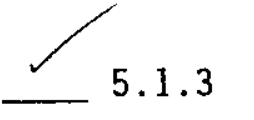

ENSURE GAMMA CART riser extension tool is mounted on the applicable riser.

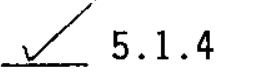

ENSURE GAMMA CART is placed in line with riser extension tool to facilitate installation of probe and cables.

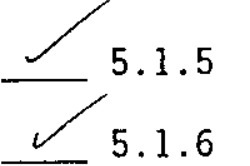

CHECK route to riser for obstacles and clearances.

LEVEL cart using jacks.

5.1.7 CONNECT gamma cart power cables, as follows:

- One end to gamma cart power receptacle

- $\quad$ ther end to surtable power source-dunction Bo*, IB 101-100, Power Receptrete, OR Junction-Box, IB 101101

CONNECT gamma cart communications cable, as follows:

- One end to gamma cart communications receptacle

- Other end to Tank 241-AZ-101 Gamma Cart A AND/OR B

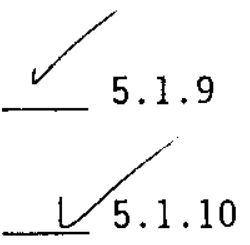
Data Collection Subsystem communications receptacle

PLACE Gamma Cart "RAISE OFF LOWER" switch in the LOWER position.

CHECK that detector probe cable is resting in the Gamma cart boom cable reel. 


\section{1 SETUP (Cont).}

\section{CAUTION}

If sufficient tension is NOT held on the detector probe cable as the cable is being let out, the cable could become entangled.

NOTE - Step 5.1.11 and 5.1.12 require two operators to perform continuous action until step 5.1 .12 is complete.

5.1.11 HoLD tension on the detector probe cable until step 5.1.12 is completed.

5.1.12 PRESS AND HOLD "RESET" button until enough detector probe cable is let-out that will allow placement of the detector cable through riser extension collar AND into riser drywe11, AND

RELEASE the "RESET" button.

5.1.13 INSTALL the proper detector probe on the detector probe cable.

5.1.14 ENSURE that the detector probe connections are correct and tight. AND

INSERT probe into riser extension tool.

5.1.15 ENSURE limit switch cable is connected from limit switch on riser extension tool, to the connection point on the front of the GAMMA CART.

5.1.16 ENSURE the "Raise - Off - Lower" selector switch is in the "OFF" position.

5.1.17 ENSURE the emergency stop button is pulled out.

POSITION the "SPEED" control potentiometer to MIN speed (fully counter-clockwise). 


\subsection{SETUP (Cont).}

\section{CAUTION}

There is no limit switch to stop the motion. When the cable is fully unwound. The cable will rewind backwards on the reel. Damage to the cable may result.

NOTE - When the cart is first powered up, or the emergency stop button has been pushed, or power has been restored after a power failure, the cable reel will not move up or down until "RESET" button is activated.

- The "Raise-OFF-Lower" Switch is Manually controlled and is Operator Dependent.

5.1.19 ENSURE LOCAL/REMOTE switch is in the "LOCAL" position.

5.1.20 ENERGIZE the Cart.

5.1.21 SET the "SPEED" potentiometer to 2 on the GAMMA Cart.

5.1.22 SET the "RAISE -OFF- LOWER" switch to the "LOWER" position.

5.1 .23 PUSH "EMERGENCY STOP" button on GAMMA CART.

(1) 5.1 .24 VERIFY the system has stopped.

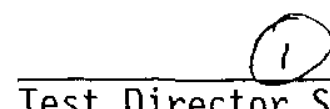

Test Director Signature $\quad$ Date

Test Director Print Name

(1)

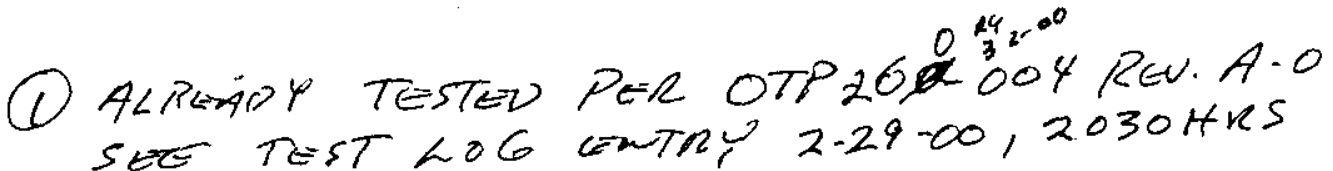

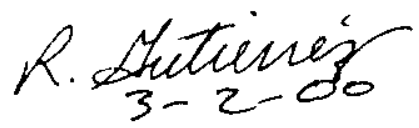




\subsection{SETUP (Cont).}

(1) 5.1.25 SET the "RAISE-OFF-LOWER" switch to the "RAISE" position.

(1) 5.1 .26 PULL "EMERGENCY STOP" out on GAMMA CART.

(1) 5.1 .27 PUSH the "RESET" button on GAMMA CART to resume.

(1) 5.1 .28 ENSURE 1 imit switch activates when probe returns to the zero position.

(1) 5.1 .29 SET the "RAISE-OFF-LOWER" switch to the "OFF" pos
(1) 5.1 .30 SET "SPEED" potentiometer to MIN.
5.1 .31 POSITION The "LOCAL REMOTE" switch to "REMOTE".
(1) 5.1 .32 VERIFY by signing below section 5.1 is complete.

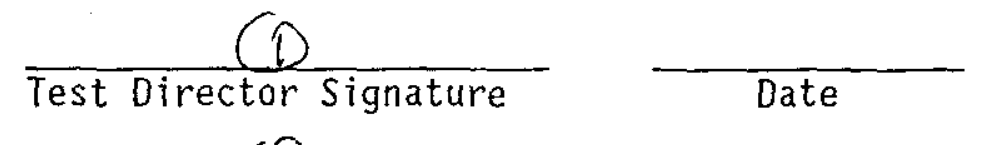

$\frac{(0}{\text { Test Director Print Name }}$
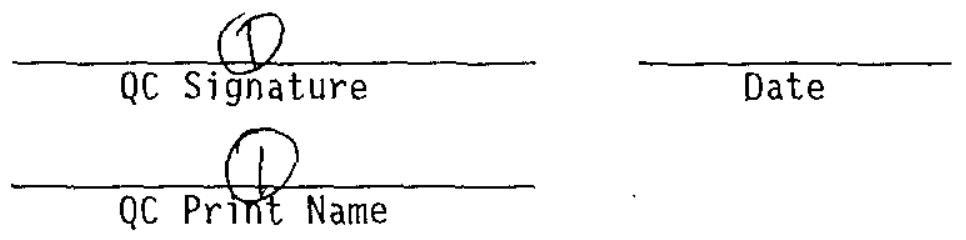

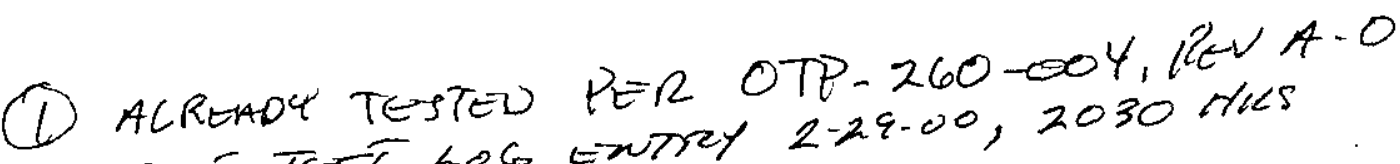
SEE TEST LOG Extrey 2-2.9.00, $2030 \mathrm{H}$ HS

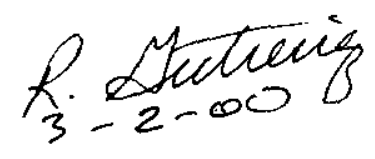




\subsection{TEST INCREMENTAL SAMPLE MODE}

\section{SETUP}

NOTE - All Steps in this section apply to either cart, except in those steps where the specific cart is indicated.

\section{INSTRUMENT CHECK}

5.2.1 IF the pushbutton for Tank 241-AZ-101 Gamma Cart A AND/0R B Data Collection System Central Processing Unit (CPU), AND/OR associated MONITOR, are NOT ON, PRESS the

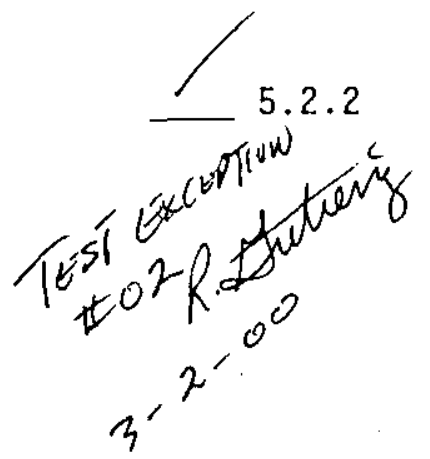
applicable ON pushbuttons.

ENSURE the following systems are ON AND

ENSURE settings are correct for the following:

- ORTEC MINIBIN

- POWER SUPPLY

Detector Bias Power Supply (HVPS): ORTEC Mod. 478.

- $k V: .5$

- 0 to 1000V: (+60 volts)

Amplifier (AMP): ORTEC Mod. 673

- COARSE GAIN: 200

- FINE GAIN: 0.680

- SHAPING TIME: Both knobs set to 2 microseconds

- $\quad$ PZ Adjust: Do NOT change settings (in this procedure)

- BLR: Switch in AUTO (up) position

- INPUTS: Switch in POS (up) position BNC cable on terminal (from pre amplifjer)

- OUTPUTS: cable on UNIPOLAR terminal(to single channel Analyzer)

5.2.3 WHEN WINDOWS login screen appears CLICK ON "CANCEL". 


\subsection{TEST INCREMENTAL SAMPLE MODE (Cont).}

NOTE - After canceling windows login, GAMMA CART software should automatically load.

5.2.4 VERIFY "GAMMA CART SPECTRUM ANALYZER AND CONTROL SYSTEM" screen is displayed on Tank 241-AZ-101 Gamma Cart A AND/OR B Data Collection System Monitor.

$\frac{\text { Rich Yfaterf }}{\text { Test Director signature }} \frac{3-2-00}{\text { Date }}$ $\frac{\text { Rich Gutieney }}{\text { Test Director Print Name }}$

5.2 .5 SELECT "Login" on the "GAMMA CART SPECTRUM ANALYZER AND CONTROL SYSTEM" screen.

NOTE - LOGIN passwords and information may be obtained from Test Director.

5.2.6 LOG-IN.

5.2.7 VERIFY LOCAL/REMOTE switch on display screen is in "REMOTE" position.

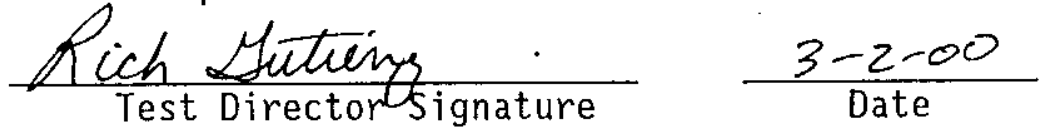
Lich Gutierrez

Test Director Print Name 


\subsection{TEST INCREMENTAL SAMPLE MODE (Cont).}

\section{IESTING}

(1) 5.2.8 SELECT "Config" on the "Gamma Cart Display" screen.

(1) 5.2 .9 ENTER the following data for selected riser on the "Configuration - Display" screen by pulling down applicable menu:

\begin{tabular}{|c|c|}
\hline POSITION & DATA \\
\hline Tank Number: & $A Z-101$ \\
\hline Cart: & $A O R B$ \\
\hline Riser ID: ft. & $\begin{array}{l}\text { Selected riser number } \\
\text { NOTE - } \quad \text { Riser depth is } \\
\text { automatically computed } \\
\text { from software upon input } \\
\text { of riser ID\#. }\end{array}$ \\
\hline Probe Type: & $\begin{array}{l}1-4 \text { as applicable } \\
\text { (Normal is } 1 \text { or } 2 \text { for Cart A and } 3 \text {. } \\
\text { or } 4 \text { for Cart B) }\end{array}$ \\
\hline Survey Time: & Sec. (As determined by Test Director) \\
\hline
\end{tabular}

(1) 5.2.10 ENSURE REAL/LIVE toggle button indicates "LIVE".

(1) 5.2.11 On the Data Collection Configuration window, SELECT the "Incremental" button.

INCREMENTAL PARAMETERS

(1) 5.2.12 INPUT the following Sample Collection Data:

\begin{tabular}{|l|l|}
\hline $\begin{array}{l}\text { Sample Start } \\
\text { Depth: }\end{array}$ & $55.0 \mathrm{ft}$ \\
\hline Interval Size: & $10.0 \mathrm{ft}$ \\
\hline Sample End Depth: & $5.0 \mathrm{ft}$ \\
\hline
\end{tabular}

\begin{tabular}{|c|c|}
\hline Number: & DATA \\
\hline ID-101 \\
\hline NOTE - $\begin{array}{c}\text { Selected riser number } \\
\text { Riser depth is } \\
\text { automatically computed } \\
\text { from software upon input } \\
\text { of riser ID\#. }\end{array}$ \\
Type: & $\begin{array}{l}1-4 \text { as applicable } \\
\text { (Normal is } 1 \text { or 2 for Cart A and 3 } \\
\text { or 4 for Cart B) }\end{array}$ \\
\hline Sec. (As determined by Test Director)
\end{tabular}

(1) AlResad TESTLD per OTP-260-00Y, ReV. At-O SEE TR=5T LOC GWTT2Y 2-29-00, 2030 HKS R.stuturis

\begin{tabular}{|c|c|c|c|c|}
\hline CONTINUOUS & 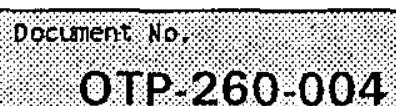 & Revmod & Referes bater & Pagor \\
\hline
\end{tabular}




\subsection{TEST INCREMENTAL SAMPLE MODE (Cont).}

(1) 5.2 .13 CLICK ON "SAVE".

(1) 5.2.14 CLICK ON "EXIT".

NOTE - $\quad$ Test Engineer may manipulate parameters at any time during the following steps as necessary to ensure data retrieval and system configuration, with concurrence of Test Director.

- After the following step, the program should automatically run.

(1) 5.2 .15 CLICK oN "Start" button.

(1) 5.2.16 CLICK ON "EMERGENCY STOP" button on computer screen.

(1) 5.2.17 VERIFY system stopped.

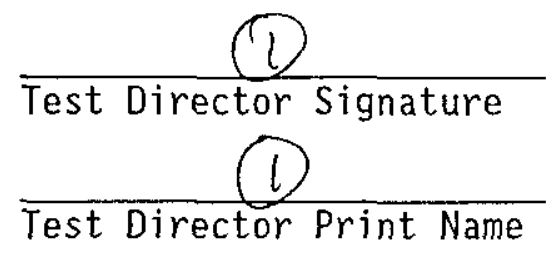

(1) 5.2.18 CLICK ON "EMERGENCY STOP" again to RESET the emergency stop button on computer screen.

(1) 5.2.19 CLICK ON "ZERO" on display screen.

(1) 5.2.20 ENSURE GAMMA PROBE begins to RAISE.

(1) 5.2.21 CLICK ON "STOP" button on display screen.

(1) ALRESOY TESTED PEX OTP-260-004, REUA-O SEE तEST hOG GuTPY 2.24-00,2030 सRS

$$
\begin{aligned}
& \text { R. Sfuting } \\
& 3-2-00
\end{aligned}
$$




\subsection{TEST INCREMENTAL SAMPLE MODE (Cont).}

(1) 5.2 .22 VERIFY System stopped.

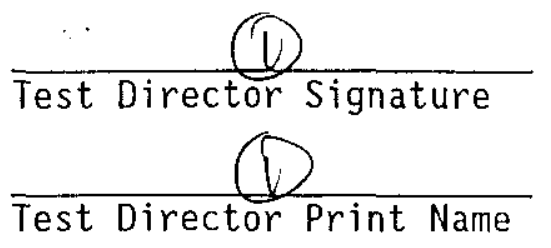

(1) 5.2 .23 CLICK ON "ZER0" again on display screen.

(1) 5.2.24 ENSURE GAMMA PROBE begins to RAISE.

(1) 5.2.25 When probe and system zeros, CLICK ON "START" on display screen.

(1) 5.2.26 VERIFY system resumed program.

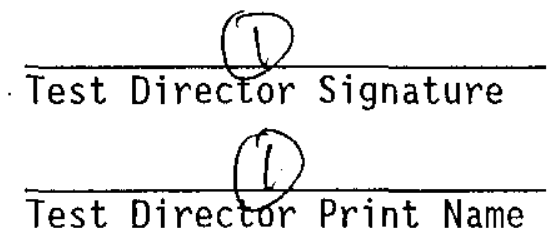

(1) 5.2.27 CLICK ON "STOP" button on computer screen.

(1) 5.2 .28 VERIFY system stopped.

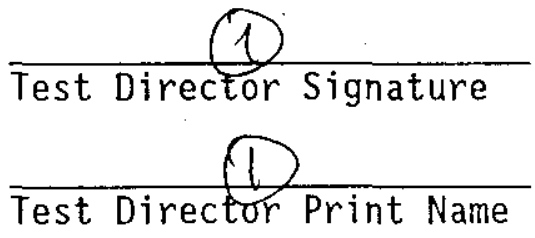

(1) 5.2.29 CLICK ON "ZERO" on display screen.

(1) 5.2 .30 When probe and system zeros, CLICK ON "START" on display screen.

(1) 5.2.31 VERIFY System resumed program.

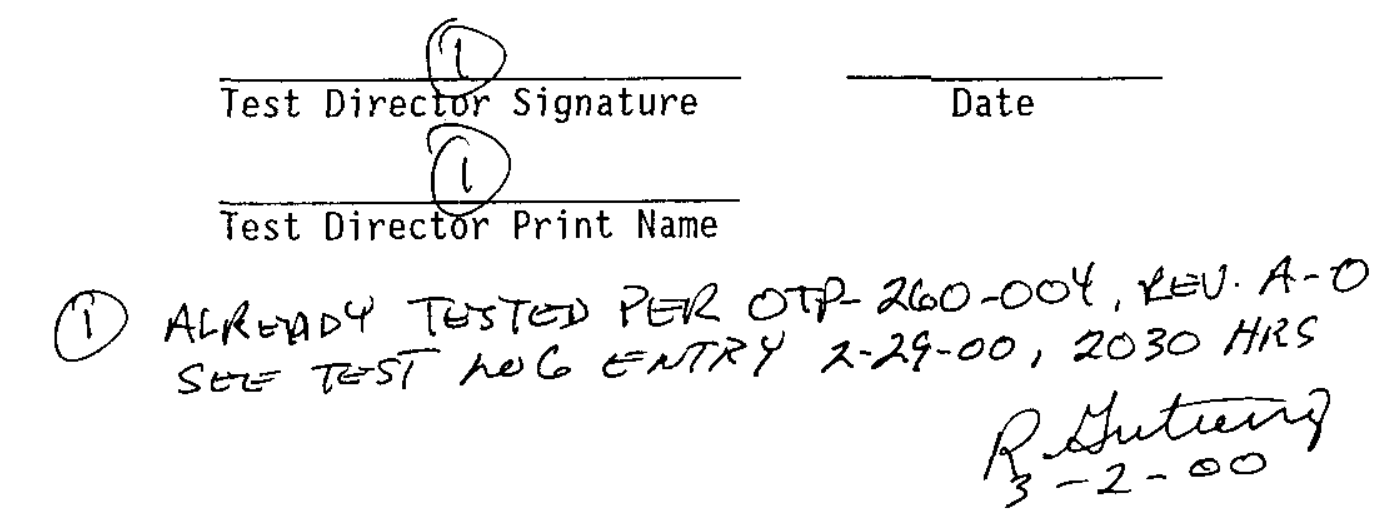

Date

Date

Date 


\subsection{TEST INCREMENTAL SAMPLE MODE (Cont).}

(1) 5.2.32 Test Engineer ENSURE data is received, AND both hard-copy and electronic files can be retrieved.

(1) 5.2.33 VERIFY system automatically ZEROs and data is collected at zero position.

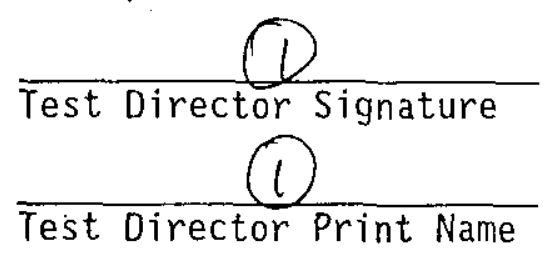

Date

NOTE - The steps in section 5.1, applicable to the Emergency stop, need not be repeated if completed for an individual GAMMA CART. The Emergency stop on BOTH GAMMA CART A and B, need to be tested only once.

NOTE - It is NOT necessary to do ALL risers in one procedure. Test Director is responsible for ensuring ALL risers have been profiled by one AND/OR the other GAMMA CART(S).

(1) 5.2 .34

REPEAT applicable SETUP Steps in section 5.1 AND Incremental testing steps 5.2.1 - 5.2.15 AND Steps 5.2.32 and 5.2 .33 for each of the following risers and depths per Test Director's direction.

(1) ACREADY TESTED PER OTP-260-00Y REV.A.O STE TEST LOO ENTRY $2.29-\infty, 2030$ tars R Notring

TABLE I

\begin{tabular}{|l|l|}
\hline RISER & $\begin{array}{l}\text { Depth } \\
\text { inches }(\mathrm{ft})\end{array}$ \\
\hline $14 \mathrm{~A}$ & $660(55.0)$ \\
\hline $14 \mathrm{C}$ & $660(55.0)$ \\
\hline $14 \mathrm{D}$ & $660(55.0)$ \\
\hline $14 \mathrm{~F}$ & $660(55.0)$ \\
\hline $14 \mathrm{G}$ & $660(55.0)$ \\
\hline $14 \mathrm{~B}$ & $660(55.0)$ \\
\hline $14 \mathrm{E}$ & $660(55.0)$ \\
\hline $15 \mathrm{I}$ & $684(57.0)$ \\
\hline $15 \mathrm{C}$ & $684(57.0)$ \\
\hline $15 \mathrm{E}$ & $684(57.0)$ \\
\hline $15 \mathrm{~B}$ & $684(57.0)$ \\
\hline $15 \mathrm{~F}$ & $684(57.0)$ \\
\hline
\end{tabular}




\subsection{INCREMENTAL SAMPLE MODE (Cont).}

NOTE - In the following Table, Test Director N/A blocks that are tested with a different GAMMA CART.

(1) 5.2.35 VERIFY the applicable riser in step 5.2.34 has been tested.

TABLE II

\begin{tabular}{|l|l||}
\hline RISER & TEST DIRECTOR SIGNATURE \\
\hline $14 \mathrm{~A}$ & \\
\hline $14 \mathrm{C}$ & \\
\hline $14 \mathrm{D}$ & \\
$14 \mathrm{~F}$ & \\
\hline $14 \mathrm{G}$, & \\
\hline $14 \mathrm{~B}$ & \\
\hline $14 \mathrm{E}$ & \\
\hline $15 \mathrm{I}$, & \\
\hline $15 \mathrm{C}$ & \\
\hline $15 \mathrm{E}$. & \\
\hline $15 \mathrm{~B}$ & \\
\hline $15 \mathrm{~F}$ & \\
\hline
\end{tabular}

(1) 5.2 .36 VERIFY by signing below section 5.2 is complete.

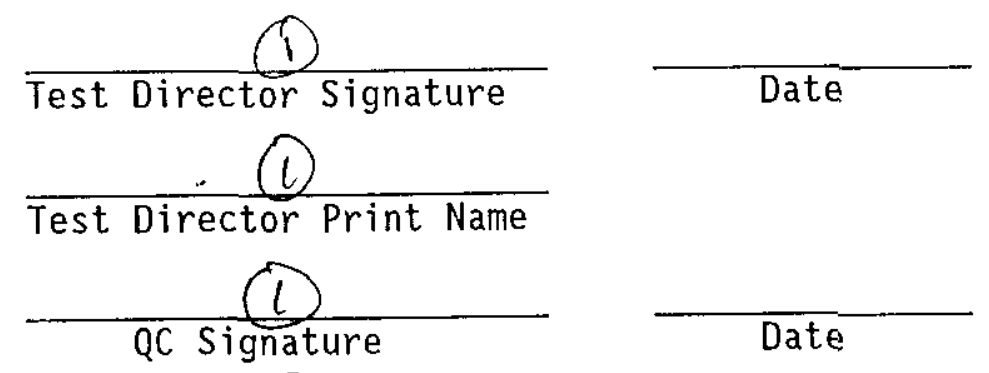
QC Print Name

(1) hLREAY TESTOD PEM OTP-260-00Y REU.A-O SCE TEST $\angle 06$ GTRY $2-29-00,2030$ ARS

R. Sothiry 


\subsection{TEST USER DEFINED MODE}

5.3.1 ENSURE applicable SETUP Steps in section 5.1 are completed.

CART CONTROL SCREEN

5.3.2 On the Gamma Cart Control, CLICK oN the "Config." button.

5.3.3 INPUT the following data:

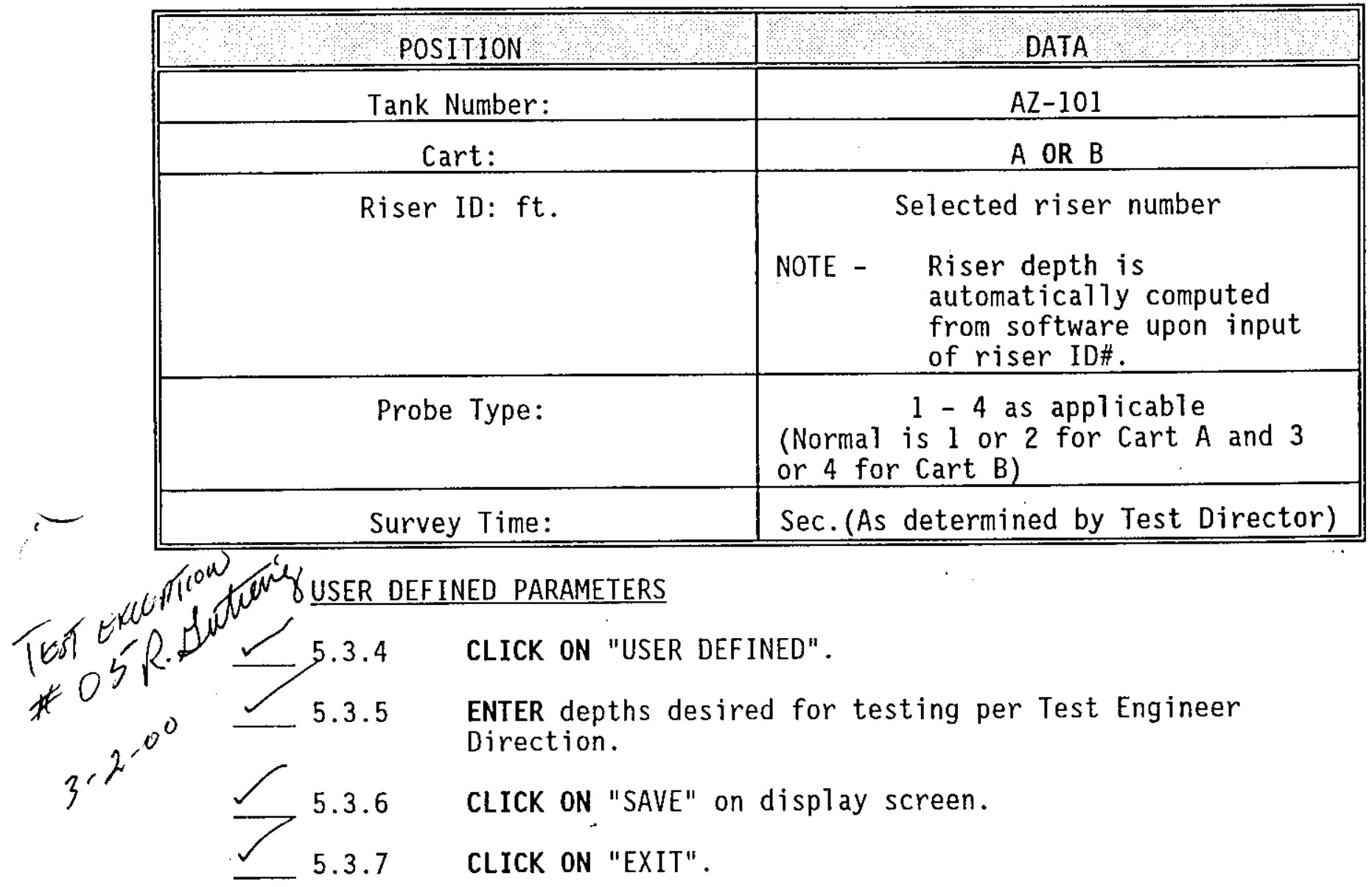




\subsection{TEST USER DEFINED MODE (Cont).}

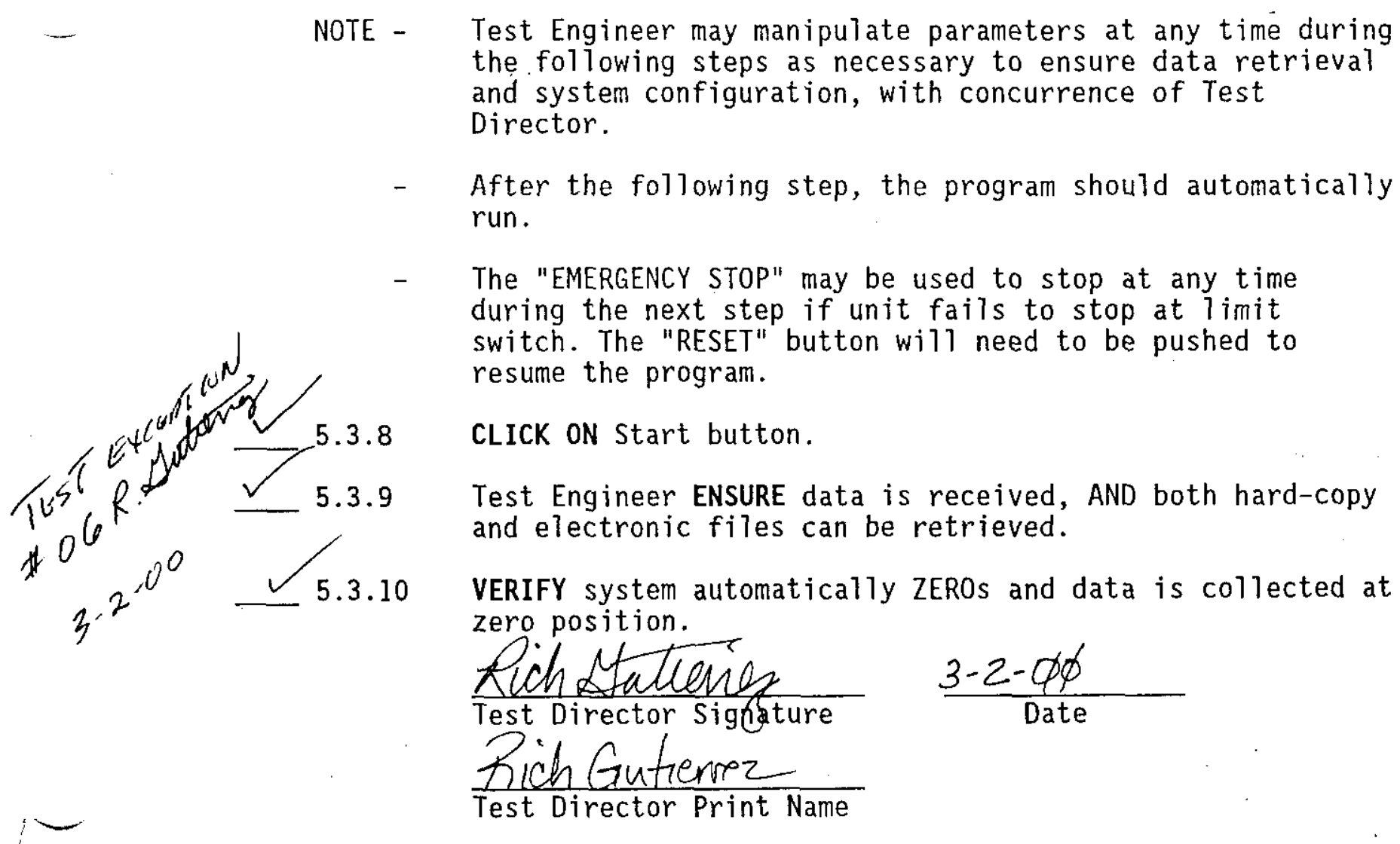

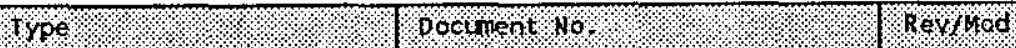
CONTINUOUS
OTP 260 -004
A.2
86 eastorte $02 / 23 / 2000$ 
5.3 TEST USER DEFINED MODE (Cont).

5.3.11 CLICK ON "LOGOUT" on display screen.

5.3.12 REMOVE Probe, riser extension tool, and associated equipment AND

STORE per Test Director direction.

OR

CONTINUE in this procedure.

5.3.13 REPEAT the steps in this section (5.3) as directed for any risers as directed by Test Director.

5.3.14 VERIFY by signing below section 5.3 is complete.

Sech Luturi $\frac{3-2-00}{\text { Date }}$

Rich Gutierve?

Test Dtreetor Print Name

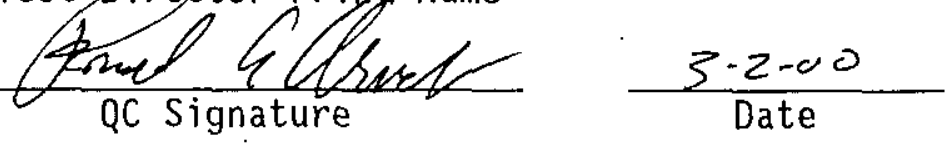

$\frac{\text { Rowreo A. Trad }}{\text { QC Print Name }}$ 
RISER 14F

GAMMA CART - B 


\section{1-AZ GAMMA CART OPERATIONAL TEST PROCEDURE}

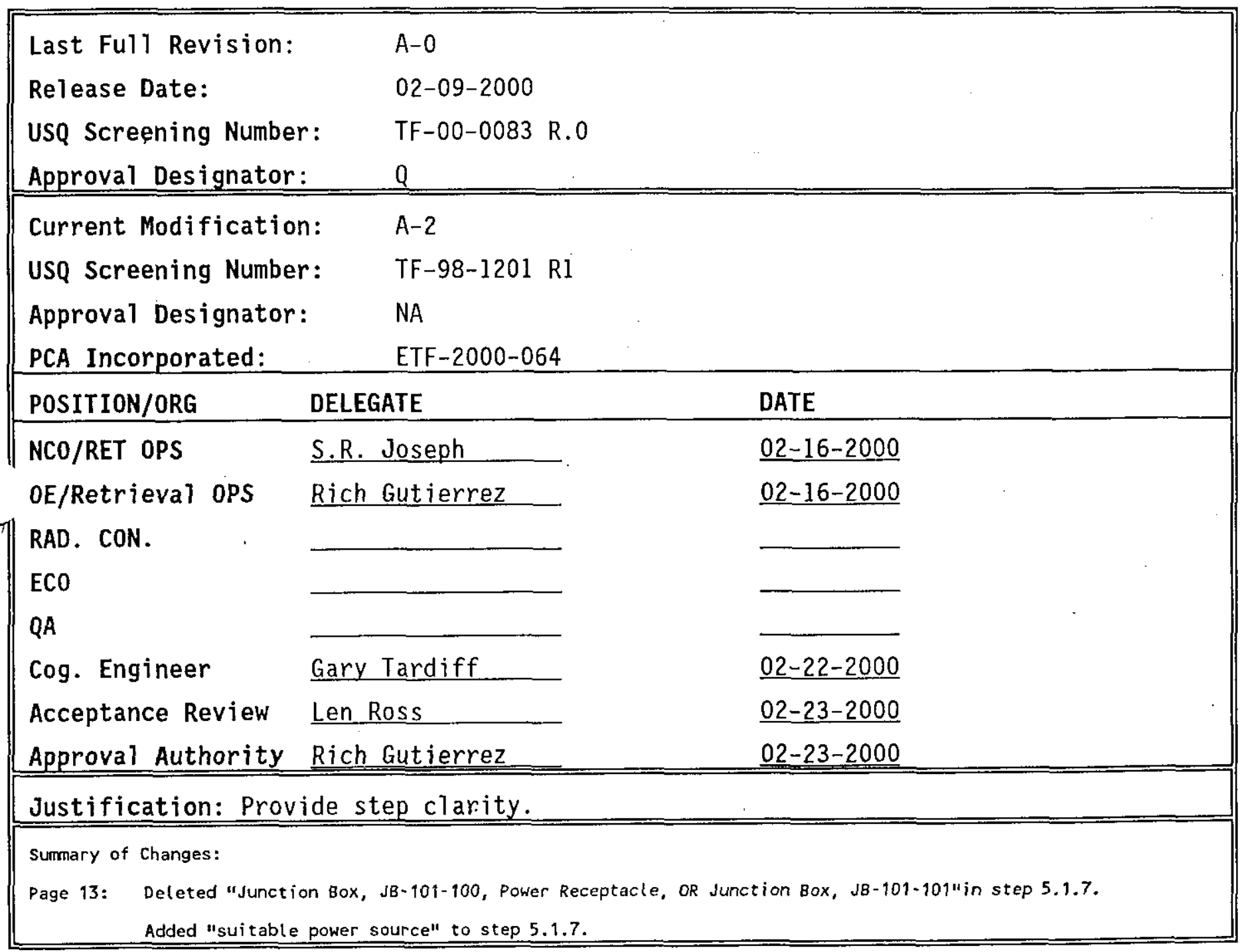

$$
\begin{aligned}
& \text { GAmma CART B } \\
& \text { Riseir 14F } \\
& \text { Refuturiy } 3 / 200
\end{aligned}
$$




\subsection{PREREQUISITES}

\subsection{SPECIAL TOOLS, EQUIPMENT, AND SUPPLIES}

The following supplies may be needed to perform this procedure:

- Riser Swabbing equipment

- Riser extension tool

\subsection{PERFORMANCE DOCUMENTS}

The following procedures may be needed to perform this procedure:

- TO-040-333 LIQUID OBSERVATION WELL (LOW) SURVEILLANCE VAN STARTUP AND OPERATION PROCEDURE

\subsection{CONDITIONS AND ACTIONS}

NOTE - All signators on this procedure shall document their signature on Procedure Signature Sheet.

4.3.1 All pre-testing and inspection of the system or portions of the system to be tested has been completed.

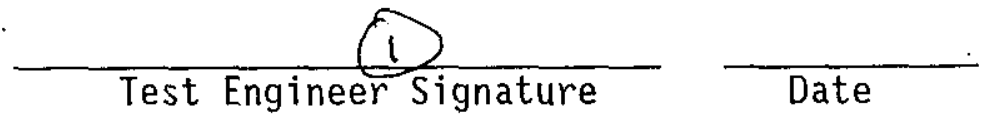

4.3.2 A pre-job briefing has been held. and all participants have been thoroughly briefed on job safety, hazards, and their responsibilities before performing this ATP.

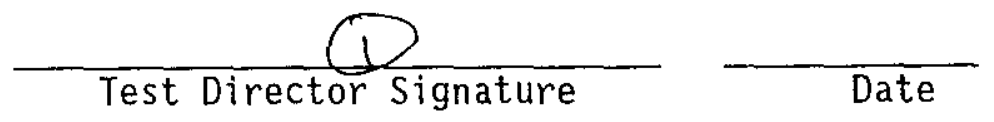

4.3.3 Test Director VERIFY section 4.3 has been COMPLETED.

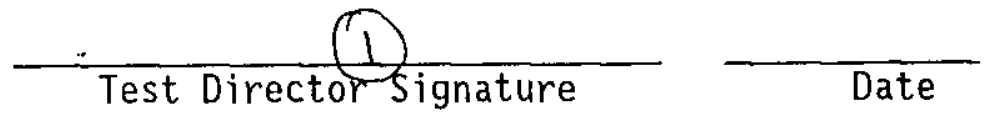

(1) ALFGADY TBSTED PER OTP-260-0004, REV.A-O

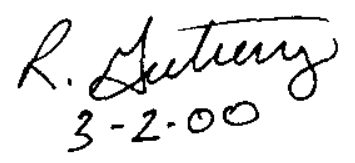




\subsection{PROCEDURE}

\subsection{SETUP}

NOTE -- This procedure may be repeated for either GAMMA CART A or GAMMA CART B as applicable. N/A may be entered in blocks or steps per Test Director as applicable.

5.1.1 RECORD GAMMA CART CPU number for the system being tested. GAMMA CART IDENTIFIER \# $B \quad \frac{\text { WST } y 403}{\text { CPU Number }}$

\section{$\underline{V} 5.1 .2$}

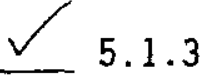

$\checkmark 5.1 .4$

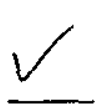

5.1 .5

5.1 .6

5.1 .7
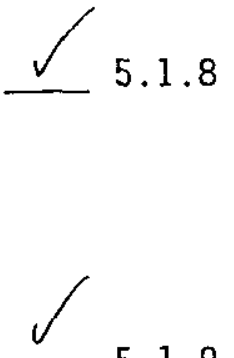

5.1 .9

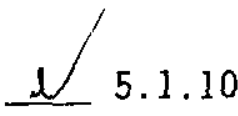

PERFORM cleanliness check in applicable riser listed on TABLE II, per section 5.10 in procedure TO-040-333 latest rev, prior to mounting riser extension tool.

ENSURE GAMMA CART riser extension tool is mounted on the applicable riser.

ENSURE GAMMA CART is placed in 1 ine with riser extension tool to facilitate installation of probe and cables.

CHECK route to riser for obstacles and clearances.

LEVEL cart using jacks.

CONNECT gamma cart power cables, as follows:

- One end to gamma cart power receptacle

- Other end to sultable power source-Junction-Box; IB 101 100, Power reeeptacle, OR Junction Box, JB $101-101$

CONNECT gamma cart communications cable, as follows:

- One end to gamma cart communications receptacle

- $\quad$ ther end to Tank 241-AZ-101 Gamma Cart A AND/OR B Data Collection Subsystem communications receptacle

PLACE Gamma Cart "RAISE OFF LOWER" switch in the LOWER position.

CHECK that detector probe cable is resting in the Gamma Cart boom cable reel. 


\subsection{SETUP (Cont).}

\section{CAUTION}

If sufficient tension is NOT held on the detector probe cable as the cable is being let out, the cable could become entangled.

NOTE - Step 5.1.11 and 5.1 .12 require two operators to perform continuous action until step 5.1 .12 is complete.

5.1.11 HOLD tension on the detector probe cable until step 5.1.12 is completed.

$\checkmark 5.1 .12$

PRESS AND HOLD "RESET" button until enough detector probe cable is let-out that will allow placement of the detector cable through riser extension collar AND into riser drywe 11, AND

RELEASE the "RESET" button.

5.1.13 INSTALL the proper detector probe on the detector probe cable.

$\checkmark$ 5.1.14 ENSURE that the detector probe connections are correct and tight. AND

INSERT probe into riser extension tool.

$\underset{ }{\top} 5.1 .15$

ENSURE limit switch cable is connected from limit switch on riser extension tool, to the connection point on the front of the GAMMA CART.

$\stackrel{\Upsilon}{ } 5.1 .16$

ENSURE the "Raise - Off - Lower" selector switch is in the "OFF" position.

$\checkmark .1 .17$
$\square$
$\square .1 .18$

ENSURE the emergency stop button is pulled out.

POSITION the "SPEED" control potentiometer to MIN speed (fully counter-clockwise). 


\subsection{SETUP (Cont).}

\section{CAUTION}

There is no limit switch to stop the motion when the cable is fully unwound. The cable will rewind backwards on the reel. Damage to the cable may result.

NOTE - When the cart is first powered up, or the emergency stop button has been pushed, or power has been restored after a power failure, the cable reel will not move up or down until "RESET" button is activated.

- The "Raise-OFF-Lower" Switch is Manually controlled and is Operator Dependent.

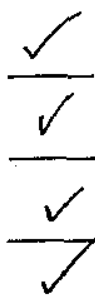

5.1.19 ENSURE LOCAL/REMOTE switch is in the "LOCAL" position.

5.1.20 ENERGIZE the Cart.

5.1.21 SET the "SPEED" potentiometer to 2 on the GAMMA Cart.

5.1.22 SET the "RAISE -OFF- LOWER" switch to the "LOWER" position.

(1) 5.1 .23 PUSH "EMERGENCY STOP" button on GAMMA CART.

(1) 5.1 .24 VERIFY the system has stopped.

Fich yetieng $\frac{3-2-00}{\text { Date }}$

Rech Gutionrer

Test Director Print Name

(I) ALREHOY TESTED PER OTP.260-00Y, REV.A-O SEZ $=$ TEST wol wutry $2.28 .00 .2030 \mathrm{bHS}$

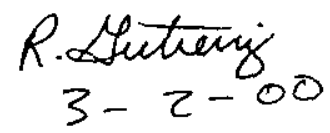




\subsection{SETUP (Cont).}

12 5.1.25 SET the "RAISE-OFF-LOWER" switch to the "RAISE" position.

(1) 5.1 .26 PULL "EMERGENCY STOP" out on GAMMA CART.

(1) 5.1.27 PUSH the "RESET" button on GAMMA CART to resume.

(1) 5.1.28 ENSURE 1 imit switch activates when probe returns to the zero position.

(1) 5.1.29 SET the "RAISE-OFF-LOWER" switch to the "OFF" position.

(1) 5.1 .30 SET "SPEED" potentiometer to MIN.

(1) 5.1.31 POSITION The "LOCAL REMOTE" switch to "REMOTE".

(1) 5.1 .32 VERIFY by signing below section 5.1 is complete.

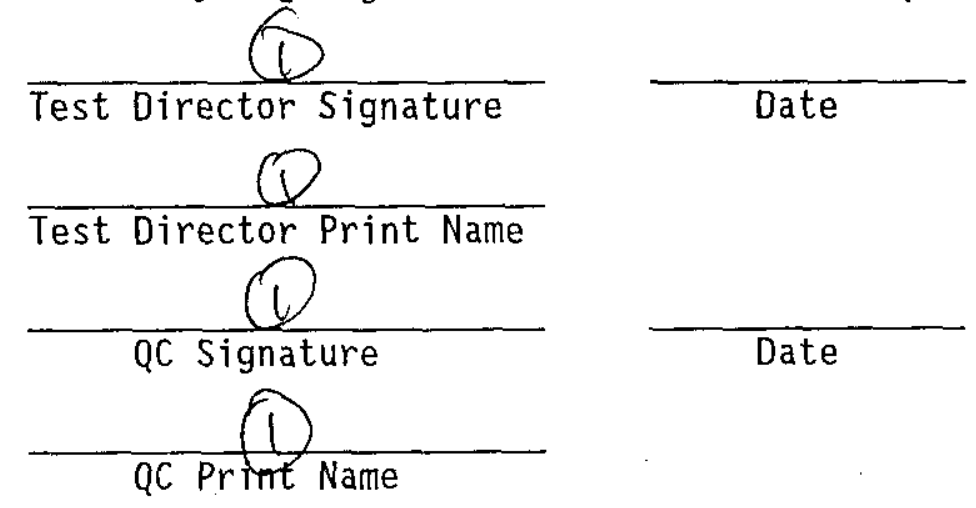

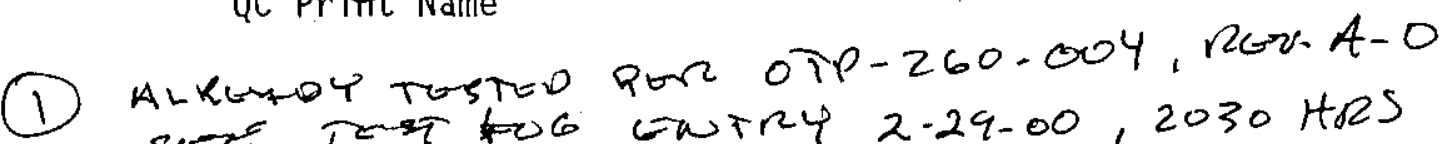

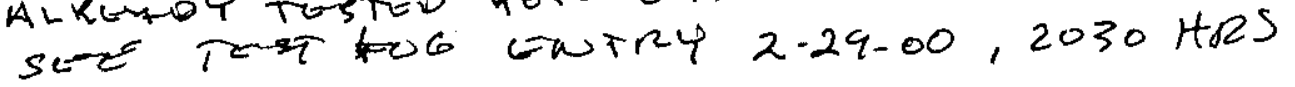

$$
\begin{aligned}
& R \text { suting } \\
& 3-2-00
\end{aligned}
$$




\subsection{TEST INCREMENTAL SAMPLE MODE}

SETUP

NOTE - AlT'Steps in this section apply to either cart, except in those steps where the specific cart is indicated.

\section{INSTRUMENT CHECK}

5.2.1 IF the pushbutton for Tank 241-AZ-101 Gamma Cart A AND/OR B Data Collection System Central Processing Unit (CPU), AND/OR associated MONITOR, are NOT ON, PRESS the applicable ON pushbuttons.

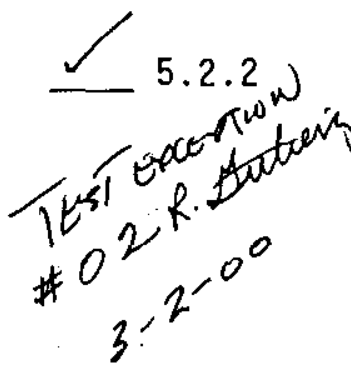

ENSURE the following systems are ON AND

ENSURE settings are correct for the following:

- ORTEC MINIBIN

- POWER SUPPLY

Detector Bias Power Supply (HVPS): ORTEC Mod. 478.

- $\mathrm{kV}: .5$

- 0 to 1000V: ( +60 volts)

Amplifjer (AMP): ORTEC Mod. 673

- COARSE GAIN: 200

- FINE GAIN: 0.680

- SHAPING TIME: Both knobs set to 2 microseconds

- PZ Adjust: DO NOT change settings (in this procedure)

- BLR: Switch in AUTO (up) position

- INPUTS: Switch in POS (up) position BNC cable on terminal (from pre amplifier)

- $\quad$ OUTPUTS: cable on UNIPOLAR terminal(to single channel Analyzer)

5.2.3 WHEN WINDOWS login screen appears CLICK ON "CANCEL". 
5.2 TEST INCREMENTAL SAMPLE MODE (Cont).

NOTE - After canceling windows login, GAMMA CART software should automatically load.

5.2.4 VERIFY "GAMMA CART SPECTRUM ANALYZER AND CONTROL SYSTEM" screen is displayed on Tank 241-AZ-101 Gamma Cart A AND/OR B Data Collection System Monitor.

$$
\frac{\text { Rich Mutriug }}{\text { Test Directod Signature }} \frac{3-2-00}{\text { Date }}
$$

Rich Gutiene?

Test Director Print Name

5.2 .5 SELECT "Login" on the "GAMMA CART SPECTRUM ANALYZER AND CONTROL SYSTEM" screen.

NOTE - LOGIN passwords and information may be obtained from Test Director.

$\sim 5.2 .6$ LOG-IN.

5.2.7 VERIFY LOCAL/REMOTE switch on display screen is in "REMOTE" position.

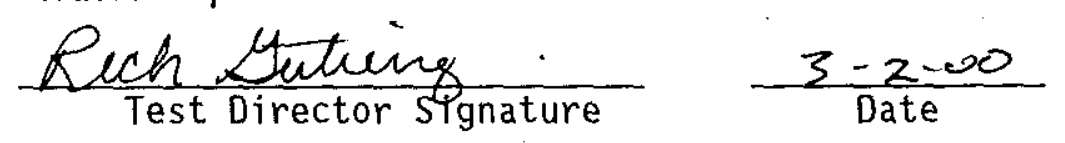

Rich Gutierez

Test Director Print Name 


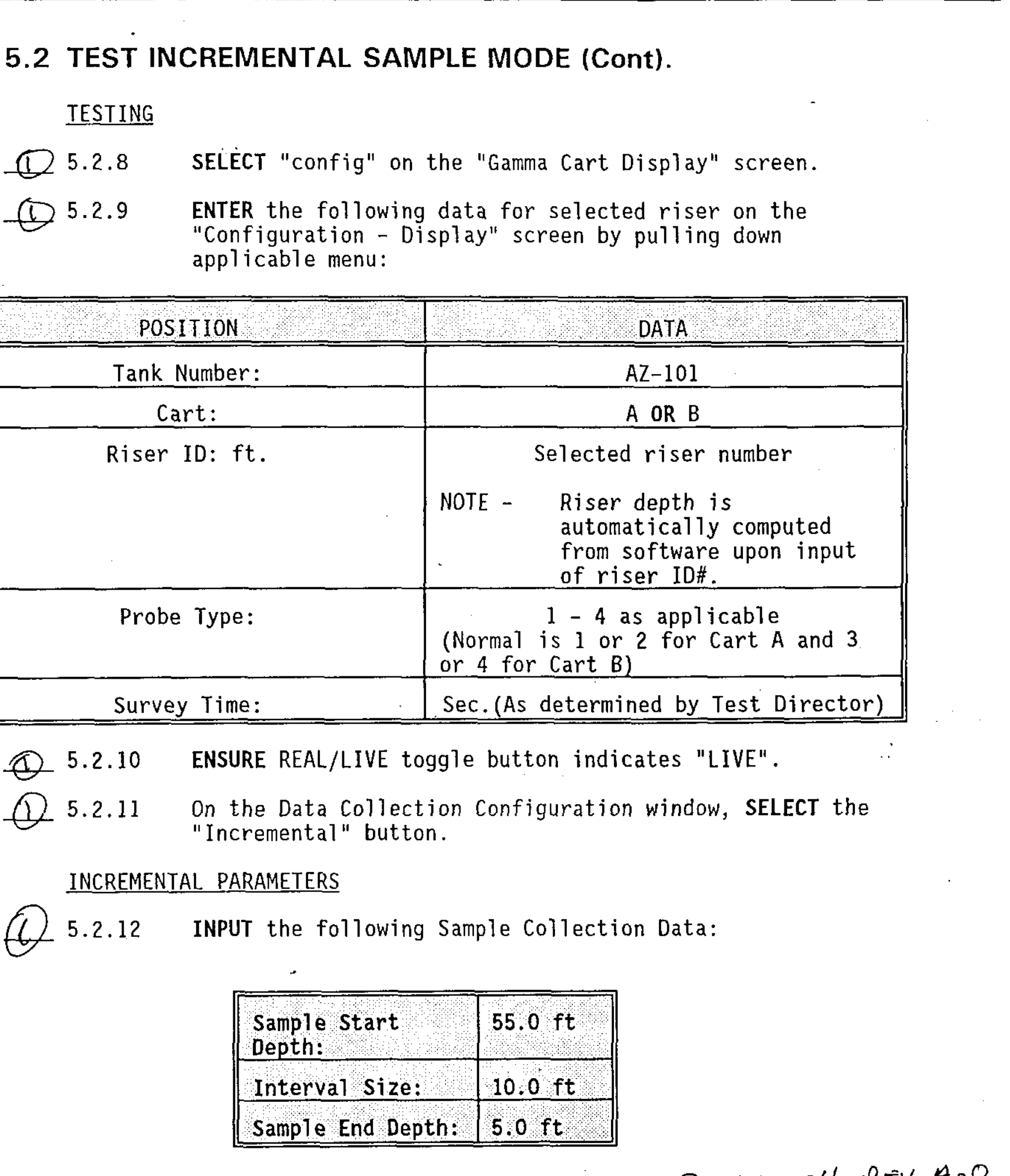

\section{TESTING}

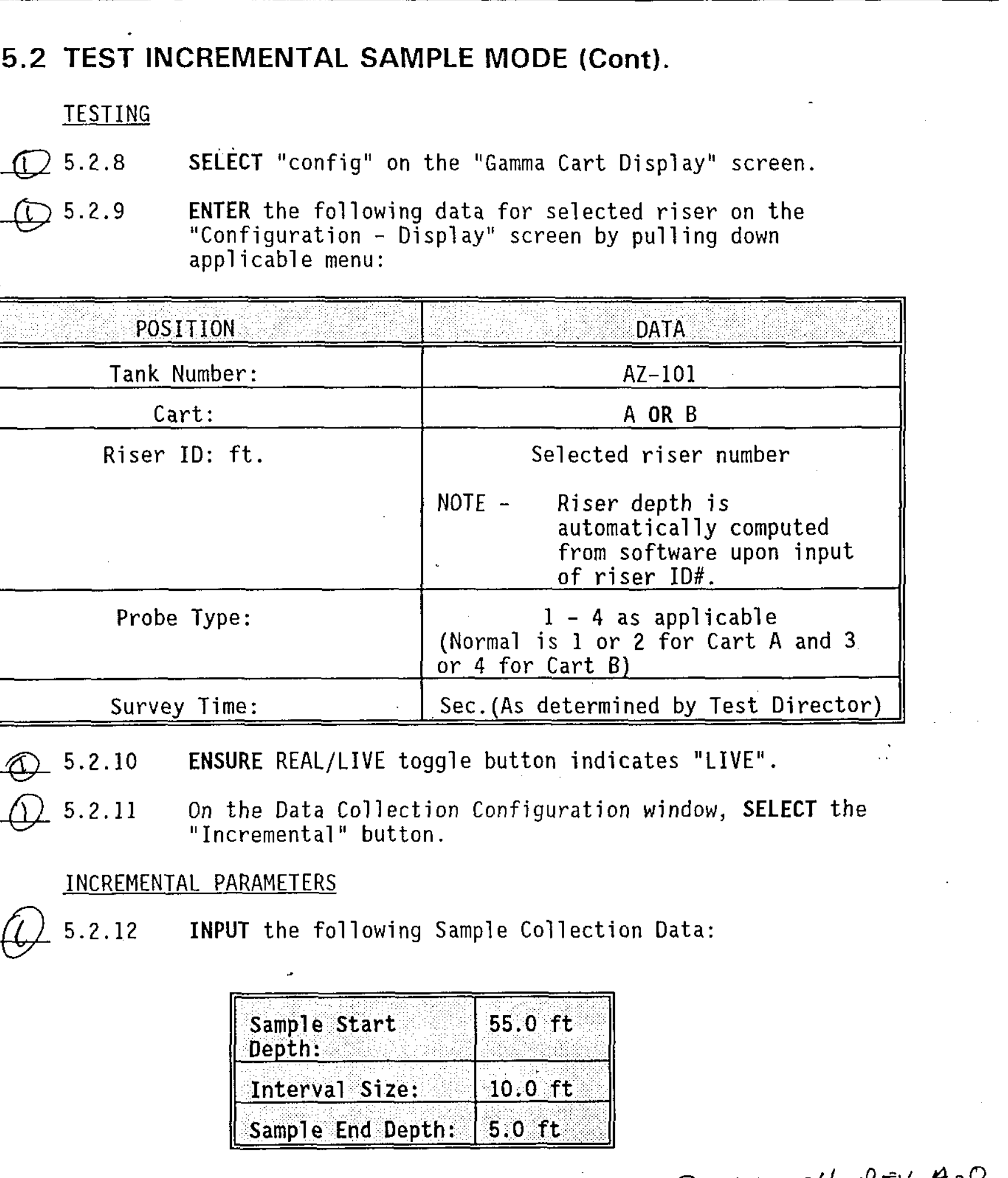

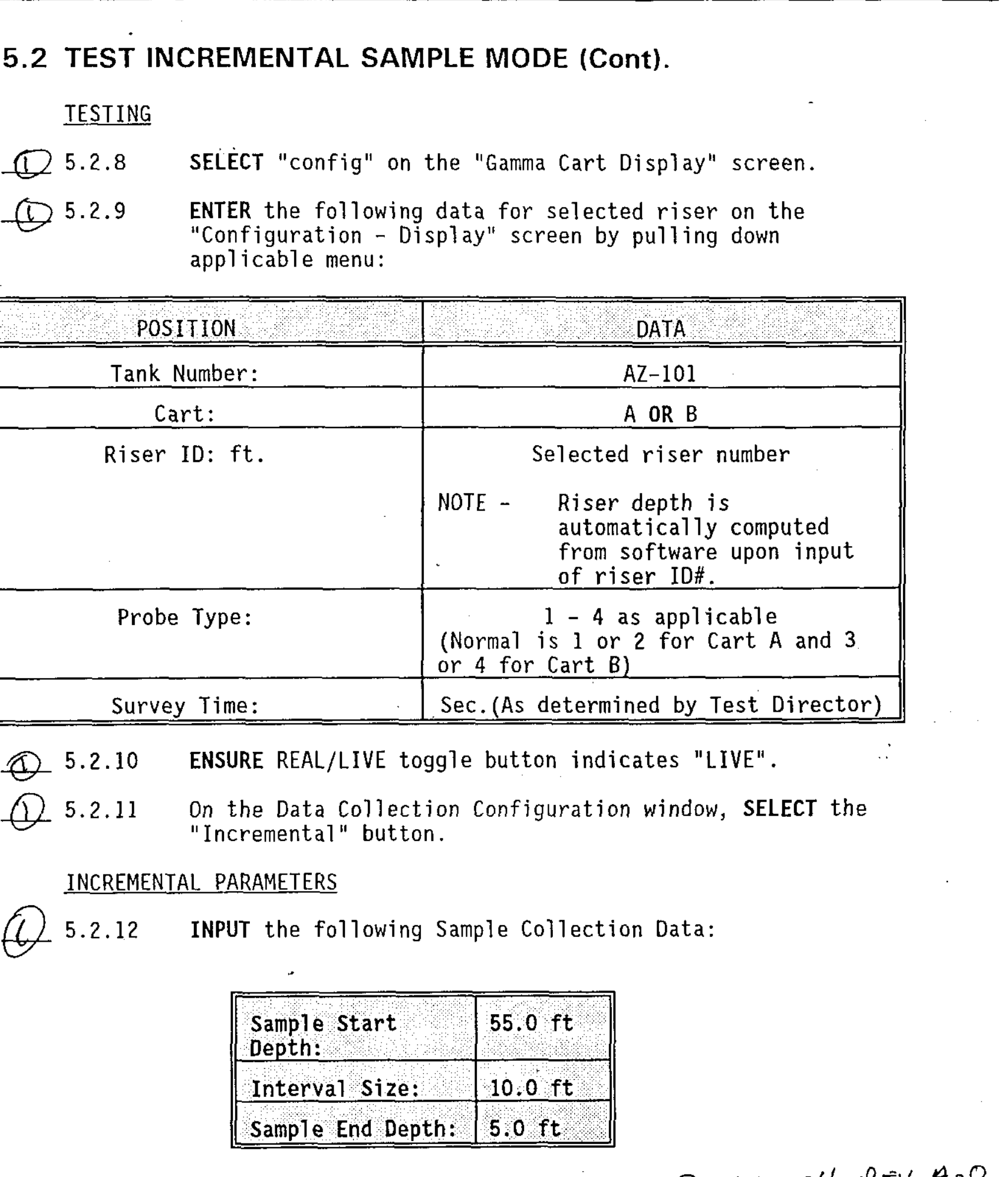

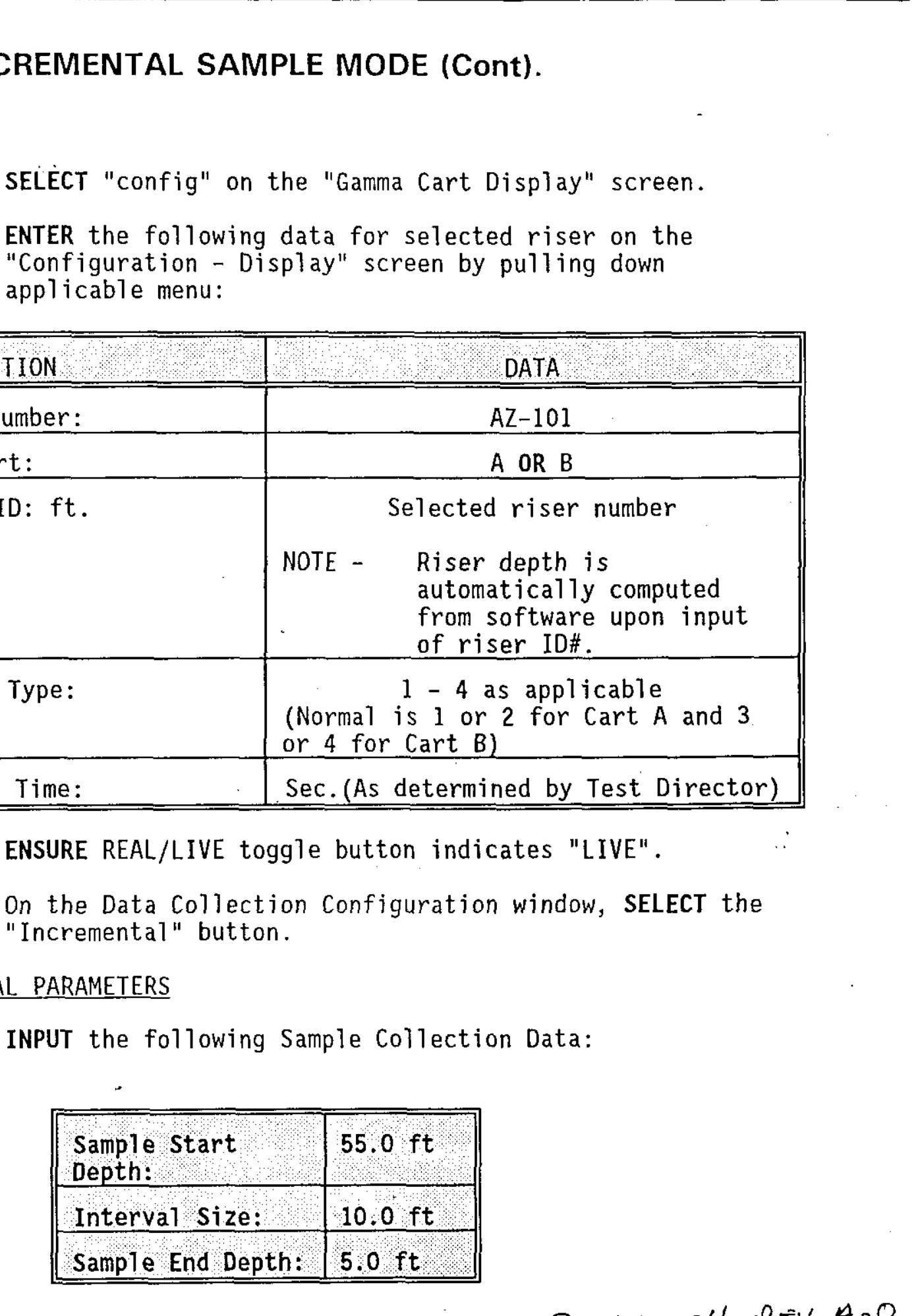

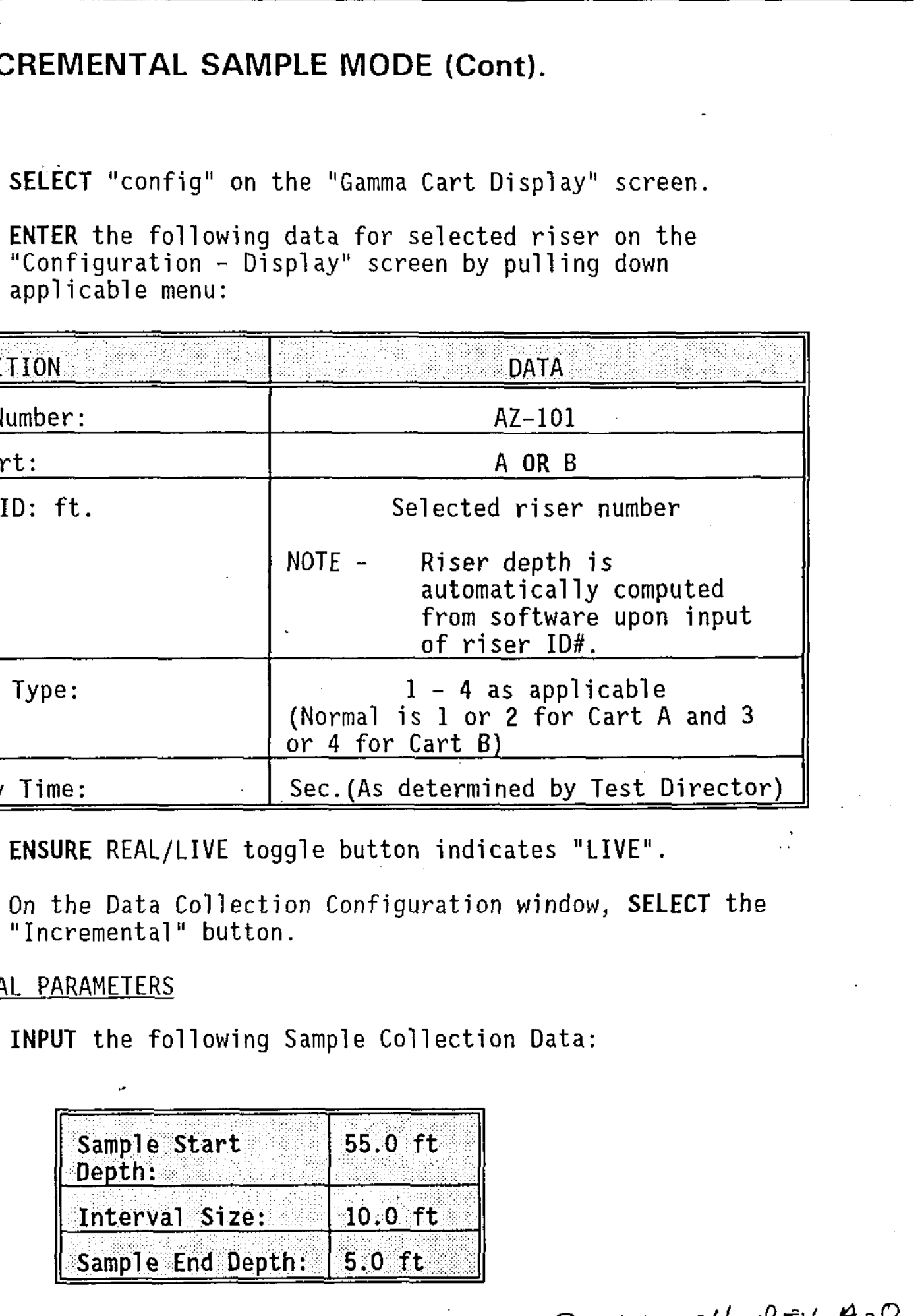

\begin{tabular}{|c|c|}
\hline POSITION & DATA \\
\hline Tank Number: & $A Z-101$ \\
\hline Cart: & A OR B \\
\hline Riser ID: ft. & $\begin{array}{l}\text { Selected riser number } \\
\text { NOTE - } \quad \text { Riser depth is } \\
\text { automatically computed } \\
\text { from software upon input } \\
\text { of riser ID\#. }\end{array}$ \\
\hline Probe Type: & $\begin{array}{l}1-4 \text { as applicable } \\
\text { (Normal is } 1 \text { or } 2 \text { for Cart } A \text { and } 3 \\
\text { or } 4 \text { for Cart B) }\end{array}$ \\
\hline Survey Time: & Sec. (As determined by Test Director) \\
\hline
\end{tabular}

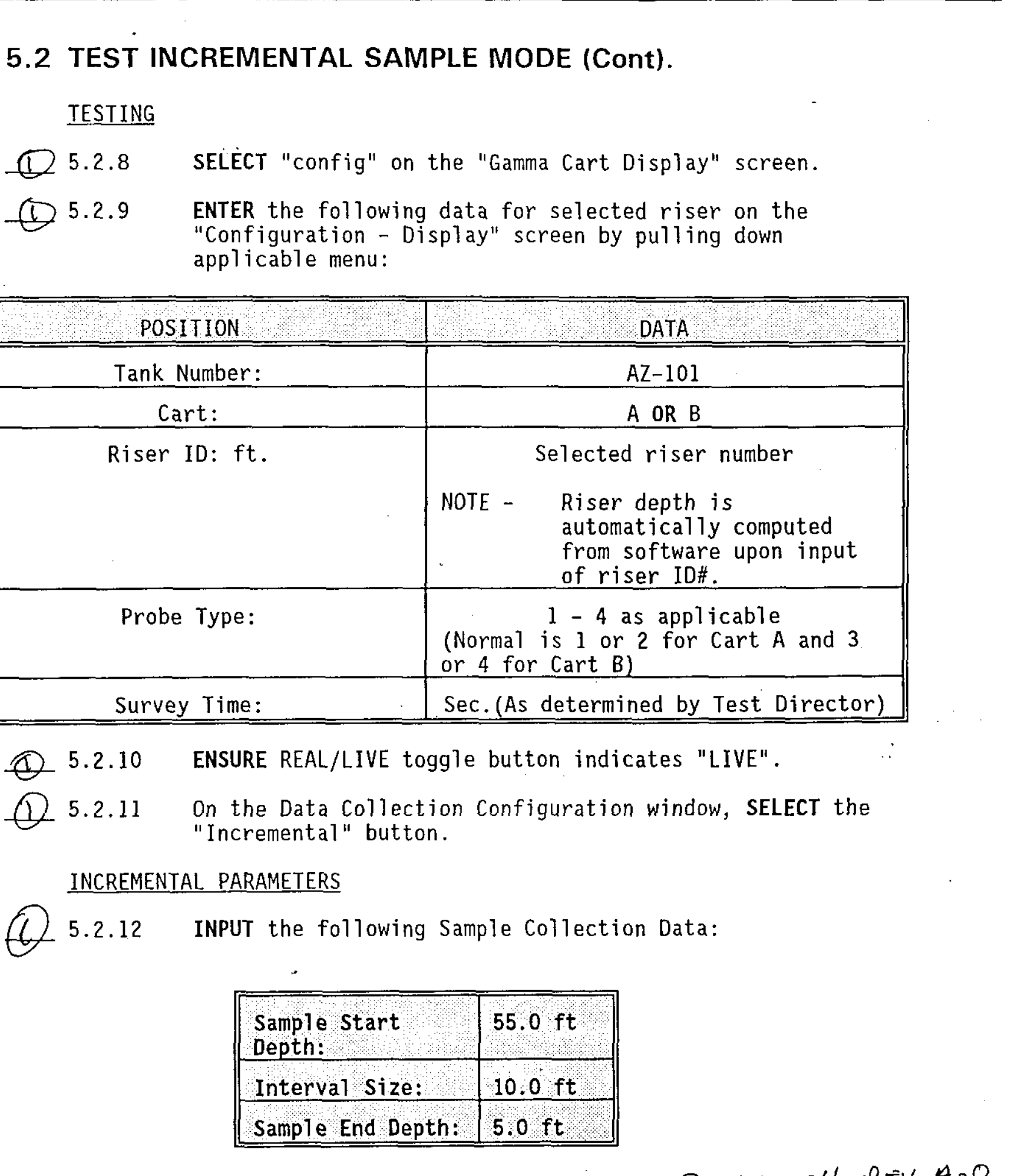

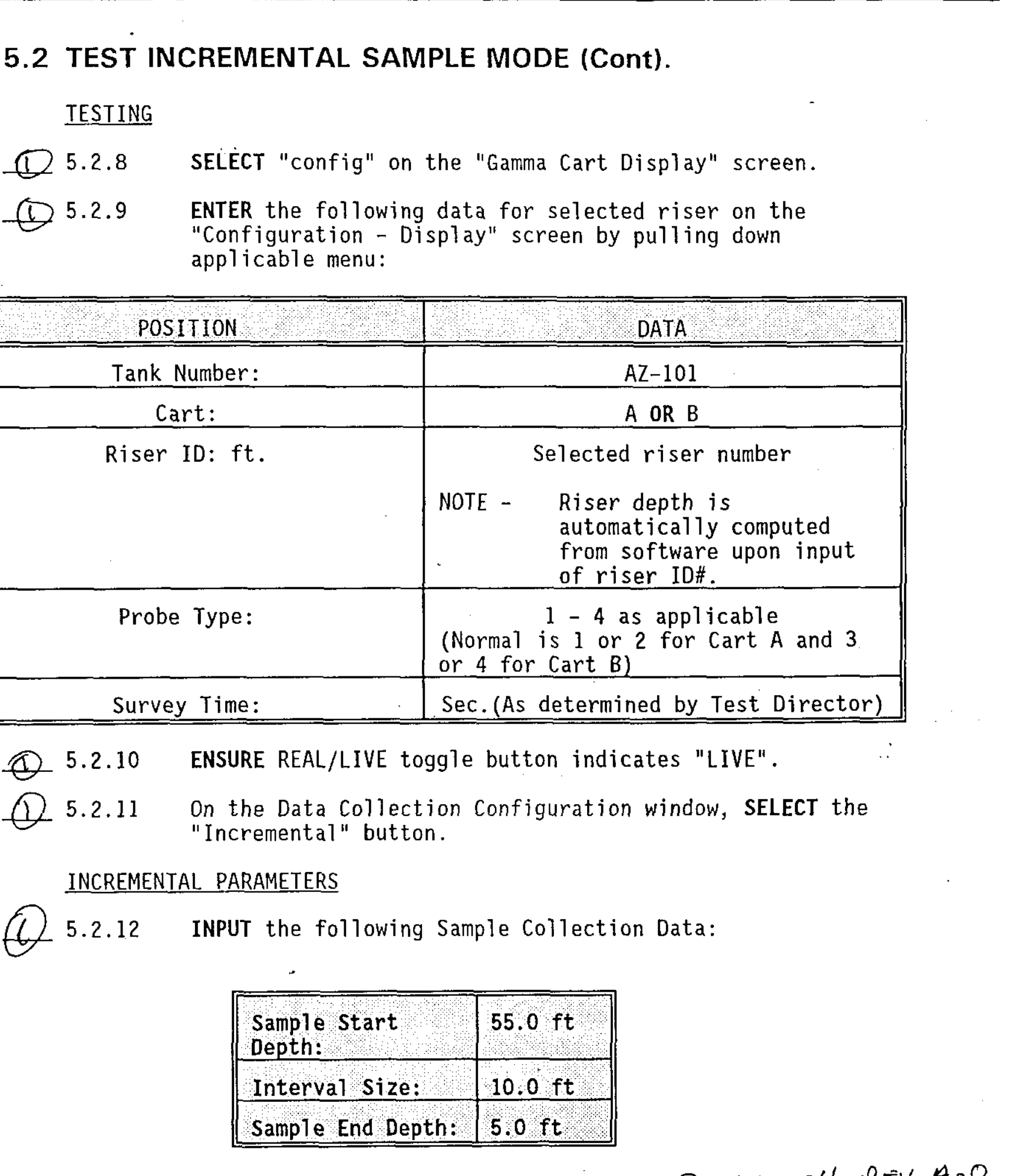

CREMENTAL SAMPLE MODE (Cont).
SELECT "config" on the "Gamma Cart Display" screen.
ENTER the following data for selected riser on the
"Configuration - Display" screen by pulling down
appl icable menu:

INCREMENTAL PARAMETERS

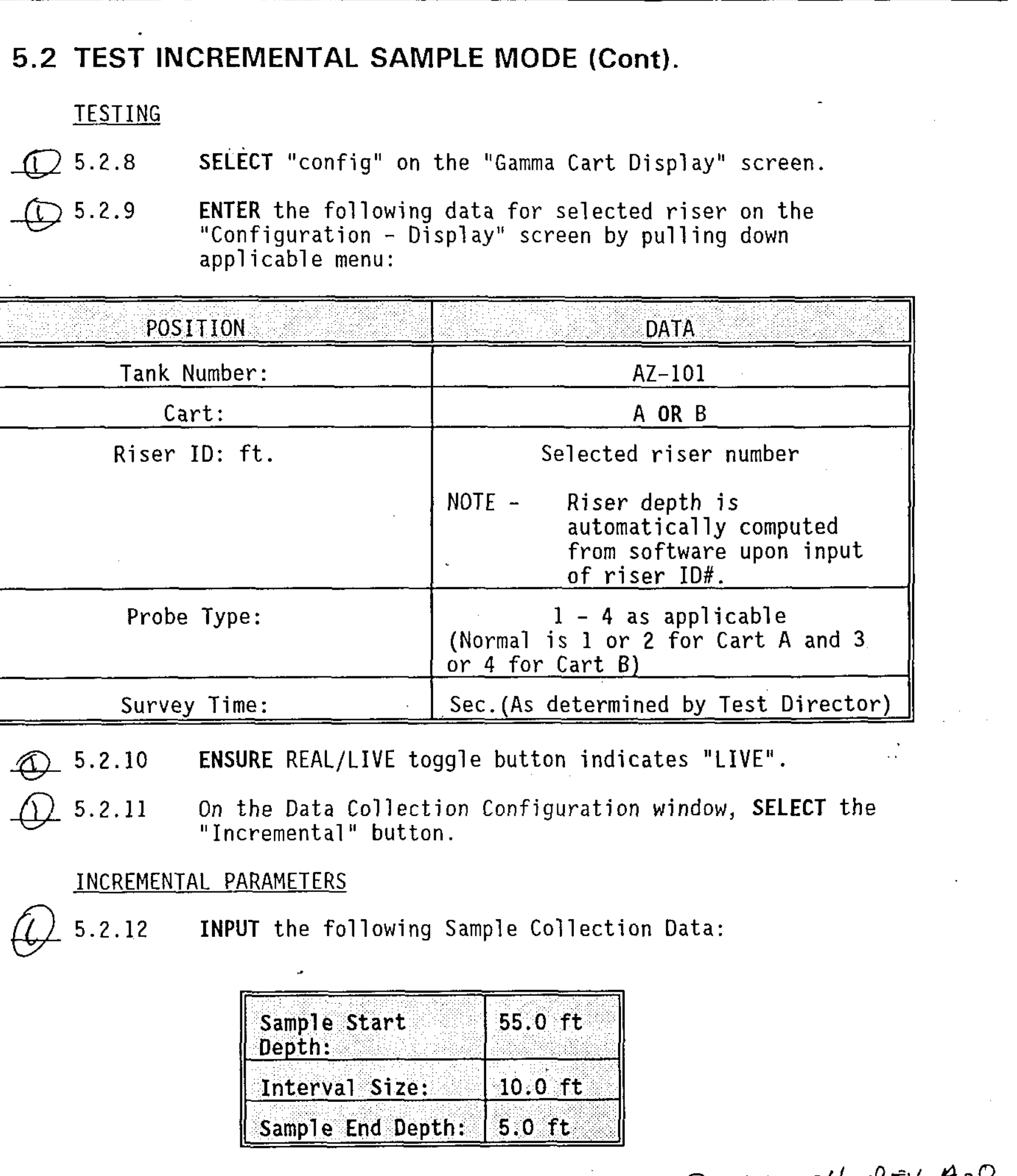

\begin{tabular}{|l|l|}
\hline Sample start & $55.0 \mathrm{ft}$ \\
Depth: & \\
\hline Interval Size: & $10.0 \mathrm{ft}$ \\
\hline Samp 1e End Depth: & $5.0 \mathrm{ft}$ \\
\hline
\end{tabular}

(1) ALROASDY TESTOD PER OTP-260-004, REV. A-O SeE tost hol extry $2.29-00,2030 \mathrm{lth}$ $R \cdot$ Syetheng
$3-2-0 \infty$ 


\subsection{TEST INCREMENTAL SAMPLE MODE (Cont).}

\section{(1) 5.2.13 CLICK ON "SAVE". \\ (1) 5.2 .14 CLICK ON "EXIT".}

NOTE - . Test Engineer may manipulate parameters at any time during the following steps as necessary to ensure data retrieval and system configuration, with concurrence of Test Director.

- After the following step, the program should automatically run.
(1)
5.2 .15
CLICK ON "Start" button.
5.2 .16
CLICK ON "EMERGENCY STOP" button on computer screen.
5.2.17. VERIFY System stopped.

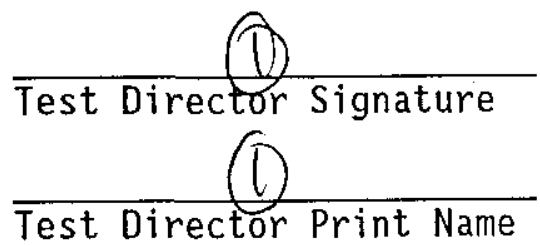

(1)

5.2 .18

CLICK ON "EMERGENCY STOP" again to RESET the emergency stop button on computer screen.

CLICK ON "ZERO" on display screen.

ENSURE GAMMA PROBE begins to RAISE.

CLICK ON "STOP" button on display screen.

(i) ALkOMDP TRSTED PER OTP-260-0OY, REV Al SEE. TEST $\angle 06$ EWTRY 2-29.00, 2030 HRS 
RPP-6104 RP

WORKING COPY

Printed on. Mar $1,00.12 .39 \mathrm{pm}$

5.2 TEST INCREMENTAL SAMPLE MODE (Cont).

(1) 5.2 .22 VERIFY system stopped.
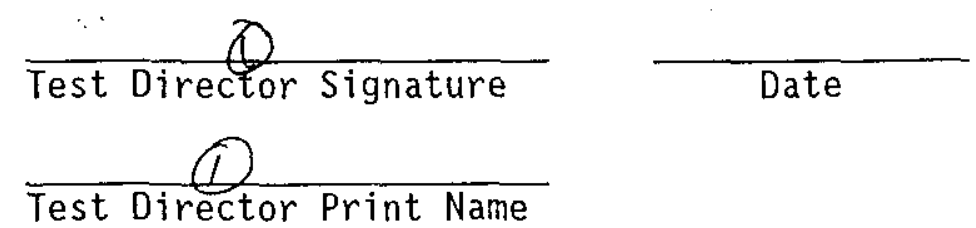

(1) 5.2.23 CLICK ON "ZERO" again on display screen.

(D) 5.2.24 ENSURE GAMMA PROBE begins to RAISE.

(1) 5.2.25 When probe and system zeros, CLICK ON "START" on display screen.

(1) 5.2.26 VERIFY system resumed program.

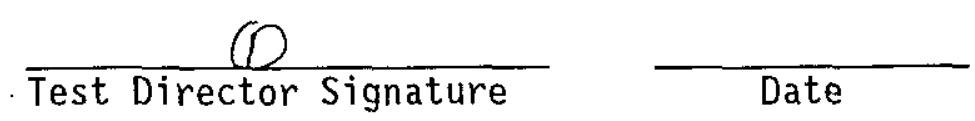

(1)

Test Director Print Name

(1) 5.2.27 CLICK ON "STOP" button on computer screen.

(1) 5.2 .28 VERIFY system stopped.

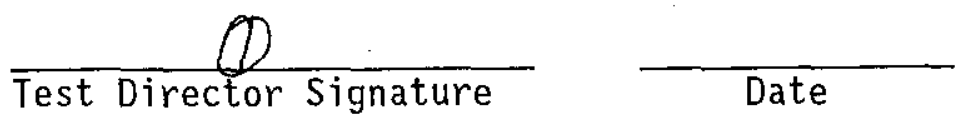

Test Director Signature Date

(1)

Test Director Print Name

(1) 5.2.29 CLICK ON "ZERO" on display screen.

(1) 5.2.30 When probe and system zeros, CLICK ON "START" on display screen.

(1) 5.2 .31 VERIFY system resumed program.

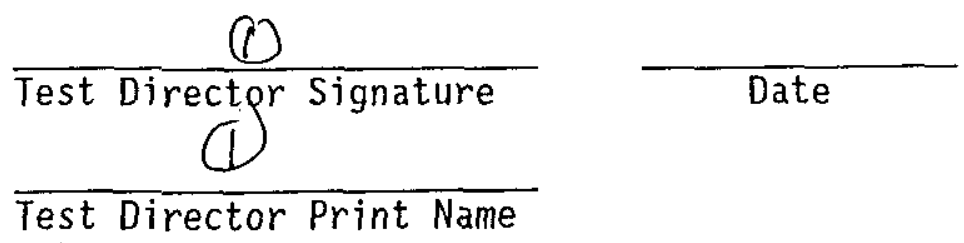
(1) already tested on OTP-320-004 Rev A-O

Rusutionif 3/2/00

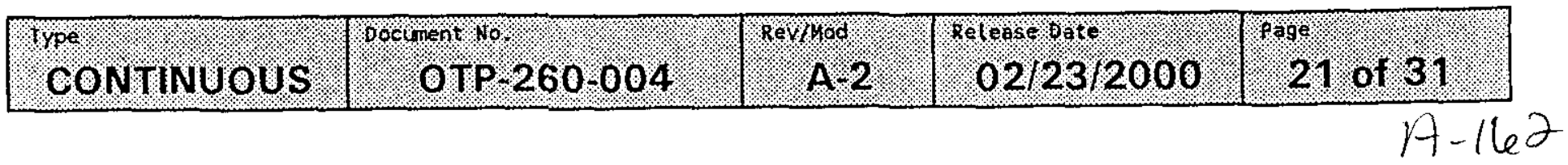




\subsection{TEST INCREMENTAL SAMPLE MODE (Cont).}

(1) 5.2.32 Test Engineer ENSURE data is received, AND both hard-copy and electronic files can be retrieved.

(1) 5.2.33 VERIFY system automatically ZEROs and data is collected at zero position.

$\frac{Q}{\text { Test Director Signature }}$
$\frac{(1)}{\text { Test Director Print Name }}$

NOTE - The steps in section 5.1, applicable to the Emergency stop, need not be repeated if completed for an individual GAMMA CART. The Emergency stop on BOTH GAMMA CART A and B, need to be tested only once.

NOTE - It is NOT necessary to do ALL risers in one procedure. Test Director is responsible for ensuring ALL risers have been profiled by one AND/OR the other GAMMA CART(S).

5.2.34 REPEAT applicable SETUP Steps in section 5.1 AND Incremental testing steps 5.2.1 - 5.2.15 AND Steps 5.2.32 and 5.2.33 for each of the following risers and depths per Test Director's direction.

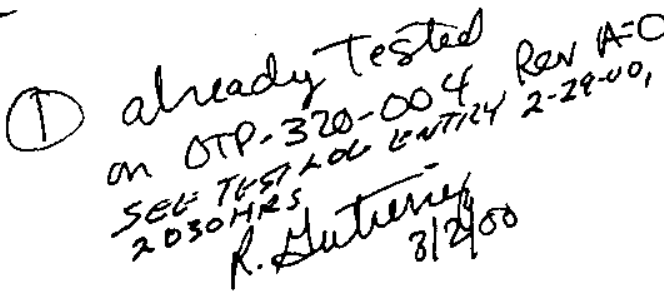

TABLE I

\begin{tabular}{|c|l|}
\hline RISER & $\begin{array}{l}\text { Depth } \\
\text { inches }(\mathrm{ft})\end{array}$ \\
\hline $14 \mathrm{~A}$ & $660(55.0)$ \\
$14 \mathrm{C}$ & $660(55.0)$ \\
\hline $14 \mathrm{D}$ & $660(55.0)$ \\
\hline $14 \mathrm{~F}$ & $660(55.0)$ \\
\hline $14 \mathrm{G}$ & $660(55.0)$ \\
\hline $14 \mathrm{~B}$ & $660(55.0)$ \\
\hline $14 \mathrm{E}$ & $660(55.0)$ \\
\hline $15 \mathrm{I}$ & $684(57.0)$ \\
\hline $15 \mathrm{C}$ & $684(57.0)$ \\
\hline $15 \mathrm{E}$ & $684(57.0)$ \\
\hline $15 \mathrm{~B}$ & $684(57.0)$ \\
\hline $15 \mathrm{~F}$ & $684(57.0)$ \\
\hline
\end{tabular}


5.2 INCREMENTAL SAMPLE MODE (Cont).

NOTE - In the following Table, Test Director N/A blocks that are tested with a different GAMMA CART.

(1) 5.2.35 VERIFY the applicable riser in step 5.2 .34 has been tested.

TABLE II

\begin{tabular}{||l|l||}
\hline RISER & TEST DIRECTOR SIGNATURE \\
\hline $14 \mathrm{~A}$ & \\
\hline $14 \mathrm{C}$ & \\
\hline $14 \mathrm{D}$ & \\
\hline $14 \mathrm{~F}$ & \\
\hline $14 \mathrm{G}$ & \\
\hline $14 \mathrm{~B}$ & \\
\hline $14 \mathrm{E}$ & \\
\hline $15 \mathrm{I}$ & \\
\hline $15 \mathrm{C}$ & \\
\hline $15 \mathrm{E}$ & \\
\hline $15 \mathrm{~B}$ & \\
\hline $15 \mathrm{~F}$ & \\
\hline
\end{tabular}

(1) 5.2.36 VERIFY by signing below section 5.2 is complete.

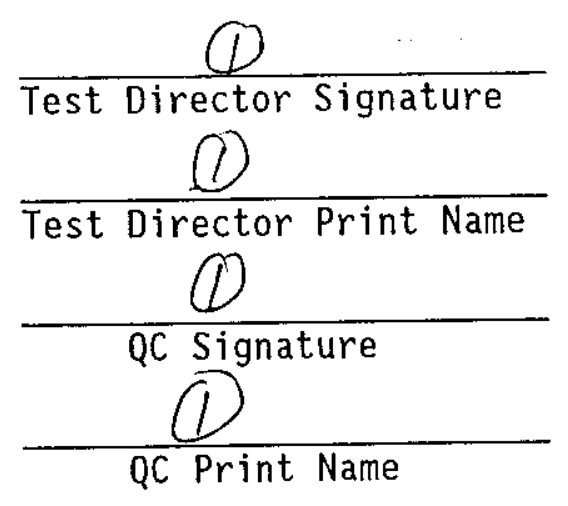

(1) alveady tested on OTP- $320-004$ hev A-O

$$
\text { R. Hetieng 3/2/00 }
$$




\subsection{TEST USER DEFINED MODE}

$\checkmark$ 5.3.1 ENSURE applicable SETUP Steps in section 5.1 are completed.

CART CONTROL SCREEN

$\checkmark$ 5.3.2 On the Gamma Cart Control, CLICK ON the "Config." button.

5.3.3 INPUT the following data:

\begin{tabular}{|c|c|}
\hline POSITION & DATA \\
\hline Tank Number: & $A Z-101$ \\
\hline Cart: & A OR B \\
\hline Riser ID: ft. & $\begin{array}{l}\text { Selected riser number } \\
\text { NOTE - } \quad \text { Riser depth is } \\
\text { automatically computed } \\
\text { from software upon input } \\
\text { of riser. ID\#. }\end{array}$ \\
\hline Probe Type: & $\begin{array}{l}1-4 \text { as applicable } \\
\text { (Normal is } 1 \text { or } 2 \text { for Cart } A \text { and } 3 \\
\text { or } 4 \text { for Cart B) }\end{array}$ \\
\hline Survey Time: & Sec. (As determined by Test Director) \\
\hline
\end{tabular}

\section{USER DEFINED PARAMETERS}

5.3.4 CLICK ON "USER DEFINED".

5.3.5 ENTER depths desired for testing per Test Engineer Direction.

5.3 .6 CLICK ON "SAVE" on display screen.

$\simeq \quad 5.3 .7$ CLICK ON "EXIT". 


\subsection{TEST USER DEFINED MODE (Cont).}

NOTE - Test Engineer may manipulate parameters at any time during the following steps as necessary to ensure data retrieval and system configuration, with concurrence of Test Director.

- After the following step, the program should automatically run.

- The "EMERGENCY STOP" may be used to stop at any time during the next step if unit fails to stop at limit switch. The "RESET" button will need to be pushed to resume the program.
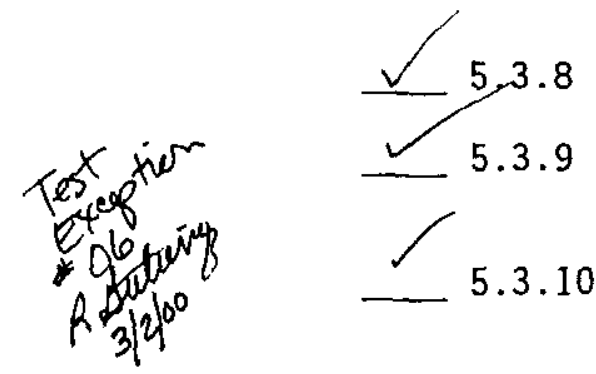

CLICK oN Start button.

Test Engineer ENSURE data is received, AND both hard-copy and electronic files can be retrieved.

VERIFY system automatically ZEROs and data is collected at zero position.
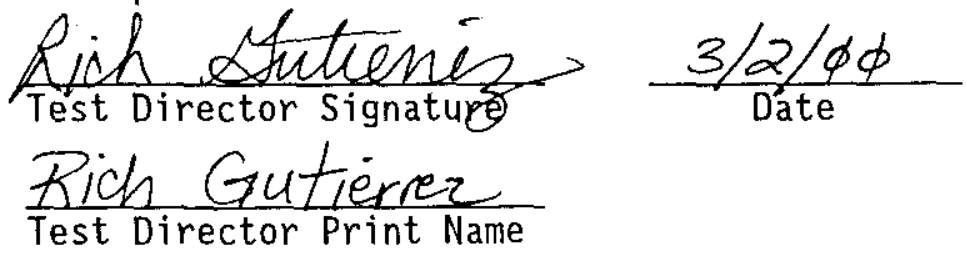


\subsection{TEST USER DEFINED MODE (Cont).}

5.3.11 CLICK ON "LOGOUT" on display screen.

5.3.12 REMOVE Probe, riser extension tool, and associated equipment AND

STORE per Test Director direction.

$$
\text { OR }
$$

CONTINUE in this procedure.

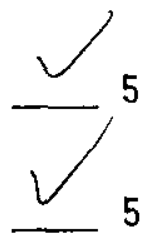

5.3.13 REPEAT the steps in this section (5.3) as directed for any risers as directed by Test Director.

5.3.14 VERIFY by signing below section 5.3 is complete.

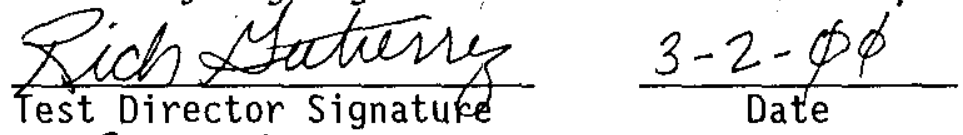

$\frac{\text { Dich Gutiener }}{\text { Test Direetor Print Name }}$

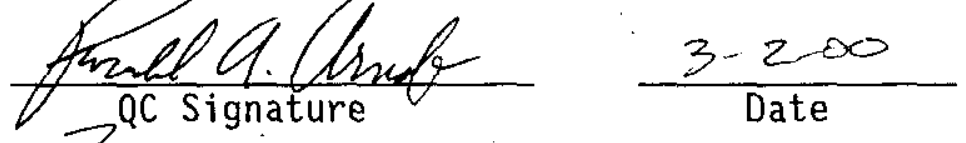

$\frac{\text { Lowase A. AhosT }}{\text { QC Print Name }}$ 
RPP-6104 RO

RISER 15I

GAMMA CART - B 


\section{1-AZ GAMINA CART OPERATIONAL TEST PROCEDURE}

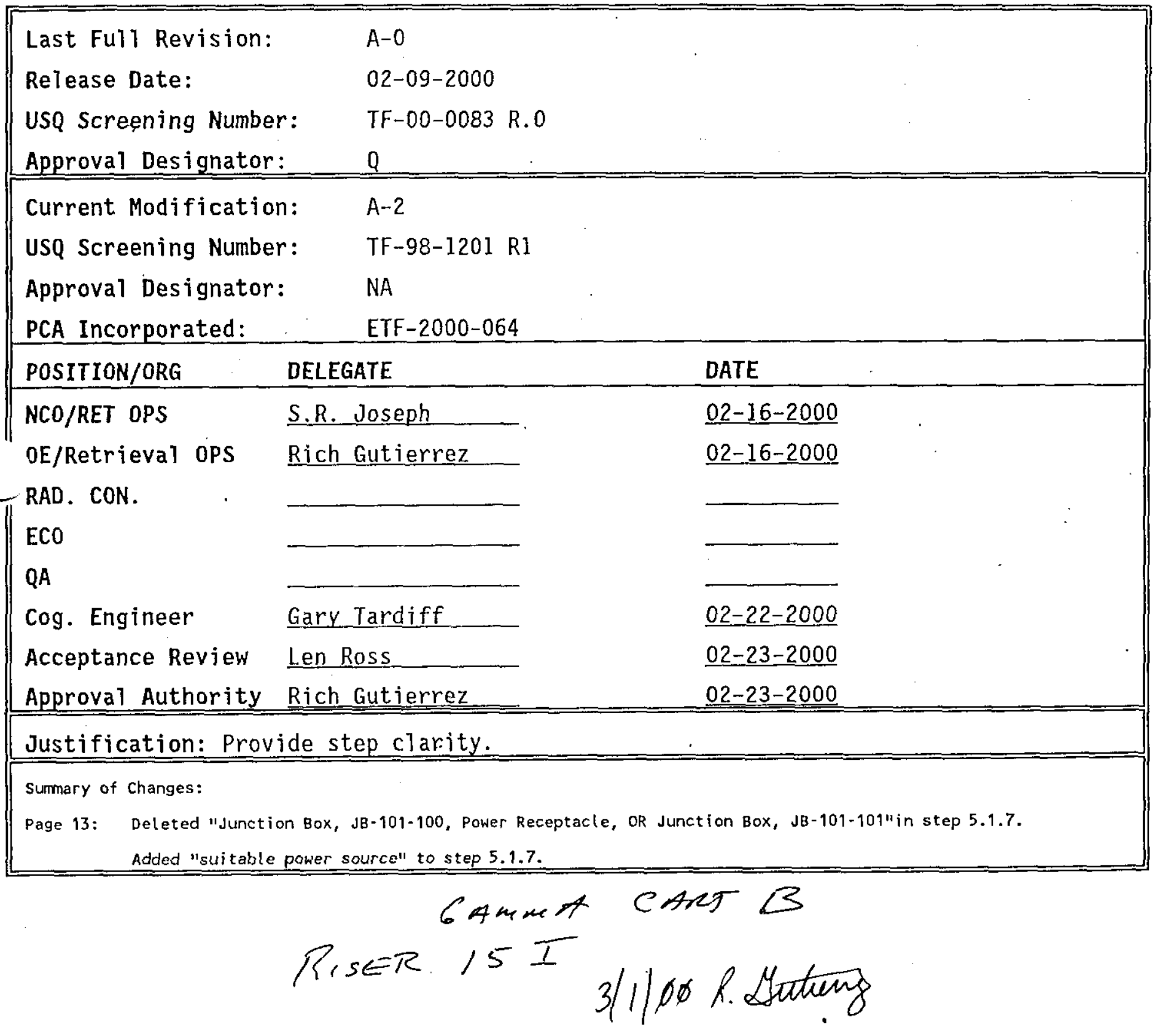




\subsection{PREREQUISITES}

\subsection{SPECIAL TOOLS, EOUIPMENT, AND SUPPLIES}

The following supplies may be needed to perform this procedure:

- Riser Swabbing equipment

- Riser extension tool

\subsection{PERFORMANCE DOCUMENTS}

The following procedures may be needed to perform this procedure:

- T0-040-333 LIQUID OBSERVATION WELL (LOW) SURVEILLANCE VAN STARTUP AND OPERATION PROCEDURE

\subsection{CONDITIONS AND ACTIONS}

NOTE - All signators on this procedure shall document their signature on Procedure Signature Sheet.

4.3.1 All pre-testing and inspection of the system or portions of the system to be tested has been completed.

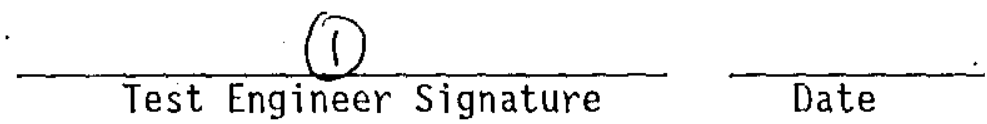

4.3.2 A pre-job briefing has been held. and all participants have been thoroughly briefed on job safety, hazards, and their responsibilities before performing this ATP.

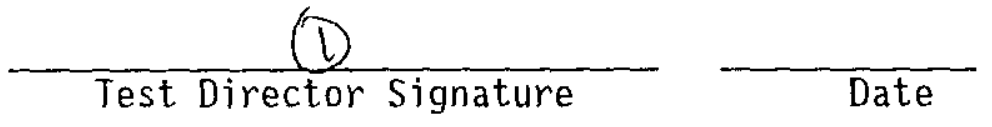

4.3.3 Test Director VERIFY section 4.3 has been COMPLETED.

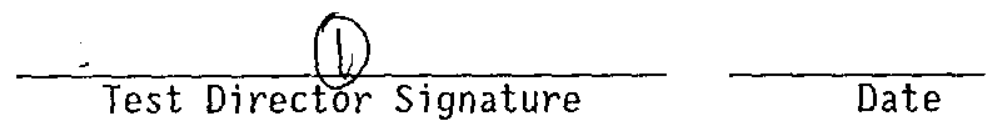

(1) ALAEADY TESTEP PERL OTP-260-DOY, REU. A.O

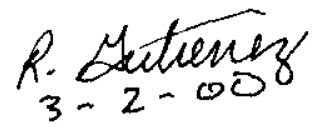




\subsection{PROCEDURE}

5.1 SETUP

NOTE - This procedure may be repeated for either GAMMA CART A or GAMMA CART B as applicable. N/A may be entered in blocks or steps per Test Director as applicable.

5.1.1 RECORD GAMMA CART CPU number for the system being tested. GAMMA CART IDENTIFIER \# $\frac{\text { WST-RY } 403}{\text { CPU Number }}$

5.1.2 PERFORM cleanliness check in applicable riser listed on TABLE II, per section 5.10 in procedure T0-040-333 latest rev, prior to mounting riser extension tool.

ENSURE GAMMA CART riser extension tool is mounted on the applicable riser.

5.1.4 ENSURE GAMMA CART is placed in line with riser extension
tool to facilitate installation of probe and cables.

5.1.4 ENSURE GAMMA CART is placed in line with riser exten
tool to facilitate installation of probe and cables.

5.1.5 CHECK route to riser for obstacles and clearances.

5.1.6 LEVEL cart using jacks.

5.1.7 CONNECT gamma cart power cables, as follows:

- One end to gamma cart power receptacle

- Other end to sultabre oover source-Junction Box$J B$ - 101 100, power Receptacle, on Junction Box; HB-101-101

5.1.8 CONNECT gamma cart communications cable, as follows:

- Oné end to gamma cart communications receptacle

- $\quad$ Other end to Tank 241-AZ-101 Gamma Cart A AND/OR B Data Collection Subsystem communications receptacle

PLACE Gamma Cart "RAISE OFF LOWER" switch in the LOWER position.

5.1.10 CHECK that detector probe cable is resting in the Gamma Cart boom cable reel. 


\subsection{SETUP (Cont).}

\section{CAUTION}

If sufficient tension is NOT held on the detector probe cable as the cable is being let out, the cable could become entangled.

NOTE - Step 5.1 .11 and 5.1 .12 require two operators to perform continuous action until step 5.1 .12 is complete.

$\checkmark$ 5.1.11 HOLD tension on the detector probe cable until step 5.1 .12 is completed.

5.1.12 PRESS AND HOLD "RESET" button until enough detector probe cable is let-out that will allow placement of the detector cable through riser extension collar AND into riser drywe 17, AND

RELEASE the "RESET" button.

5.1.13 INSTALL the proper detector probe on the detector probe cable.

5.1.14 ENSURE that the detector probe connections are correct and tight. AND

INSERT probe into riser extension tool.

5.1.15 ENSURE limit switch cable is connected from limit switch on riser extension tool, to the connection point on the front of the GAMMA CART.

5.1.16 ENSURE the "Raise - Off - Lower" selector switch is in the "OFF" position.

W 5.1.17 ENSURE the emergency stop button is pulled out.

5.1.18 POSITION the "SPEED" control potentiometer to MIN speed (fully counter-clockwise). 


\subsection{SETUP (Cont).}

\section{CAUTION}

There is no limit switch to stop the motion. When the cable is fully unwound. The cable will rewind backwards on the reel. Damage to the cable may result.

NOTE - When the cart is first powered up, or the emergency stop button has been pushed, or power has been restored after a power failure, the cable reel will. not move up or down unti1 "RESET" button is activated.

- The "Raise-OFF-Lower" Switch is Manually controlled and is Operator Dependent.

$\sim$ 5.1.19 ENSURE LOCAL/REMOTE switch is in the "LOCAL" position.

5.1.20 ENERGIZE the Cart.

5.1 .21

SET the "SPEED" potentiometer to 2 on the GAMMA Cart.

5.1.22 SET the "RAISE -OFF- LOWER" switch to the "LOWER" position.

(1) 5.1.23 PUSH "EMERGENCY STOP" button on GAMMA CART.

(1) 5.1 .24 VERIFY the system has stopped.
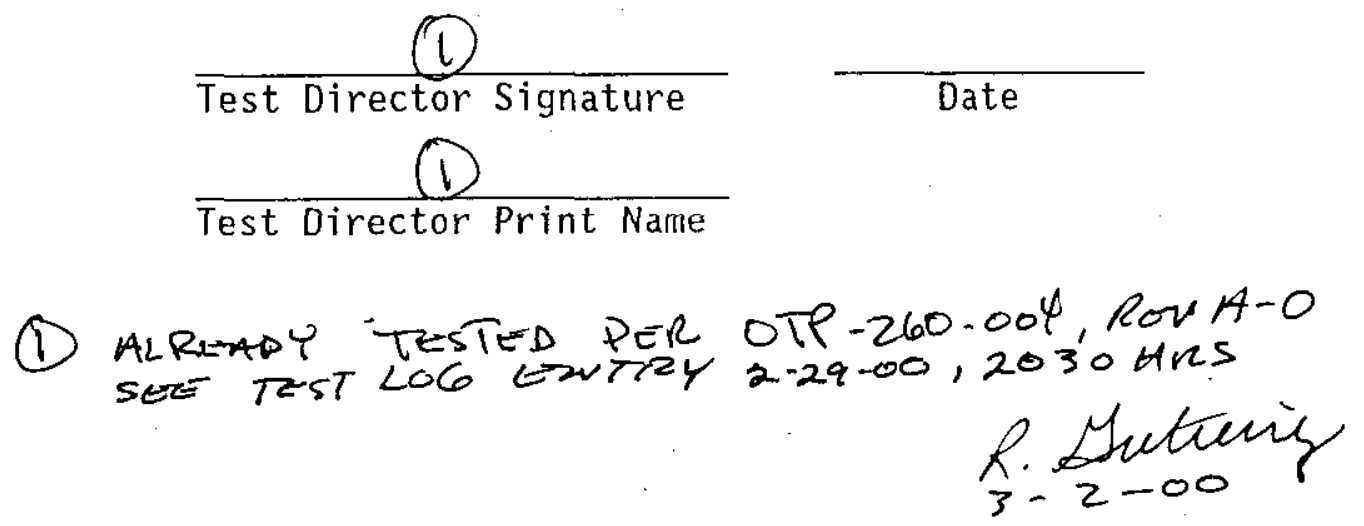


\subsection{SETUP (Cont).}

(1) 5.1 .25 SET the "RAISE-OFF-LOWER" switch to the "RAISE" position.

(1) 5.1 .26 PULi "EMERGENCY STOP" out on GAMMA CART.

(1) 5.1.27 PUSH the "RESET" button on GAMMA CART to resume.

(1) 5.1.28 ENSURE limit switch activates when probe returns to the zero position.

(1) 5.1.29 SET the "RAISE-OFF-LOWER" switch to the "OFF" position.

(1) 5.1 .30 SET "SPEED" potentiometer to MIN.

(1) 5.1.31 POSITION The "LOCAL REMOTE" switch to "REMOTE".

(1) 5.1 .32 VERIFY by signing below section 5.1 is complete.

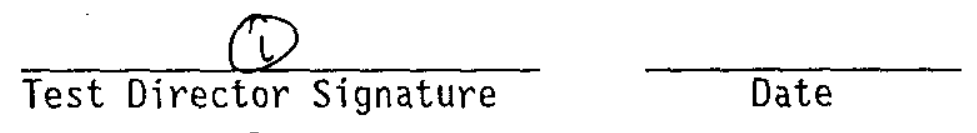

(1)

Test Director Print Name

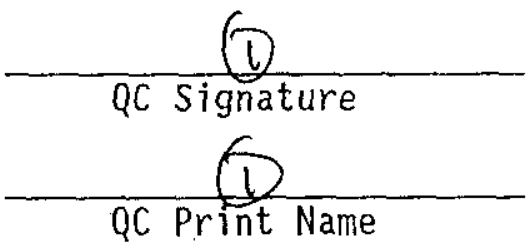

Date

(1) ALRaTD TESTED PER OTP.260.004, REV. A-O SEE TEST LOG ENTI2Y 2-2q00, $2030 \mathrm{H} / 2 \mathrm{~S}$ 


\subsection{TEST INCREMENTAL SAMPLE MODE}

SETUP

NOTE - AlT'Steps in this section apply to either cart, except in those steps where the specific cart is indicated.

\section{INSTRUMENT CHECK}

5.2.1 IF the pushbutton for Tank 241-AZ-101 Gamma Cart A AND/OR

$B$ Data Collection System Central Processing Unit (CPU), AND/OR associated MONITOR, are NOT ON, PRESS the applicable oN pushbuttons.

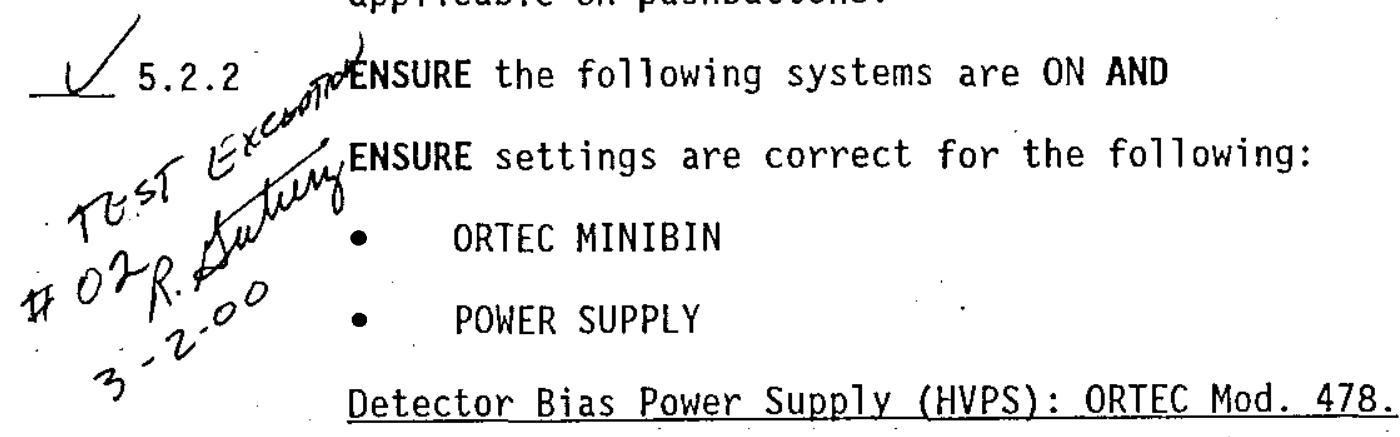

- $\mathrm{kV}: .5$

- 0 to $1000 \mathrm{~V}:(+60$ volts)

Amplifier (AMP): ORTEC Mod. 673

- COARSE GAIN: 200

- FINE GAIN: 0.680

- SHAPING TIME: Both knobs set to 2 microseconds

- PZ Adjust: Do NOT change settings (in this procedure)

- BLR: Switch in AUTO (up) position

- INPUTS: Switch in POS (up) position BNC cable on terminal (from pre amplifier)

- OUTPUTS: cable on UNIPOLAR terminat(to single channel Analyzer)

5.2.3 WHEN WINDOWS login screen appears CLICK ON "CANCEL". 


\subsection{TEST INCREMENTAL SAMPLE MODE (Cont).}

NOTE - After canceling windows login, GAMMA CART software should automatically load.

5.2.4 VERIFY "GAMMA CART SPECTRUM ANALYZER AND CONTROL SYSTEM" screen is displayed on Tank 241-AZ-101 Gamma Cart A AND/OR B Data Collection System Monitor.

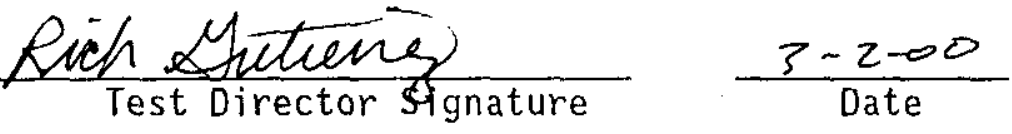

Rich Gutierres

Test Director Print Name

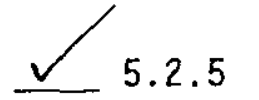

SELECT "Login" on the "GAMMA CART SPECTRUM ANALYZER AND CONTROL SYSTEM" screen.

NOTE - LOGIN passwords and information may be obtained from Test Director.

5.2.6 LOG-IN.

5.2.7 VERIFY LOCAL/REMOTE switch on display screen is in "REMOTE" pOSition.

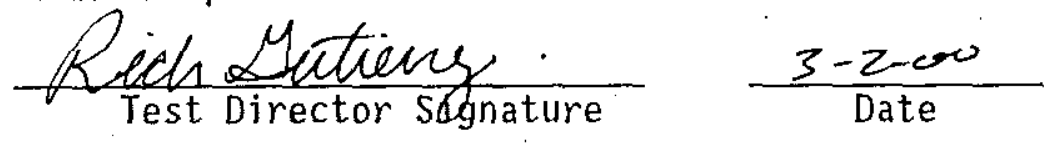

\section{Rich Gutiojrer}

Test Director Print Name 


\subsection{TEST INCREMENTAL SAMPLE MODE (Cont).}

\section{TESTING}

(1) 5.2.8 SELECT "config" on the "Gamma Cart Display" screen.

(1) 5.2.9 ENTER the following data for selected riser on the "Configuration - Display" screen by pulling down applicable menu:

\begin{tabular}{|c|c|}
\hline POSITION & DATA \\
\hline Tank Number: & $A Z-101$ \\
\hline Cart: & $A O R B$ \\
\hline Riser ID: $\mathrm{ft}$. & $\begin{array}{ll} & \text { Selected riser number } \\
\text { NOTE - } \quad & \text { Riser depth is } \\
\text { automaticaliy computed } \\
\text { from software upon input } \\
\text { of riser ID\#. }\end{array}$ \\
\hline Probe Type: & $\begin{array}{l}1-4 \text { as applicable } \\
\text { (Normal is } 1 \text { or } 2 \text { for Cart A and } 3 \text {. } \\
\text { or } 4 \text { for Cart B) }\end{array}$ \\
\hline Survey Time: & Sec. (As determined by Test Director) \\
\hline
\end{tabular}

Q 5.2.10 ENSURE REAL/LIVE toggle button indicates "LIVE".

(1) 5.2.11 On the Data Collection Configuration window, SELECT the

"Incremental" button.

INCREMENTAL PARAMETERS

(10) 5.2.12 INPUT the following Sample Collection Data:

\begin{tabular}{|l|l|}
\hline $\begin{array}{l}\text { Sample Start } \\
\text { Depth: }\end{array}$ & $55.0 \mathrm{ft}$ \\
\hline Interval Size: & $10.0 \mathrm{ft}$ \\
\hline Sample End Depth: & $5.0 \mathrm{ft}$ \\
\hline
\end{tabular}

(1) ALROADY TEST PER OTP-i60-00Y, RLO. A-O
LOC EUTRY $2-29-00,2030$ Hres Lece TE-ST LOC EuTry $2-29-00,2030$ Hreting $3-2-00$ 


\subsection{TEST INCREMENTAL SAMPLE MODE (Cont).}

Q 5.2 .13 CLICK ON "SAVE".

(1) 5.2 .14 CLICK ON "EXIT".

NOTE - . Test Engineer may manipulate parameters at any time during the following steps as necessary to ensure data retrieval and system configuration, with concurrence of Test Director.

- After the following step, the program should automatically run.

(1) 5.2 .15 CLICK ON "Start" button.

(1) 5.2.16 CLICK ON "EMERGENCY STOP" button on computer screen.

(D) 5.2.17. VERIFY System stopped.

Test Director Signature

(1) 5.2.18 CLICK ON "EMERGENCY STOP" again to RESET the emergency stop button on computer screen.

(2) 5.2 .19 CLICK ON "ZERO" on display screen.

D 5.2.20 ENSURE GAMMA PROBE begins to RAISE.

(1) 5.2.21 CLICK ON "STOP" button on display screen.

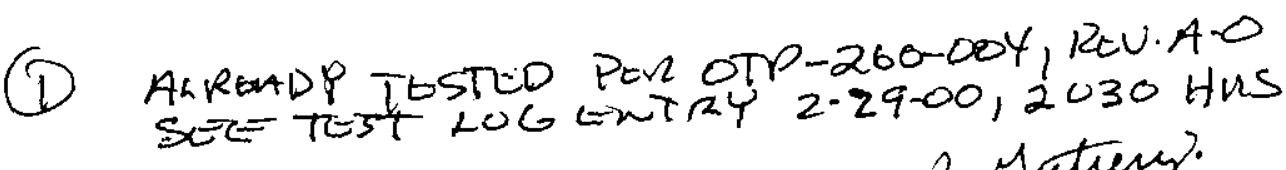

$$
\begin{aligned}
& \text { R. Statien. } \\
& 3-2 \text {-0o }
\end{aligned}
$$


RPP-6104 RC

WORKING COPY

Printed on: Mar 1 , 00.12 .39 . pro

5.2 TEST INCREMENTAL SAMPLE MODE (Cont).

(1) 5.2 .22 VERIFY System stopped.

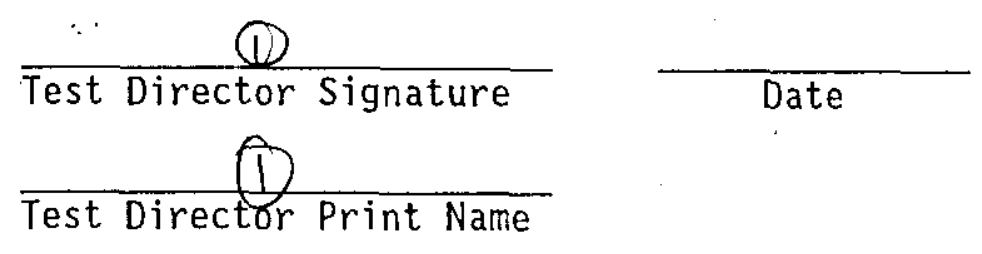

(1) 5.2.23 CLICK ON "ZERO" again on display screen.

(1) 5.2.24 ENSURE GAMMA PROBE begins to RAISE.

(1) 5.2 .25 When probe and system zeros, CLICK ON "START" on display screen.

(1) 5.2 .26 VERIFY system resumed program.

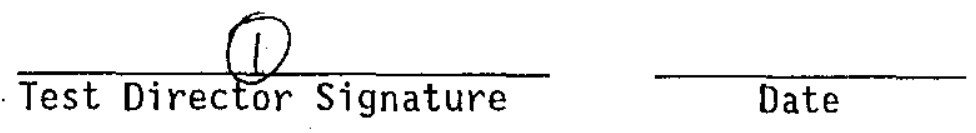

(1) 5.2.27 CLICK ON "STOP" button on computer screen.

(1) 5.2 .28 VERIFY System stopped.

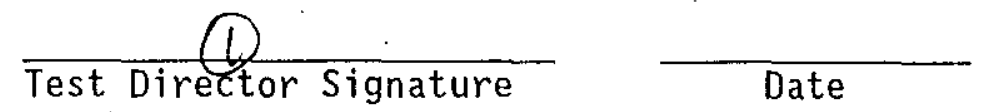

(1) 5.2.29 CLICK ON "ZERO" on display screen.

(1) 5.2.30 When probe and system zeros, CLICK ON "START" on display screen.

(1) 5.2 .31 VERIFY system resumed program.

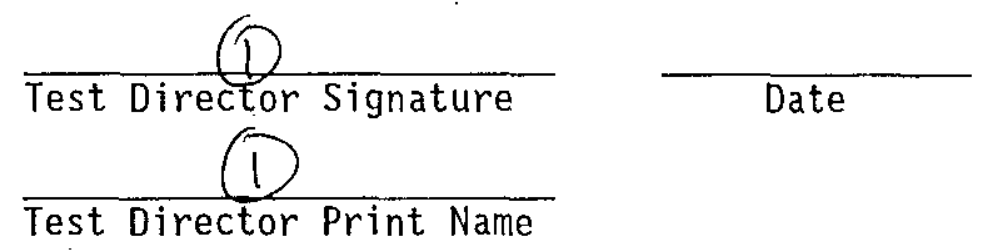

(1) ALREADY TESTED PER OTP. $260-004$, REV. ADO SEE TEST LOG ENTIRU 2-2900, 2030 HRS

3-2-00 R. Shouting

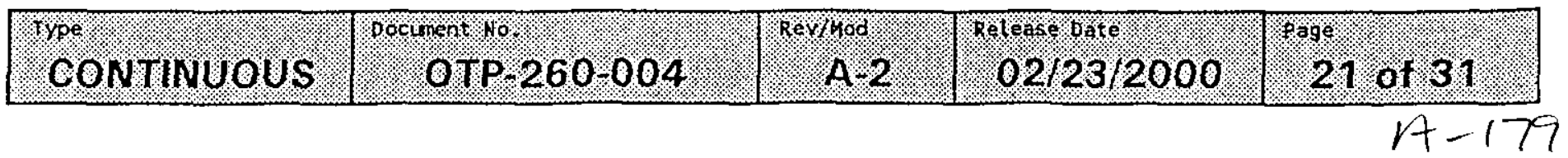




\subsection{TEST INCREMENTAL SAMPLE MODE (Cont).}

(1) 5.2.32 Test Engineer ENSURE data is received, AND both hard-copy and electronic files can be retrieved.

D 5.2 .33 VERIFY system automatically ZEROs and data is collected at zero position.

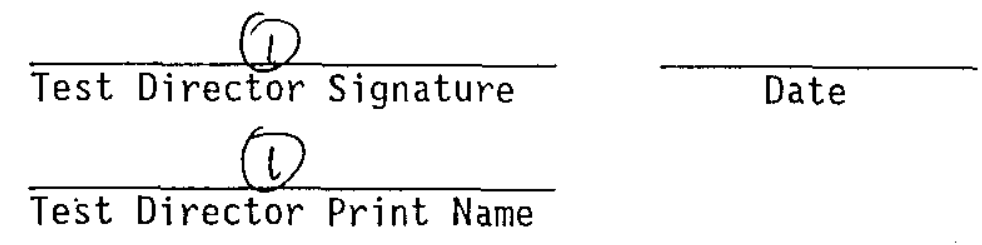

NOTE - The steps in section 5.1, applicable to the Emergency stop, need not be repeated if completed for an individual GAMMA CART. The Emergency stop on BOTH GAMMA CART A and B, need to be tested only once.

NOTE - It is NOT necessary to do ALL risers in one procedure. Test Director is responsible for ensuring $A L L$ risers have been profiled by one AND/OR the other GAMMA CART(S).

REPEAT applicable SETUP Steps in section 5.1 AND Incremental testing steps 5.2.1 - 5.2.15 AND Steps 5.2.32 and 5.2.33 for each of the following risers and depths per Test Director's direction.

TABLE I

(1) ALRGHDY TESTEO PER OTP. $260-004$ RGV. A-O SEE TZST LOG ENTKY SEE T2ST 206 1.2030 tres R. Sutieng $3-2.00$

\begin{tabular}{|c|c|}
\hline RISER & $\begin{array}{l}\text { Depth } \\
\text { inches }(\mathrm{ft})\end{array}$ \\
\hline $14 \mathrm{~A}$ & $660(55.0)$ \\
\hline $14 \mathrm{C}$ & $660(55,0)$ \\
\hline $14 \mathrm{D}$ & $660(55.0)$ \\
\hline $14 \mathrm{~F}$ & $660(55.0)$ \\
\hline $14 \mathrm{G}$ & $660(55.0)$ \\
\hline $14 \mathrm{~B}$ & $660(55.0)$ \\
\hline $14 \mathrm{E}$ & $660(55,0)$ \\
\hline $15 \mathrm{I}$ & $684(57,0)$ \\
\hline $15 \mathrm{C}$ & $684(57.0)$ \\
\hline $15 \mathrm{E}$ & $684(57.0)$ \\
\hline $15 B$ & $684(57.0)$ \\
\hline $15 \mathrm{~F}$ & $684(57.0)$ \\
\hline
\end{tabular}




\subsection{INCREMENTAL SAMPLE MODE (Cont).}

NOTE -- In the following Table, Test Director N/A blocks that are teșted with a different GAMMA CART.

(1) 5.2.35 VERIFY the applicable riser in step 5.2.34 has been tested.

TABLE II

\begin{tabular}{|c|c|}
\hline RISER & TEST DIRECTOR SIGNATURE \\
\hline $14 \mathrm{~A}$ & \\
\hline $14 C$ & \\
\hline 140 & \\
\hline $14 \mathrm{~F}$ & \\
\hline $14 \mathrm{G}$ & . \\
\hline $14 \mathrm{~B}$ & \\
\hline $14 \mathrm{E}$ & \\
\hline $15 \mathrm{I}$ & \\
\hline $15 \mathrm{C}$ & . \\
\hline $15 \mathrm{E}$ & \\
\hline $15 B$ & \\
\hline $15 F$ & \\
\hline
\end{tabular}

(1) 5.2 .36 VERIFY by signing below section 5.2 is complete.
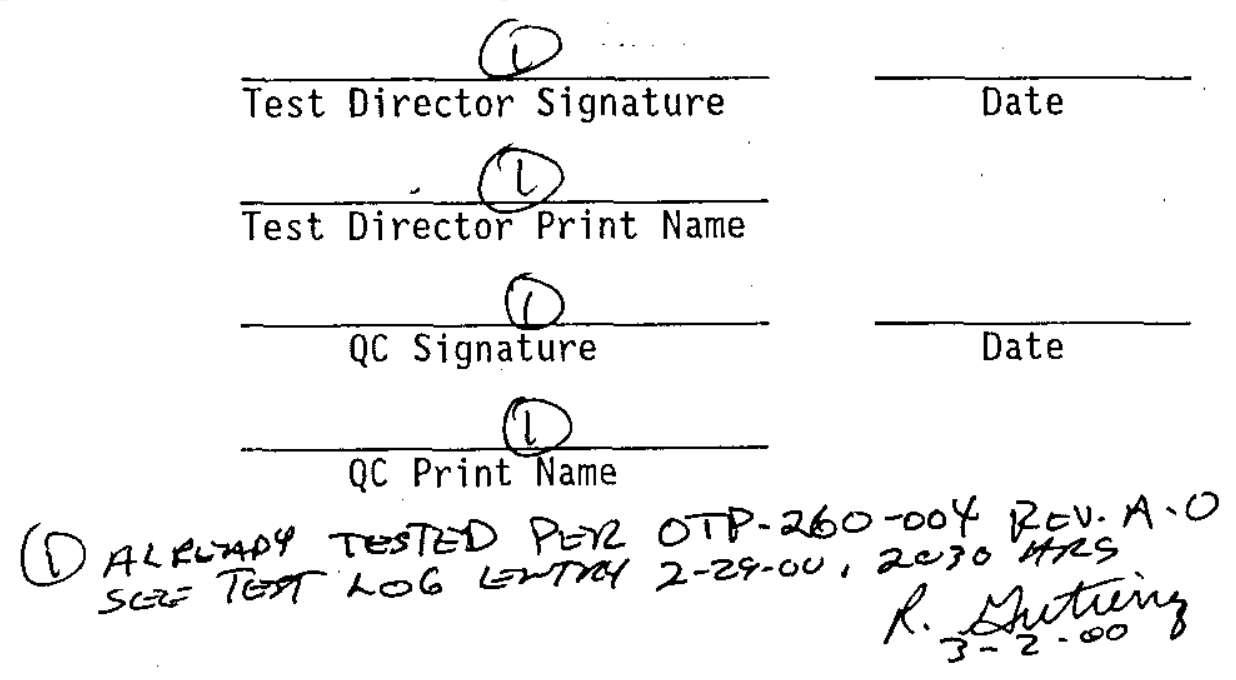


\section{WORKING COPY}

Printed on: Iar 1, 00.12 .39 pm

\subsection{TEST USER DEFINED MODE}

5.3.1 ENSURE applicable SETUP Steps in section 5.1 are completed.

CART CONTROL SCREEN

5.3.2 On the Gamma Cart Control, CLICK oN the "Config." button.

5.3.3 INPUT the following data:

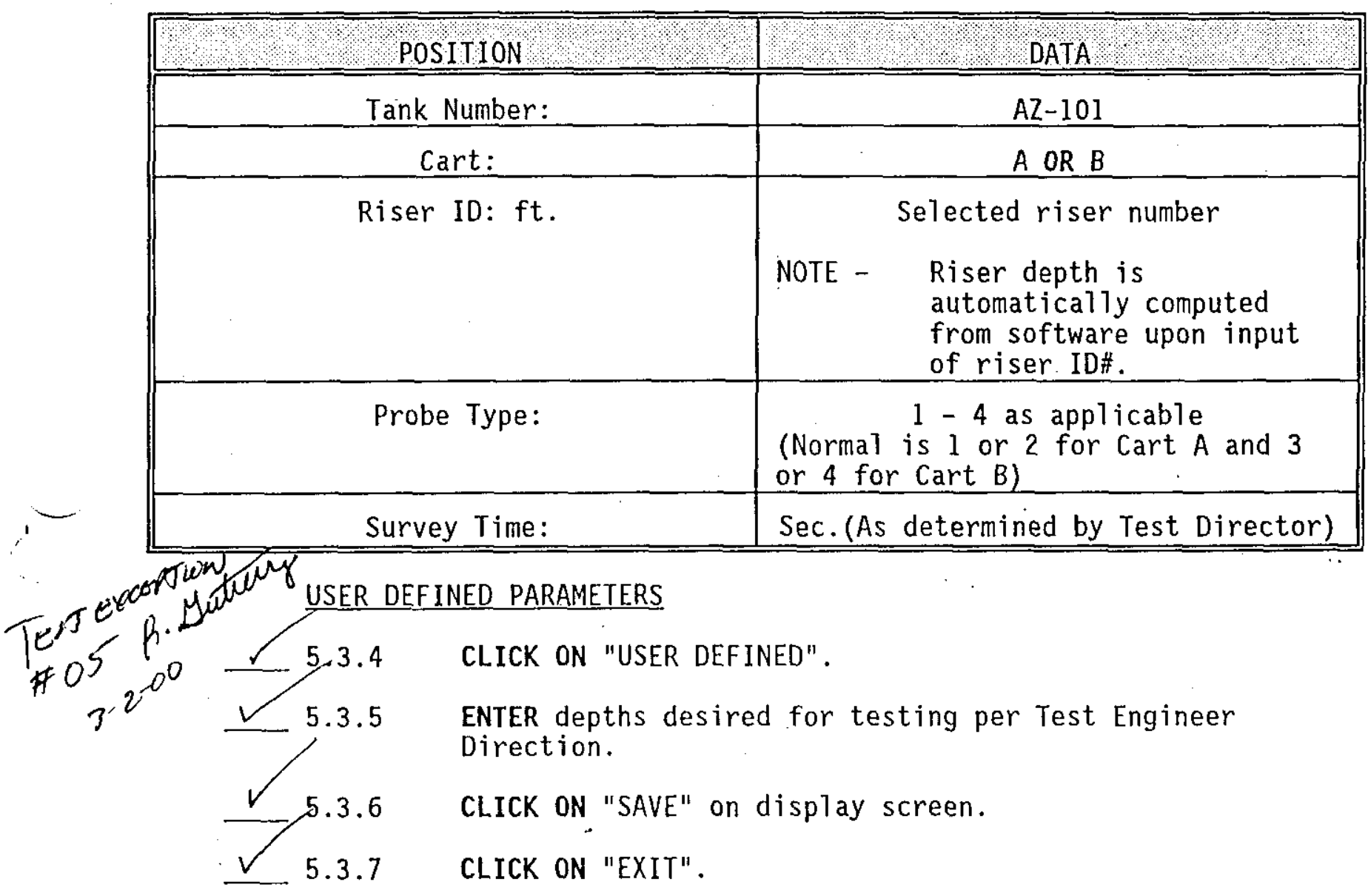




\subsection{TEST USER DEFINED MODE (Cont).}

NOTE - Test Engineer may manipulate parameters at any timé during the following steps as necessary to ensure data retrieval and system configuration, with concurrence of Test Director.

- After the following step, the program should automatically run.

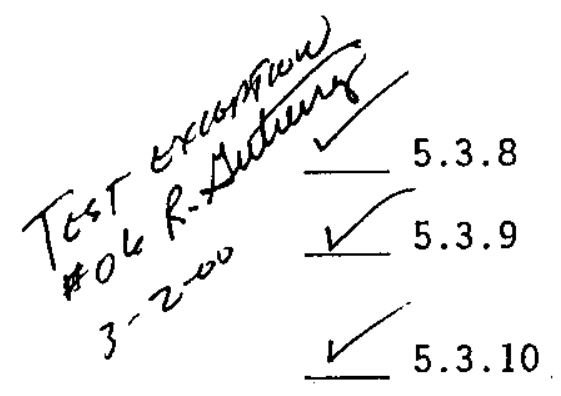

The "EMERGENCY sTOP" may be used to stop at any time during the next step if unit fails to stop at limit switch. The "RESET" button will need to be pushed to resume the program.

CLICK ON Start button.

Test Engineer ENSURE data is received, AND both hard-copy and electronic files can be retrieved.

VERIFY system automatically ZEROs and data is collected at zero position.

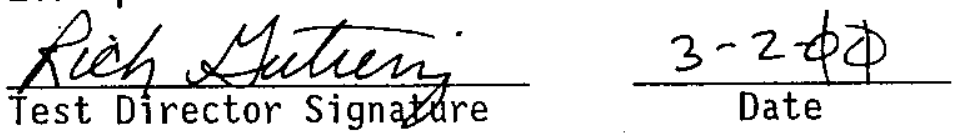

$\frac{\text { Rich Gutierrez }}{\text { Test Director Print Name }}$ 


\subsection{TEST USER DEFINED MODE (Cont).}

5.3.11 CLICK ON "LOGOUT" on display screen.

5.3.12 REMOVE Probe, riser extension toot, and associated equipment AND

STORE per Test Director direction.

\section{OR}

CONTINUE in this procedure.

5.3.13 REPEAT the steps in this section (5.3) as directed for any risers as directed by Test Director.

5.3.14 VERIFY by signing beTow section 5.3 is complete.

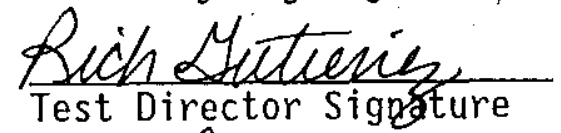

Bich Gutierrez

Test Director Printaname

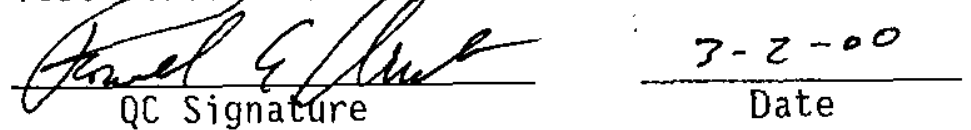

$\frac{\text { Rower Q. Rnwor }}{\text { QC Print Name }}$

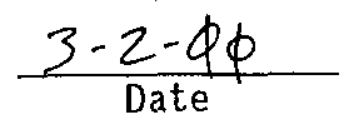


RISER 14D

GAMMA CART - A 


\section{1-AZ GAMMA CART OPERATIONAL TEST PROCEDURE}

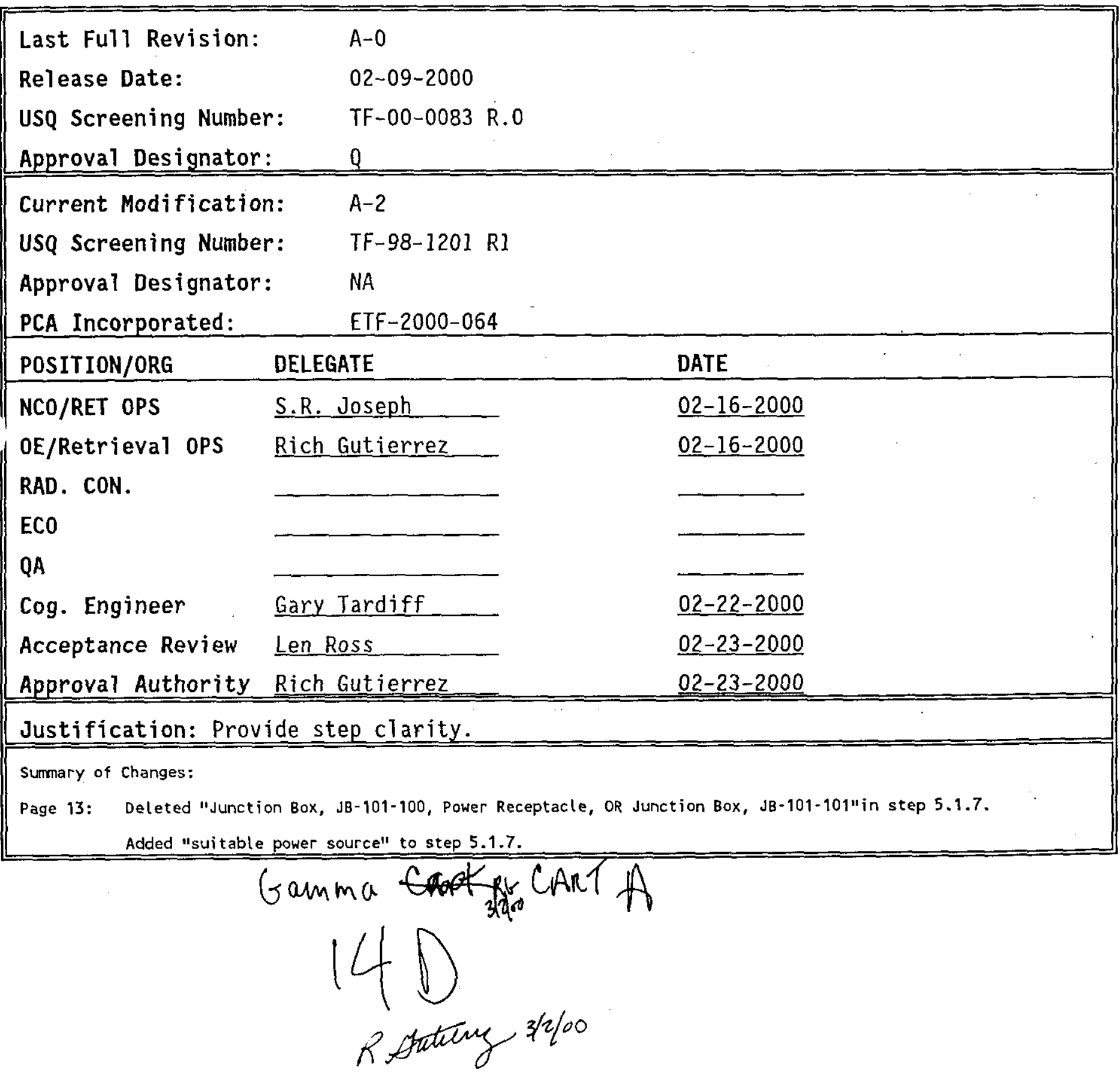

\begin{tabular}{|c|c|c|c|c|}
\hline Tror & 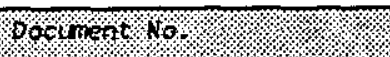 & 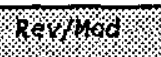 & 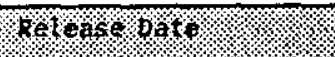 & f \\
\hline OONWINLOSS & OTP 260.04 & : & $=02123 \% 200$ & 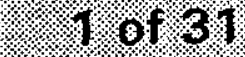 \\
\hline
\end{tabular}




\subsection{PREREQUISITES}

\subsection{SPECIAL TOOLS, EQUIPMENT, AND SUPPLIES}

The following supplies may be needed to perform this procedure:

- Riser Swabbing equipment

- Riser extension tool

\subsection{PERFORMANCE DOCUMENTS}

The following procedures may be needed to perform this procedure:

- T0-040-333 LIQUID OBSERVATION WELL (LOW) SURVEILLANCE VAN STARTUP AND OPERATION PROCEDURE

\subsection{CONDITIONS AND ACTIONS}

NOTE - All signators on this procedure sha11 document their signature on Procedure Signature Sheet.

4.3.1 A1l pre-testing and inspection of the system or portions of the system to be tested has boen completed.

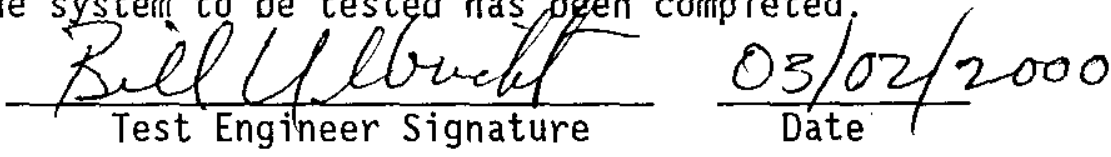

4.3.2 A pre-job briefing has been held. and ail participants have been thoroughly briefed on job safety, hazards, and their responsibilities before performing this ATP.

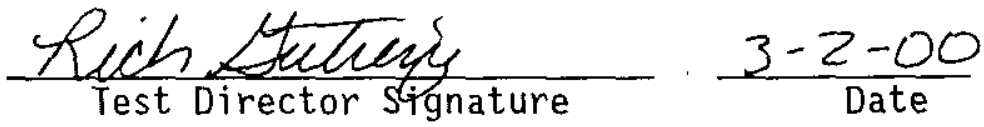

4.3.3 Test Director VERIFY section 4.3 has been COMPLETED. $\frac{\text { Rich Lutueng }}{\text { Test Director Signature }} \frac{3-2-00}{\text { Date }}$ 


\subsection{PROCEDURE}

\subsection{SETUP}

NOTE - This procedure may be repeated for either GAMMA CART A or GAMMA CART $B$ as applicable. N/A may be entered in blocks or steps per Test Director as applicable.

5.1.1 RECORD GAMMA CART CPU number for the system being tested. GAMMA CART IDENTIFIER \# $\frac{\omega C 68789}{\text { CPU Number }}$

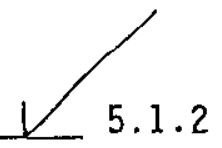

PERFORM cleanliness check in applicable riser listed on TABLE II, per section 5.10 in procedure T0-040-333 latest rev, prior to mounting riser extension tool.

ENSURE GAMMA CART riser extension tool is mounted on the applicable riser.

ENSURE GAMMA CART is placed in 1 ine with riser extension tool to facilitate installation of probe and cables.

5.1.5 CHECK route to riser for obstacles and clearances.

5.1.6 LEVEL cart using jacks.

5.1.7 CONNECT gamma cart power cables; as follows:

- One end to gamma cart power receptacle

- Other end to surtagle oower sourlee-Junction Box, IB 101-100, power Receptacle, OR Junction Box; JB $101-101$

5.1.8 CONNECT gamma cart communications cable, as follows:

- One' end to gamma cart communications receptacle

- $\quad$ ther end to Tank 241-AZ-101 Gamma Cart A AND/OR B

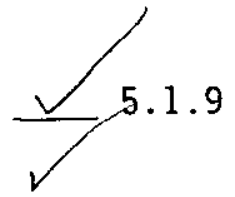

Data Collection Subsystem communications receptacle

PLACE Gamma Cart "RAISE OFF LOWER" switch in the LOWER position.

5.1.10 CHECK that detector probe cable is resting in the Gamma Cart boom cable reel. 


\subsection{SETUP (Cont).}

\section{CAUTION}

If sufficient tension is NOT held on the detector probe cable as the cable is being let out, the cable could become entangled.

NOTE - Step 5.1 .11 and 5.1 .12 require two operators to perform continuous action until step 5.1 .12 is complete.

5.1.11 HOLD tension on the detector probe cable until step 5.1:12 is completed.

5.1.12 PRESS AND HOLD "RESET" button until enough detector probe cable is let-out that will allow placement of the detector cable through riser extension collar AND into riser drywe11, AND

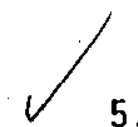

RELEASE the "RESET" button.

5.1.13 INSTALL the proper detector probe on the detector probe cable.

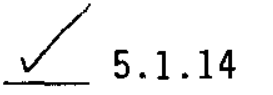

ENSURE that the detector probe connections are correct and tight. AND

INSERT probe into riser extension tool.

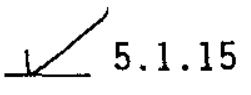

ENSURE limit switch cable is connected from limit switch on riser extension tool, to the connection point on the

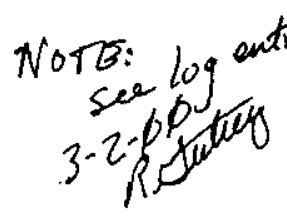
front of the GAMMA CART.

5.1.16 ENSURE the "Raise - Off - Lower" selector switch is in the "OFF" position.

5.1.17 ENSURE the emergency stop button is pulled out.

5.1.18 POSITION the "SPEED" control potentiometer to MIN speed (fully counter-clockwise). 


\subsection{SETUP (Cont).}

\section{CAUTION}

There is no limit switch to stop the motion when the cable is fully unwound. The cable will rewind backwards on the reel. Damage to the cable may result.

NOTE - When the cart is first powered up, or the emergency stop button has been pushed, or power has been restored after a power failure, the cabie reel will not move up or down until "RESET" button is activated.

- The "Raise-OFF-Lower" Switch is Manually controlled and is Operator Dependent.

5.1.19 ENSURE LOCAL/REMOTE switch is in the "LOCAL" position.

5.1.20 ENERGIZE the Cart.

5.1.21 SET the "SPEED" potentiometer to 2 on the GAMMA Cart.

5.1.22 SET the "RAISE -OFF- LOWER" switch to the "LOWER" position.

5.1.23 PUSH "EMERGENCY STOP" button on GAMMA CART.

5.1.24. VERIFY the system has stopped.

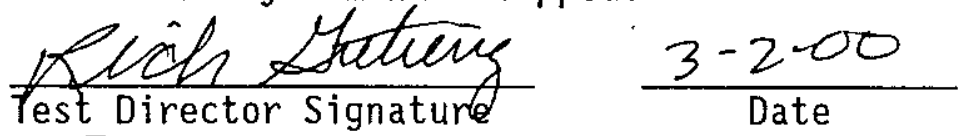

$\frac{\text { Rich Gutienrez }}{\text { Test Director Print Name }}$ 


\subsection{SETUP (Cont).}

5.1.25 SET the "RAISE-OFF-LOWER" switch to the "RAISE" position.

5.1.26 PULLL "EMERGENCY STOP" out on GAMMA CART.

5.1.27 PUSH the "RESET" button on GAMMA CART to resume.

5.1.28 ENSURE limit switch activates when probe returns to the zero position.

5.1.29 SET the "RAISE-OFF-LOWER" switch to the "OFF" position.

5.1.30 SET "SPEED" potentiometer to MIN.

5.1.31 POSITION The "LOCAL REMOTE" switch to "REMOTE".

5.1.32 VERIFY by signing below section 5.1 is complete.

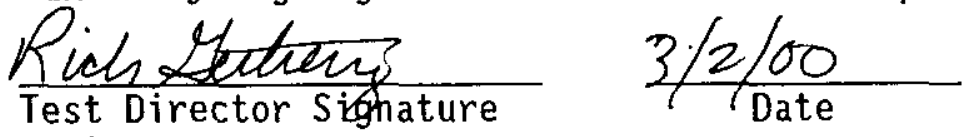

Pich Gutienvez

Test Director Print Name

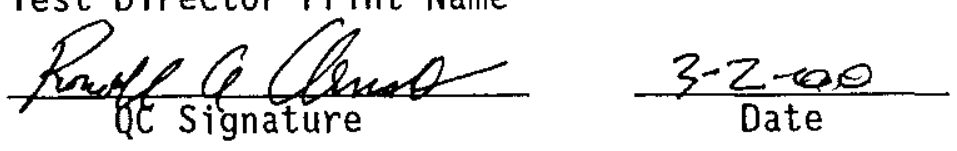

$\frac{\text { Socace A.ARar }}{\text { QC Print Name }}$

$$
\text { Date }
$$




\subsection{TEST INCREMENTAL SAMPLE MODE}

SETUP

NOTE - AlT Steps in this section apply to either cart, except in those steps where the specific cart is indicated.

\section{INSTRUMENT CHECK}

5.2.1 IF the pushbutton for Tank 241-AZ-101 Gamma Cart A AND/OR $B$ Data Collection System Central Processing Unit (CPU), AND/OR asSOciated MONITOR, are NOT ON, PRESS the applicable ON pushbuttons.

5.2.2 ENSURE the following systems are ON AND

ENSURE settings are correct for the following:

- ORTEC MINIBIN

- POWER SUPPLy

Détector Bias Power Supply (HVPS): ORTEC Mod. 478.

- $\mathrm{kV}: 5-()$

- o to 1000v: t 1000 volts)

- Power ion

Ampl ifjer (AMP): ORTEC Mod. 673

- coarse gain: zoo 500

- fine gain: 0.68010 .40

- SHAPING TIME: Both-knobs-set to 2 miteroseconds / isec

- PZ Adjust: Do-NOT-change-settings (in this progodure)

- BLR: Switch in AUTO (up) position

- INPUTS: Switch in POS (up) position BNC cable on terminal (from pre amplifier)

- OUTPUTS: cable on UNIPQLAR terminal(to single channel Analyzer) is on the back.

5.2.3 WHEN WINDOWS login screen appears CLICK ON "CANCEL".

\begin{tabular}{|c|c|c|c|c|}
\hline 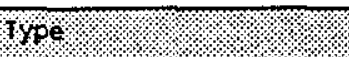 & 1004n-7\% & reyplod & 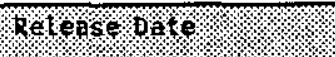 & pas. \\
\hline CONTINUOUS & OTP 260.004 & 42 & $02 / 2312000$ & 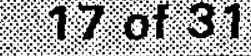 \\
\hline
\end{tabular}




\subsection{TEST INCREMENTAL SAMPLE MODE (Cont).}

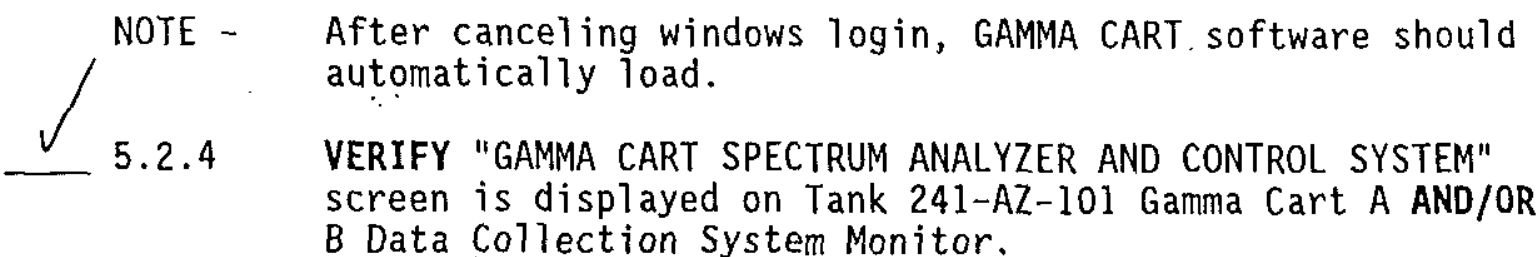
$B$ Data Collection System Monitor.
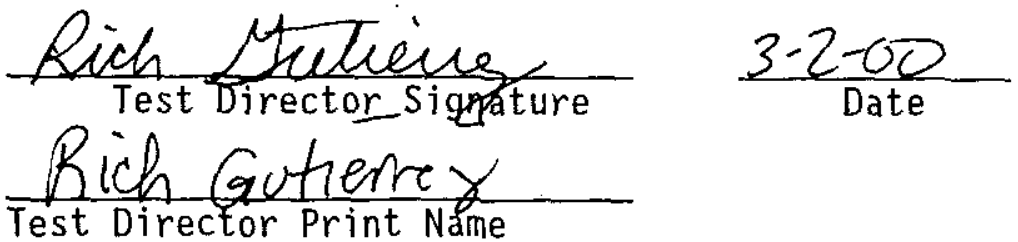

\section{$\stackrel{S .2 .5}{ }+5$}

SELECT "Login" on the "GAMMA CART SPECTRUM ANALYZER AND CONTROL SYSTEM" screen.
NOTE - LOGIN passwords and information may be obtained from Test Director.
5.2.6 LOG-IN.

5.2.7 VERIFY LOCAL/REMOTE switch on display screen is in "REMOTE" pOsition.

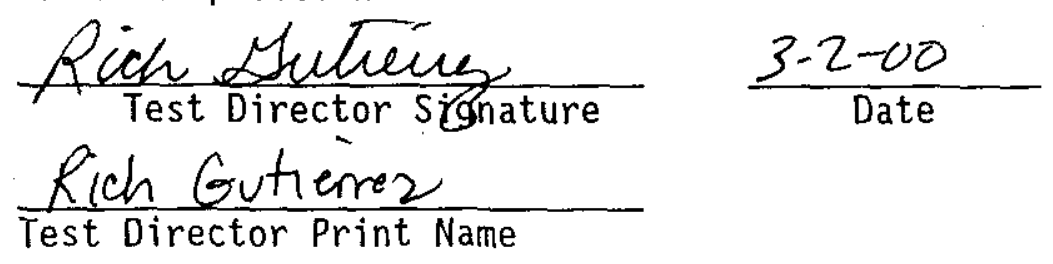




\subsection{TEST INCREMENTAL SAMPLE MODE (Cont).}

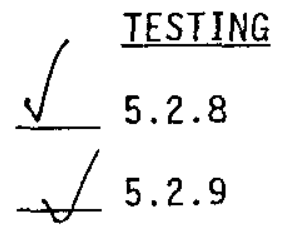

SELECT "config" on the "Gamma Cart Display" screen.

ENTER the following data for selected riser on the "Configuration - Display" screen by pulling down applicable menu:

\begin{tabular}{|c|c|}
\hline POSITION & DATA \\
\hline Tank Number: & $A Z-101$ \\
\hline Cart: & A OR B \\
\hline Riser ID: $\mathrm{ft}$. & $\begin{array}{ll} & \text { Selected riser number } \\
\text { NOTE - } & \text { Riser depth is } \\
\text { automatically computed } \\
\text { from software upon input } \\
\text { of riser ID\#. }\end{array}$ \\
\hline Probe Type: & $\begin{array}{l}1-4 \text { as applicable } \\
\text { (Normal is } 1 \text { or } 2 \text { for Cart A and } 3 \\
\text { or } 4 \text { for Cart B) }\end{array}$ \\
\hline Survey Time: & Sec. (As determined by Test Director) \\
\hline
\end{tabular}

$\sqrt{ } / 5.2 .10$ ENSURE REAL/LIVE toggle button indicates "LIVE".

5.2.11 On the Data Collection Configuration window, SELECT the "Incrementa]" button.

INCREMENTAL PARAMETERS

5.2.12 INPUT the following Sample Collection Data:

\begin{tabular}{|l|l|l|l|}
\hline $\begin{array}{l}\text { Sample Start: } \\
\text { Depth: }\end{array}$ & $55.0 \mathrm{ft}$ \\
\hline Interval Size: & $10.0 \mathrm{ft}$ \\
\hline Sample End Depth: & $5.0 \mathrm{ft}:$ \\
\hline
\end{tabular}




\subsection{TEST INCREMENTAL SAMPLE MODE (Cont).}

$\checkmark$ 5.2.13 CLICK ON "SAVE".

5.2.14 CLICK ON "EXIT".

NOTE - Test Engineer may manipulate parameters at any time during the following steps as necessary to ensure data retrieval and system configuration, with concurrence of Test Director.

- After the following step, the program should automatically run.

5.2.15 CLICK ON "Start" button.

5.2.16 CLICK ON "EMERGENCY STOP" button on computer screen.

5.2.17 VERIFY System stopped.

$\frac{\text { Pich Mutremez }}{\text { Test Director Signature }} \frac{3-2 \text {-od }}{\text { Date }}$

$\frac{\text { Aich Gutieney }}{\text { Test Director Print Wame }}$

5.2.18 CLICK ON "EMERGENCY STOP" again to RESET the emergency stop button on computer screen.

5.2.19 CLICK ON "ZERO" on display screen.

5.2.20 ENSURE GAMMA PROBE begins to RAISE.

5.2.21 CLICK ON "STOP" button on display screen. 


\subsection{TEST INCREMENTAL SAMPLE MODE (CONt).}

5.2.22 VERIFY System stopped.

Rich Latiens.

Test Director Sighature

Bich Gutiemes

Test Director Priñt Name

$\frac{3 \cdot 2-00}{\text { Date }}$

5.2.23 CLICK ON "ZERO" again on display screen.

5.2.24 ENSURE GAMMA PROBE begins to RAISE.

5.2.25 When probe and system zeros, CLICK ON "START" on display screen.

* 5.2.26 VERIFY System resumed program.

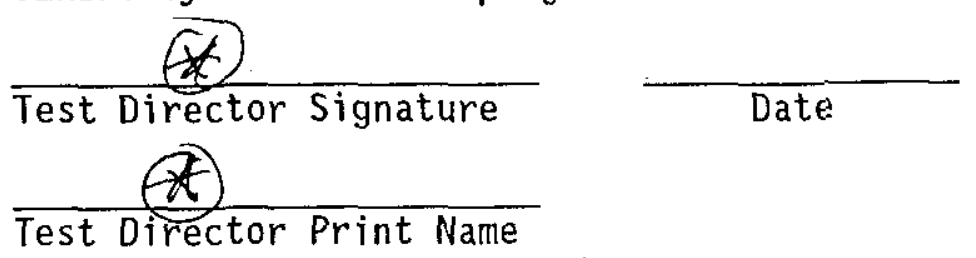

(20) 5.2.27 CLICK ON "STOP" button on computer screen.

5.2.28 VERIFY system stopped.

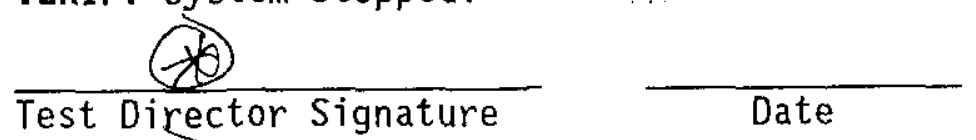

Test Director Print Name

5.2 .29 CLICK ON "ZERO" on display screen.

* 5.2 .30 When probe and system zeros, CLICK ON "START" on display screen.

5.2.31 VERIFY System resumed program.

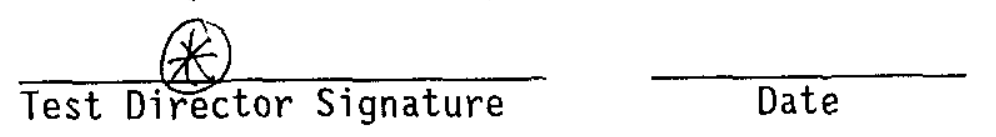

(2)

Test Director Print Name

(*) See TEST LOG ENTRY $3 / 2 / 00,2015$ entry R. Stutieng $3 / 2 / 00$

\begin{tabular}{|c|c|}
\hline CDNTINUOUS & porimentitis \\
\hline
\end{tabular}

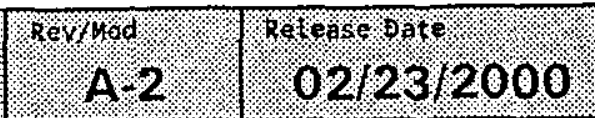




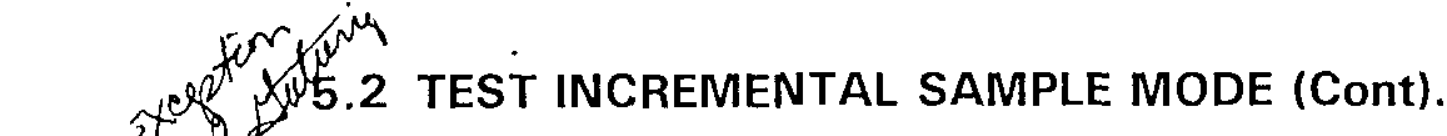

5.2.32 Test Engineer ENSURE data is received, AND both hard-copy and electronic files can be retrieved.

5.2.33 VERIFY system automatically ZEROs and data is collected at zero position.

$\frac{\text { Rich Statume }}{\text { Test Director Signature }} \frac{3-2-\phi \phi}{\text { Date }}$

$\frac{\text { Rieh Gutierrz }}{\text { Test Director Print Name }}$

NOTE - The steps in section 5.1, applicable to the Emergency stop, need not be repeated if completed for an individual GAMMA CART. The Emergency stop on BOTH GAMMA CART A and B, need to be tested only once.

NOTE - It is NOT necessary to do ALL risers in one procedure.

Test Director is responsible for ensuring ALL risers have been profiled by one AND/OR the other GAMMA CART(S).

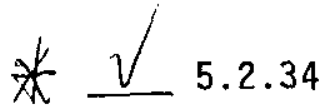

REPEAT applicable SETUP Steps in section 5.1 AND

Incremental testing steps 5.2.1 - 5.2.15 AND Steps 5.2.32 and 5.2.33 for each of the following risers and depths per Test Director's direction.

TABLE I

\begin{tabular}{|c|l|}
\hline RISER & Depth \\
inches $(\mathrm{ft})$ \\
\hline $14 \mathrm{~A}$ & $660(55.0)$ \\
\hline $14 \mathrm{C}$ & $660(55.0)$ \\
\hline $14 \mathrm{D}$ & $660(55.0)$ \\
\hline $14 \mathrm{~F}$ & $660(55.0)$ \\
\hline $14 \mathrm{G}$ & $660(55.0)$ \\
\hline $14 \mathrm{~B}$ & $660(55,0)$ \\
\hline $14 \mathrm{E}$ & $660(55.0)$ \\
\hline $15 \mathrm{I}$ & $684(57,0)$ \\
\hline $15 \mathrm{C}$ & $684(57.0)$ \\
\hline $15 \mathrm{E}$ & $684(57.0)$ \\
\hline $15 \mathrm{~B}$ & $684(57.0)$ \\
\hline $15 \mathrm{~F}$ & $684(57,0)$ \\
\hline
\end{tabular}

140 riser completed with this procedme. 


\subsection{INCREMENTAL SAMPLE MODE (Cont).}

NOTE - In the following Table, Test Director N/A blocks that are tested with a different GAMMA CART.

5.2.35 VERIFY the applicable riser in step 5.2.34 has been tested.

TABLE II

\begin{tabular}{|c|c|}
\hline RISER & TEST DIRECTOR SIGNATURE \\
\hline $14 \mathrm{~A}$ & N/t \\
\hline $14 \mathrm{C}$ & \\
\hline 140 & R.stellary $3 / 2 / 00$ \\
\hline $14 \mathrm{~F}$ & \\
\hline 146 & \\
\hline $14 \mathrm{~B}$ & \\
\hline $14 \mathrm{E}$ & \\
\hline $15 \mathrm{I}$ & \\
\hline $15 \mathrm{C}$ & \\
\hline $15 \mathrm{E}$ & \\
\hline $15 B$ & \\
\hline $15 \mathrm{~F}$ & \\
\hline
\end{tabular}

5.2.36 VERIFY by signing below section 5.2 is complete.

$\frac{\text { Rich Mutrency }}{\text { Test Director Signature }} \frac{3-2-00}{\text { Date }}$

Rich Gutierve2

Test Director Print Name

QC Signature

Date

QC Print Name

UNRESILVED TEST ERcoutrows nT THAS TIme 


\subsection{TEST USER DEFINED MODE}

$\checkmark$ 5.3.1 ENSURE applicable SETUP Steps in section 5.1 are completed.

\section{CART CONTROL SCREEN}
5.3.2 On the Gamma Cart Control, CLICK oN the "Config." button.
5.3.3 INPUT the following data:

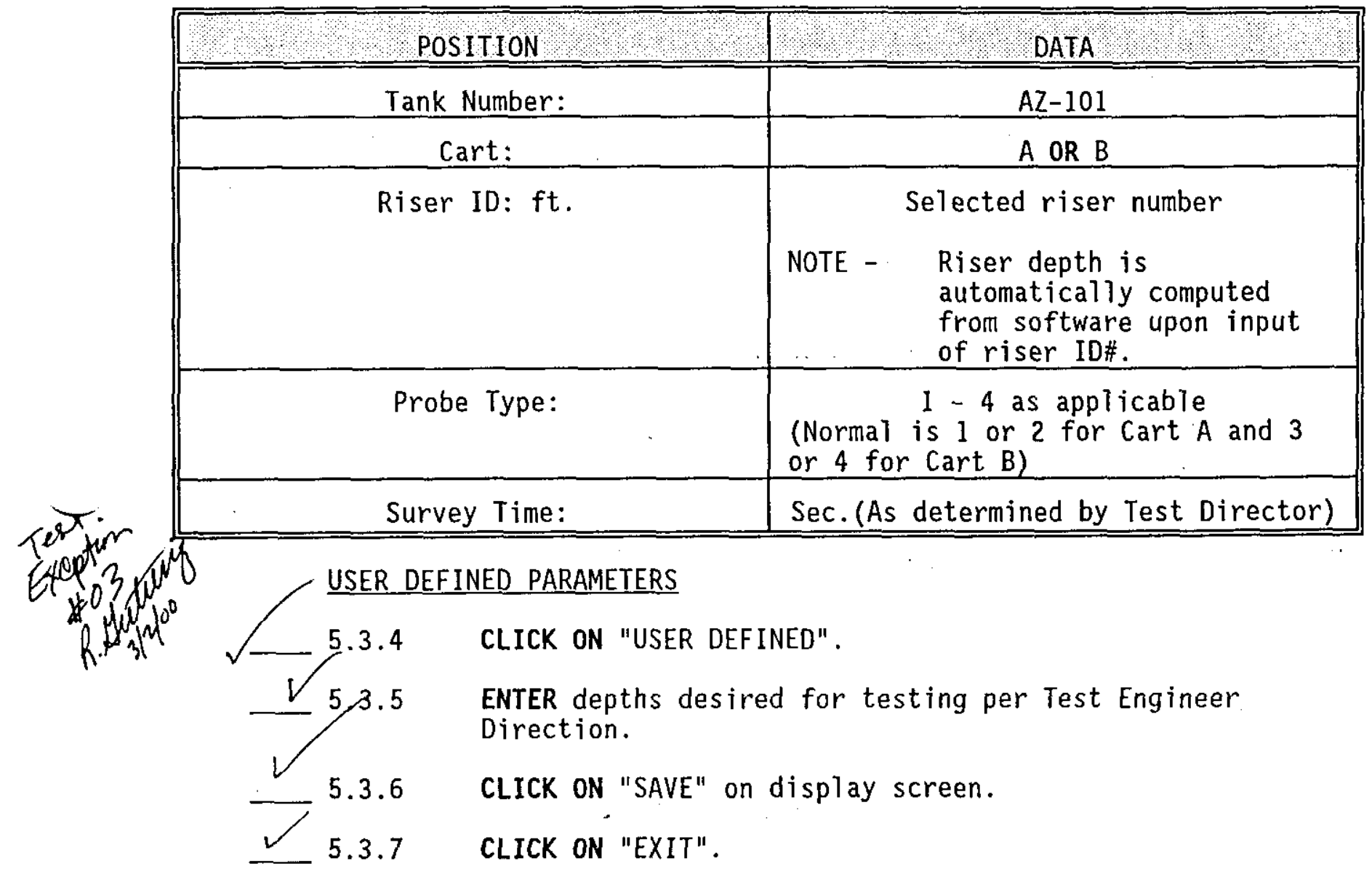




\subsection{TEST USER DEFINED MODE (Cont).}

NOTE - Test Engineer may manipulate parameters at any time during the following steps as necessary to ensure data retrieval and system configuration, with concurrence of Test Director.

- After the following step, the program should automatically run.

- The "EMERGENCY STOP" may be used to stop at any time during the next step if unit fails to stop at 1 imit
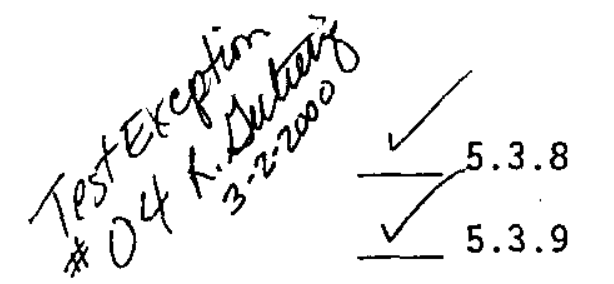
switch. The "RESET" button will need to be pushed to resume the program.

\section{CLICK ON Start button.}

Test Engineer ENSURE data is received, AND both hard-copy and electronic files can be retrieved.

5.3.10 VERIFY system automatically ZEROs and data is collected at zero position.

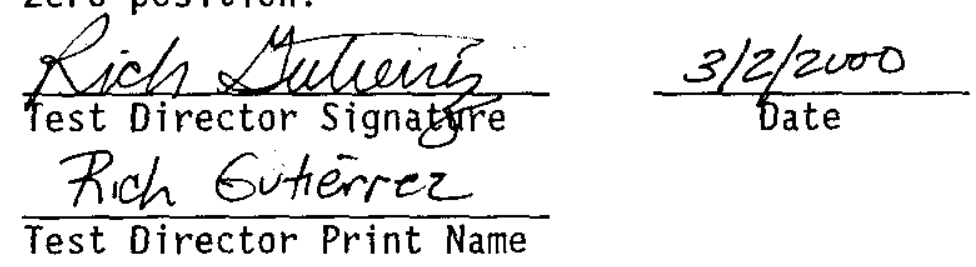




\subsection{TEST USER DEFINED MODE (Cont).}

5.3.11 CLICK ON "LOGOUT" on display screen.

5.3.12 REMOVE Probe, riser extension tool, and associated equipment AND

STORE per Test Director direction.

\section{OR}

CONTINUE in this procedure.

5.3.13 REPEAT the steps in this section (5.3) as directed for any risers as directed by Test Director.

5.3.14 VERIFY by signing below section 5.3 is complete.

$\frac{\text { Rich Hutueng }}{\text { Test Director sibnature }} \frac{3 / 2 / 2000}{\text { Date }}$

Rich Gutierrez

Test Otrector Print Name

$\frac{\text { timel Af find }}{\text { QC Signature }} \frac{3 / 2 / 00}{\text { Date }}$

Rownen Z. Atrunt

QC Print Name 


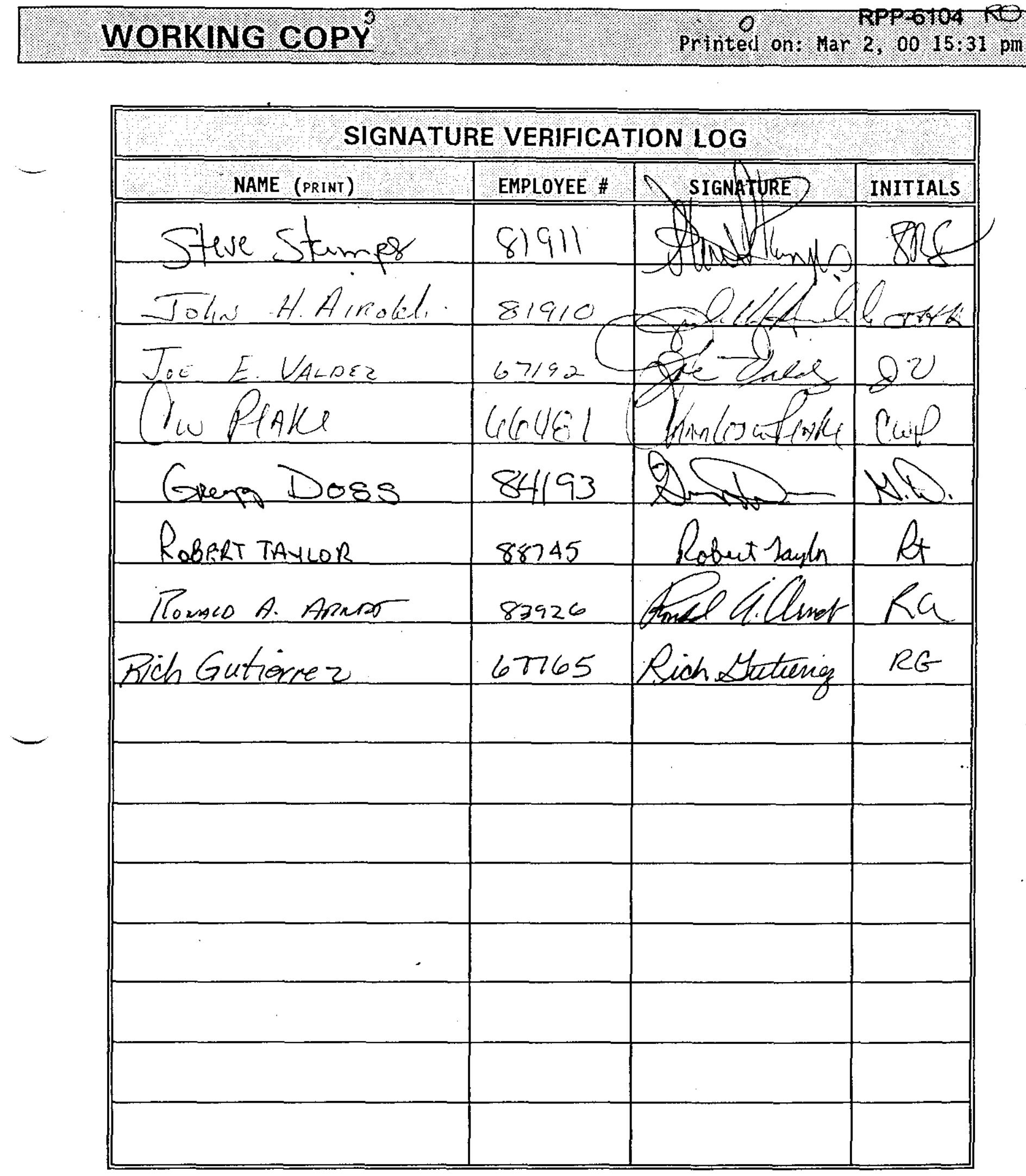

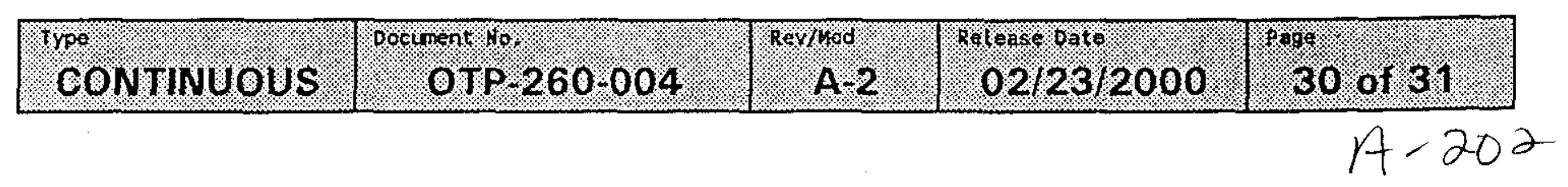




\section{RISER 15B \\ GAMMA CART - A}

A-203 


\section{1-AZ GAMMA CART OPERATIONAL TEST PROCEDURE}

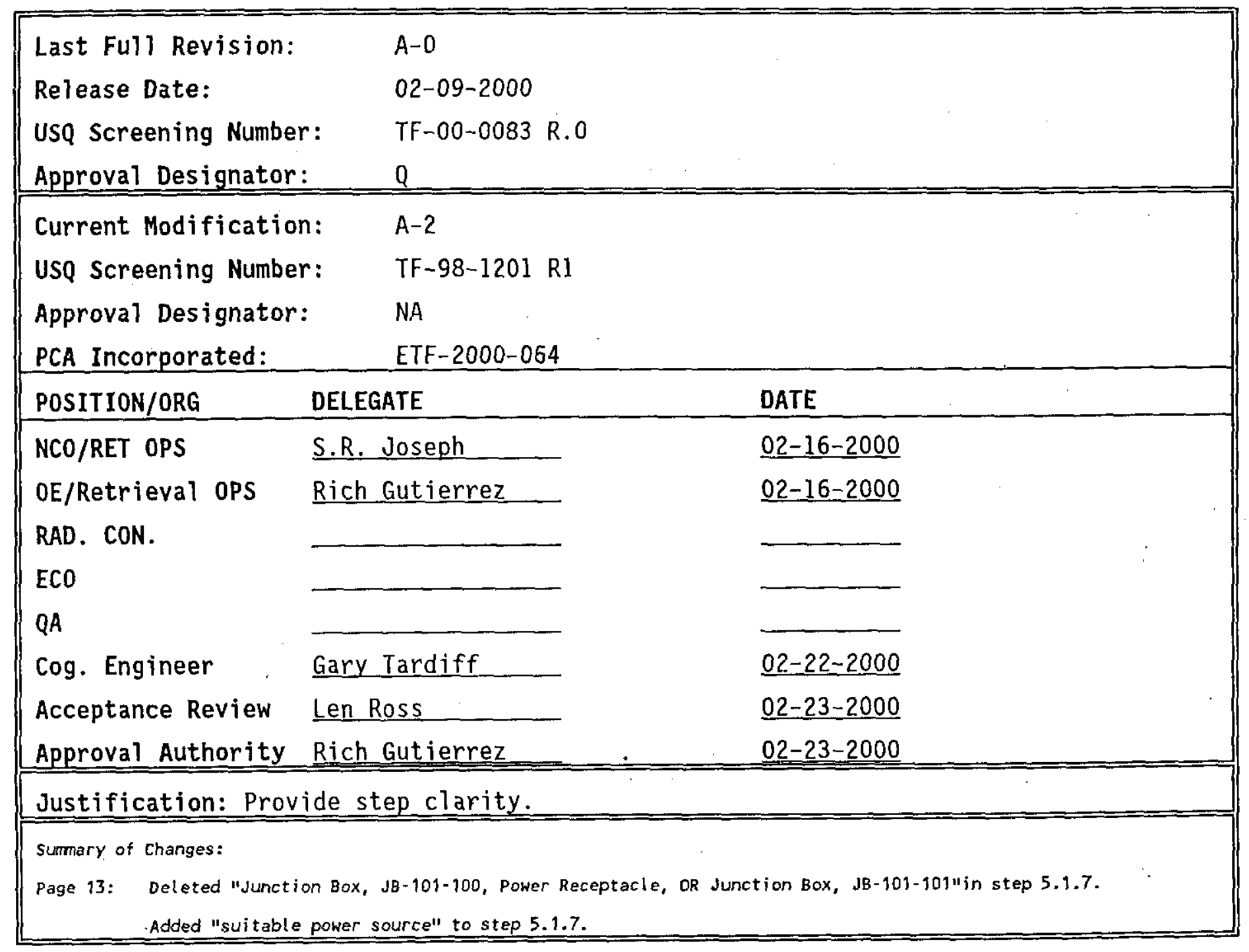

$$
\begin{aligned}
& \text { GAmwnt CMat A (Probe 4) } \\
& \text { Riser } / 5 B \\
& \text { Rysutering }
\end{aligned}
$$

\begin{tabular}{|c|c|c|c|c|}
\hline SONTINUOUS & 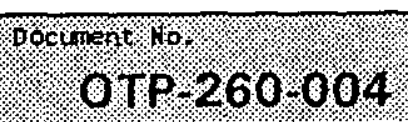 & ReVinod & 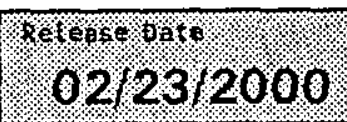 & forf \\
\hline
\end{tabular}




\subsection{PREREQUISITES}

\subsection{SPECIAL TOOLS, EQUIPMENT, AND SUPPLIES}

The following supplies may be needed to perform this procedure:

- Riser Swabbing equipment

- Riser extension tool

\subsection{PERFORMANCE DOCUMENTS}

The following procedures may be needed to perform this procedure:

- TO-040-333 LIQUID OBSERVATION WELL (LOW) SURVEILLANCE VAN STARTUP AND OPERATION PROCEDURE

\subsection{CONDITIONS AND ACTIONS}

NOTE - All signators on this procedure shall document their signature on Procedure Signature Sheet.

4.3.1 All pre-testing and inspection of the system or portions of the system to be tested has been completed.

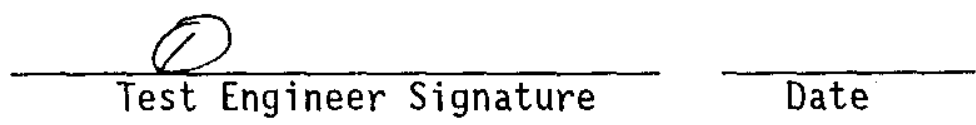

4.3.2 A pre-job briefing has been held. and all participants have been thoroughly briefed on job safety, hazards, and their responsibilities before performing this ATP.

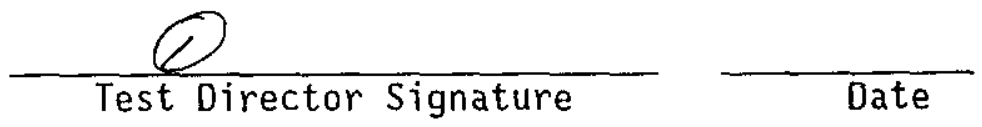

4.3.3 Test Director VERIFY section 4.3 has been COMPLETED. (D)

Test Director Signature

(1) abready completed on OAP-260-004, Rev A-2, dated 3/2/00. R. Sutieng $3 / 6 / 2000$ 


\subsection{PROCEDURE}

\subsection{SETUP}

NOTE - This procedure may be repeated for either GAMMA CART A or GAMMA CART B as applicable. N/A may be entered in blocks or steps per Test Director as applicable.

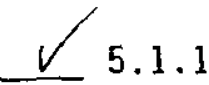

RECORD GAMMA CART CPU number for the system being tested. GAMMA CART IDENTIFIER \#

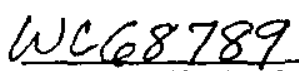

\section{CPU Number}

5.1.2 PERFORM cleanliness check in applicable riser listed on TABLE II, per section 5.10 in procedure T0-040-333 latest rev, prior to mounting riser extension tool.

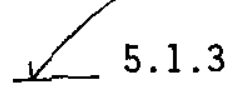

ENSURE GAMMA CART riser extension tool is mounted on the applicable riser.

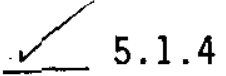

ENSURE GAMMA CART is placed in line with riser extension tool to facilitate installation of probe and cables.

5.1.5 CHECK route to riser for obstacles and clearances.

5.1.6 LEVEL cart using jacks.

5.1.7 CONNECT gamma cart power cables; as follows:

- One end to gamma cart power receptacle

- Other end to sultajlo gover source-Junction Bax, JB $101-100$, - Power Receptacle, OR Junction Box, J8-101-101

5.1.8 CONNECT gamma cart communications cable, as follows:

- One end to gamma cart communications receptacle

- $\quad$ ther end to Tank 241-AZ-101 Gamma Cart A AND/OR B Data Collection Subsystem communications receptacle

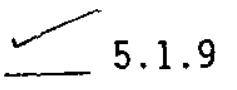

PLACE Gamma Cart "RAISE OFF LOWER" switch in the LOWER position.

5.1 .10

CHECK that detector probe cable is resting in the Gamma Cart boom cable reel. 


\subsection{SETUP (Cont).}

\section{CAUTION}

If sufficient tension is NOT held on the detector probe cable as the cable is being let out, the cable could become entangled.

NOTE - Step 5.1.11 and 5.1 .12 require two operators to perform continuous action until step 5.1 .12 is complete.

5.1.11 HOLD tension on the detector probe cable until step 5.1:12 is completed.

5.1.12 PRESS ANO HOLO "RESET" button unti7 enough detector probe cable is let-out that will allow placement of the detector cable through riser extension collar AND into riser drywe 11, AND

RELEASE the "RESET" button.

5.1 .13 INSTALL the proper detector probe on the detector probe cable.

5.1.14 ENSURE that the detector probe connections are correct and tight. AND

INSERT probe into riser extension tool.

5.1.15 ENSURE limit switch cable is connected from 1 imit switch on riser extension tool, to the connection point on the front of the GAMMA CART.

$\sqsubset$ 5.1.16 ENSURE the "Raise - Off - Lower" selector switch is in the "OFF" position.

5.1.17 ENSURE the emergency stop button is pulled out.

5.1.18 POSITION the "SPEED" control potentiometer to MIN speed (fully counter-clockwise). 


\subsection{SETUP (Cont).}

\section{CAUTION}

There is no limit switch to stop the motion when the cable is fully unwound. The cable will rewind backwards on the reel. Damage to the cable may result.

NOTE - When the cart is first powered up, or the emergency stop button has been pushed, or power has been restored after a power failure, the cable reel will not move up or down until "RESET" button is activated.

- The "Raise-OFF-Lower" Switch is Manually controlled and is Operator Dependent.

5.1.19 ENSURE LOCAL/REMOTE switch is in the "LOCAL" position.

5.1.20 ENERGIZE the Cart.

5.1.21 SET the "SPEED" potentiometer to 2 on the GAMMA cart.

5.1.22 SET the "RAISE -OFF-"LOWER" switch to the "LOWER" position.

(1) 5.1 .23 PUSH "EMERGENCY STOP" button on GAMMA CART.

(1) 5.1.24. VERIFY the system has stopped.

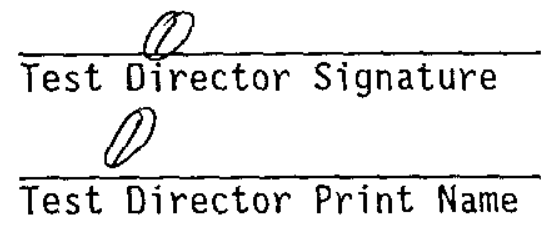

(1) abrady tested per 0Tp-260-004, RevA.2, dated 3/2/00. R.Atuting 3/6/2000 


\subsection{SETUP (Cont).}

(1) 5.1.25 SET the "RAISE-OFF-LOWER" switch to the "RAISE" position.

(1) 5.1.26 PULL "EMERGENCY STOP" out on GAMMA CART.

12 P.1.27 PUSH the "RESET" button on GAMMA CART to resume.

(1) 5.1.28 ENSURE limit switch activates when probe returns to the zero position.

(1) 5.1.29 SET the "RAISE-OFF-LOWER" switch to the "OFF" position.

(1) 5.1.30 SET "SPEED" potentiometer to MIN.

5.1.31 POSITION The "LOCAL REMOTE" switch to "REMOTE".

5.1.32 VERIFY by signing below section 5.1 is complete.
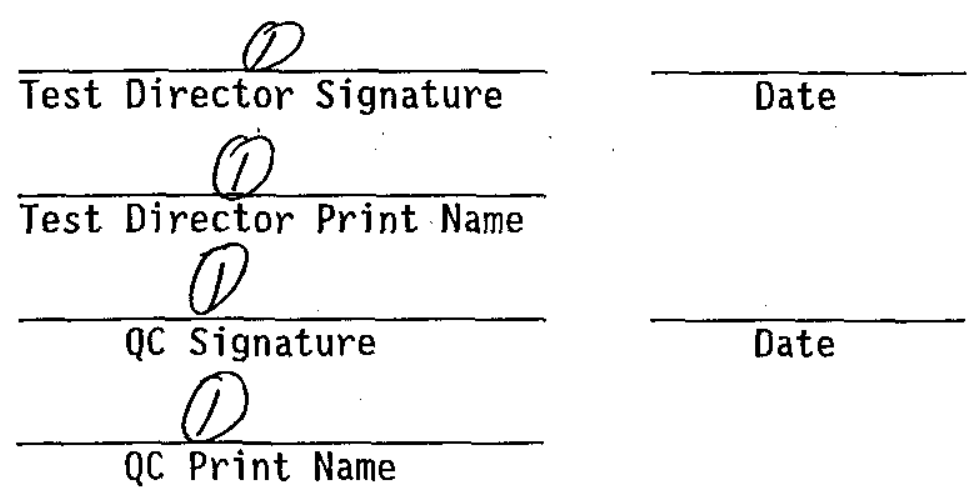

(1) already tecto per OTP-260.004, Rer A-2, dated 3/200. R. Sketuing 3/6/2000 


\subsection{TEST INCREMENTAL SAMPLE MODE}

\section{SETUP}

NOTE - AlT Steps in this section apply to either cart, except in those steps where the specific cart is indicated.

\section{INSTRUMENT CHECK}

- 5.2.1 IF the pushbutton for Tank 241-AZ-101 Gamma Cart A AND/OR $B$ Data Collection System Central Processing Unit (CPU), AND/OR associated MONITOR, are NOT ON, PRESS the applicable oN pushbuttons.

5.2.2 ENSURE the following systems are ON AND

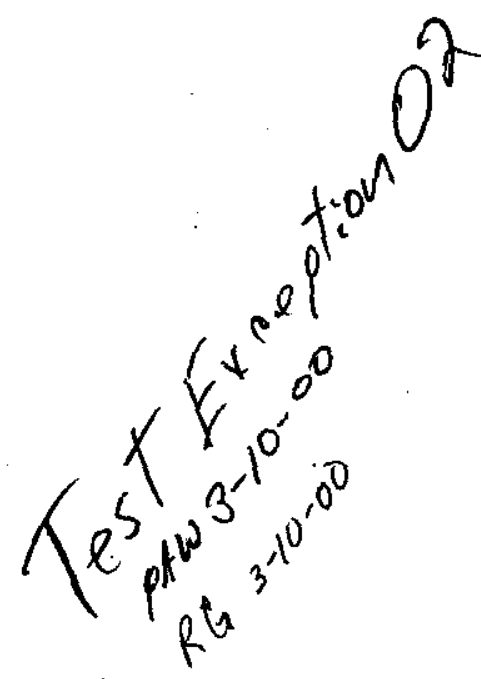

ENSURE settings are correct for the following:

- ORTEC MINIBIN

- POWER SUPPLY

Détector Bias Power Supply (HVPS): ORTEC Mod. 478.

$-\mathrm{kV}: .5$

- 0 to $1000 \mathrm{~V}:(+60$ volts)

Amplifier (AMP): ORTEC Mod. 673

- COARSE GAIN: 200

- FINE GAIN: 0.680

- SHAPING TIME: Both knobs set to 2 microseconds

- PZ Adjust: Do NOT change settings (in this procedure)

- BLR: Switch in AUTO (up) position

- INPUTS: Switch in POS (up) position BNC cable on terminal (from pre amplifier)

- OUTPUTS: cable on UNIPOLAR terminal (to single channel Analyzer)

$\complement^{5.2 .3}$ WHEN WINDOWS 7 ogin screen appears CLICK ON "CANCEL". 
$R P P-6100$

WORKING COPY

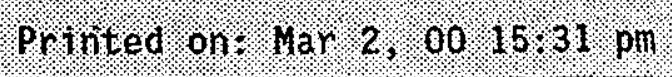

5.2 TEST INCREMENTAL SAMPLE MODE (Cont).

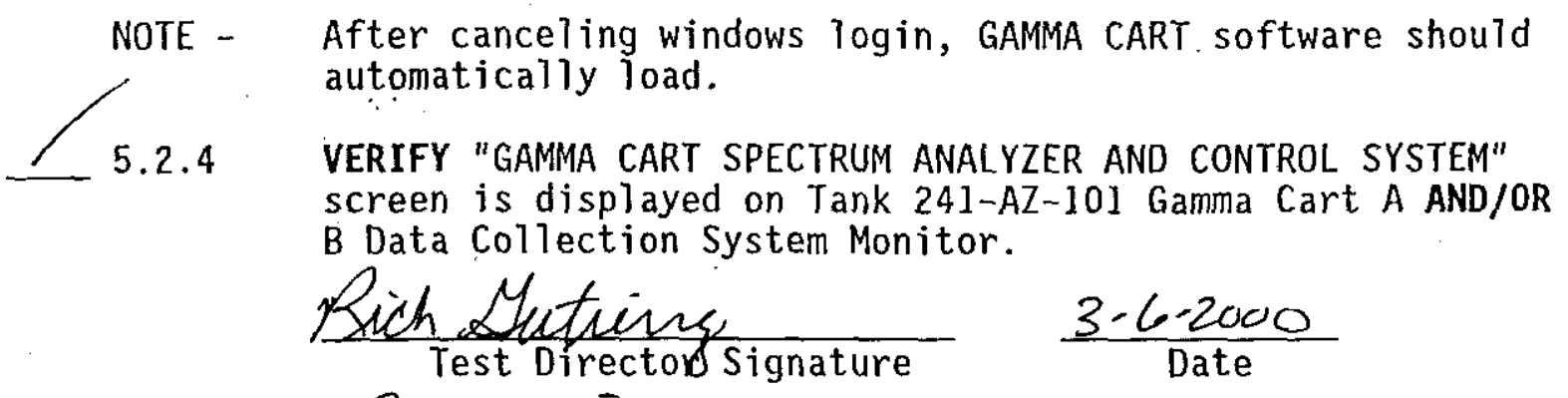

Rich Gutiener

Test Director Print Name

SELECT "Login" on the "GAMMA CART SPECTRUM ANALYZER AND CONTROL SYSTEM" screen.
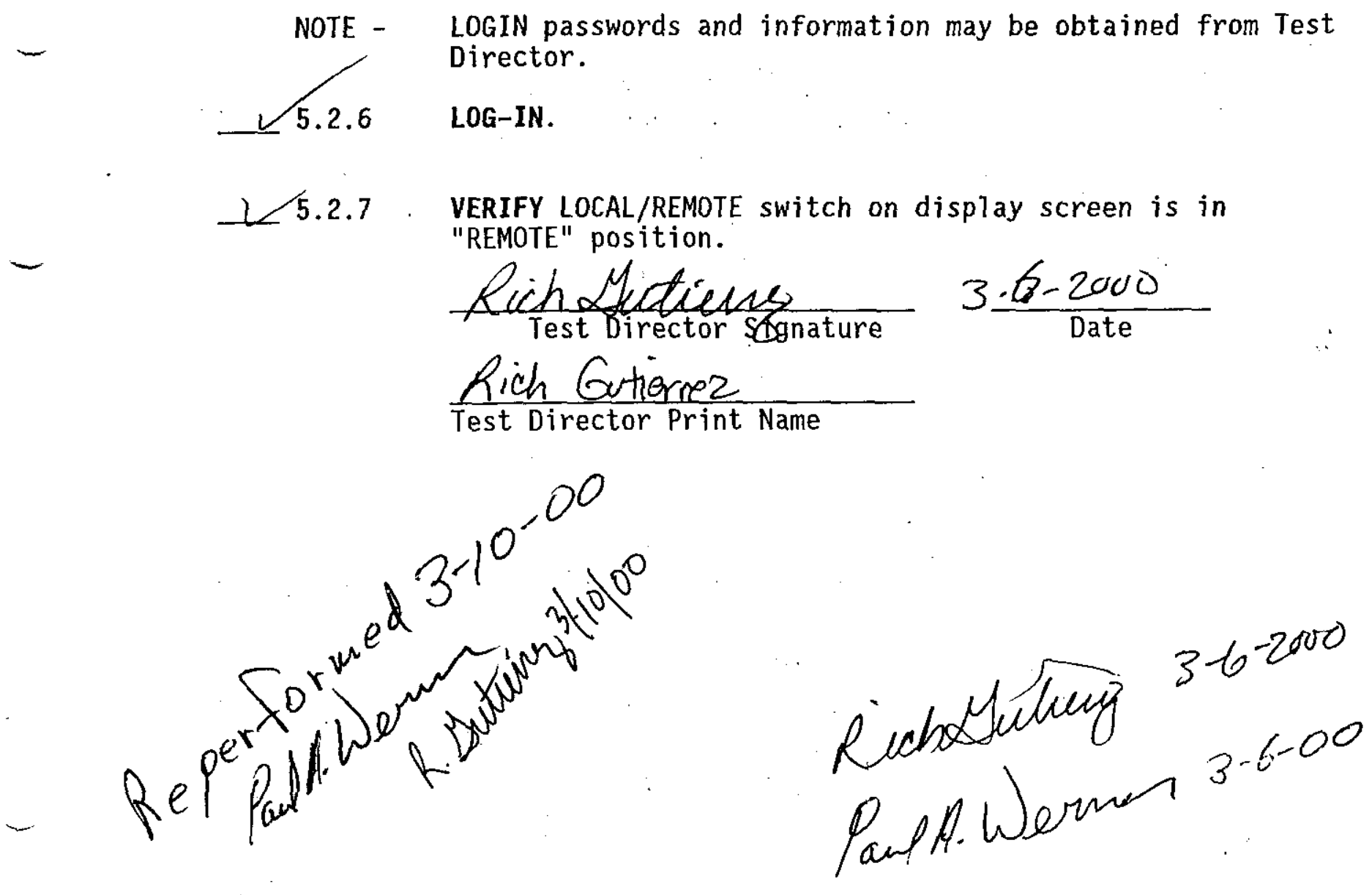

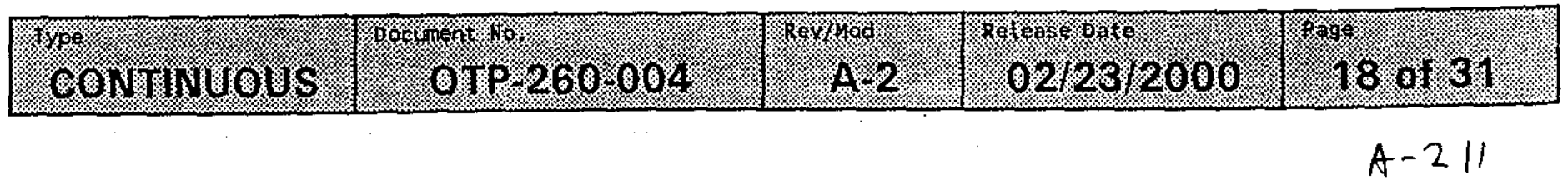




\subsection{TEST INCREMENTAL SAMPLE MODE (Cont).}

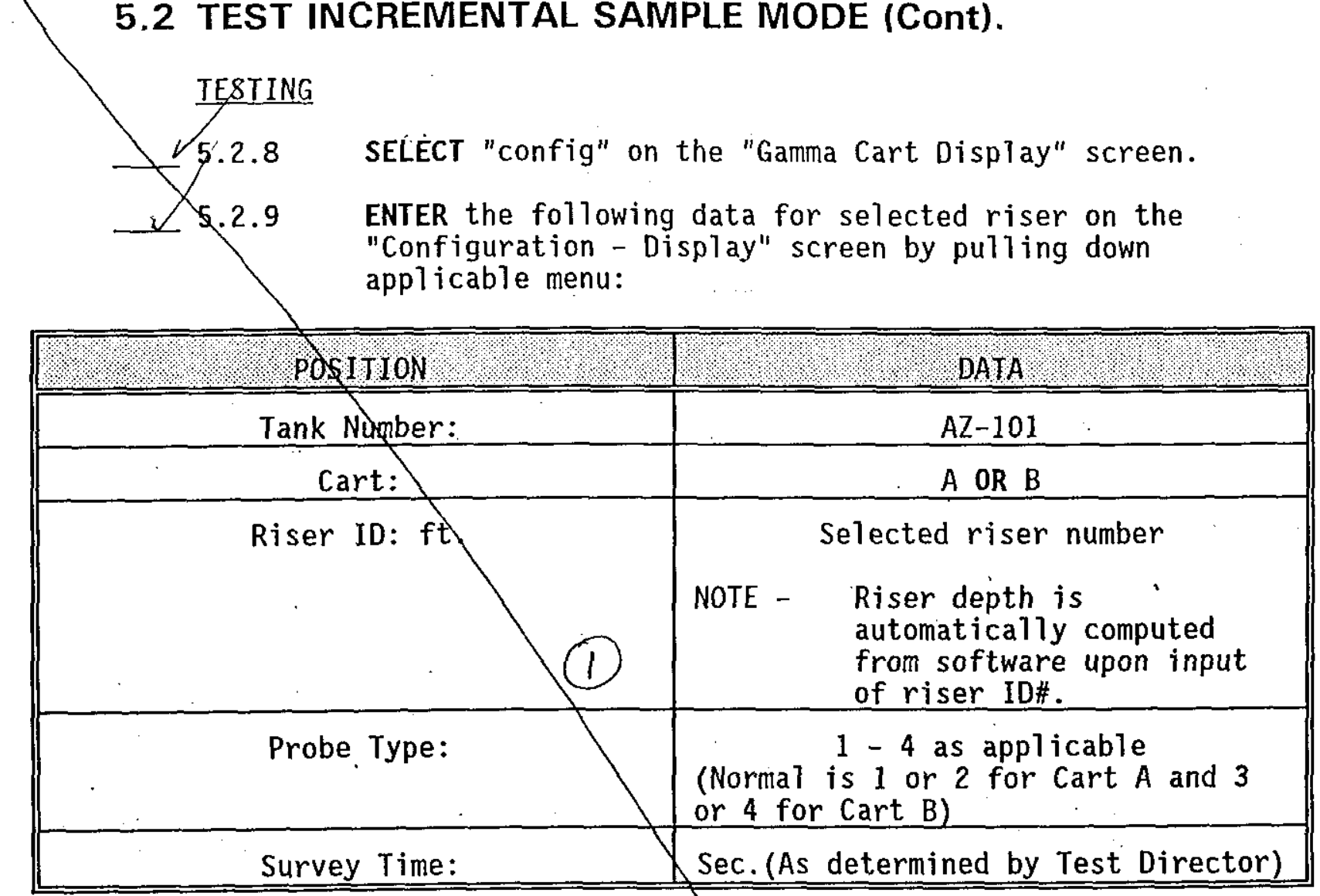

$\checkmark$ 5.2.10 ENSURE REAL/LIVE toggle button indicates "LIVE".

5.2.11 On the Data Collection Configuration window, SELECT the "Incremental." button.

INCREMENTAL PARAMETERS

5.2.12 INPUT the following Sample Collection Data:

\begin{tabular}{|l|l|l|}
\hline Sample Start: & $55.0 \mathrm{ft}$ \\
Depth: & \\
\hline Interval Size: & $10.0 \mathrm{ft}$ \\
\hline Sample End Depth: & $5.0 \mathrm{ft}$ \\
\hline
\end{tabular}

(1) Steps not needed, previously tested on OTP-260-004 ReV A.2 3/2/20dD

R. Jitieng $3 / 6 / 00$ 


\subsection{TEST INCREMENTAL SAMPLE MODE (Cont).}

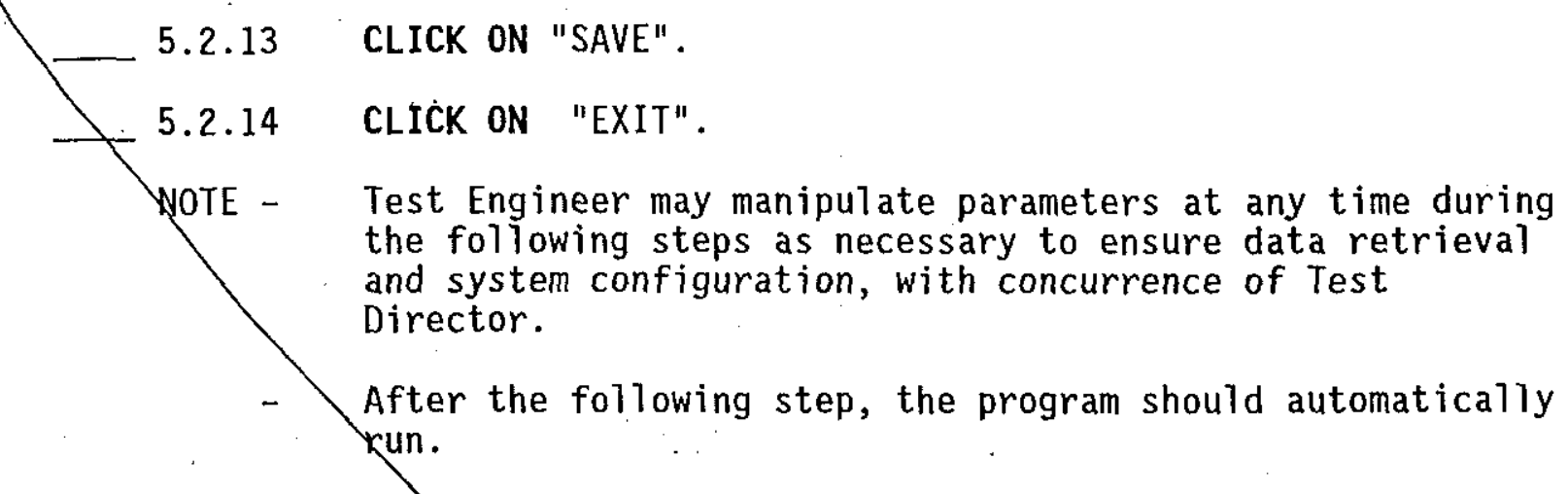

_ 5.2.15 CLICK ON "Start" button.

_ 5.2.16 CLICK ON "EMERGENCY STOP" button on computer screen:

_ 5.2 .17 VERIFY System stopped.
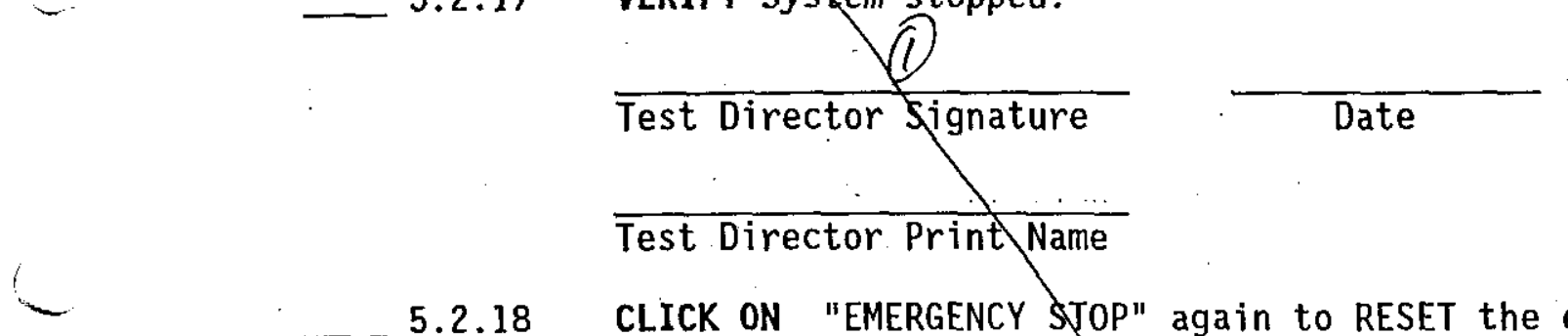

5.2.18 CLICK ON "EMERGENCY SJOP" again to RESET the emergency stop button on computer screen.

— 5.2.19 CLICK ON "ZERO" on display screen.

_ 5.2.20 ENSURE GAMMA PROBE begins to RAISE.

5.2.21 CLICK ON "STOP" button on display screen.

(1) see note on poge 19.
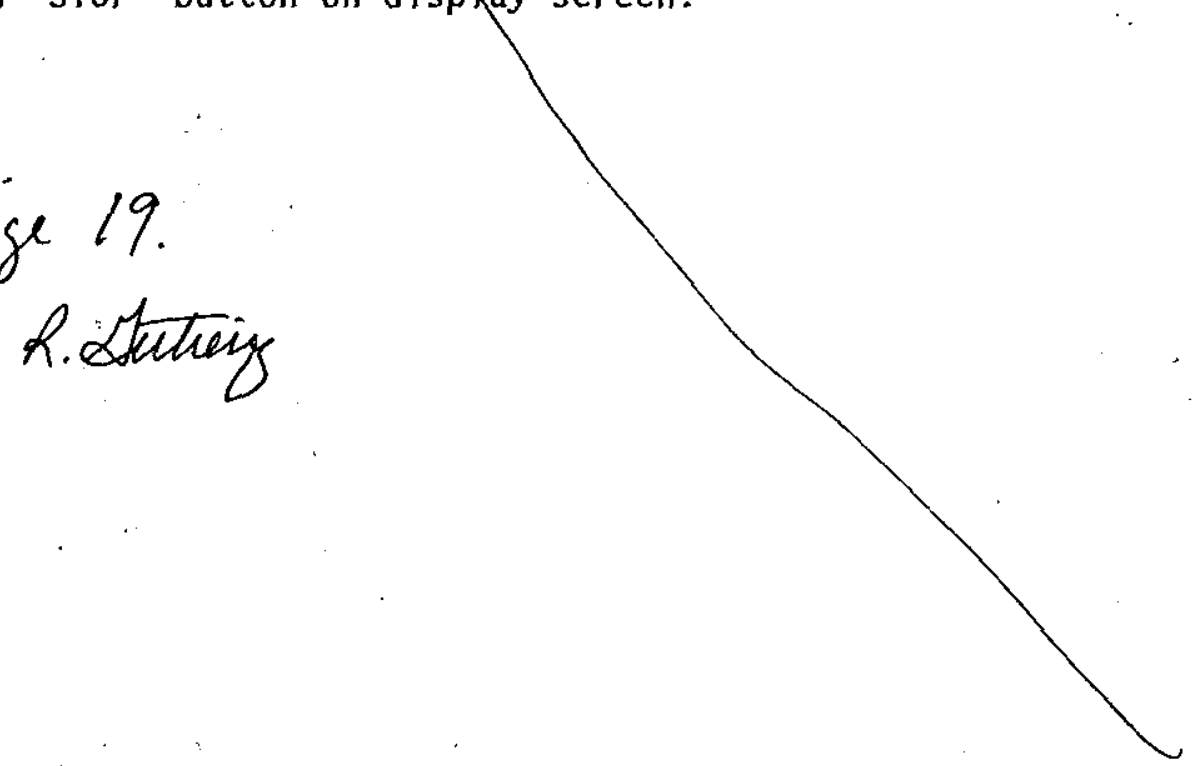
$R P P-6104 R O$

WORKING COPY

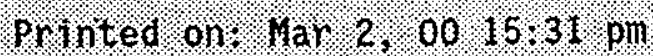

5.2 TEST INCREMENTAL SAMPLE MODE (Cont).

5.2.22 VERIFY System stopped.

$\overline{\text { Test Director Signature }}$

Test Director Print Name

5.2. 23 CLICK ON "ZERO" again on display screen.

5.2.24 ENSURE GAMMA PROBE begins to RAISE.

5.2 .25

When probe and system zeros, CLICK ON "START" on display screen.

5.2.26 VERTEY System resumed program.

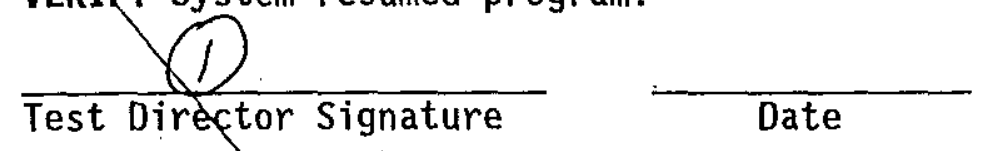

Test Director Print Name

5.2.27 CLICK ON "STOP" button on computer screen.

5.2.28 VERIFY System stopped.

Test Director Signature

Date

Test Director Print Name

5.2.29 CLICK ON "ZERO" on display screen.

5.2.30 When probe and system zeros, CLICK ON "START" on display screen.

5.2.31 VERIFY System resumed program.

Test Director Signature

Test Director Print Name

(1) see note on Page 19

R. Luting 3/6/2000

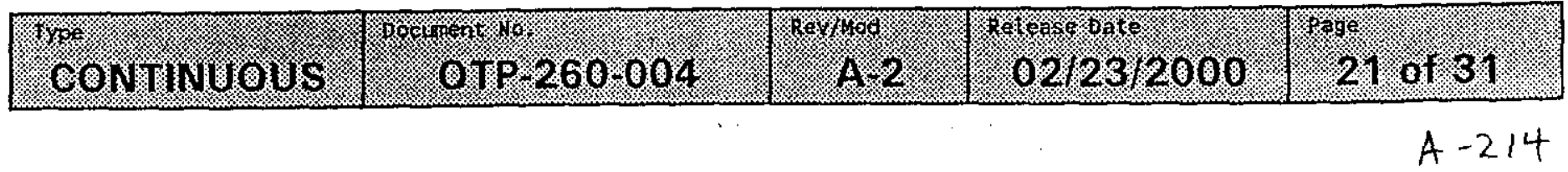




\subsection{TEST INCREMENTAL SAMPLE MODE (Cont).}

5.2.32 Test Engineer ENSURE data is received, AND both hard-copy and electronic files can be retrieved.

5.2.33 VERIFY system automatically ZEROs and data is collected at zero position.

4

Test Director Signature Date

Test Director Print Name

NOTE - The steps in section 5.1, applicable to the Emergency stop, need not be repeated if completed for an individual GAMMA CART. The Emergency stop on BOTH GAMMA CART A and B, need to be tested only once.

NOTE - It is NOT necessary to do ALL risers in one procedure. Test Direktor is responsible for ensuring ALL risers have been profiled by one AND/OR the other GAMMA CART(S).

5.2.34 REPEAT applicable SETUP Steps in section 5.1 AND

Incremental testing steps 5.2.1 - 5.2.15 AND Steps 5.2.32 and 5.2.33 for each of the following risers and depths per Test Director's direction.

(1) see note on page 19

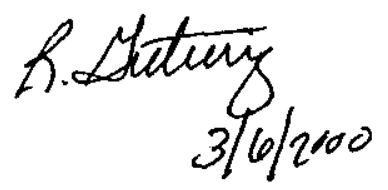

TABLE I

\begin{tabular}{c|c|c|c|}
\hline See note on page 19 RISER & Depth) \\
inches (ft)
\end{tabular}
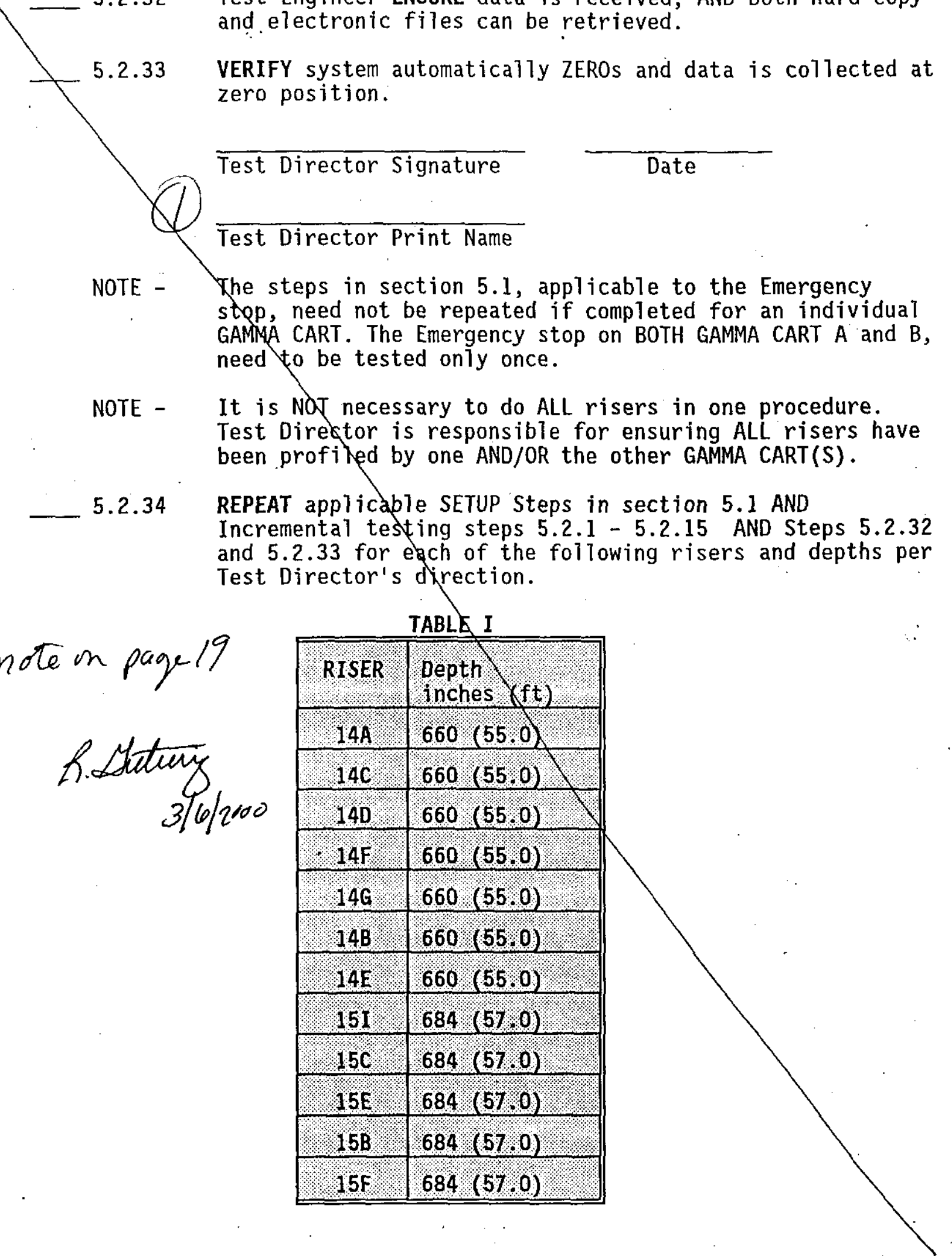

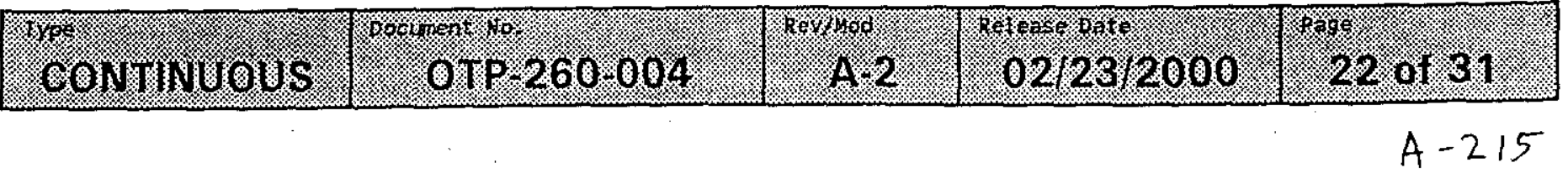


$R P P-6104 R O$

WORKING COPY

Printed on: Mar 2, 00 15:31 pm

5.2 INCREMENTAL SAMPLE MODE (Cont).

NOTE - In the following Table, Test Director N/A blocks that are tested with a different GAMMA CART.

5.2.35 VERIFY the applicable riser in step 5.2.34 has been tested.

TABLE II

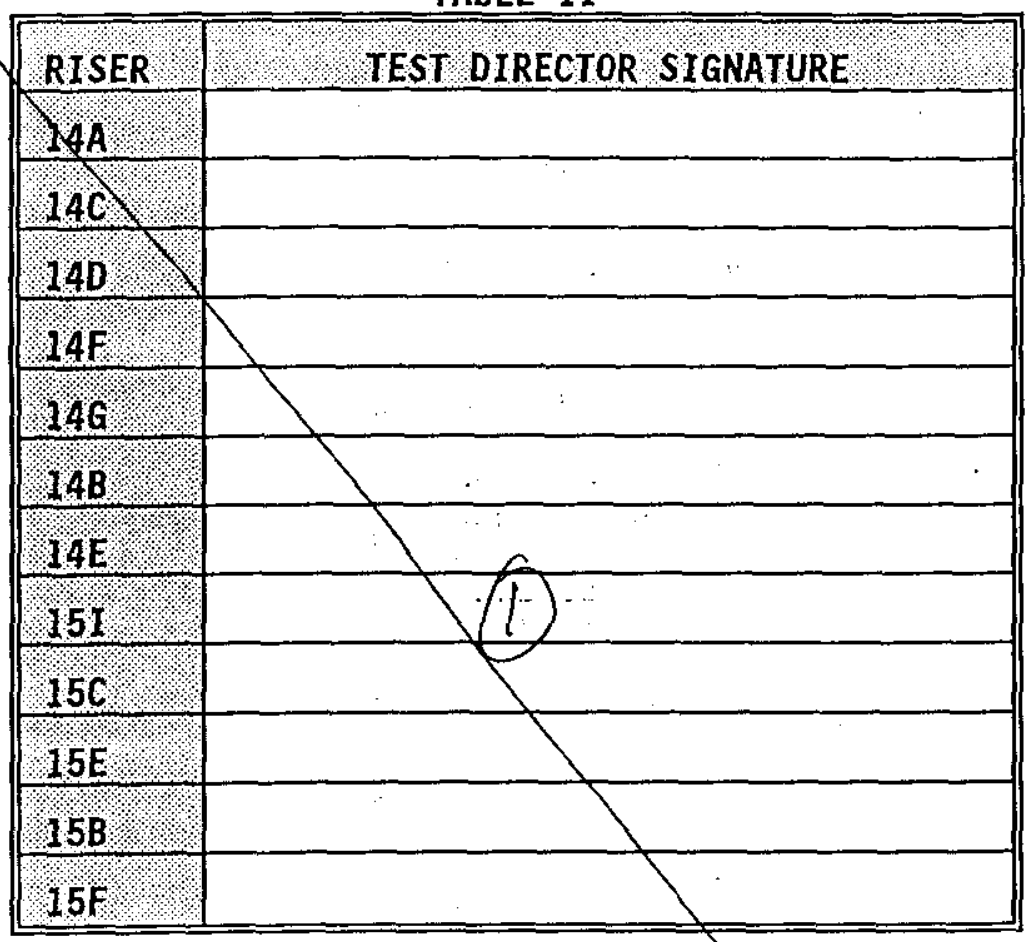

5.2.36 VERIFY by signing below section 5.2 is complete.

Test Director Signature

Rate

Test Director Print Name

QC Signature

Date

QC Print Name

(1) See note on Page 19. R. Asetieng 3/6) 3000

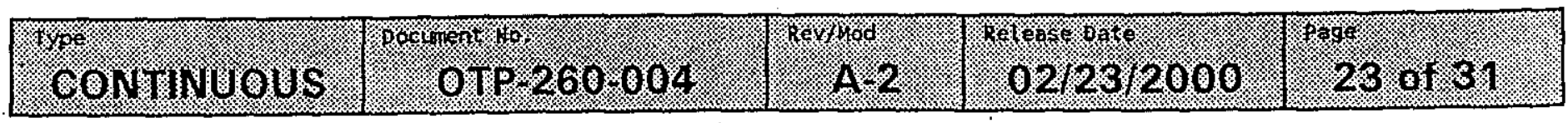

$A-216$ 


\subsection{TEST USER DEFINED MODE}

L.3.1 ENSURE applicable SETUP Steps in section 5.1 are completed.

\section{CART CONTROL SCREEN}

$1 / 5.3 .2$ On the Gamma Cart Control, CLICK oN the "Config." button.

5.3.3 INPUT the following data:

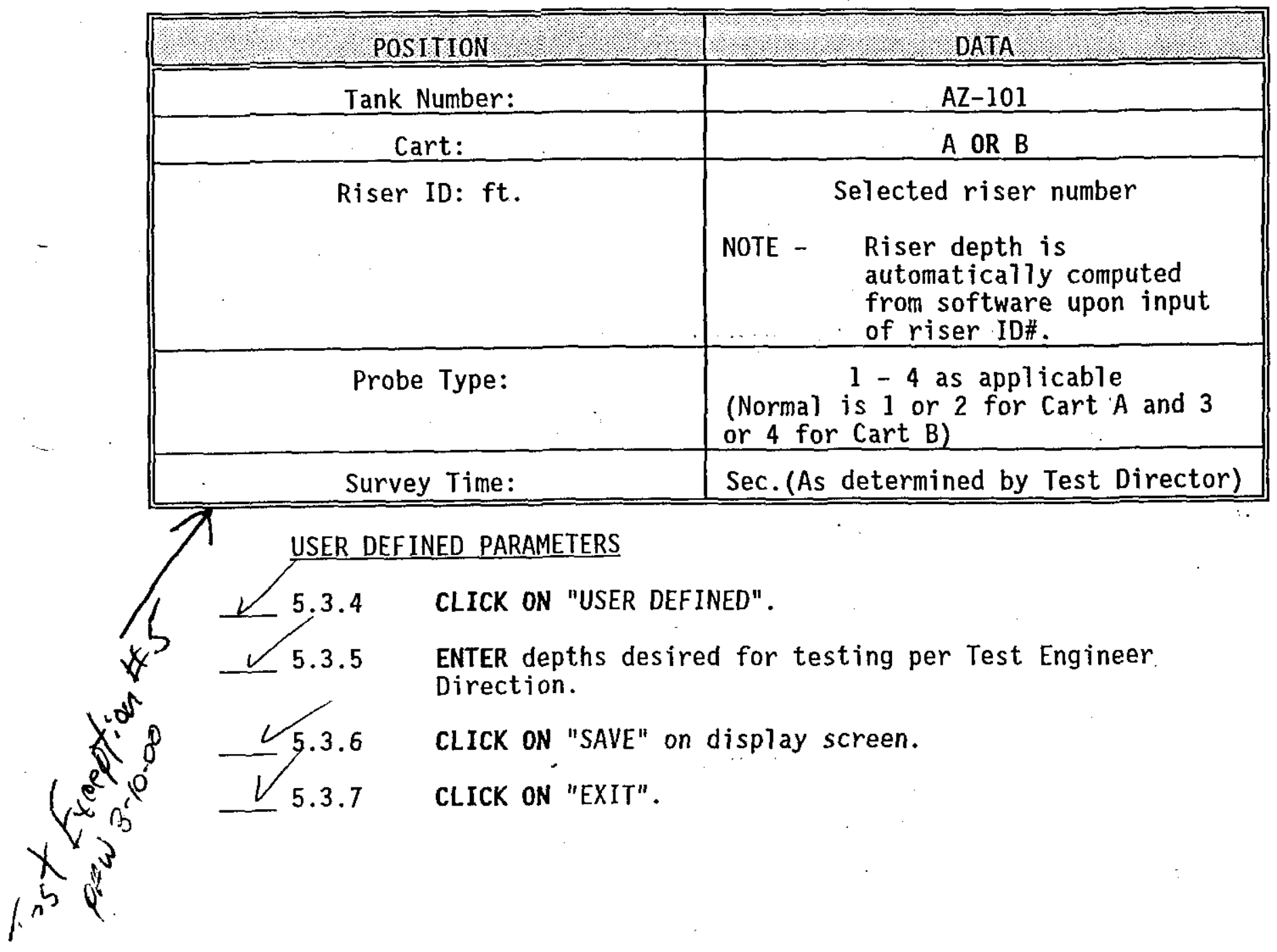




\subsection{TEST USER DEFINED MODE (Cont).}

NOTE - Test Engineer may manipulate parameters at any time during the following steps as necessary to ensure data retrieval and system configuration, with concurrence of Test Director.

- After the following step, the program should automatically run.

- The "EMERGENCY STOP" may be used to stop at any time during the next step if unit fails to stop at limit

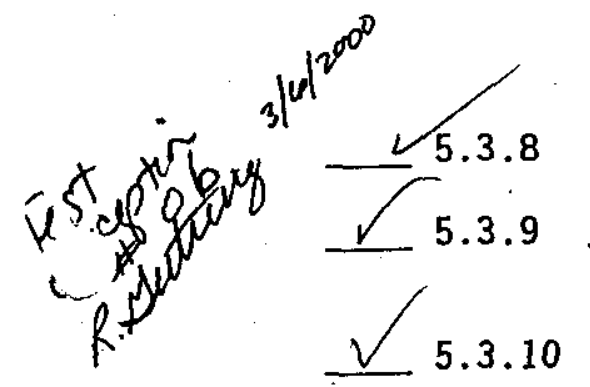
switch. The "RESET" button will need to be pushed to resume the program.

CLICK oN Start button.

Test Engineer ENSURE data is received, AND both hard-copy and electronic files can be retrieved.

VERIFY system automatically ZEROs and data is collected at zero position.

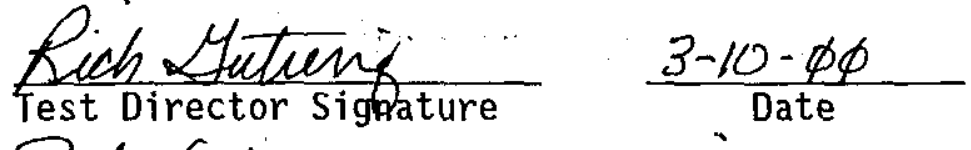

Rich Gutierrez

Test Director Print Name 
$R P P-6104 R O$

WORKING COPY

P. Inter on. Mar $2.00 .96 .31 \mathrm{pm}$

5.3 TEST USER DEFINED MODE (Cont).

$\sqrt{\square} 5.11$
$\stackrel{5}{\square} 5.12$

CLICK ON "LOGOUT" on display screen.

REMOVE Probe, riser extension tool, and associated equipment AND

STORE per Test Director direction.

OR

CONTINUE in this procedure.

$\simeq 5.3 .13$

REPEAT the steps in this section (5.3) as directed for any risers as directed by Test Director.

$\leftarrow 5.3 .14$

VERIFY by signing below section 5.3 is complete.

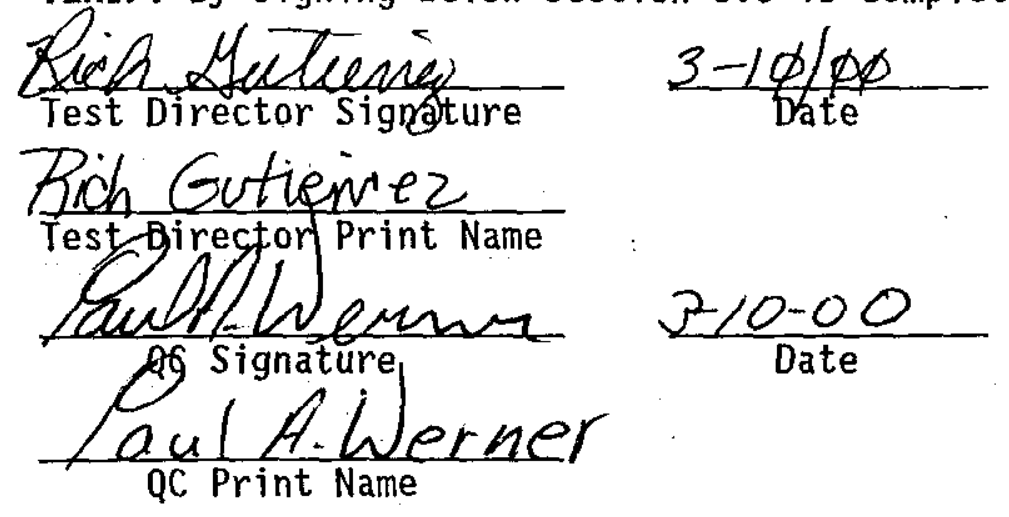

$$
\text { Riser } 15 B
$$

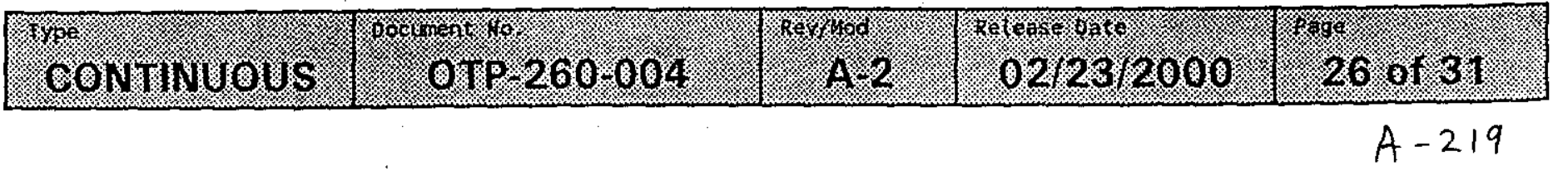


RISER 15C

GAMMA CART - A

$A-220$ 


\section{1-AZ GAMMA CART OPERATIONAL TEST PROCEDURE}

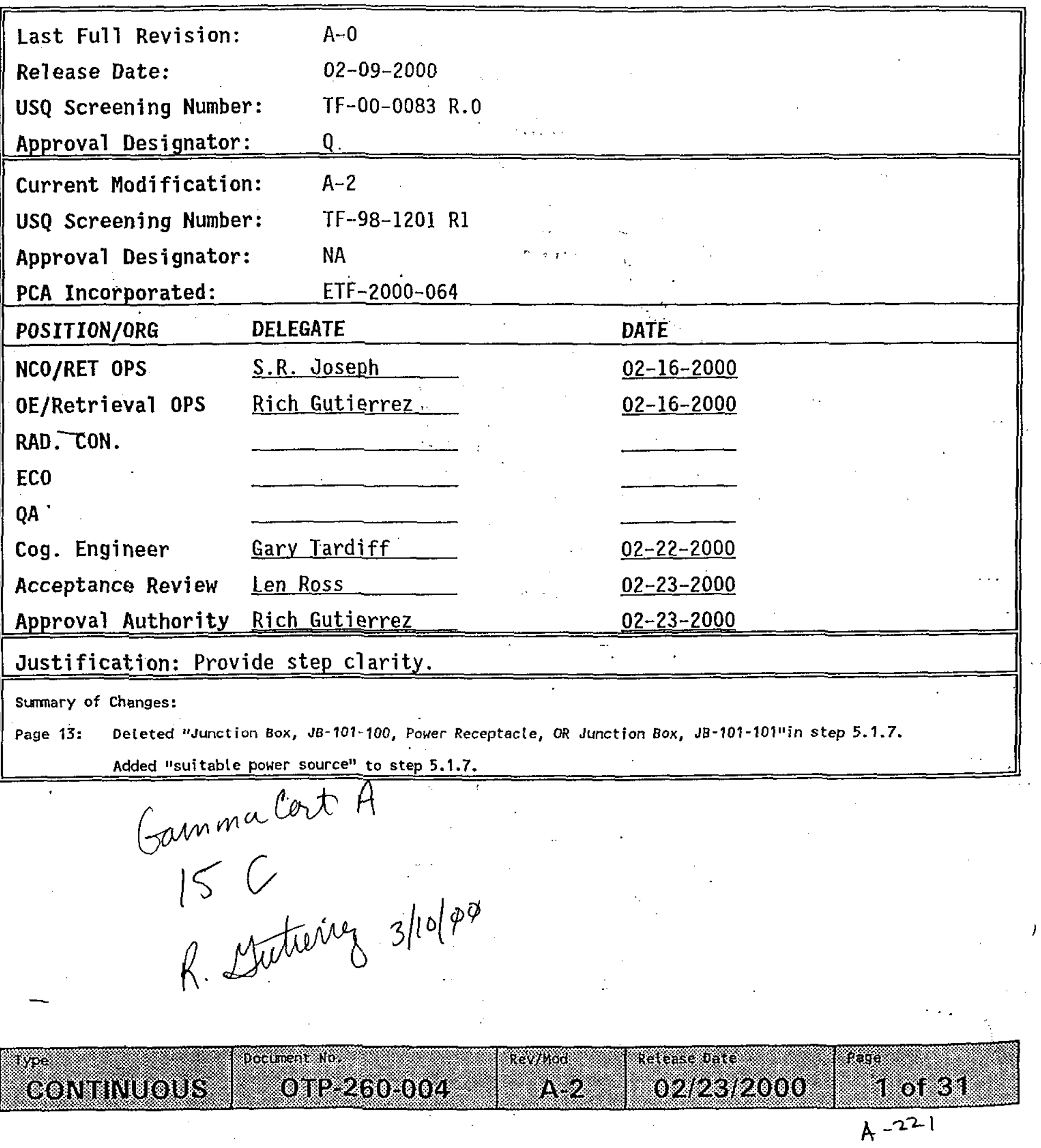


$R P P-6104 R O$

WORKING COPY

Printed on. if ar. 10, $00: 8.09$ atm

4.0 PREREQUISITES

4.1 SPECIAL TOOLS, EQUIPMENT, AND SUPPLIES

The following supplies may be needed to perform this procedure:

- Riser Swabbing equipment

- Riser extension tool

4.2 PERFORMANCE DOCUMENTS

The following procedures may be needed to perform this procedure:

- TO-040-333 LIQUID OBSERVATION WELL (LOW) SURVEILLANCE VAN STARTUP AND OPERATION PROCEDURE

4.3 CONDITIONS AND ACTIONS

NOTE - A11 signatory on this procedure shall document their signature on Procedure Signature Sheet.

4.3.1 All pretesting and inspection of the system or portions of the system to be tested has been completed.

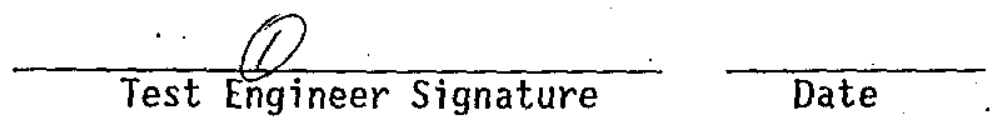

4.3.2 A pre-job briefing has been held. and all participants have been thoroughly briefed on job safety, hazards, and their responsibilities before performing this ATP.

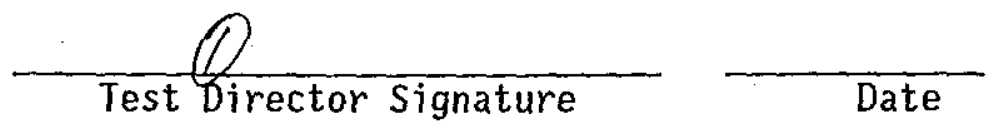

4.3.3 Test Director VERIFY section 4.3 has been COMPLETED.

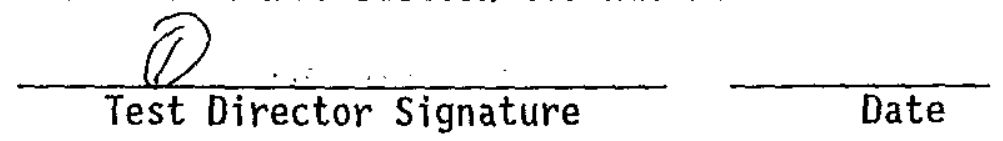

Q. Previously tested on OPP-2600004 Rev $A=0$.

R. Autieny 3/10/00

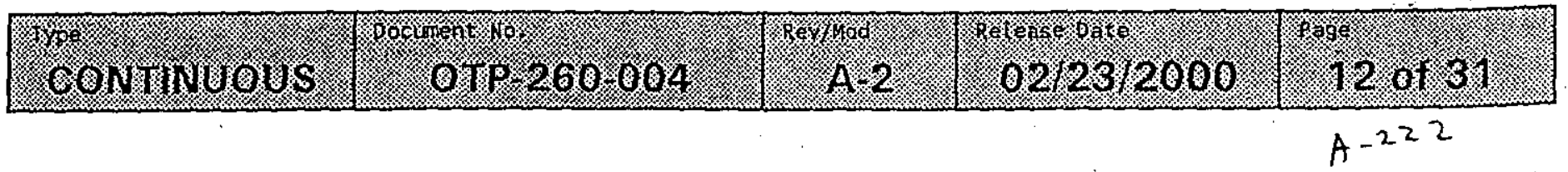




\subsection{PROCEDURE}

\subsection{SETUP}

NOTE - This procedure may be repeated for either GAMMA CART A or GAMMA CART B as applicable. N/A may be entered in blocks or steps per Test Director as applicable.

5.1.1 RECORD GAMMA CART CPU number for the system being tested. GAMMA CART IDENTIFIER \#A $\frac{\text { WC } 68789}{\text { CPU Number }}$

5.1.2 PERFORM cleanliness check in applicable riser listed on TABLE II, per section 5.10 in procedure T0-040-333 latest rev, prior to mounting riser extension tool.

$\mathcal{U} 5.1 .3$

ENSURE GAMMA CART riser extension tool is mounted on the applicable riser.

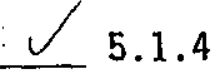

ENSURE GAMMA CART is placed in Tine with riser extension tool to facilitate installation of probe and cables.

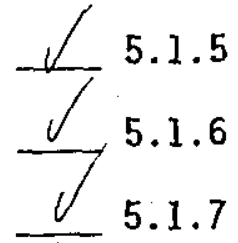

CHECK route to riser for obstacles and clearances.

LEVEL cart using jacks.

CONNECT gamma cart power cables, as follows:

- One end to gamma cart power receptacle

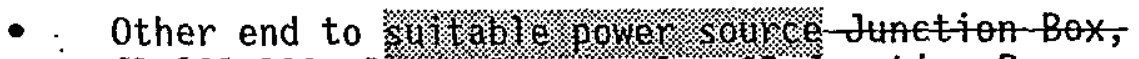
IB $101-100$, Power Receptacte, OR Junction-Box, JB $101-101$

5.1.8 CONNECT gamma cart communications cable, as follows:

- One end to gamma cart communications receptacle

- $\quad$ other end to Tank 241-AZ-101 Gamma Cart A AND/OR B Data Collection Subsystem communications receptacle

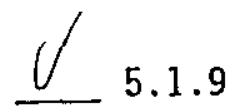

PLACE Gamma Cart "RAISE OFF LOWER" switch in the LOWER position.

$\sqrt{ } 5.1 .10$

CHECK that detector probe cable is resting in the Gamma Cart boom cable reel. 


\subsection{SETUP (Cont).}

\section{CAUTION}

If sufficient tension is NOT held on the detector probe cable as the cable is being let out, the cable could become entangled.

NOTE - Step 5.1.11 and 5.1 .12 require two operators to perform continuous action until step 5.1 .12 is complete.

5.1.11 HOLD tension on the detector probe cable until step 5.1.12 is completed.

5.1.12 PRESS AND HOLD "RESET" button until enough detector probe cable is let-out that will allow placement of the detector cable through riser extension collar AND into riser drywe 11, AND

RELEASE the "RESET" button.

5.1.13 INSTALL the proper detector probe on the detector probe cable.

5.1.14 ENSURE that the detector probe connections are correct and tight. AND

INSERT probe into riser extension: tool.

5.1.15 ENSURE limit switch cable is connected from limit switch on riser extension tool, to the connection point on the front of the GAMMA CART.

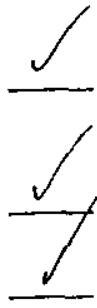

ENSURE the "Raise - Off - Lower" selector switch is in the "OFF" position.

5.1.17 ENSURE the emergency stop button is pulled out.

5.1.18 POSITION the "SPEED" control potentiometer to MIN speed (fully counter-clockwise). 
$R P P-6104 R O$

WORKING COPY

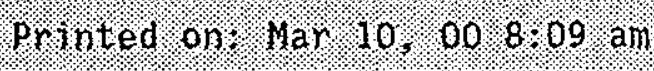

5.1 SETUP (Cont).

CAUTION

There is no limit switch to stop the motion when the cable is fully unwound. The cable will rewind backwards on the reel. Damage to the cable may result.

NOTE - When the cart is first powered up, or the emergency stop button has been pushed, or power has been restored after power failure, the cable reel will not move up or down until "RESET" button is activated.

- The "Raise-OFF-Lower" Switch is Manually controlled and is Operator Dependent.

\[ 5.1 .19 \text { ENSURE LOCAL/REMOTE switch is in the "LOCAL" position. } \]
5.1 .20 ENERGIZE the Cart.
5.1 .21 SET the "SPEED" potentiometer to 2 on the GAMMA Cart.
5.1 .22

(1) 5.1 .23 position.

(1) 5.1 .24 PUSH "EMERGENCY STOP" button on GAMMA CART.

VERIFY the system has stopped.

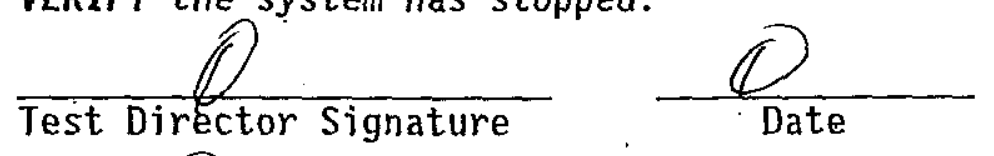

Test Director Print Name

(1) already Tested per oth-2600-00 4 Rev A-O

R. Station 3/10\%00

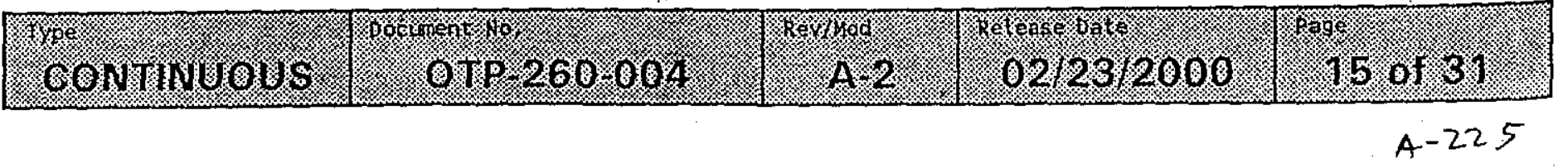


WORKING COPY

RPP- $6104 R O$

Printed ont. nar. $10.00 \% 8.09$, am

5.1 SETUP (Cont).

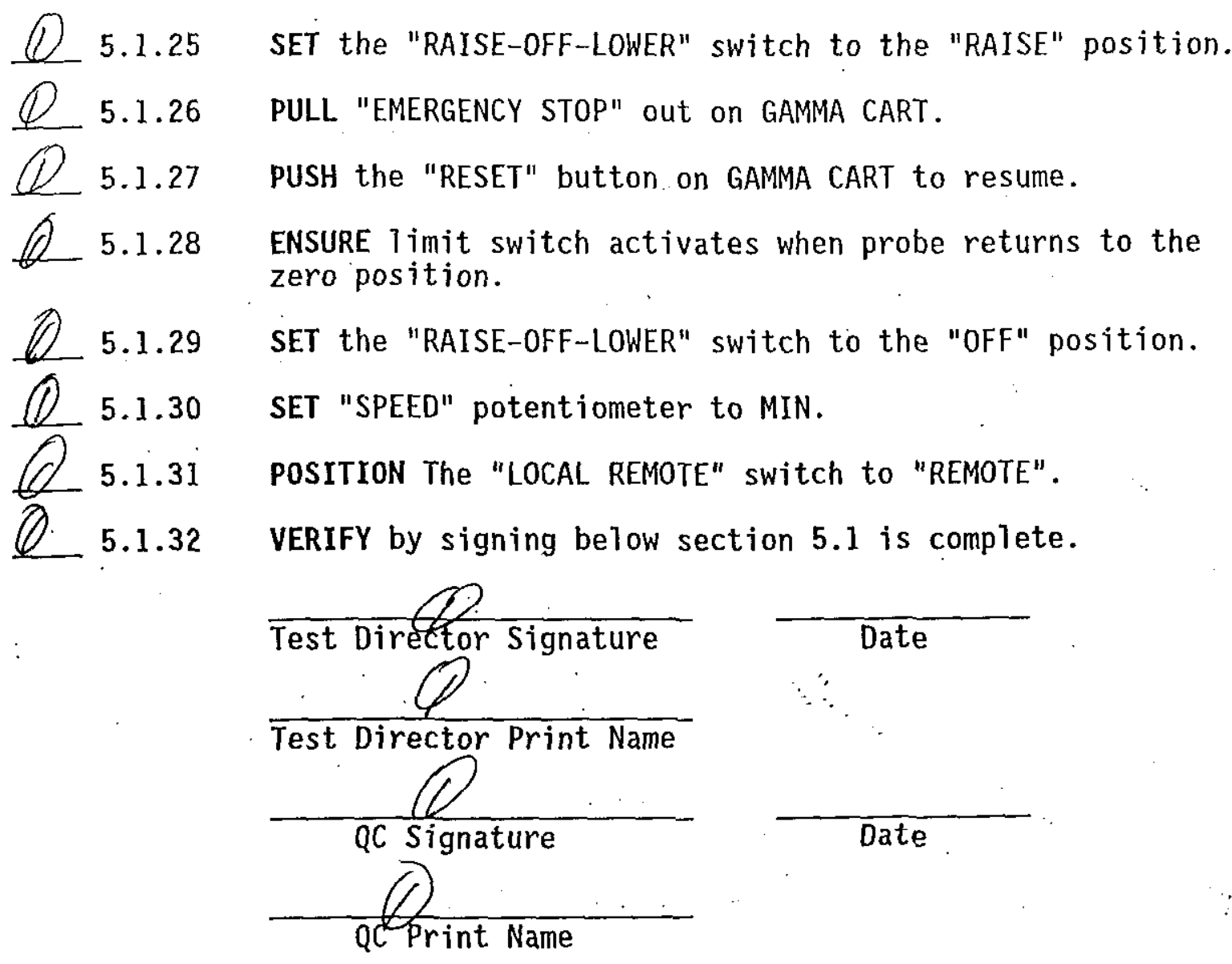

Q. previsisly tested on OTP.260-004 A-O

R.setieny 3/2/200

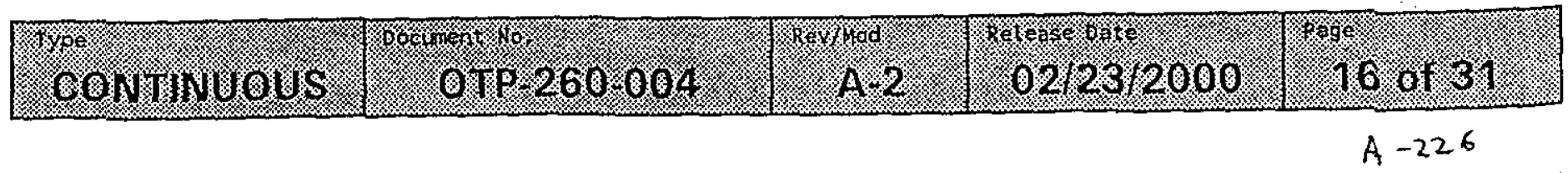




\subsection{TEST INCREMENTAL SAMPLE MODE}

\section{SETUP}

NOTE - All Steps in this section apply to either cart, except in

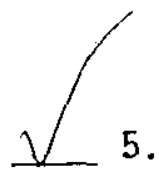
those steps where the specific cart is indicated.

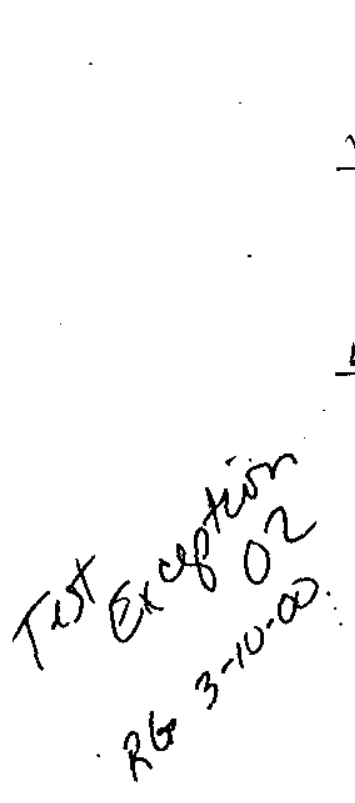

5.2.1 IF the pushbutton for Tank 241-AZ-101 Gamma Cart A AND/OR B Data Collection System Central Processing Unit (CPU), AND/OR associated MONITOR, are NOT ON, PRESS the app Ticable oN pushbuttons.

5.2.2 ENSURE the following systems are ON AND

ENSURE settings are correct for the following:

- ORTEC MINIBIN

- POWER SUPPLY

Detector Bias Power Supply (HVPS): ORTEC Mod. 478.

- $\mathrm{kV}: .5$

- 0 to 1000V: (+60 voits)

Amplifier (AMP): ORTEC Mod. 673

- COARSE GAIN: 200

- FINE GAIN: 0.680

- SHAPING TIME: Both knobs set to 2 microseconds

- PZ Adjust: Do NOT change settings (in this procedure)

- BLR: Switch in AUTO (up) position

- INPUTS: Switch in POS (up) position BNC cable on terminal (from pre amplifier)

- OUTPUTS: cable on UNIPOLAR terminal(to single channel

$\underbrace{\text { Analyzer) }}$ W.2.3 WHEN WINDOWS login screen appears CLICK ON "CANCEL".

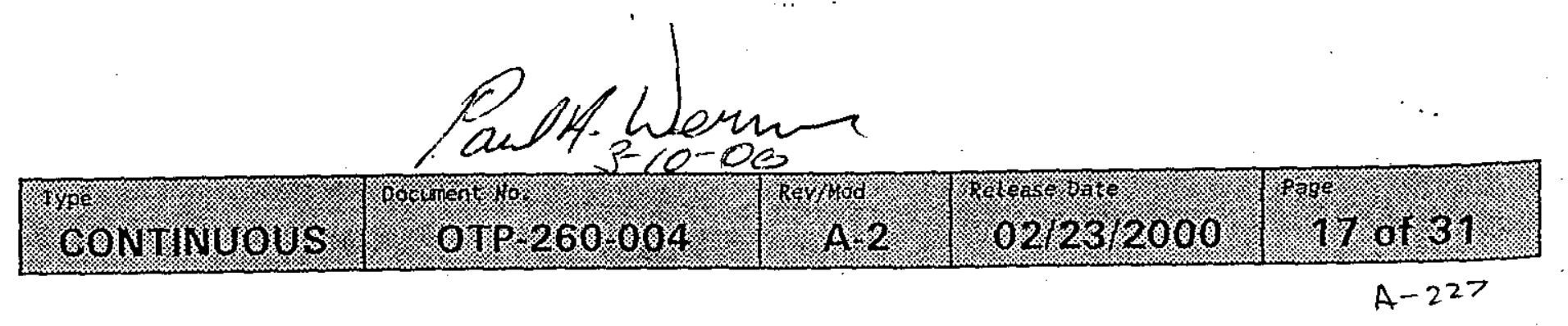


$R P P-6104 R O$

WORKING COPY

Printed on. Mar 10.00 .09 .09 ant

5.2 TEST INCREMENTAL SAMPLE MODE (Cont).

NOTE - After canceling windows login, GAMMA CART software should automatically load.

5.2.4 VERIFY "GAMMA CART SPECTRUM ANALYZER AND CONTROL SYSTEM" screen is displayed on Tank 241-AZ-101 Gamma Cart A AND/OR $B$ Data Collection System Monitor.

$\frac{\text { Rich Lutuwy }}{\text { Test Director Signature }} \frac{3-1000}{\text { Date }}$ RuchGutierrez

Test Director Print Name

5.2.5 SELECT "Login" on the "GAMMA CART SPECTRUM ANALYZER AND CONTROL SYSTEM". screen.

NOTE - LOGIN passwords and information may be obtained from Test Director.

5.2.6 LOG-IN.

5.2.7 VERIFY LOCAL/REMOTE switch on display screen is in "REMOTE" position.
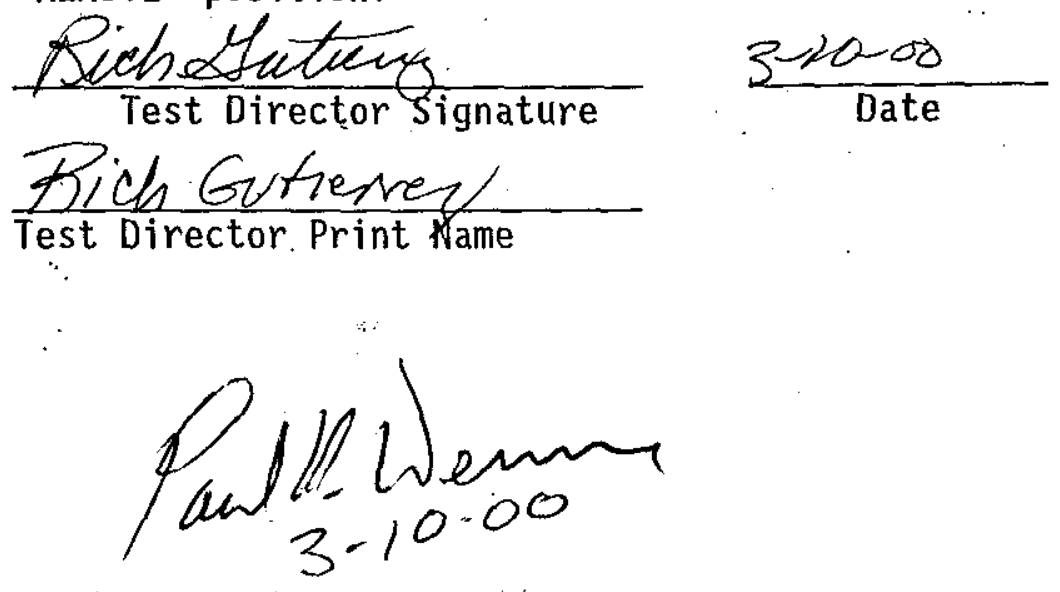

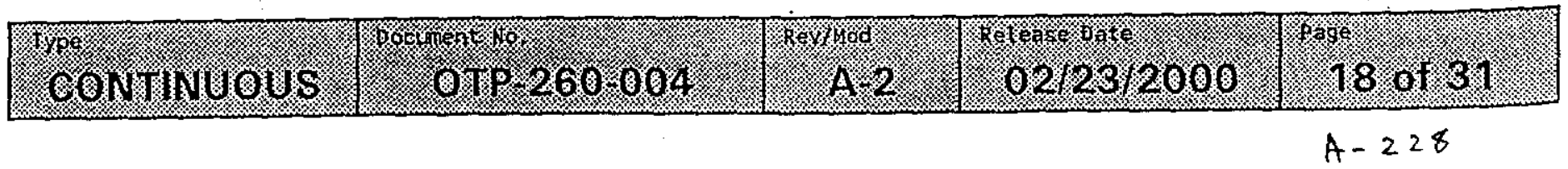




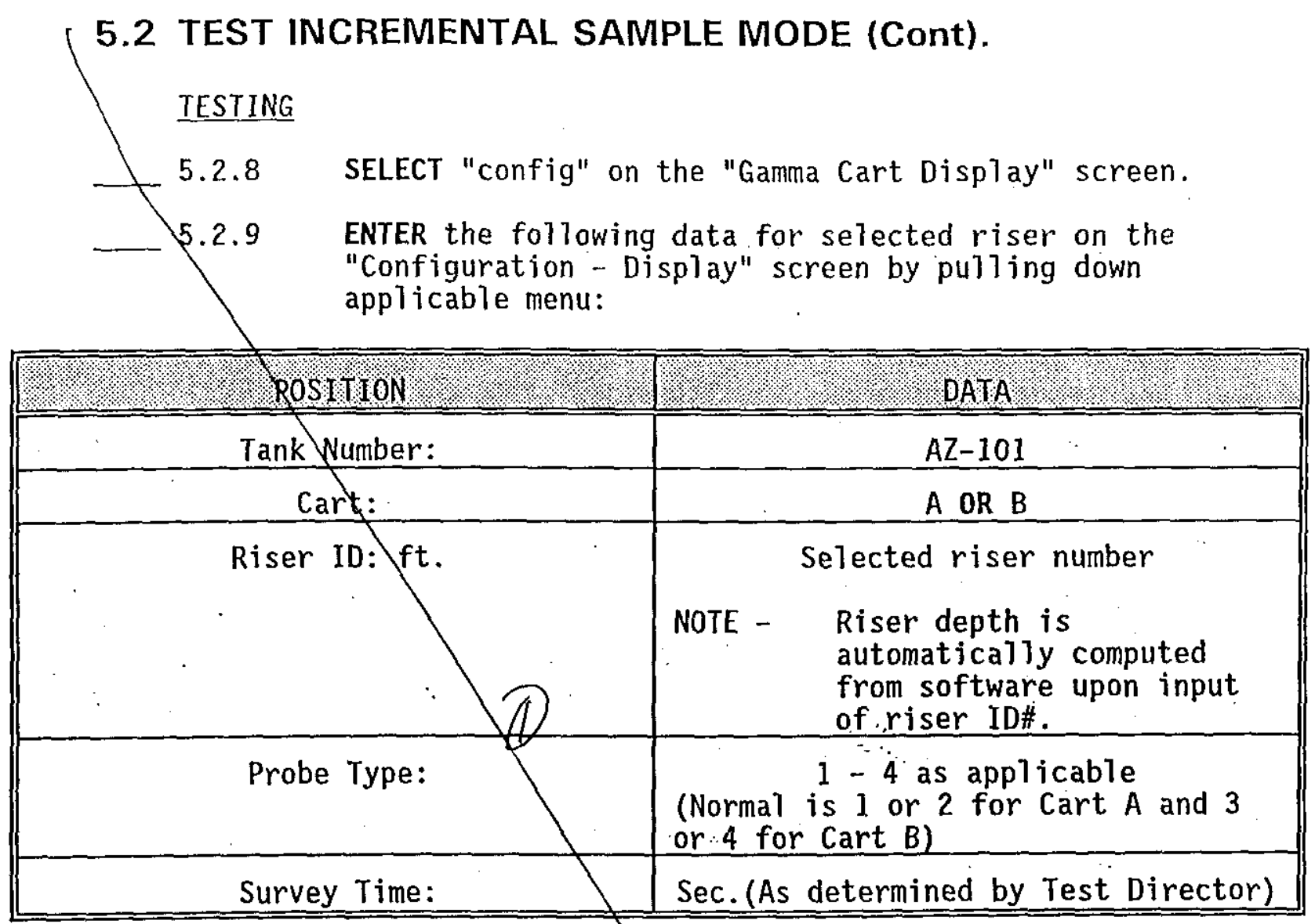

5.2.10 ENSURE REAL/LIVE toggle button indicates "LIVE".

5.2.11 On the Data Collection Configuration window, SELECT the

"Incremental" button.

INCREMENTAL PARAMETERS

5.2.12 INPUT the following Sample Collection Data:

\begin{tabular}{|c|c|}
\hline $\begin{array}{l}\text { Samplo Start } \\
\text { Depth. }\end{array}$ & $55.0+1 \mathrm{t}$ \\
\hline Interval Size. & $10.0 . \mathrm{tt}$ \\
\hline Sample End Dep & \\
\hline
\end{tabular}

(1) premiosly testad on OtR320-004 AO R. Sutury 3/10/00 
RPP-6104 RD

WORKING COPY

printed on, liar $10,000.8 .09$, an

5.2 TEST INCREMENTAL SAMPLE MODE (Cont).

5.2.13 CLICK ON "SAVE".

5.2.14 CLICK ON "EXIT".

NOTE - Test Engineer may manipulate parameters at any time during the following steps as necessary to ensure data retrieval and system configuration, with concurrence of Test Director.

After the following step, the program should automatically run.

5.2.15 CLICK ON "Start" button.

5.2.16 CLICK ON "EMERGENCY STOP" button on computer screen.

5.2.17 VERIFY System stopped.

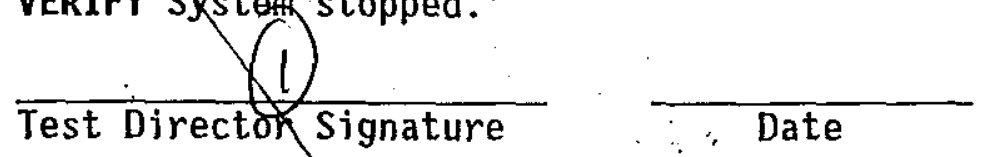

Test Director Print Name

5.2.18 CLICK ON "EMERGENCK STOP" again to RESET the emergency stop button on computer screen.

5.2.19 CLICK ON "ZERO" on display screen.

5.2.20 ENSURE GAMMA PROBE begins to RAISE.

5.2.21 CLICK ON "STOP" button on diSplay screen.

(1) previously tested in OTP-320-004 Rev A.O

R. Setting 3/10/00

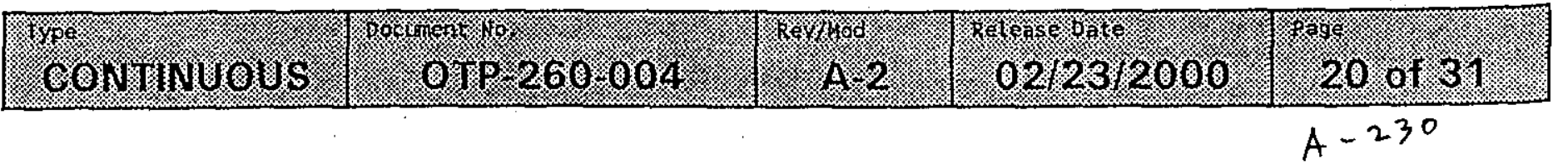


$R P P-6104$ BO

WORKING COPY

Printed on. War $10,00.8 .09$ am

5.2 TEST INCREMENTAL SAMPLE MODE (Cont).

5.2.22 VERIFY System stopped.

Test Director Signature $\quad$ Date

Test Director Print Name

CLICK ON "ZERO" again on display screen.

ENSURE GAMMA PROBE begins to RAISE.

When probe and system zeros, CLICK ON "START" on display screen.

VERIFY System resumed program.

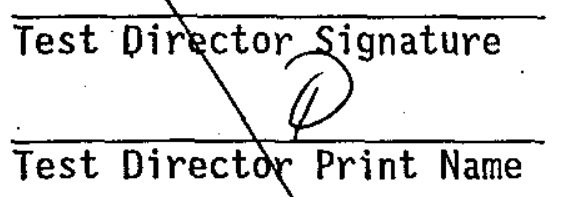

5.2 .26

5.2 .27

CLICK ON "STO PM button on computer screen.

5.2.28 VERIFY System stopped.

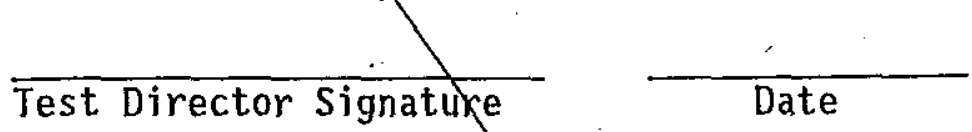

5.2.29 CLICK ON "ZERO" on display screen.

5.2.30 When probe and system zeros, CLICK ON "START" on display screen.

5.2.31 VERIFY System resumed program.

Test. Director Signature

Test Director Print Name

(1) freriosly tested on OTP-260-084 Rev A-O

hostetuye $3 /(1) / \%$

U

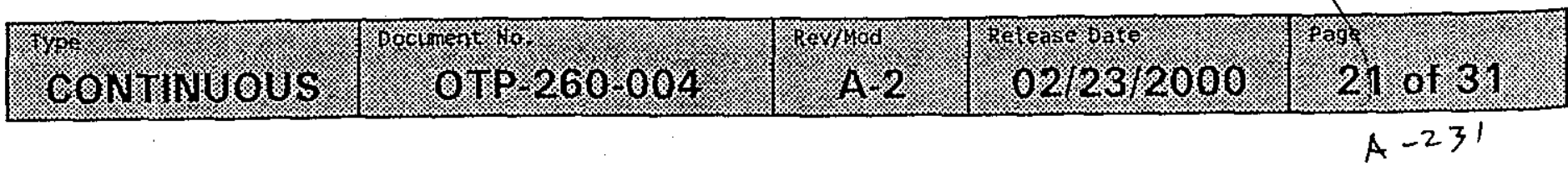




\section{(5.2 TEST INCREMENTAL SAMPLE MODE (Cont).}

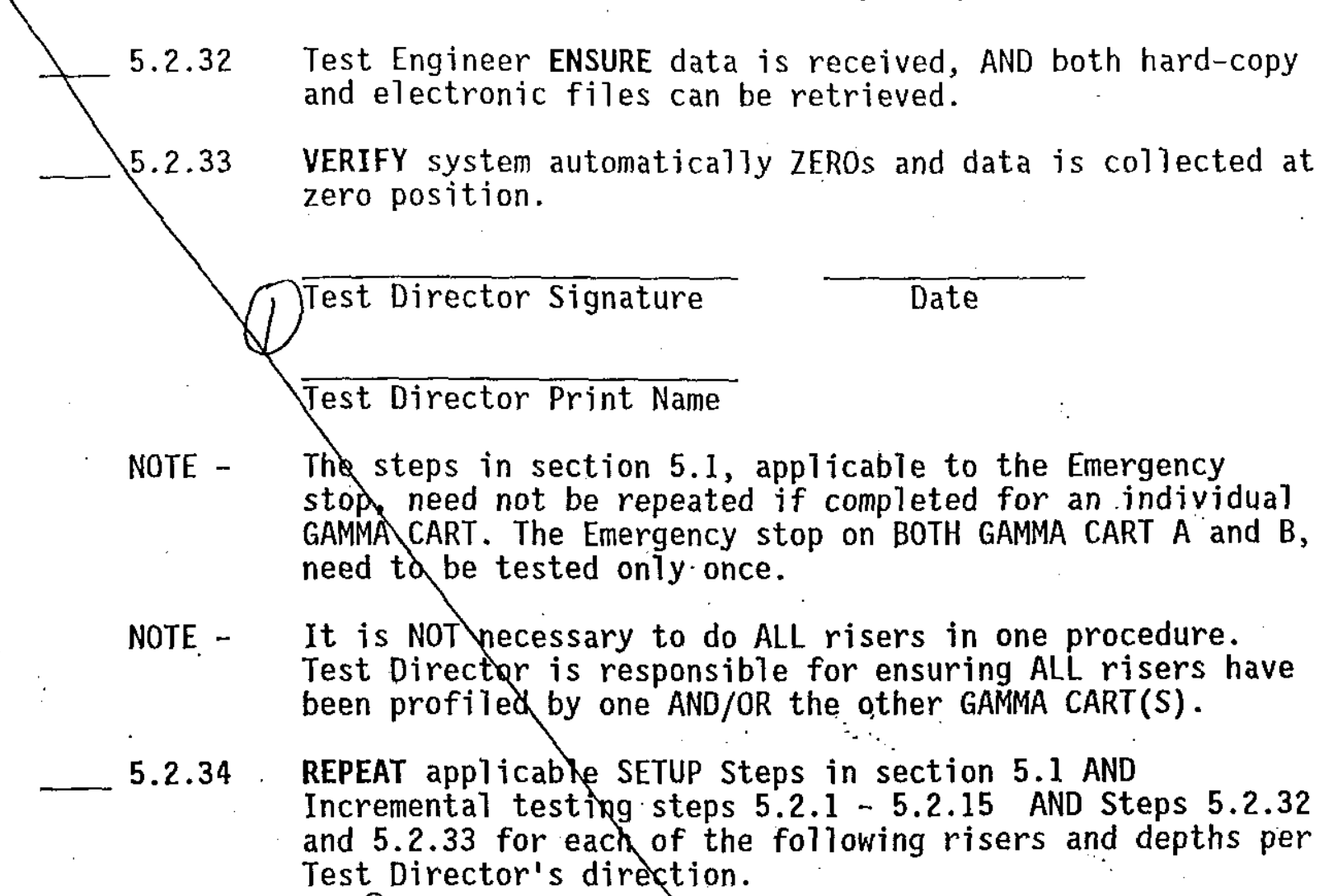

(D)

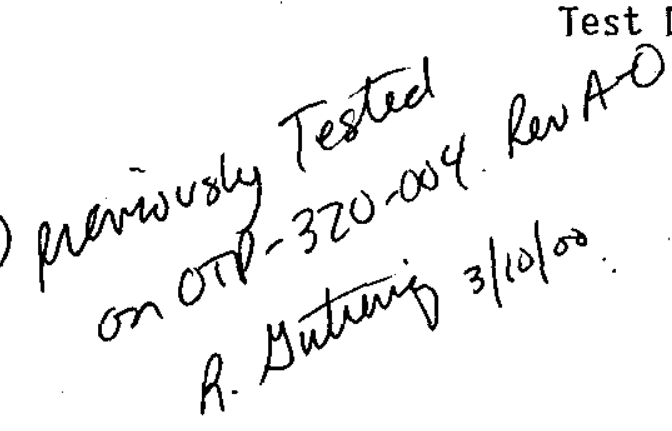

\begin{tabular}{|c|c|}
\hline RISER & Depthes \\
\hline $14 A$ & $660,(55,0)$ \\
\hline 140 & $660 \cdot(55.0)$ \\
\hline 140 & $660 \cdot(55,0)$ \\
\hline$\sqrt{47}$ & 660 - 55.0 \\
\hline $14 G$ & $660 \cdot(55,0)$ \\
\hline 148 & $660 .(55,0)$ \\
\hline $14 \mathrm{E}$ & $660:(55,0)$ \\
\hline 151 & $684 .(57,0)$ \\
\hline 150 & $684 \cdot(57,0)$ \\
\hline $15 \mathrm{E}$ & $684 .(57.0)$ \\
\hline $15 B$ & $684(57,0)$ \\
\hline $15 F$. & $684 \cdot(57,0)$ \\
\hline
\end{tabular}

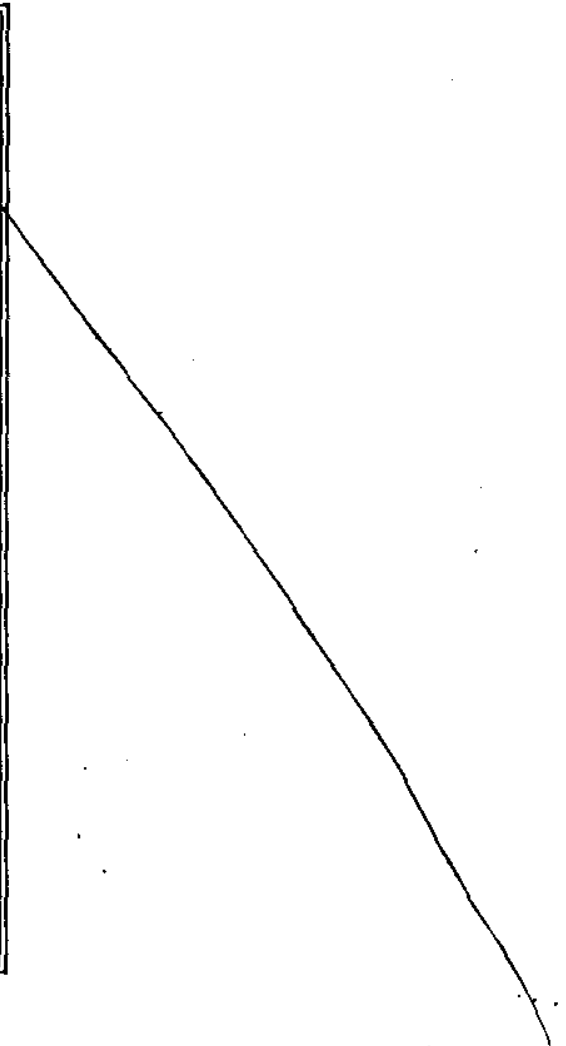


$R P P-6104 R$

WORKING COPY

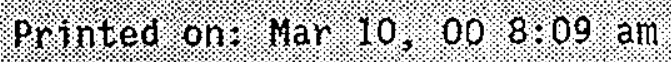

5.2 INCREMENTAL SAMPLE MODE (Cont).

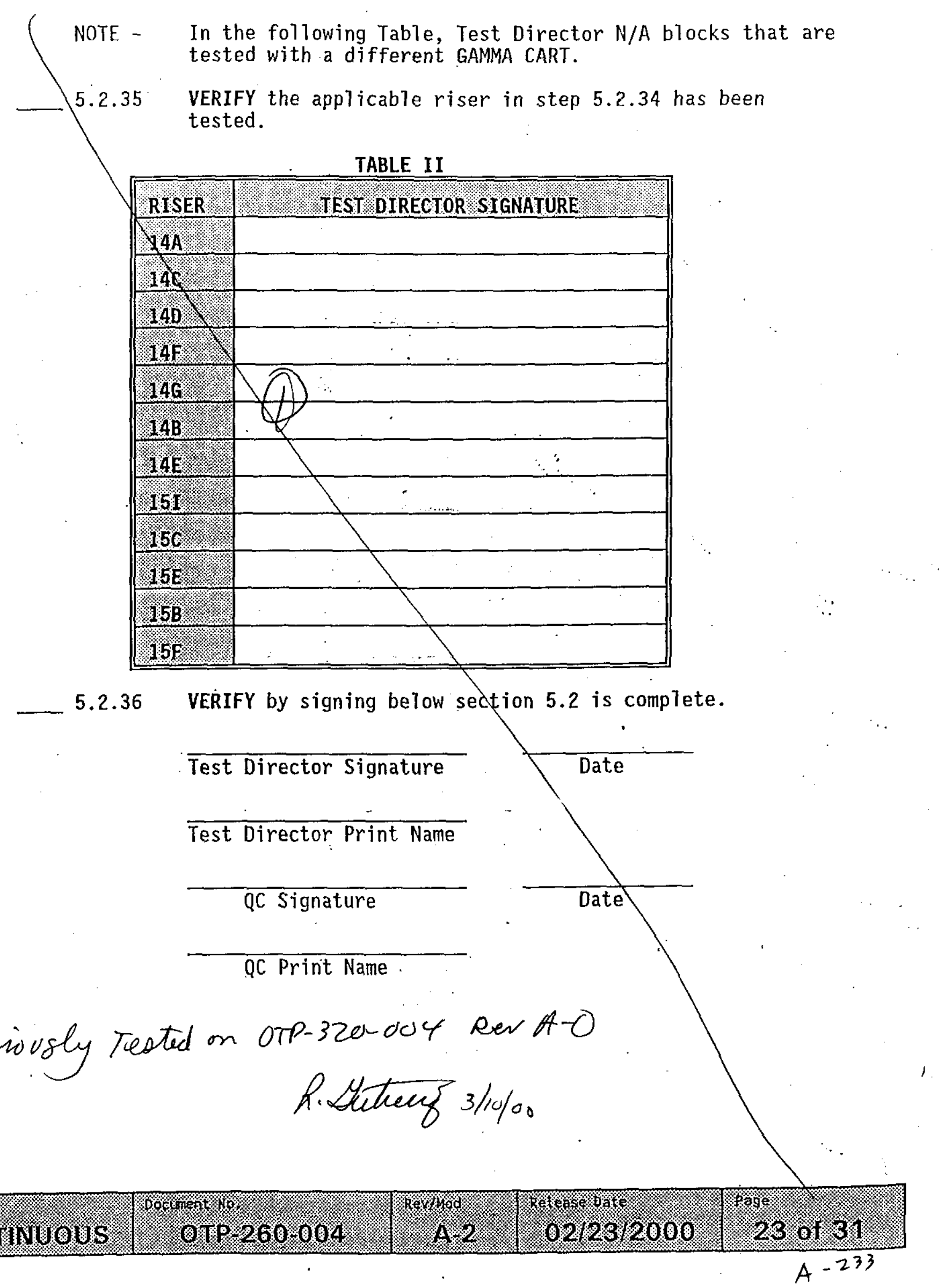




\subsection{TEST USER DEFINED MODE}

5.3.1 ENSURE applicable SETUP Steps in section 5.1 are completed.

CART CONTROL SCREEN

5.3.2 On the Gamma Cart Control, CLICK oN the "Config." button.

5.3.3 INPUT the following data:

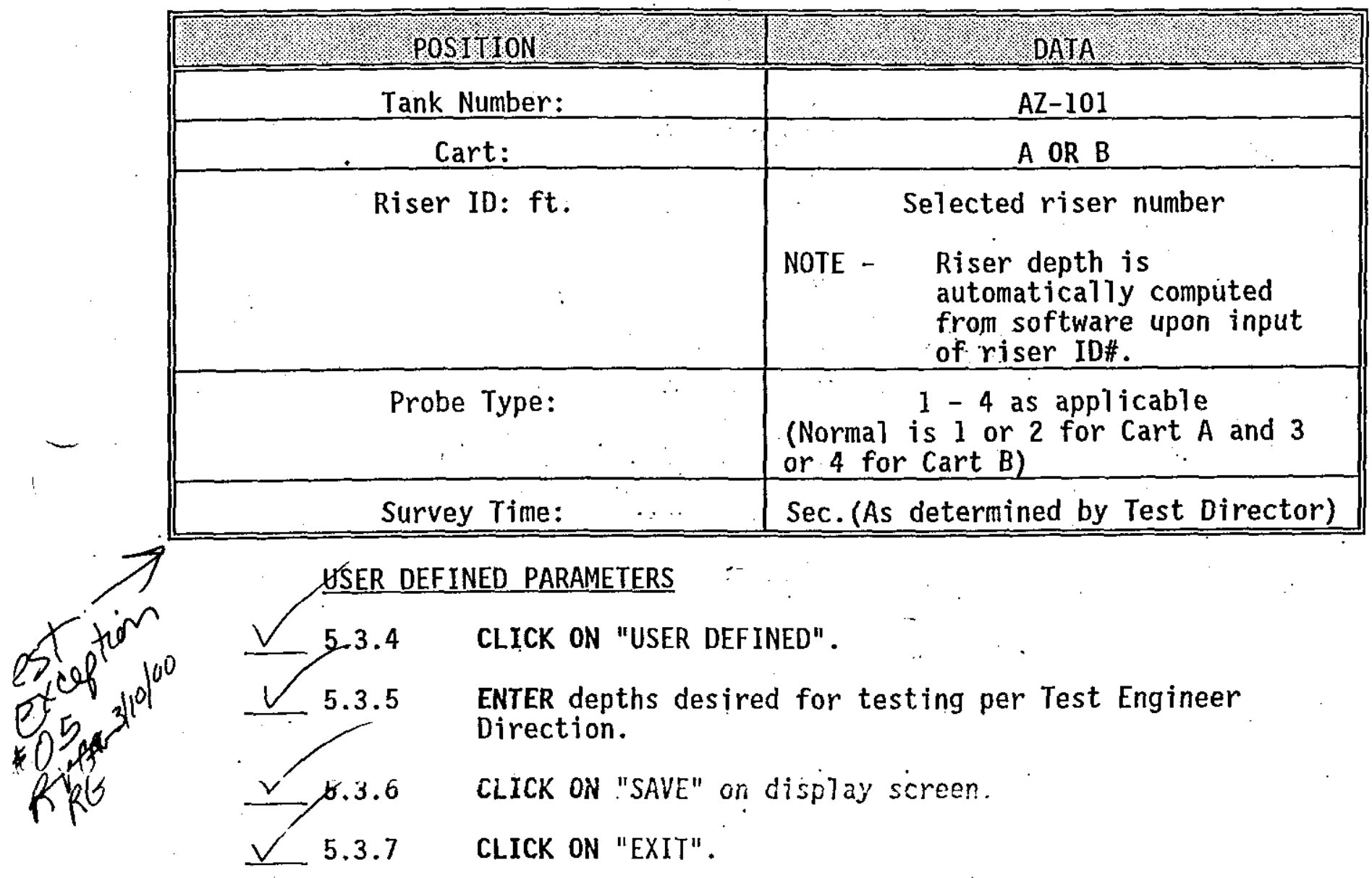




\subsection{TEST USER DEFINED MODE (Cont).}

NOTE - Test Engineer may manipulate parameters at any time during the following steps as necessary to ensure data retrieval and system configuration, with concurrence of Test Director.

- After the following step, the program should automatically run.

- The "EMERGENCY STOP" may be used to stop at any time during the next step if unit fails to stop at limit switch. The "RESET" button will need to be pushed to
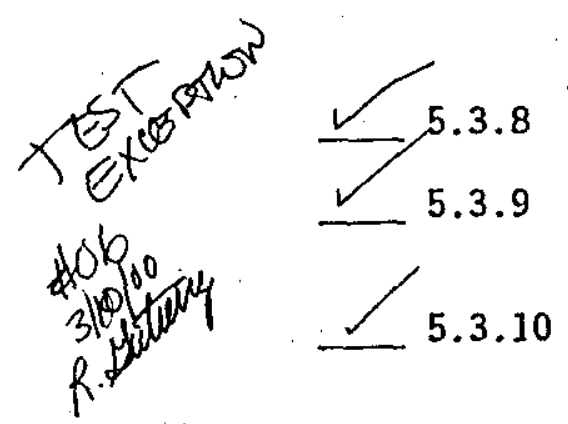
resume the program.

\section{CLICK ON Start buttion.}

Test Engineer ENSURE data is received, AND both hard-copy and electronic files can be retrieved.

VERIFY system automatically ZEROs and data is collected at zero position.
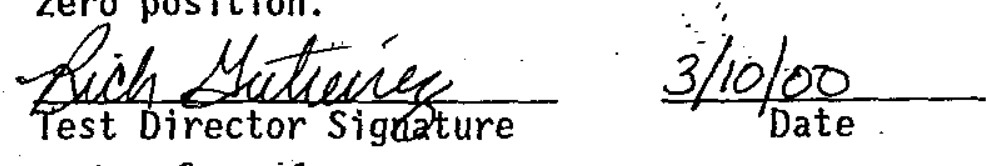

Rich Gufierrez

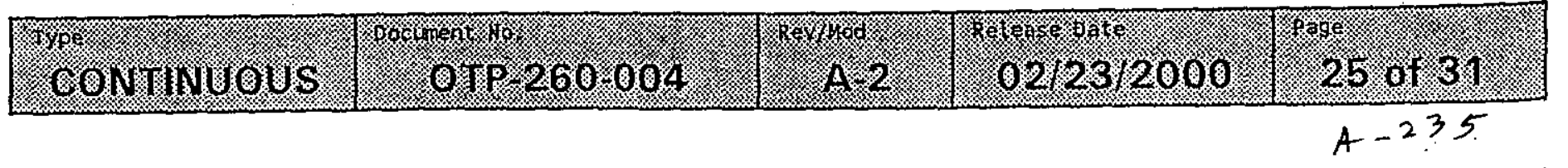


WORKING COPY

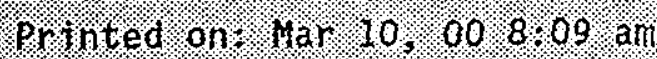

5.3 TEST USER DEFINED MODE (Cont).

5.3 .11 CLICK ON "LOGOUT" on display screen.
REMOVE Probe, riser extension tool, and associated
equipment AND
STORE per Test Director direction.

OR

CONTINUE in this procedure.

5.3.13 REPEAT the steps in this section (5.3) as directed for any risers as directed by Test Director.

$\checkmark$ 5.3.14 VERIFY by signing below section 5.3 is complete.

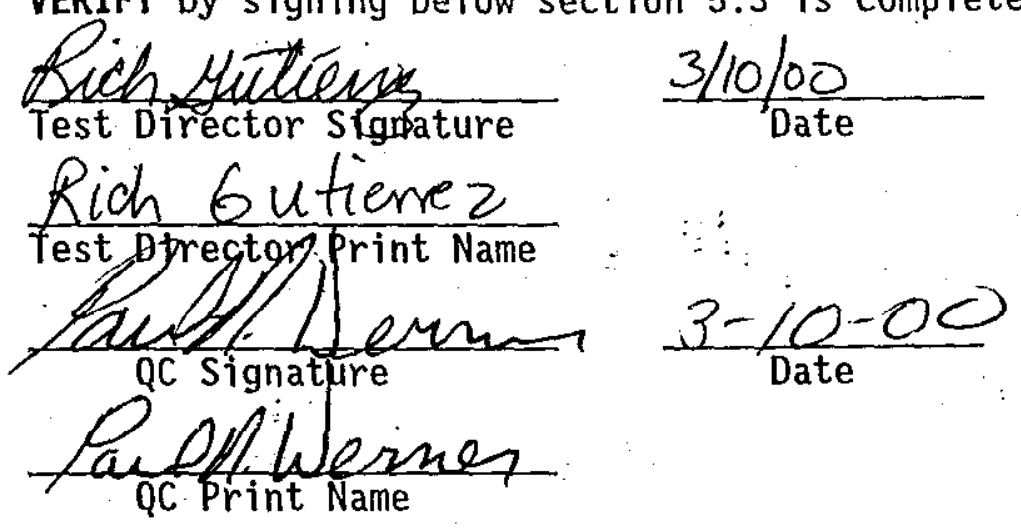

$$
\text { Riser } 150
$$

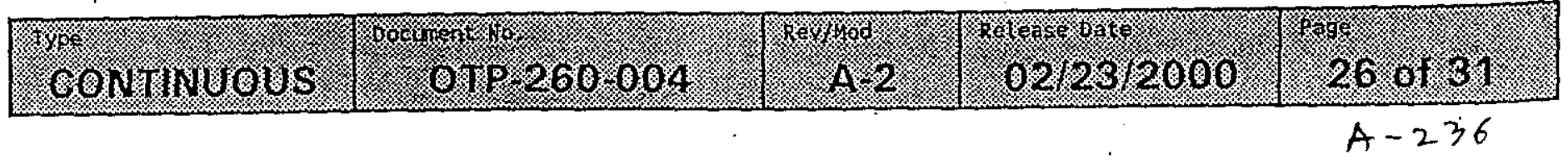

